\title{
BEITRÄGE ZUR BIOSYNTHESE DER ANTIPARASITÄREN NATURSTOFFE HORMAOMYCIN UND BORRELIDIN SOWIE

\author{
STRUKTURAUFKLÄRUNG VON
} \\ SEKUNDÄRMETABOLITEN AUS ACTINOMYCETEN
}

\author{
DISSERTATION \\ Zur Erlangung des Doktorgrades \\ der Mathematisch-Naturwissenschaftlichen Fakultäten \\ der Georg-August-Universität zu Göttingen
}

\author{
vorgelegt von \\ MARKUS RADZOM \\ aus Bad Gandersheim
}

Göttingen 2006 
D 7

Referent: PROF. DR. A. ZEECK

Korreferent: PROF. DR. A. DE MEIJERE

Tag der mündlichen Prüfung: 05. Juli 2006 
Die vorliegende Arbeit wurde im Institut für Organische und Biomolekulare Chemie der Georg-August Universität Göttingen in der Zeit von Januar 2004 bis Mai 2006 unter Anleitung von Herrn PROF. DR. A. ZEECK durchgeführt.

Mein großer Dank gilt Herrn PROF. DR. A. ZEECK für die interessante Aufgabenstellung, sein stetes Interesse am Fortgang dieser Arbeit sowie für viele wertvolle Diskussionen und Anregungen. 



\section{INHALTSVERZEICHNIS}

\section{A THEORETISCHER TEIL}

1 Einleitung 1

1.1 Naturstoffe als Leitstrukturen 1

1.2 Quellen für neue Naturstoffe 8

$\begin{array}{ll}1.3 \text { Naturstoffe in der Malariatherapie } & 10\end{array}$

1.4 Aufgabenstellung 14

2 Hormaomycin 15

2.1 Kultivierung von Streptomyces griseoflavus (Stamm W 384) 16

2.2 Chemische und Biologische Verfahren zur Derivatisierung von $\begin{array}{ll}\text { Naturstoffen } & 17\end{array}$

2.3 Vorläufer-dirigierte Biosynthese an Streptomyces griseoflavus W 384

2.3.1 Variation der 3-(2'-Nitrocyclopropyl)alanin-Einheiten 21

2.3.1.1 Fütterung von 5-Nitronorvalin 22

2.3.1.2 Fütterung von L-Ornithin 26

2.3.1.3 Fütterung von rac-2-(2'-Nitrocyclopropyl)glycin 27

2.3.1.4 Fütterung von 6-Nitronorleucin 31

2.3.1.5 Fütterung von L-5-Nitro-4-thianorvaline 36

2.3.1.6 Fütterung von L-ortho-Nitrophenylalanin 36

$\begin{array}{ll}\text { 2.3.2 Variation der 3-Methylphenylalanin-Einheiten } & 37\end{array}$

2.3.2.1 Fütterung von fluorierten Phenylalanin-Derivaten 37

2.3.2.2 Fütterung von rac-para-Chlorphenylalanin 39

2.3.2.3 Fütterung von rac-para-Brom-und Nitrophenylalanin 43

2.3.2.4 Fütterung von L-Tyrosin 43

2.3.2.5 Fütterung von rac-Phenylglycin 43

2.3.3 Variation der 5-Chlor- $N$-hydroxypyrrolcarbonsäure-Einheit 44

2.3.4 Diskussion der Ergebnisse $\quad 45$

2.4 Die Biosynthese des Hormaomycins $\quad 47$

2.4.1 Die frühe Biosynthese nichtribosomaler Peptide $\quad 47$

2.4.2 Der Mechanismus der (3-Ncp)Ala-Biosynthese 48

2.4.3 Genetische Untersuchungen zur Biosynthese des

Hormaomycins 49 
2.5 Die Struktur des Hormaomycins 53

2.5.1 Die Struktur von Hormaomycin in Lösung 53

2.5.2 Die Kristallstruktur des Hormaomycins $\quad 54$

2.5.3 Untersuchung des Zentralions im Hormaomycin 56

2.5.4 Austausch des Zentralions im Hormaomycin 57

$\begin{array}{ll}2.6 \text { Biologische Aktivitäten } & 61\end{array}$

2.6.1 Antibakterielle und antimykotische Aktivitäten 61

2.6.2 Antiparasitäre Aktivitäten 62

2.6.3 Quorum sensing $\quad 68$

3 Strukturaufklärung von Sekundärmetaboliten 69

3.1 Chemisches Screening von Actinomyceten $\quad 69$

3.1.1 Actinomyces sp. Stamm P4 70

$\begin{array}{ll}\text { 3.1.1.1 Chartreusin (44) } & 70\end{array}$

3.1.2 Actinomyces sp. Stamm M4-1 71

$\begin{array}{ll}3.1 .2 .1 & \text { Isoflavone }\end{array}$

$\begin{array}{ll}\text { 3.1.2.2 Borrelidin (15) } & 72\end{array}$

3.2 HPLC-DAD Screening 74

3.2.1 Streptomyces sp. Stamm Tü 6319

3.2.1.1 Germicidin A (49) und Germicidin B (50) 75

3.2.1.2 SEK4b (47) und AnhydroSEK4b (48) 75

$\begin{array}{lll}3.2 .1 .3 & \text { Fogacin (46) } & 77\end{array}$

3.2.1.4 Biologische Aktivitäten der Metaboliten $\quad 81$

3.2.1.5 Zur Biosynthese der Octaketide 46, 47 und 48

3.2.2 Streptomyces sp. Stamm Tü 2561

$\begin{array}{ll}4 \text { Borrelidin } & 88\end{array}$

4.1 Allgemeines 88

4.2 Die Biosynthese des Borrelidins $\quad 89$

4.2.1 Fermentationskurve 93

4.2.2 Fütterung von $\left[1-{ }^{13} \mathrm{C}\right]$ Acetat $\quad 94$

4.2.3 Fütterung von $\left[1-{ }^{13} \mathrm{C}\right]$ Propionat $\quad 95$

4.2.4 Fütterung von $\left[1,2-{ }^{13} \mathrm{C}_{2}\right]$ Acetat 96

4.2.5 Fütterung von $\left[\mathrm{U}-^{13} \mathrm{C}\right]$ Glycerin 96

4.2.6 Fütterung von $\left[2-{ }^{13} \mathrm{C}\right]$ Acetat 98

4.2.7 Fütterung von $\left[2,3,5,6-d_{4}\right]-,\left[1-{ }^{13} \mathrm{C}\right]$ Tyrosin und $d_{3}$-Acetat 98

4.2.8 Diskussion der Biosynthese 98 
4.3 Vorläufer-dirigierte Biosynthese am Borrelidin 100

$\begin{array}{ll}\text { 4.3.1 Allgemeines } & 100\end{array}$

4.3.2 Vorläufer-dirigierte Biosynthese an Streptomyces sp. S 1495

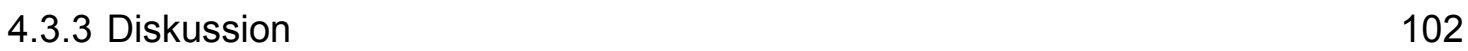

5 Zusammenfassung der Ergebnisse 103

5.1 Untersuchungen am Hormaomycin-Produzenten Streptomyces $\begin{array}{ll}\text { griseoflavus (Stamm W 384) } & 103\end{array}$

5.2 Strukturaufklärung von Sekundärmetaboliten 106

5.3 Untersuchungen am Borrelidin-Produzenten Streptomyces sp. S 1495

B EXPERIMENTELLER TEIL

1 Allgemeines 108

1.1 Instrumentelle Analytik 108

$\begin{array}{ll}1.2 \text { Chromatographische Methoden } & 109\end{array}$

$\begin{array}{ll}1.3 \text { Mikrobiologische Methoden } & 111\end{array}$

$\begin{array}{ll}1.4 \text { Allgemeine Arbeitsvorschriften } & 113\end{array}$

2 Untersuchungen am Hormaomycin-Produzenten Streptomyces $\begin{array}{ll}\text { griseoflavus (Stamm W 384) } & 114\end{array}$

$\begin{array}{ll}2.1 \text { Stammhaltung } & 114\end{array}$

$\begin{array}{ll}\text { 2.1.1 Agarplatten } & 114\end{array}$

2.1.2 Langzeitkonservierung 114

$\begin{array}{ll}\text { 2.1.3 Kultivierung } & 114\end{array}$

2.2 Isolierung und Charakterisierung von Hormaomycin 115

2.2.1 Untersuchungen des Hormaomycin-Zentralions 115

2.3 Vorläufer-dirigierte Biosynthese an Streptomyces griseoflavus W 384

2.3.1 Variation der 3-(2'-Nitrocyclopropyl)alanin-Einheiten 120

2.3.1.1 Isolierung und Charakterisierung der Hormaomycinderivate aus Fütterungsexperimenten mit $\left(\mathrm{NO}_{2}\right) \mathrm{Nva}$ und (2-Ncp)Gly

2.3.1.2 Isolierung und Charakterisierung der Hormaomycinderivate aus Fütterungsexperimenten mit $\left(\mathrm{NO}_{2}\right) \mathrm{Nle}$ 
2.3.2 Variation der 3-Methylphenylalanin-Einheiten

2.3.2.1 Isolierung und Charakterisierung der Hormaomycinderivate aus Fütterungsexperimenten mit para-substituierten Phenylalaninderivaten

2.3.2.2 Isolierung und Charakterisierung der Hormaomycinderivate aus Fütterungsexperimenten mit Fluorphenylalaninderivaten

2.3.3 Variation der 5-Chlor- $N$-hydroxypyrrol-2-carbonsäure-Einheit

2.4 Untersuchung der Hormaomycin-Biosynthese an E. coli-Mutanten

2.4.1 Stammhaltung

2.4.1.1 Agarplatten

$\begin{array}{ll}\text { 2.4.1.2 Langzeitkonservierung } & 141\end{array}$

$\begin{array}{ll}2.4 .1 .3 \text { Kultivierung } & 141\end{array}$

$\begin{array}{ll}2.4 .1 .4 \text { Aufarbeitung } & 141\end{array}$

3 Strukturaufklärung von Sekundärmetaboliten 142

3.1 Substanzen aus dem chemischen Screening 142

$\begin{array}{ll}3.1 .1 & \text { Stammhaltung } \\ & 142\end{array}$

$\begin{array}{ll}\text { 3.1.2 Chemisches Screening } & 142\end{array}$

3.1.3 Substanzen aus Actinomyces sp. Stamm P4 143

3.1.4 Substanzen aus Actinomyces sp. Stamm M4-1 145

3.2 Charakterisierung der Metaboliten aus Streptomyces sp. Stamm Tü 6319

3.3 Charakterisierung der Metaboliten aus Streptomyces sp. Stamm Tü 2561

4 Untersuchungen an Streptomyces sp. S 1495

4.1 Fermentationskurve

4.2 Biosyntheseuntersuchungen 153

4.3 Vorläufer-dirigierte Biosynthese 


\section{A THEORETISCHER TEIL}

\section{Einleitung}

\subsection{Naturstoffe als Leitstrukturen}

Zwischen 1900 und 1997 ist die Lebenserwartung in den Industrienationen um mehr als $60 \%$ auf über 76 Jahre gestiegen. ${ }^{1}$ Beachtet man hierbei die Hauptursachen der Sterblichkeit, so fällt die dramatische Verringerung der durch Infektionskrankheiten wie Tuberkulose, Lungenentzündung oder Durchfallerkrankungen verursachten Mortalität auf. Zu Anfang des letzten Jahrhunderts waren allein diese drei Krankheitsbilder für $30 \%$ aller Todesfälle verantwortlich, während sie zum heutigen Zeitpunkt nur ca. 1 \% (hauptsächlich Lungenentzündung nach Influenzainfektion) hierzu beitragen. ${ }^{2}$ Neben Verbesserungen in der Hygiene und Trinkwasserqualität ist diese Entwicklung vor allem auf die Entdeckung antibiotisch wirksamer Naturstoffe zurückzuführen.

Den Beginn des Zeitalters moderner Antiinfektiva leitete A. FLEMING 1928 mit der Entdeckung des Penicillins ein. ${ }^{3}$ Die Substanz wurde 1941 in der Struktur aufgeklärt und im darauf folgenden Jahr erstmals zur Behandlung von Wundinfektionen bei Soldaten angewandt. Mit diesem ersten Erfolg war der Siegeszug von Sekundärmetaboliten aus Bakterien und Pilzen als Therapeutika nicht mehr aufzuhalten, das „Goldene Zeitalter" der Antibiotikaforschung war angebrochen.

Die Penicilline (1) sind bis heute die erfolgreichste Antibiotika-Substanzklasse und dienen zugleich auch als Leitstruktur. Ausgangspunkt ist das fermentativ gewonnene Penicillin G, welches zu 6-Aminopenicillinsäure deacyliert wurde. Dieses kann anschließend mit verschiedensten Säurederivaten umgesetzt werden, um Substanzen mit verbesserten Eigenschaften zu generieren. Insgesamt beträgt die Zahl der so gewonnenen Penicilline über 10.000. ${ }^{4}$ Mit den Aminoglykosiden ${ }^{5}$, Makroliden ${ }^{6}$, Tetracyclinen ${ }^{7}$, u.a. konnten andere Substanzklassen mit unterschiedlichen Wirkmechanismen aus Streptomyceten isoliert werden. Die Anwendung dieser Antibiotika führte in den USA bis 1952 zu einem Absinken der Sterblichkeit bei Infektionskrankheiten um jährlich $8.2 \%{ }^{8}$ Allerdings muss angemerkt werden, dass viele der vermeintlich chronischen Erkrankungen häufig durch Infektionen hervorgerufen werden, aber statistisch als solche nicht erfasst werden. Beispiel hierfür sind durch Chlamydien verursachte koronare Herzkrankheiten. ${ }^{1}$

Die beschriebene Entwicklung führte zu der Annahme, dass ein Sieg über die Infektionskrankheiten errungen sei. Wie falsch diese Einschätzung war, zeigte sich ca. 50 Jahre nach der bahnbrechenden Entdeckung von A. FLEMING. 


\section{Resistenzentwicklung und ihre Folgen}

1981 wurde erstmals seit Einführung der Antibiotikatherapie eine Zunahme der durch Infektionskrankheiten verursachten Todesfälle beobachtet (bis 2002: $4.8 \%$ pro Jahr). ${ }^{1}$ Hauptursache hierfür ist die durch den immer häufigeren Einsatz dieser Stoffe entstandene Resistenzausbildung. So entwickeln viele Staphylokokken $\beta$-Lactamasen, die in der Lage sind den $\beta$-Lactamring der Penicilline zu öffnen, was zu einem Verlust der Aktivität führt. Als Ersatzmedikamente für die Behandlung von Infektionen mit Penicillin-resistenten Staphylococcus aureus (PRSA) und anderen Gram-positiven Pathogenen wurden in den sechziger Jahren Methicillin und die aus dem Pilz Cephalosporium acremonium isolierten Cephalosporine $(2)^{9}$ eingeführt. Erste Resistenzen waren bei Methicillin schon ein Jahr nach der Einführung zu beobachten, heutzutage ist die Substanz bei $50 \%$ der PRSA inaktiv. Während $\beta$-Lactamasen bei 2 zuerst keine Ringöffnungen durchzuführen vermochten, führte die Anpassungfähigkeit der Mikroorganismen später auch hier zur Inaktivierung der Substanzen durch den gleichen Mechanismus wie bei den Penicillinen. Diese Resistenz kann in einigen Fällen durch die in den siebziger Jahren eingeführten Kombinationen von Penicillinen und Cephalosporinen mit $\beta$-Lactamaseinhibitoren wie Clavulansäure (3) oder Sulbactam (4) umgangen werden. ${ }^{10}$ Die Inhibitoren $\mathbf{3}$ und $\mathbf{4}$ binden kovalent an die $\beta$ Lactamasen, welche dadurch inaktiviert werden. Eine zweite Resistenzform gegenüber Penicillinen findet sich in MRSA (Methicillin-resistenter Staphylococcus aureus) durch die Induktion der Expression zusätzlicher Penicillin Binding Proteins (PBP) durch die Antibiotika selbst. ${ }^{11}$ Diese neuen PBP's besitzen nur eine geringe Bindungsaffinität gegenüber 1 und 2.

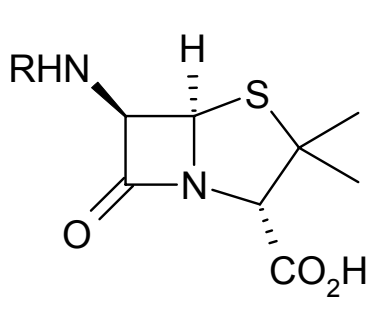

1

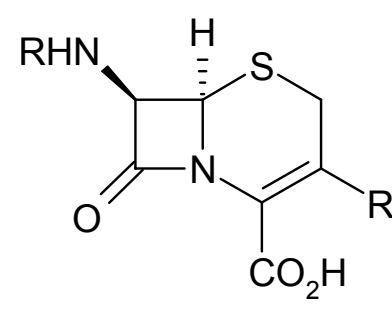

2

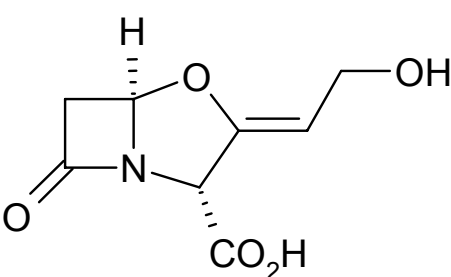

3

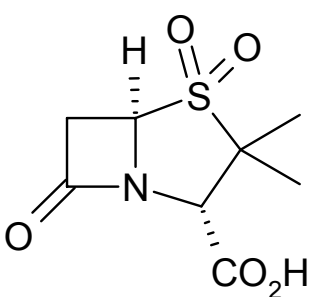

4

Als letzte Behandlungsmöglichkeit für MRSA galten lange Zeit Glykopeptide wie das Vancomycin (5), für das erst 1986 Resistenzen auftraten. Der Naturstoff $\mathbf{5}$ greift wie auch 1 und 2 in die Peptidoglycansynthese bakterieller Zellwände ein. ${ }^{12}$ Resistenzen gegenüber 5 entwickeln sich durch eine Veränderung der Bindungsstelle. Das D-Ala-D-Ala-Dipeptid des Peptidoglycan-Zellwand Vorläufers wird hierbei gegen D-Ala-D-Lac ausgetauscht, was einem Austausch einer Amid- gegen eine Estergruppe entspricht. ${ }^{13}$ Durch diese Veränderung zum Depsipetid-Terminus kann 5 nur mit einer 1000fach verringerten Affinität an die Zielstruktur binden. ${ }^{14}$ Die hierdurch verringerte Aktivität wird durch das Fehlen der fünften Wasserstoffbrückenbindung zwischen $\mathbf{5}$ und dem D-Ala-D-Lac-Depsipetid verursacht und 
kann durch synthetische Veränderung des Grundgerüstes von 5 aufgefangen werden. So zeigt das $\left[\psi\left[\mathrm{CH}_{2} \mathrm{NH}\right] \mathrm{Tpg}^{4}\right]$ Vancomycinaglykon (6) gute Aktivitäten gegen Vancomycinresistente Enterococci faecalis. ${ }^{15}$

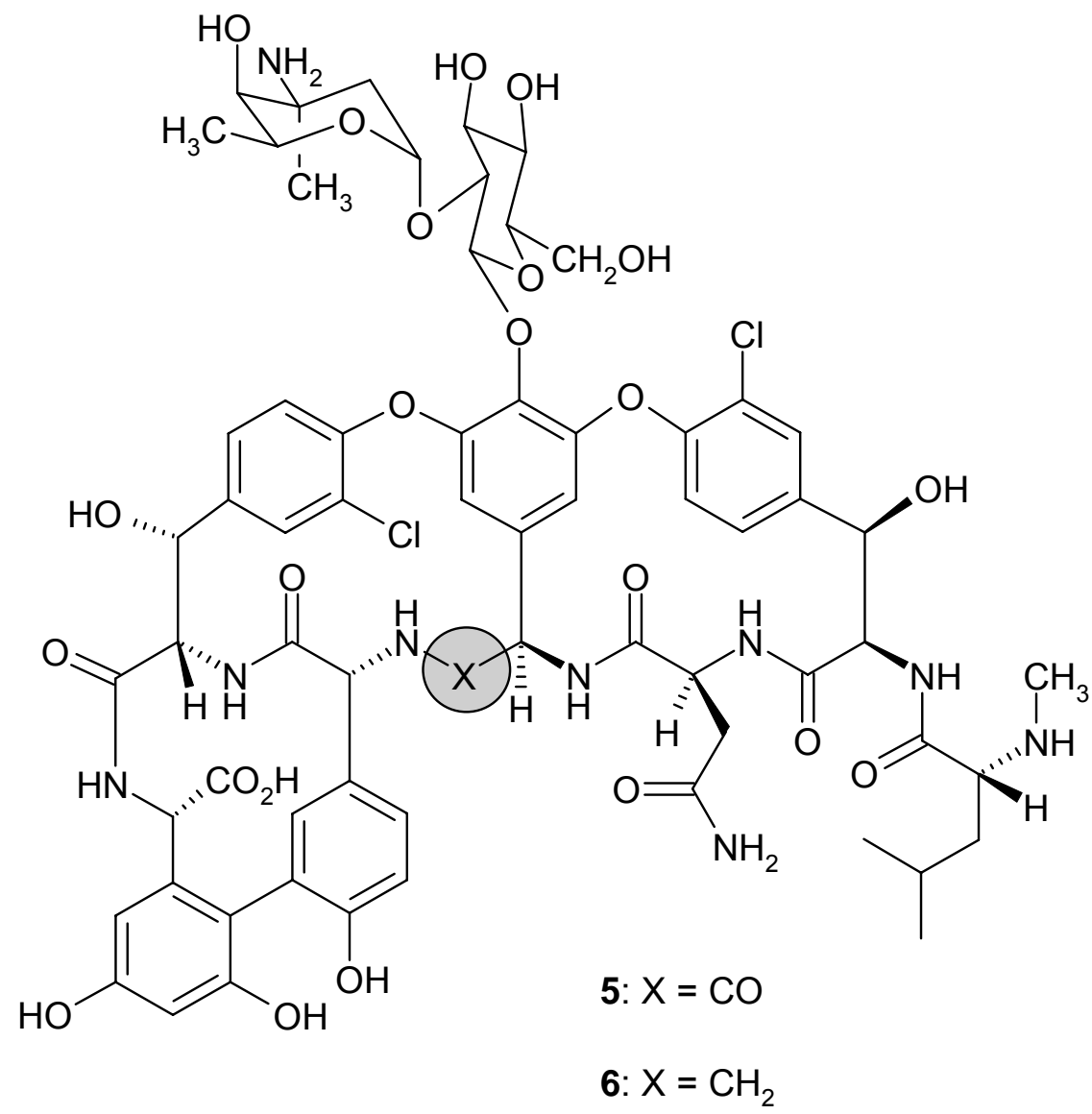

Zur Therapie Vancomycin-resistenter Bakterien sind in jüngster Zeit das Quinupristin/Dalfopristin Kombipräparat Synercid ${ }^{\circledR}$ (2002) und das synthetisch gewonnene Linezolid (7, Handelsname Zyvox ${ }^{\circledR}$ ) zugelassen worden. Beide sind „Antibiotika des letzten Ausweges“ für die Behandlung von MDR (ㅆultiple Drug Resistant) Bakterien. Hierbei muss zusätzlich beachtet werden, dass jede Art von Resistenz zu enormen Kosten führt. In den USA werden allein die durch Infektionen mit resistenten Staphylokokken verursachten Therapiekosten auf jährlich 24-36 Milliarden US-\$ geschätzt. ${ }^{16}$ Mikroorganismen waren immer in der Lage, sich durch evolutionäre Entwicklung an unwirtliche Umgebungen sowie die Anwesenheit antibiotischer Substanzen anzupassen. Somit werden sich Resistenzen also nie vermeiden lassen. Eine Verlängerung der Phase bis zum ersten Auftreten einer Resistenz kann lediglich durch die Verwendung von Antibiotika mit engem Wirkspektrum und deren moderaten Einsatz erreicht werden. Es gilt hierbei, den durch den Menschen verursachten evolutionären Druck so gering wie möglich zu halten. 
Was können wir von Naturstoffen lernen?

Seit Anfang der achtziger Jahre des 20. Jahrhunderts ist zu beobachten, das pharmazeutische Firmen sich aus der Naturstoffforschung zurückziehen und synthetisch gewonnene Substanzen bevorzugen. Ein Grund hierfür ist die Entwicklung des HighThroughput Screenings. Diese Testsysteme ermöglichen die Prüfung der biologischen Aktivität von tausenden Substanzen pro Tag. Die Naturstoffforschung kann, im Gegensatz zu den riesigen Substanzbibliotheken aus der High-Throughput Synthese ${ }^{17}$, diese Quantität nicht erzeugen, da die Kultivierung der Organismen und die Isolierung einzelner Substanzen viel mehr Zeit in Anspruch nimmt. Kombinatorische Synthesemethoden haben in der Wirkstoffforschung bisher nicht zu neuen Leitsubstanzen geführt. Aus der klassischen Wirkstoffsynthese sind in den letzten 20 Jahren jedoch die Fluorchinolone (z.B. Ciprofloxacin, 8) und Linezolid (7) hervorgegangen.

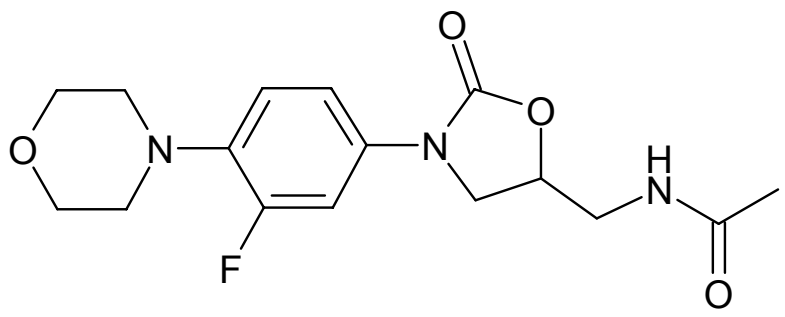

7

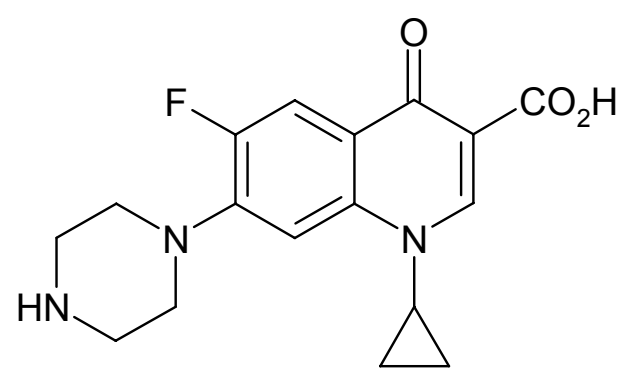

8

Statistische Untersuchungen über den Zeitraum von 1981 bis 2002 zeigen eine Überlegenheit von Naturstoffen gegenüber rein synthetischen Substanzbibliotheken bei der Wirkstoffsuche. So sind $75 \%$ aller neuen antibakteriellen Substanzen Naturstoffe oder ihre Derivate. ${ }^{18}$ Für alle in dieser Zeit neu zugelassenen Arzneien nimmt ihr Anteil $28 \%$, bei den onkologischen Pharmazeutika fast $50 \%$ ein.

Wie kann die herausragende Stellung von Naturstoffen erklärt werden? Ein großer Unterschied zwischen synthetischen und Naturstoff-Substanzbibliotheken wird bei dem Vergleich ihrer Strukturkomplementarität deutlich, der durch fast alle in dieser Arbeit präsentierten Substanzen anschaulich wird (vgl. z.B. 5 mit 7). ${ }^{19}$ So ist der Anteil von Stickstoff-, Schwefel- sowie Halogenatomen in Naturstoffen deutlich geringer, während eine leicht erhöhte Sauerstoffanzahl sowie eine größere Molmasse zu verzeichnen ist. Zudem sind in Naturstoffen wesentlich mehr $\mathrm{sp}^{3}$-hybridisierte Brückenkopfatome, Etherbrücken, Ringe und Chiralitätszentren bei geringerer Anzahl von Aromaten zu finden. ${ }^{20}$

Der vielleicht wichtigste Unterschied zwischen Naturstoffen und synthetischen Verbindungen liegt in der Nutzung von funktionellen (und somit potentiell pharmakophoren) Gruppen. Generell sind in Naturstoffen deutlich mehr sauerstoffhaltige Gruppen wie Alkohole oder Epoxide enthalten, weiterhin finden sich hochreaktive Gruppen, wie in den Endiinen. In 
synthetischen Bibliotheken hingegen müssen solche Substituenten vermieden werden, da sie in den meisten Synthesen aufwendig zu schützen wären. Für den Aufbau einer Substanzbibliothek durch Kombinatorische Synthese ist die Zahl der zugänglichen Substanzen maßgebend, was oftmals einen Verlust an biologisch relevanter chemischer Komplexität zur Folge hat. ${ }^{21}$ Diese Charakteristika verleihen Naturstoffen im Gegensatz zu vielen Syntheseprodukten ein Höchstmaß an struktureller Diversität und dreidimensionaler Stabilität. Vor allem starre Grundgerüste sind wichtig, um eine selektive Wechselwirkung der funktionellen Gruppen am Wirkort zu ermöglichen.

Eine fortwährende Suche nach neuen Leitstrukturen sowie die Verbesserung bekannter Therapeutika ist Bedingung für den entscheidenden Vorsprung im Wettlauf zwischen Pathogenen und Menschen. Hierfür wie auch für andere Wirkstoffklassen sollen im Folgenden Beispiele angeführt werden.

\section{Auffinden und Verwendung neuer Leitstrukturen}

Antibiotika sollten immer eine ausreichende Differenzierung zwischen pro- und eukaryotischen Zellen aufweisen. Am Besten ist es wenn Enzyme gehemmt werden, die es nur bei Bakterien, nicht aber beim Menschen gibt. Ein Beispiel für ein Target dieser Art ist die Tetrahydrofolat-Biosynthese, welche nur in Bakterien $\mathrm{zu}$ finden ist. Hierbei wird Tetrahydrofolat aus para-Aminobenzoesäure (pABA) aufgebaut. Inhibitoren dieses metabolischen Weges sind z.B. die Sulfonamide oder das Trimethoprim. In einem modifizierten Agardiffusionstest können durch Zusatz von mit pABA-getränkten Teststreifen Extrakte von Kulturen auf ihre spezifische inhibitorische Wirkung getestet werden. ${ }^{22}$ In diesem Screening sind von FIEDLER et al. aus dem marinen Actinomyceten Verrucosispora AB 18-032 die drei Abyssomycine B-D isoliert worden. ${ }^{23}$ Abyssomycin C (9a) zeigt eine sehr hohe Aktivität gegen multiresistente Staphylococcus aureus-Stämme. Als Wirkmechanismus wird eine irreversible Bindung an die Chorismatmutase über eine Michael-Addition an dem C-7/C-9-Akzeptorsystem angenommen. Dies erklärt zudem die antibakterielle Unwirksamkeit der Abyssomycine $B$ und $D$, welche nicht über ein solches System verfügen. In den zwei Jahren seit Entdeckung der Abyssomicine sind zwei Synthesen zu Partialstrukturen sowie zwei Totalsynthesen publiziert worden. ${ }^{24}$ Die Totalsynthese von NicOLAOU et al. ${ }^{24 a}$ ermöglicht zudem die Gewinnung des atrop-Abyssomycins (9b), welches gegen MRSA eine 1.5fach größere Aktivität als 9a besitzt. 


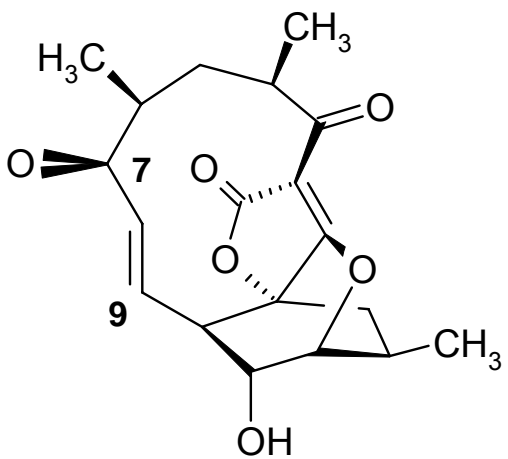

$9 a$

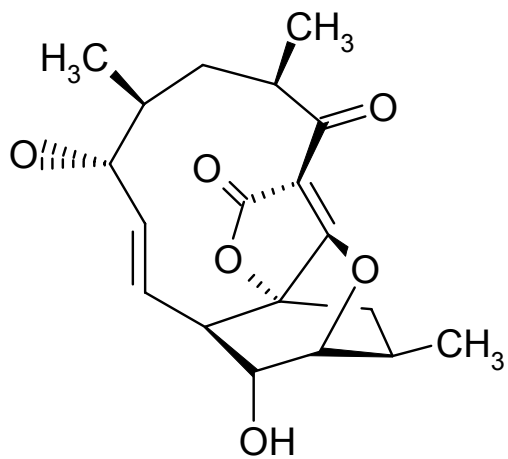

$9 b$

Für das Auffinden von neuen Leitstrukturen mit neuen Targets ist nicht immer ein aufwendiges Screening unbekannter Mikroorganismen nötig. So fand eine Arbeitsgruppe der Bayer HealthCare AG bei Patentrecherchen ein Substanzgemisch, welches trotz hoher Aktivität gegen resistente Stämme nie in seiner Struktur aufgeklärt wurde. ${ }^{25}$ Durch Anwendung moderner Methoden war dies jedoch möglich und die Substanzen des Gemisches konnten als Cyclopeptide mit der aktiven Komponente ADEP-1 (10a) identifiziert werden. ${ }^{26}$ Nach geglückter Totalsynthese wurden Derivate wie ADEP-2 (10b) und ADEP-4 (10c) synthetisiert, welche die Aktivität des Naturstoffs übertreffen.<smiles>[R]C(=O)N[C@@H](Cc1ccccc1)C(=O)N[C@@H](COC(=O)[C@@H]1C[C@H](C)CN1C(=O)[C@H](C)NC(=O)C(C)N(C)C(=O)C1CCCN1C(=O)[C@H]1C[C@H](C)CN1)Cc1ccccc1</smiles>

10a: $\mathrm{R}=[$<smiles>CC(NC(=O)C1CCCCCC1)C(=O)N1C[C@@H](C)CC1C(=O)OC[C@@H](C)C(=O)N1CCCC1C(=O)N1CCCCC1</smiles>

10<smiles>[R]C(=O)N[C@@H](Cc1cc(F)cc(F)c1)C(N)=O</smiles><smiles></smiles>

In 10b,c sind Wasserstoffatome durch Fluoratome ersetzt (vgl. Kap. 2.3.2, S. 37), weitere Veränderungen finden sich im Grundgerüst und in der Seitenkette. In biologischen Assays mit radioaktiv markierten Vorläufern an Bacillus subtilis konnte nachgewiesen werden, dass 10a-c nicht über die herkömmlichen antibakteriellen Targets (DNA-, RNA-, Protein-, Zellwand- und Fettsäurebiosynthese) angreifen, vielmehr ließ sich mit einer ADEPresistenten E. coli-Mutante eine Protease (ClpP) als Resistenzverursacher identifizieren. In 
der Mutante existiert eine Punktmutation, welche in anderen Stämmen nicht vorhanden ist. ClpP-Proteasen sind in der Regel stark regulierte Systeme, welche nur nach Aktivierung durch Clp-ATPasen aktiv werden können. Die neuen Antibiotika 10a-c hingegen verursachen durch Bindung an ClpP eine Aktivierung ohne die Regulationsenzyme, woraufhin ein ungehinderter proteolytischer Abbau einsetzt, der das Absterben der Zelle auslöst. In vitro Tests auf antibiotische Aktivität an Nagern zeigen für 10c eine im Vergleich zu Linezolid (7) zehnfach höhere Aktivität.

Wie erwähnt nehmen Naturstoffe auch im Bereich der Antitumorwirkstoffe eine privilegierte Stellung ein. Ein Beispiel hierfür sind Endiine wie $\gamma_{1}{ }^{\prime}$-Calicheamycin (11a ${ }^{27}$ mit einer extrem innovativen Struktur. Sie besitzen ein hochreaktives konjugiertes olefinisches System, welches über ein Diradikal zur Aromatisierung befähigt ist. Das Diradikal beschädigt die DNA und verursacht damit den Zelltod. Endiine gehören zu den am stärksten cytotoxisch wirkenden Substanzen die je entdeckt wurden. Der LC $_{50}$-Wert von 11a liegt im Bereich $10^{-17} \mathrm{M}$, was theoretisch einem Molekül pro Zelle entspricht. Die starke Toxizität wird durch eine hohe DNA-Spezifität des Endiin-„Sprengkopfes“ und des die Aromatisierung auslösenden Disulfid-Redoxsystems hervorgerufen. ${ }^{28}$ Problematisch für einen klinischen Einsatz von 11a ist jedoch, dass keine Spezifität der Substanz bezüglich Tumorzellen besteht. Die Verknüpfung von 11a mit einem rekombinant gewonnenen IgG4-kappaAntikörper führte zu dem Konjugat Gemtuzumab-Ozogamicin (Mylotarg ${ }^{\circledR}, \mathbf{1 1 b}$ ), ${ }^{29}$ durch welches eine hohe Spezifität gegenüber Tumorzellen erreicht wird.

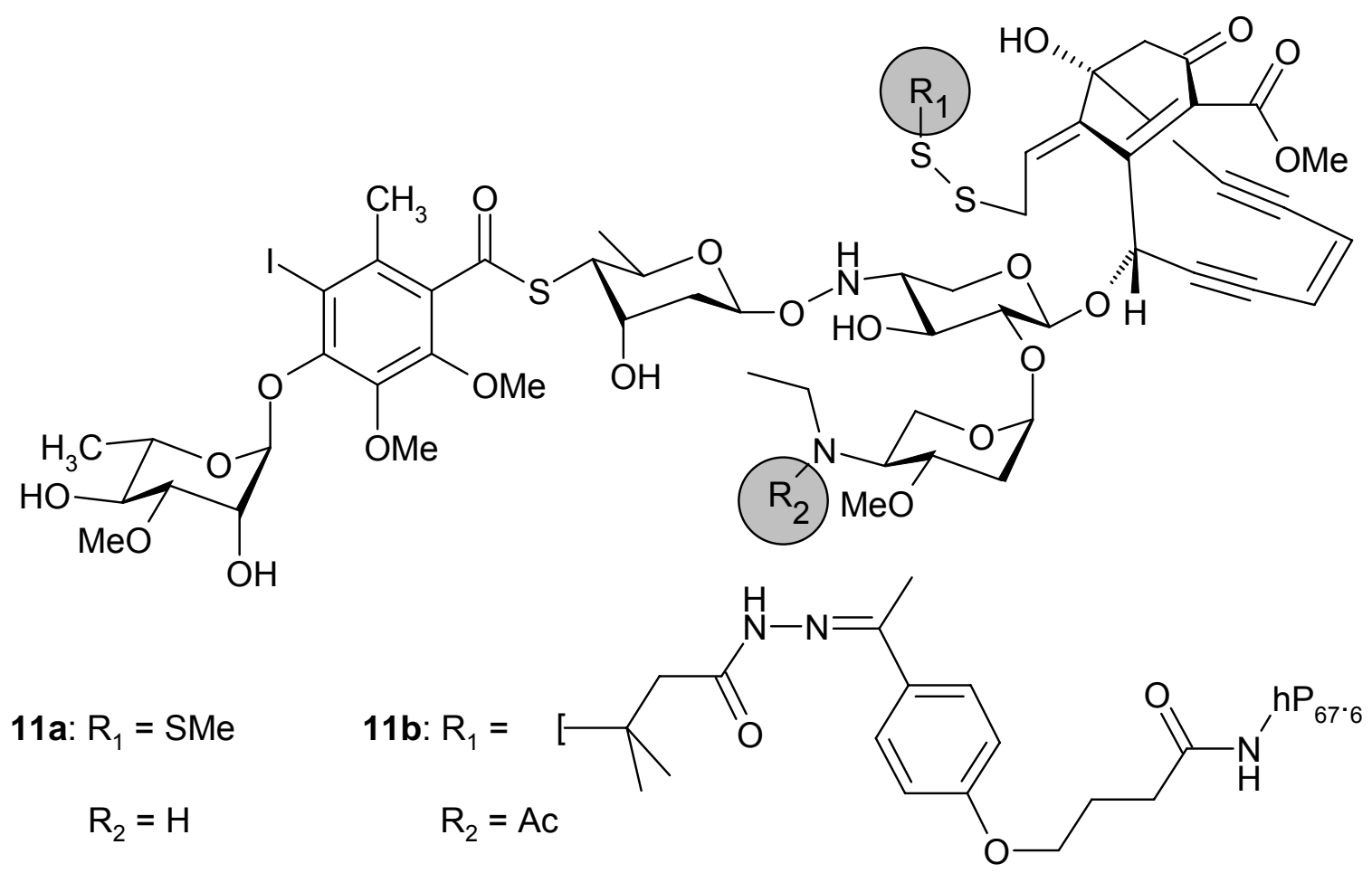


Die Entwicklung von 11b führt zu einem vollkommen neuen Feld der Krebstherapie und kann dazu dienen, unspezifischen aber stark cytotoxischen Substanzen den Weg in die Chemotherapie zu ebnen. Inzwischen gelang die Konjugation von 11a mit einem weiteren Antikörper, die Substanz befindet sich in Klinischen Studien der Phase I gegen NonHODGKIN-Lymphome. ${ }^{30}$

Auch in der Krebstherapie gibt es Beispiele, dass altbekannte Substanzen unerwartete Eigenschaften besitzen. So wurde unlängst der Sojamehlbestandteil Daidzein (12a) (s. Kap. 3.1.2, S. 71) unerwartet zu einer neuen Leitstruktur. Ein Derivat von 12a, das Phenoxodiol (12b), wie auch der Naturstoff sind Inhibitoren des Caspase-regulierenden Enzyms XIAP. Unter Einwirkung von 12a,b kommt es somit zu einer vermehrten Apoptose der behandelten Zellen. ${ }^{31}$ Der therapeutische Nutzen von 12b wird momentan in Klinischen Studien der Phase II untersucht. ${ }^{30}$<smiles>O=c1c(-c2ccc(O)cc2)coc2cc(O)ccc12</smiles>

$12 a$<smiles>Oc1ccc(C2=Cc3ccc(O)cc3OC2)cc1</smiles>

$12 b$

\subsection{Quellen für neue Naturstoffe}

Bei der Suche nach neuen Naturstoffen ist der steigende Anteil bekannter Substanzen bei der Isolierung von Sekundärmetaboliten aus Mikroorganismen ein Problem. Dies führte zu der Annahme, dass der Pool an in der Natur vorhandenen Metaboliten nahezu ausgeschöpft sei. Genomische Analysen von Mikroorganismen sowie von Erdproben weisen jedoch in eine andere Richtung. In einem Gramm einer Erdprobe aus Wäldern lassen sich durchschnittlich $4 \times 10^{7}$, aus Weideland sogar $2 \times 10^{9}$ prokaryotische Zellen nachweisen. Durch Metagenomanalysen ergibt sich eine Zahl von 2.000-18.000 unterschiedlichen Genomen pro Gramm Erde. Zum jetzigen Zeitpunkt sind insgesamt $20.683^{32}$ Prokaryonten bekannt, woraus ersichtlich ist, dass in einem Gramm Erde ähnlich viel genetische Information wie in allen bekannten Prokaryonten vorhanden ist. ${ }^{33}$ Es kann davon ausgegangen werden, dass bisher nur ca. $1 \%$ aller Mikroorganismen kultivierbar sind. Umgangen wird dieses Problem bei der heterologen Expression von gefundenen Genabschnitten in besser kultivierbaren Organismen wie E. coli.

Die genetische Analyse von Mikroorganismen kann zudem genutzt werden, dass Biosynthesepotential eines Stammes zu offenbaren. Die vollständige Sequenzierung von Streptomyces coelicolor ${ }^{34}$ zeigte, dass dieser wahrscheinlich am besten untersuchte 
Sekundärmetabolitenproduzent 18 Biosynthese-Gencluster besitzt, ${ }^{35}$ wobei bisher lediglich sechs Substanzen isoliert werden konnten (s. Abb. 1 sowie Kap. 3.2.1.5, S. 81). Ähnliches kann bei dem Hormaomycin-Produzenten Streptomyces griseoflavus W 384 beobachtet werden, außer dem Peptidlacton konnte bisher kein weiterer Naturstoff gefunden werden, obwohl ein weiterer NRPS-(Nonribosomale Peptidsynthetase) sowie zwei PKS(Polyketidşynthase) Gencluster im Genom zu finden sind. ${ }^{36}$

Abb. 1:

Isolierte NRPS/PKS-

Metaboliten (blau) und

Gesamtzahl von NRPS-

/PKS-Biosynthesegen-

clustern (gelb) in

verschiedenen

Mikroorganismen. ${ }^{36,37}$
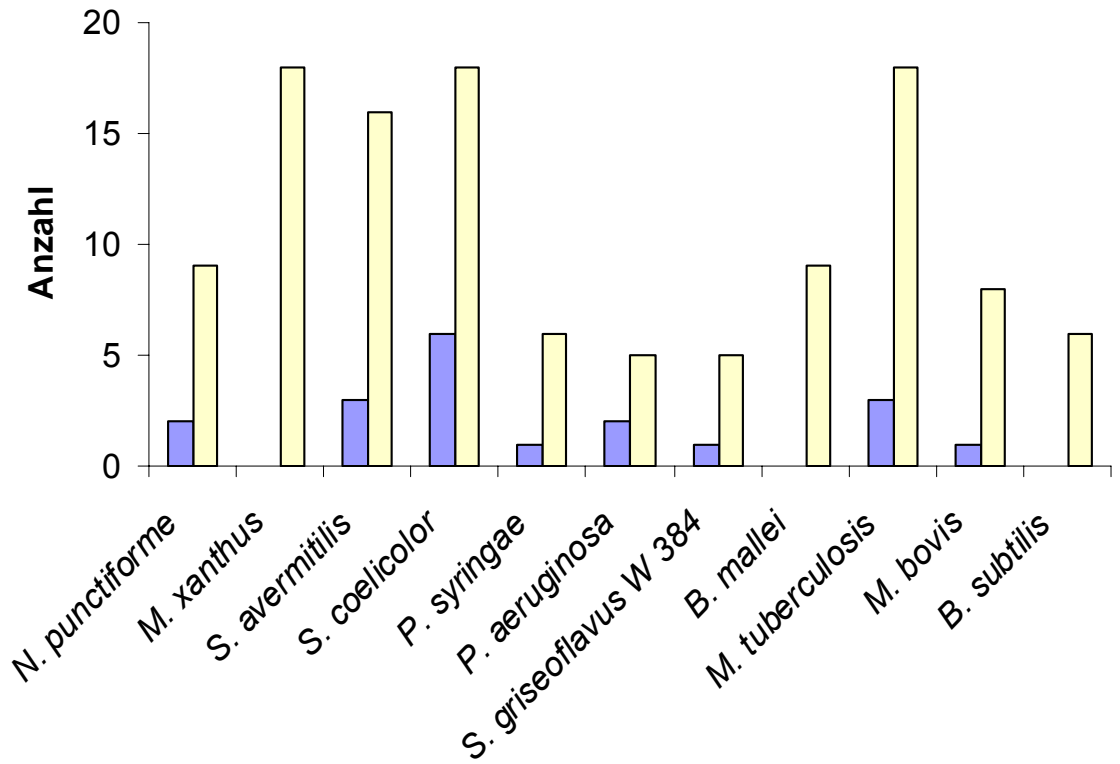

Für die Gewinnung neuer Leitstrukturen ist somit das Aktivieren von solchen "stillen“ Biosynthesegenclustern ein attraktives Ziel. Der einfachste, kostengünstigste und schnellste Weg hierzu ist der sogenannte OSMAC-Ansatz (one strain - $\underline{\text { many }}$ compounds). ${ }^{38}$ Hierbei wird durch Variation von Kultivierungsparametern, wie Nährmedienbestandteilen, Belüftung, Zusatz organischer Lösungsmittel etc., versucht, die stillen Gencluster zu aktivieren und die Produktion neuer Metaboliten anzuregen. So konnten aus dem Aspinonen-Produzenten Aspergillus ochraceus DSM7428 15 zusätzliche Metaboliten verschiedener Strukturklassen gewonnen werden.

Ein gezielterer Ansatz bedient sich des so genannten „genome mining“, bei welchem anhand genetischer Informationen über Biosynthesegencluster die Struktur eines potentiellen Metaboliten vorausgesagt wird. In S. coelicolor ist der inaktive Gencluster cch zu finden, welcher für eine NRPS codiert. Mit bioinformatischen Methoden können durch Vergleich der gefundenen mit schon bekannten Adenylierungsdomänen dieser NRPS Aussagen über die wahrscheinlich zum Aufbau des Peptids verwendeten Aminosäuren gemacht werden. In Verbindung mit der Kolinearitätsregel ${ }^{39}$ lässt sich so eine Struktur postulieren. Für cch kann nach diesem Prinzip ein aus L- $\delta-N$-Formyl- $\delta-N$-hydroxyornithin (hfOrn), L-Threonin und L- $\delta$ $\mathrm{N}$-Hydroxyornithin zusammengesetztes Tripeptid (13a) vorhergesagt werden, weitere Informationen lassen auf ein potentielles Siderophor schließen. ${ }^{40}$ Bei Kultivierung des 
Stammes unter Eisenausschluss wird anstelle von 13a ein neues Tetrapeptid, Coelichelin (13b) gefunden. Das Siderophor 13b zeigt die vorausgesagten Aminosäuren, wird allerdings im Widerspruch zur Kolinearitätsregel durch iterativen Gebrauch eines Moduls aufgebaut. Dieses Beispiel zeigt die Grenzen der Methode auf. Bei verbesserter Kenntnis der Biosynthese von Sekundärmetaboliten kann sie jedoch zukünftig von Nutzen für das Auffinden neuer Naturstoffe aus bekannten Stämmen sein. Es bleibt zu erwähnen, dass die Sequenzierung eines Genoms große Kosten verursacht und 13b in einem OSMAC-Ansatz mit der entsprechenden Nährmedienvariation mit geringerem Zeitaufwand und weitaus geringeren Kosten hätte gefunden werden können.<smiles>CC(O)C(NC(=O)[C@@H](N)CCCN(O)C=O)C(=O)N(O)CCCC(N)C(=O)O</smiles>

$13 a$<smiles>CC(O)C(NC(=O)C(N)CCCN(OO)C(=O)O)C(=O)N(CCCC(NC(=O)[C@H](N)CCCN(O[Tl])C(=O)O)C(=O)O)OO</smiles>

$13 b$

\subsection{Naturstoffe in der Malariatherapie}

Malaria (lat.: mala aria $=$ schlechte Luft) ist eine durch humanpathogene Protozoen hervorgerufene Infektionskrankheit. Die Erreger werden von der weiblichen Anophelesmücke übertragen und führen zu einer Primärinfektion der Leber. Im anschließenden Blutstadium der Krankheit werden Erythrozyten befallen, in welchen sich die Parasiten vermehren. Bei der Freisetzung der Protozoen aus den infizierten Erythrozyten kommt es zu einem Austreten von Zellbestandteilen, welche das charakteristische Fieber auslösen. Die Gattung Plasmodium falciparum verursacht das schwerste der vier bekannten Krankheitsbilder, die Malaria tropica. Dieser Erreger bewirkt die Einlagerung spezieller Proteine in die Erythrozytenmembran, die zu einer Anhaftung infizierter Blutkörperchen an prävenöse Kapillaren führen. So hervorgerufene Verschlüsse der Blutgefäße führen schließlich zum Tod.

Zum heutigen Zeitpunkt leben ca. 2.2 Milliarden Menschen in Plasmodium-Endemiegebieten, von ihnen erkranken jährlich rund 500 Millionen an Malaria. ${ }^{41}$ Die Sterblichkeit ist vor allem bei Kindern hoch, insgesamt werden 1.5-3.0 Millionen Todesfälle geschätzt. ${ }^{42}$ Trotz dieser immensen Zahlen sind lediglich fünf von insgesamt 1.300 seit 1975 entwickelten 
Medikamenten Antimalaria-Wirkstoffe, ${ }^{43}$ nahezu alle genutzten Präparate sind weitaus älter. Diese Entwicklung ist vor allem auf den Rückgang kolonialer Interessen der Industrienationen und die geringe Kaufkraft in Entwicklungsländern zurückzuführen.

\section{Antimalaria-Wirkstoffe aus Pflanzen}

Chinin war die erste chemische Reinsubstanz in der Malariatherapie. Der Naturstoff konnte 1820 aus der Rinde des in den Anden beheimateten Cinchona-Baumes isoliert werden. Indios benutzten die Rinde zur Fiebersenkung, somit liegt hier das erste Beispiel des oft erfolgreichen ethnomedizinischen Ansatzes bei der Wirkstoffsuche vor. ${ }^{44}$ Ausgehend vom Grundgerüst des Chinins wurden die 4- und 8-Aminochinoline (z.B. Chloroquin, Amodiaquin und Pamaquin, Primaquin) sowie die Arylaminoalkohole (z.B. Mefloquin, Halofantrin) entwickelt. Ihr Wirkmechanismus ist nicht vollständig aufgeklärt, eine Inhibierung der HämPolymerisation jedoch nachgewiesen. ${ }^{45}$

In der traditionellen chinesischen Medizin (TCM) wird der Einjährige Beifuss (Artemisia annua) seit mehr als 1500 Jahren für die Behandlung von Hämorrhoiden genutzt, seit 400 Jahren ist der Einsatz bei Fieber dokumentiert. Die Isolierung der aktiven Komponente, Artemisinin (14a, auch: Qinghaosu) gelang 1972. ${ }^{46}$ Die Substanz kann, wie viele Naturstoffe aus Pflanzen, nur in sehr geringen Ausbeuten isoliert werden, was hohe Kosten verursacht. Daher ist 14a vor allem in Afrika nur eingeschränkt als Antimalaria-Wirkstoff nutzbar. Die einzigartige Struktur des Moleküls wie die Anzahl der Ringe oder die Endoperoxidbrücke sind ein weiterer Beleg für die große chemische Diversität von Naturstoffen. Die Grundstruktur wurde bei Derivatisierungen erfolgreich genutzt, um hochpotente Wirkstoffe wie das Dihydroartemisinin (14b), Artemether (14c), Arteether (14d) und Artesunat (14e) zu entwickeln. Die pharmakophore Gruppe von 14a ist die Endoperoxidbrücke, diese kann durch ein sekundäres Ozonid wie in OZ277 (14f) ersetzt werden. Das Trioxolan $\mathbf{1 4 f}$ befindet sich derzeit in Klinischen Studien der Phase II. ${ }^{47}$
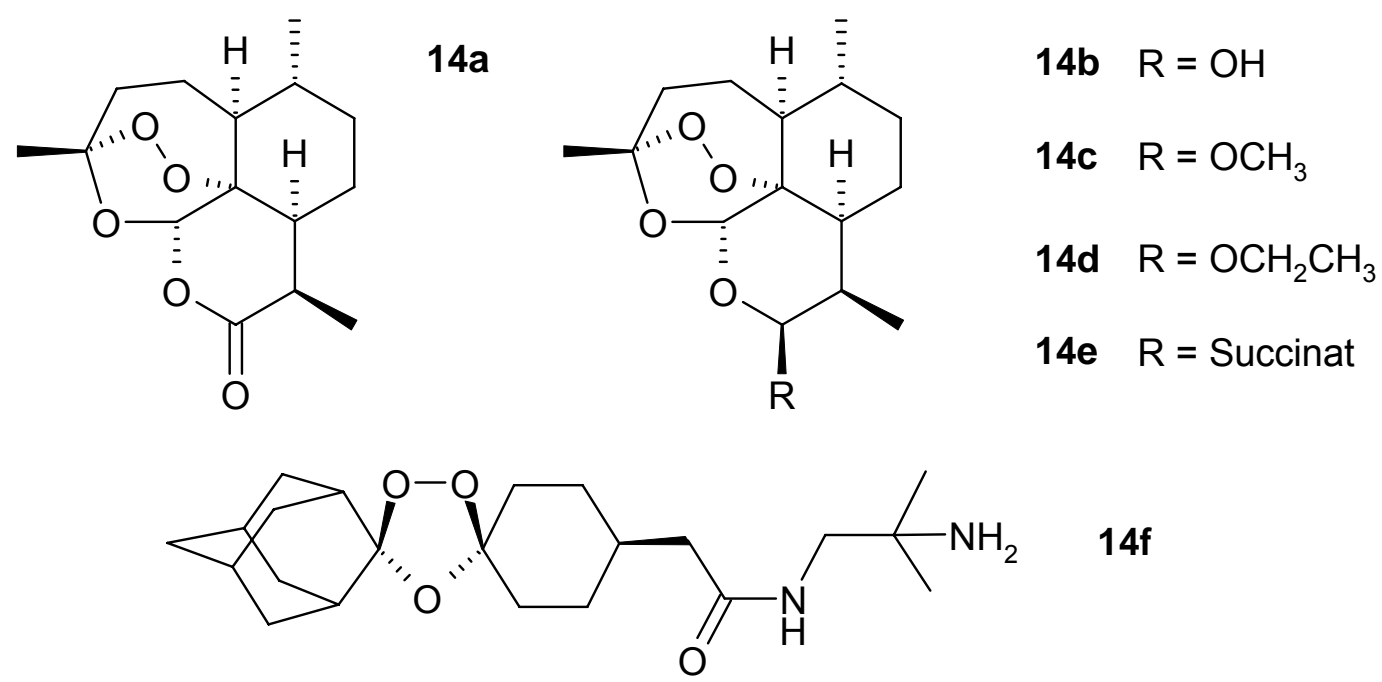


\section{Antimalaria-Wirkstoffe aus Mikroorganismen}

Tetracycline (wie z.B. Doxycyclin) sind antibakterielle Substanzen aus Mikroorganismen, die eine große Aktivität gegen Gram-positive und -negative Organismen sowie Plasmodium sp. besitzen. Ihre antibakterielle Wirkung beruht auf einer Inhibierung der Proteinbiosynthese über die Blockade der Bindung der Aminoacyl-tRNA an die 16S rRNA der 30S Untereinheit des prokaryotischen Ribosoms. In Malariaparasiten sind zwei extrachromosomale DNAs mit prokaryotischen Eigenschaften zu finden, ein ähnlicher Wirkmechnismus ist somit wahrscheinlich. Hierdurch besitzen die Tetracycline eine starke, aber langsam einsetzende antiplasmodiale Aktivität, weshalb sie nur als Kombinationspräparat oder zur Prophylaxe eingesetzt werden können. Für eine Reihe weiterer antibakteriell wirksamer Substanzen konnte diese Aktivität nachgewiesen werden. ${ }^{48}$

Ein anderer antibakteriell wirksamer Sekundärmetabolit mit Aktivität gegen Plasmodium ist das Borrelidin (15). Der Wirkmechanismus des Makrolids 15 unterscheidet sich von dem der Tetracycline. Der Parasit wird von 15 über eine Hemmung der Threonyl-tRNA-Synthetase und eine Aktivierung von Apoptose-induzierenden Enzymen abgetötet (s. Kap. 4, S. 88). ${ }^{48}$

Ein bisher von keinem Malariapräparat genutzter Angriffspunkt für Antimalaria-Wirkstoffe ist die Membran des infizierten Erythrozyten. Nach Infektion wird diese Membran durch den Parasiten verändert, damit dessen Bedarf an Nährstoffen gedeckt werden kann. Weiterhin müssen die Konzentrationen von physiologisch wichtigen lonen (wie $\mathrm{H}^{+}, \mathrm{K}^{+}, \mathrm{Na}^{+}$und $\mathrm{Ca}^{2+}$ ) angepasst werden. ${ }^{49}$ Substanzen, die Transporteigenschaften von Ionenkanälen beeinflussen oder selbst als lonencarrier fungieren, eignen sich deshalb zur Malariatherapie. Bei einem Screening mit derartigen mikrobiellen Sekundärmetaboliten wiesen VIAL et al. für 21 von 22 lonophoren eine $\mathrm{IC}_{50}$ im nanomolaren Bereich gegen Plasmodium falciparum nach. ${ }^{50}$ Eine herausragende Stellung nahm hierbei das Gramicidin D mit einer subnanomolaren Aktivität bei geringer Toxizität ein. ${ }^{51}$ Das lineare Peptid kann als dimerer Komplex in Membranen eingelagert werden und einen lonenkanal bilden. Zudem konnten für einige cyclische Peptide, welche aufgrund ihrer Struktur nicht in der Lage sind ganze Membranen zu überspannen, antiplasmodiale Aktivitäten nachgewiesen werden. Beispiele hierfür sind die Enniatine ${ }^{52}$ oder das in dieser Dissertation bearbeitete Hormaomycin (16) ${ }^{53}$ (s. Kap. 2.6.2, S. 62). Bis auf die Peptide Gramicidin D und 16 sowie die Tetracycline sind für die meisten Antimalaria-Wirkstoffe aus Mikroorganismen klinische Anwendungen aufgrund hoher Toxizität ausgeschlossen.

Resistenzen, wie für Bakterien unter Kap. 1.1 beschrieben, entwickeln sich auch in Plasmodium falciparum. In Afrika tragen die meisten Stämme Chloroquinresistenzen, während in Asien zudem Artemisinin (14a) seine Wirksamkeit langsam einbüßt. Auch das hier nicht näher beschriebene, lange Zeit erfolgreich eingesetzte, Antifolat- 
Kombinationspräparat Sulfadoxin/Pyrimethamin ist in den meisten Endemiegebieten nicht mehr zuverlässig einsetzbar. ${ }^{54}$<smiles>CC1CC(C/C=C/C=C(/C#N)C(O)C2CCC[C@@H]2C(=O)O)OC(=O)CC(O)[C@H](C)C[C@H](C)C[C@H](C)C1</smiles>

15

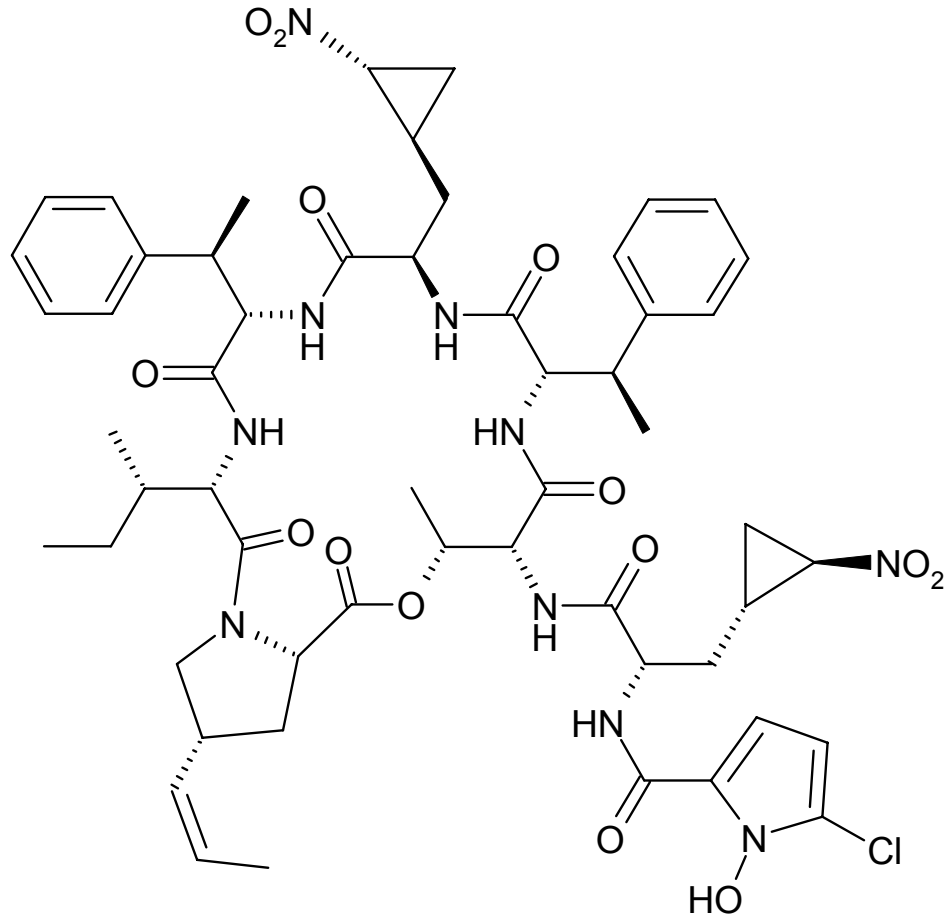

16

Die beschriebene Notwendigkeit in der Chemotherapie nach neuen Targets vor allem für die Behandlung von Infektionskrankheiten zu suchen, das bisherige Versagen kombinatorischer Ansätze in der Leitstruktursuche und der in ausgewählten Beispielen dargestellte Erfolg der Kombination von Naturstoffchemie und Organischer Synthese (und nicht ihre Konkurrenz) zeigen, dass die sekundären Naturstoffe aus Pflanzen und Mikroorganismen durch nichts zu ersetzen sind. Die Renaissance der Naturstoffchemie wird von vielen Wissenschaftlern vorausgesagt und kündigt sich weltweit an. ${ }^{55}$ 


\subsection{Aufgabenstellung}

Im Mittelpunkt der vorliegenden Dissertation steht der Hormaomycin-Produzent Streptomyces griseoflavus (Stamm W 384). Mit Hilfe der Vorläufer-dirigierten Biosynthese sollten neue Derivate des Hormaomycins (16) generiert und anschließend getestet werden, um Struktur-Wirkungsbeziehungen für das Peptidlacton 16 abzuleiten. Weiterhin sind Aussagen zur Spezifität der an der Biosynthese beteiligten Enzyme sowie zu Biosynthesemechanismen der einzelnen Aminosäuren möglich. Für eine effektive Durchführung dieser Experimente waren die Stammhaltung und Kultivierung von Streptomyces griseoflavus (Stamm W 384) hinsichtlich einer konstant hohen HormaomycinProduktion zu optimieren. Im Rahmen von Kooperationsprojekten mit den Arbeitsgruppen PROF. SHELDRICK (Institut für Anorganische Chemie, Universität Göttingen) und PROF. GRIESINGER (MPI für Biophysikalische Chemie, Göttingen) sollte der Naturstoff 16 für röntgenkristallographische und NMR-Untersuchungen in sehr reiner Form gewonnen werden. In Kooperation mit der Arbeitsgruppe PROF. PIEL (Kekulé-Institut für Organische Chemie und Biochemie, Universität Bonn) sollte der Gencluster der Hormaomycin-NRPS identifiziert werden.

In einem zweiten Arbeitsansatz sollten verschiedene Actinomyceten aus der Mongolei und Portugal einem Chemischen Screening unterzogen werden. Die hierbei ausgewählten Stämme waren in größerem Maßstab zu kultivieren, auffällige Sekundärmetaboliten zu isolieren und die Strukturen der Naturstoffe mit verschiedenen spektroskopischen Methoden aufzuklären. Hierzu gehörte auch die Strukturaufklärung von im Arbeitskreis PROF. FIEDLER (Mikrobiologisches Institut, Universität Tübingen) in einem HPLC-DADScreening aufgefallenen Sekundärmetaboliten aus Streptomyces sp. Stamm Tü 6319 und Stamm Tü 2561.

Der dritte Teil der Arbeit widmet sich dem im Chemischen Screening entdeckten BorrelidinProduzenten Actinomyces sp. Stamm M4-1. Mit inm sollte die von LEADLAY und SALAS ${ }^{56}$ mit genetischen Methoden untersuchte Biosynthese des Borrelidins (15) durch Fütterungsexperimente mit isotopenmarkierten Vorläufern verifiziert werden. Weiterhin wurde bei dem Makrolid 15 durch Einsatz der Vorläufer-dirigierten Biosynthese die Isolierung neuer Derivate angestrebt. 


\section{Hormaomycin}

Der Hormaomycin-Produzent Streptomyces griseoflavus (Stamm W 384) aus Anaradhapura (Sri Lanka) fiel im Arbeitskreis H. WOLF, H. ZÄHNER in einem Screening auf intrazelluläre Signalsubstanzen auf. ${ }^{57,58}$ Als biologisch aktive Komponente konnte das Peptidlacton Hormaomycin (16) isoliert werden, welches in der Lage ist, die Sporulation und Sekundärmetabolitenproduktion anderer Actinomyceten anzuregen (gr. hormao $=i c h$ rege an), eine selektive antibakterielle Aktivität gegen coryneforme Bakterien und eine ausgeprägte Wirkung gegen Plasmodium falciparum, den Erreger der Malaria tropica, besitzt. $^{53,59} 1984$ wurde 16 erstmals von S. OMURA et al. isoliert, eine vollständige Strukturaufklärung gelang der japanischen Arbeitsgruppe zum damaligen Zeitpunkt jedoch nicht, woraufhin sie nur eine Partialstruktur unter dem Namen Takaokamycin veröffentlichten. ${ }^{60}$ Die Identität beider Substanzen konnte später trotz Differenzen in den chemischen Verschiebungen des Protonenspektrums verifiziert werden.

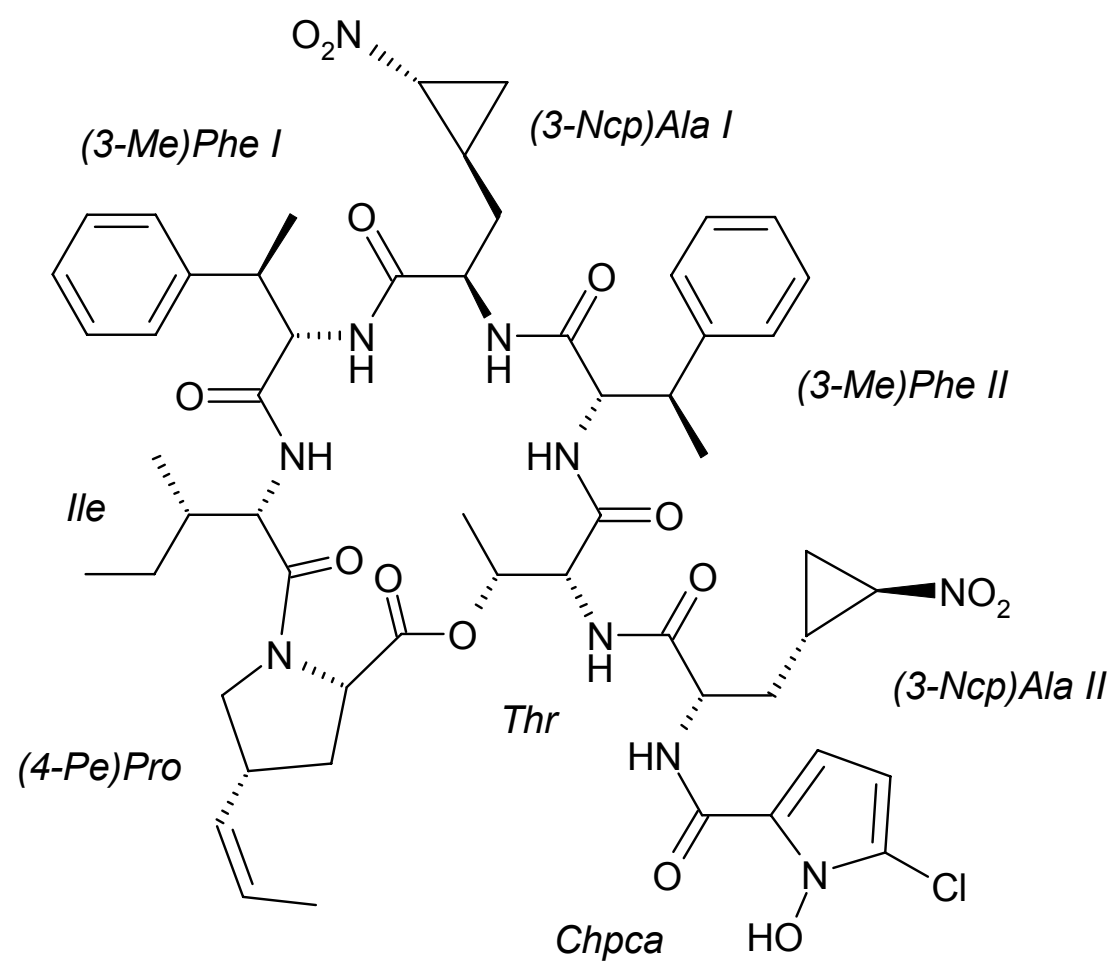

16

Neben den herausragenden biologischen Aktivitäten zeigt dieses Molekül interessante Strukturbausteine. Die Struktur wurde von E. RöSSNER aufgeklärt, ${ }^{61,62}$ erste Untersuchungen zur Aufklärung der Konfiguration von HENNE ${ }^{63}$ und RITZAU ${ }^{64}$ unternommen. ${ }^{65}$ Die vollständige Bestimmung der absoluten Konfiguration gelang durch die Arbeiten von ALVERMANN ${ }^{66}$ und die erfolgreiche Totalsynthese von 16 durch ZLATOPOLSKIY. ${ }^{67,68,69}$ Der Naturstoff 16 besteht aus einer proteinogenen [L-Isoleucin, (I/e)] und sechs nicht-proteinogenen Aminosäuren 
sowie einer an C-5 chlorierten 1-Hydroxypyrrol-2-carbonsäure [Chpca] als Startereinheit. Neben den bereits literaturbekannten nicht proteinogenen Aminosäuren L-threo-3Methylphenylalanin [( $\beta M e) P h e ~ I$ und II] und D-allo-Threonin (a-Thr) sind in 16 mit 3-(1'R,2'R)(trans-2'-Nitrocyclopropyl)alanin in D- und L-Konfiguration [(3-Ncp)Ala I und I/] sowie 4-(Z)Propenylprolin [(4Pe)Pro] drei erstmals beschriebene Aminosäuren enthalten.

\subsection{Kultivierung von Streptomyces griseoflavus Stamm W 384}

Die Kultivierung von Stamm W 384 erfolgte unter den für die Hormaomycin-Produktion von RAUCH und GEERS optimierten Bedingungen. ${ }^{70,71}$ Als wichtig für eine leichte Isolierung hatte sich die Verwendung eines synthetischen Nährmediums erwiesen, da hierbei störende Bestandteile komplexer Nährmedien nicht auftreten. Für das synthetische Nährmedium wurden Asparagin als Stickstoffquelle und Mannit als Kohlenstoffquelle genutzt, wobei ein hoher Zusatz an $\mathrm{NaCl}(25 \mathrm{~g} / \mathrm{L})$ sich gut auf die Hormaomycin-Ausbeute auswirkte. Zurückgehend auf Beobachtungen von OMURA, wonach die optimale Kultivierungstemperatur in Bezug auf Sekundärmetabolitenproduktion nicht mit der auf optimale Wachstumsbedingungen eines Stammes identisch sein muss, ${ }^{72}$ wurde von ANDRES ${ }^{59,73}$ dieser Parameter in die Ausbeuteoptimierung mit eingebracht. Fortan wurde die Absenkung der Temperatur während der Fermentation von anfänglich $27^{\circ} \mathrm{C}$ auf $20^{\circ} \mathrm{C}$ zur 20 . Stunde nach Inokulation mit der Vorkultur als Bedingung für hohe Ausbeuten ( $15 \mathrm{mg} / \mathrm{L})$ von 16 angenommen. Dieser Effekt konnte nicht mehr beobachtet werden, so dass alle Fermentationen nur noch bei konstant $27^{\circ} \mathrm{C}$ durchgeführt wurden. Die von ALVERMANN beschrieben Steigerung der Ausbeute durch Fütterung von putativen Vorläufern des Peptids, wie Prolin als Vorläufer der Chlorhydroxypyrrolcarbonsäure (Chpca), konnte bestätigt werden. Allerdings konnten die Ausbeuten durch Zufütterung von 2-Pyrrolcarbonsäure (2 $\mathrm{mM}$ ), einem vermeintlichen Intermediat der Chpca-Biosynthese, auf bis zu $45 \mathrm{mg} / \mathrm{L}$ gesteigert werden. Die Fütterungen erfolgten nach einer Wachstumsphase von $20 \mathrm{~h}$, um eine Störung des Primärstoffwechsels zu vermeiden. 


\subsection{Chemische und biologische Verfahren zur Derivatisierung von Naturstoffen}

„Wo die Natur aufhört, neue Formen entstehen zu lassen, beginnt der Mensch mit den natürlichen Dingen, mit Hilfe eben dieser Natur, eine unendliche Vielfalt der Formen zu schaffen."

Leonardo da Vinci

Wie in Kapitel 2 beschrieben zeigt das Peptidlacton 16 interessante biologische Aktivitäten, und kann somit als Leitstruktur dienen. Erste Versuche zur Derivatisierung des Naturstoffs auf chemischem Weg unternahm RITZAU ${ }^{64}$, wobei wegen der geringen Stabilität des Moleküls nur Reaktionen unter milden Bedingungen möglich waren. So gelangen z.B. die Reduktionen der Doppelbindung am Propenylprolin, an der Pyrrolcarbonsäure sowie an den Nitrofunktionalitäten der Cyclopropylalanine. ${ }^{64}$ Die Totalsynthese von 16 hingegen ermöglichte weiterreichende Derivatisierungen und konnte zu strukturellen Veränderungen am Ringsystem genutzt werden. So gelang ZLATOPOLSKIY z.B. die Darstellung des Hormaomycin-Peptidlactams (17). ${ }^{69,74}$

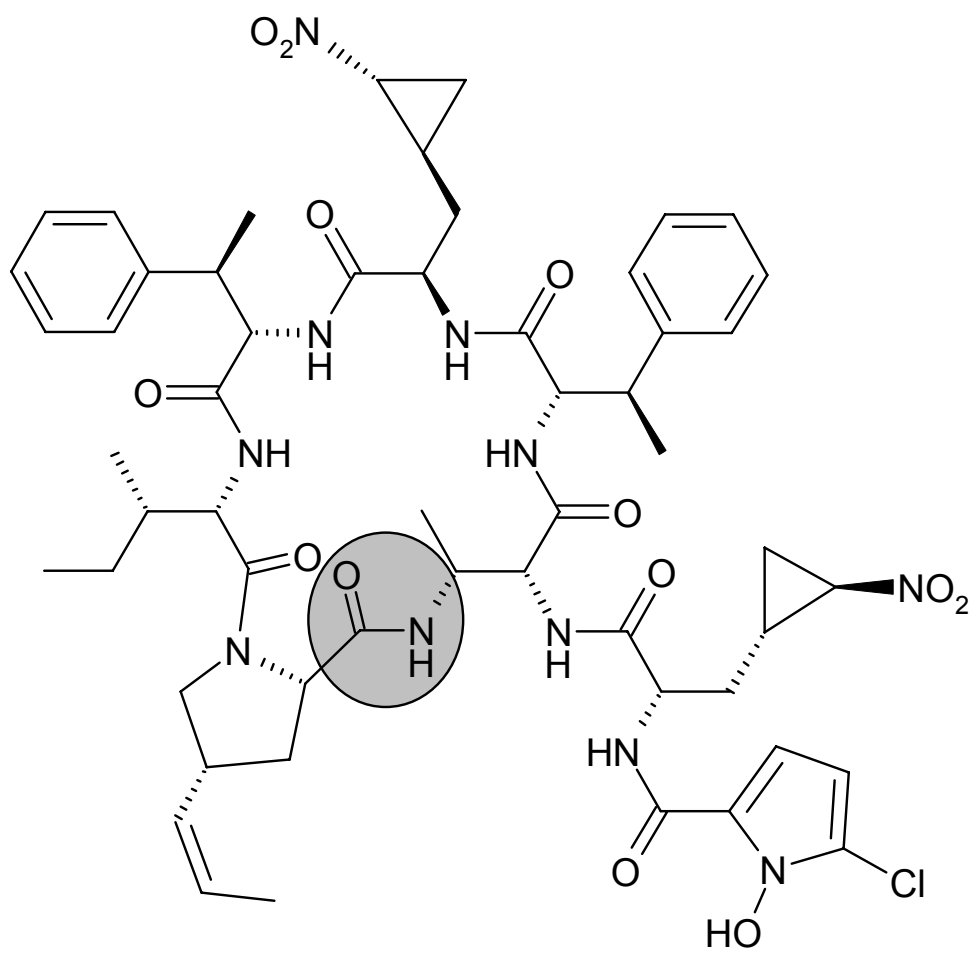

17

Neben den beschriebenen (semi-)synthetischen Veränderungen einer Leitstruktur wie 16 können biologische Methoden genutzt werden, um einen Naturstoff effektiv zu variieren und 
so Struktur-Wirkungsbeziehungen zu erkennen und/ oder eine Verbesserung der biologischen Aktivitäten zu erreichen. Für die biologische Derivatisierung von Naturstoffen können natürliche oder genetisch manipulierte Mikroorganismen, bzw. deren Enzyme genutzt werden.

Ein Beispiel für Arbeiten mit genetisch manipulierten Organismen ist die Mutasynthese. Nach RINEHART $^{75}$ umfasst sie die Generierung von Blockmutanten, Integrierung eines Mutasynthons sowie die Isolierung der Substanz. Erste Mutasyntheseexperimente wurden von SHIER ${ }^{76}$ an Streptomyces fradiae, einem Neomycin-Produzenten, durchgeführt. Der Stamm wurde unter Zusatz des Punktmutationen verursachenden $N$-Methyl- $N$ '-nitro- $N$ nitrosoguanidin kultiviert, wodurch Mutanten entstanden, die die Fähigkeit zur Aminoglykosidproduktion erst durch Zufütterung geeigneter Mutasynthons erreichten. Hierdurch konnten insgesamt fünf neue Antibiotika gewonnen werden. Ein Nachteil dieser Technik ist die durch die zufällige genetische Manipulation bedingt große Zahl entstehender Mutanten und deren aufwendige Vereinzelung.

Modernere Verfahren der Mutasynthese bedienen sich gezielter Mutationen, z.B. durch knock-out eines einzelnen Biosynthesegens. Als Beispiel für diese Derivatisierungstechnik können die Glykopeptidantibiotika Vancomycin ${ }^{77}$ und Balhimycin ${ }^{78}$ genannt werden. So ist die Deletionsmutante OP696 ${ }^{79}$ des Balhimycin-Produzenten Amycolatopsis mediterranei nicht mehr befähigt $\beta$-Hydroxytyrosin zu synthetisieren, was einen Ausfall der BalhimycinProduktion zur Folge hat. Die Zufütterung von 3-Fluor- $\beta$-Hydroxytyrosinderivaten hingegen führt zur Produktion eines neuen Antibiotikums, des Fluorbalhimycins (18).

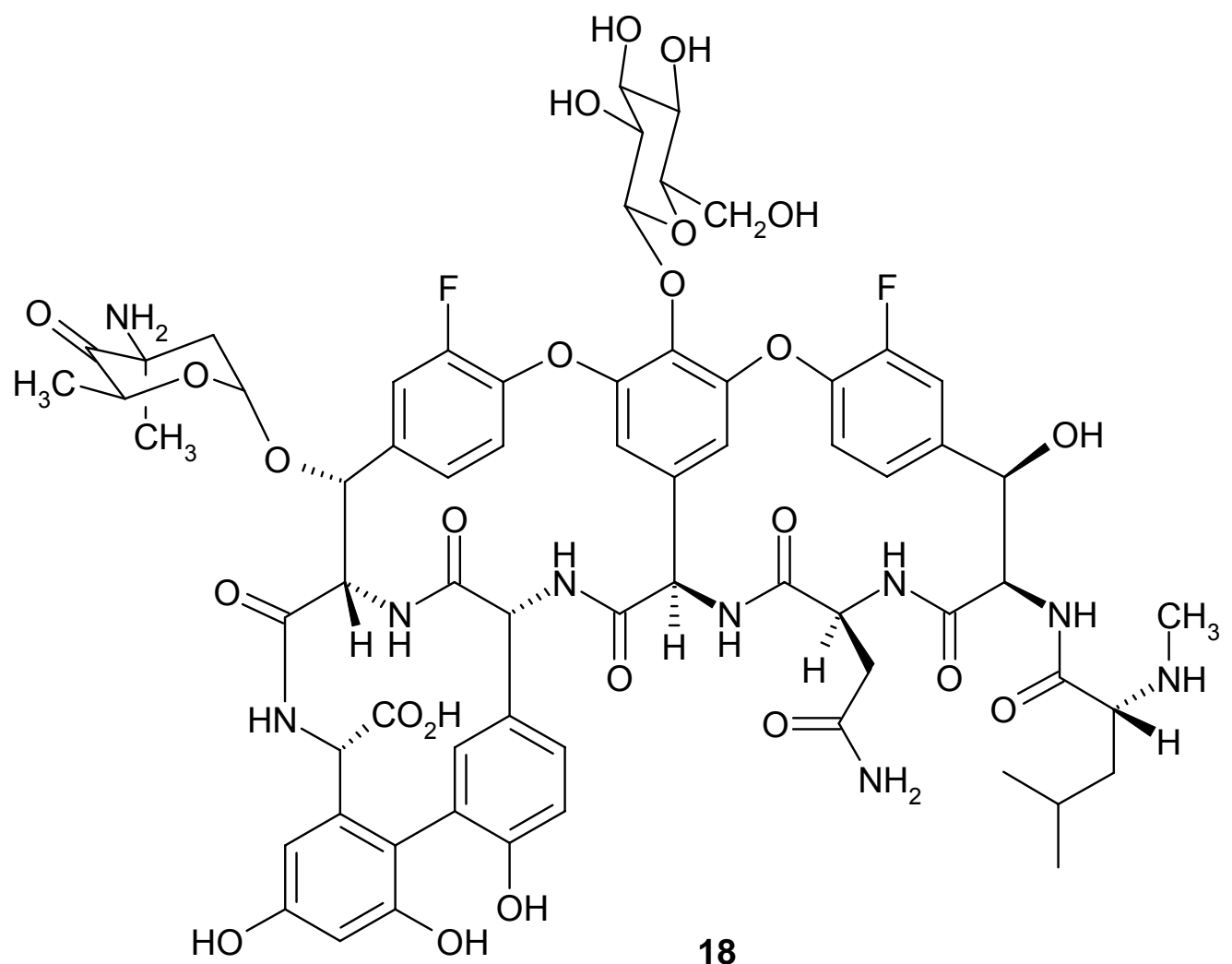


Ein Nachteil der gezielten Mutasynthese ist die nötige exakte Kenntnis des Biosynthesegenclusters des jeweiligen Naturstoffproduzenten, dazu müssen Geld und Zeit in erheblicher Größenordnung investiert werden. Wildstämme von Mikroorganismen können einfacher durch Enzyminhibitoren oder die Vorläufer-dirigierte Biosynthese zur Derivatisierung von Naturstoffen angeregt werden. Die gezielte Inhibierung von Enzymen ist möglich, wenn Vorläufer der Biosynthese eines Naturstoffs bekannt sind. Dies kann zur Akkumulation von Vorläufern oder auch Abzweigungen in Biosynthesewegen führen. ${ }^{80}$

Die Vorläufer-dirigierte Biosynthese ${ }^{81}$ nutzt eine oftmals vorhandene geringe Substratspezifität in einzelnen Modulen eines Multienzymkomplexes. Hierbei werden zu den im natürlichen Sekundärmetabolit vorkommenden Bausteinen verwandte Substanzen (bei Peptiden z.B. Aminosäuren) zu einer wachsenden Kultur gefüttert und anstelle dieser in das Zielmolekül eingebaut. ISAKA et al. ist auf diese Weise die Derivatisierung des Cyclohexadepsipeptids Beauvericin (19) durch Zufütterung unnatürlicher Aminosäuren wie D-Isoleucin sowie L- und D-allo-Isoleucin gelungen. ${ }^{82}$ Bemerkenswert an diesem Beispiel ist vor allem, dass Epimere der natürlich vorkommenden Aminosäuren in das Peptid eingebaut wurden obwohl Nichtribosomale Peptidsynthetasen (NRPS) zumeist hohe Selektivität bezüglich der C-2-Stereochemie der Aminosäuren aufweisen. ${ }^{83}$

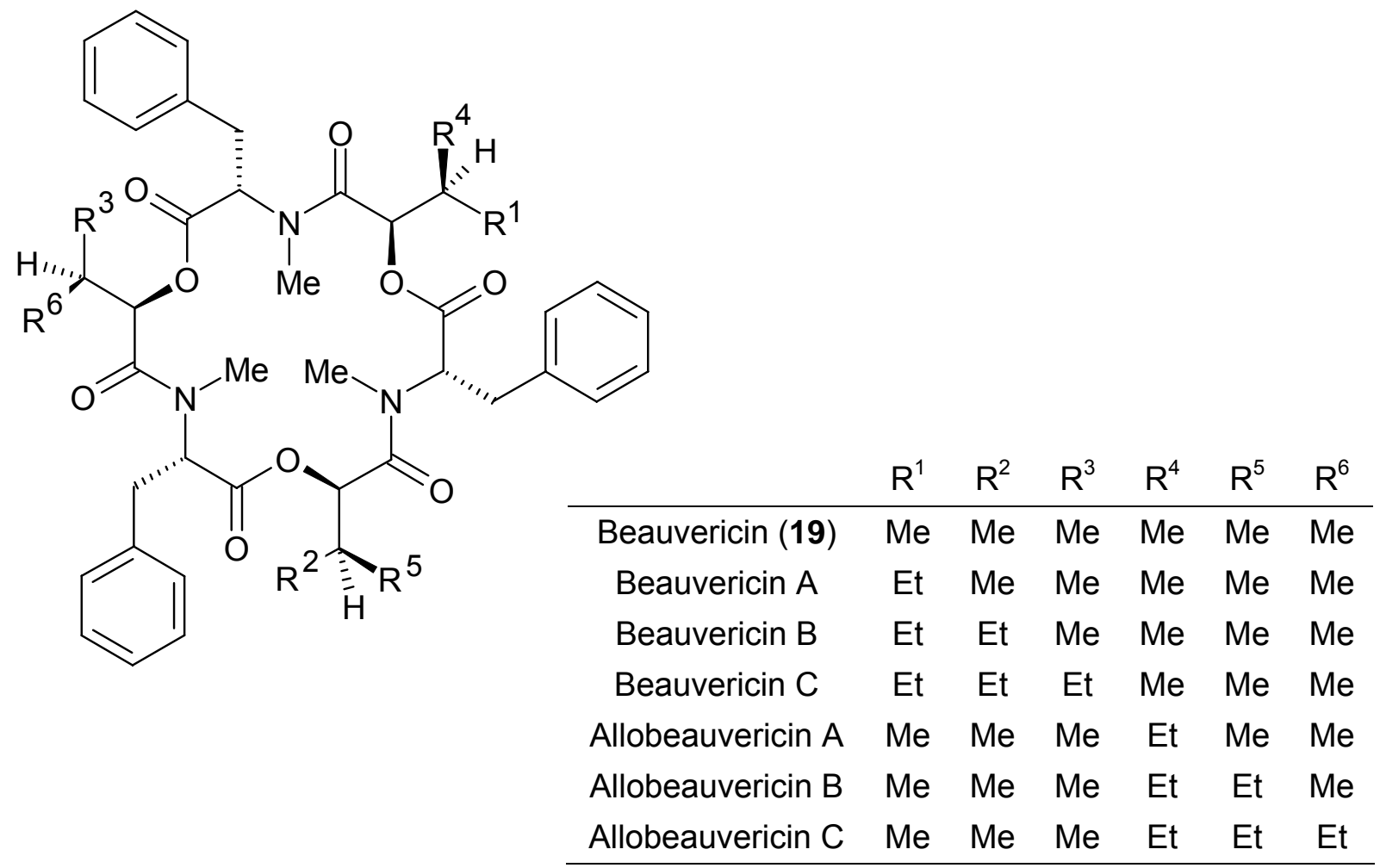

Abb. 2: Allobeauvericine durch Vorläufer-dirigierte Biosynthese an Paecilomyces tenuipes BCC1614. 
Durch die Konkurrenz zwischen der gefütterten und der natürlichen Aminosäure um den Einbau in ein Peptid entstehen bei der Vorläufer-dirigierten Biosynthese im Gegensatz zur Mutasynthese oftmals Produktgemische von mindestens zwei Substanzen. Aufgrund der Ähnlichkeit zwischen Naturstoff und Derivat kann es in Folge dessen zu Problemen bei der Isolierung von Reinsubstanzen kommen. Weiterhin enthalten viele Peptide, wie auch das Hormaomycin (16), ein und dieselbe Aminosäure mehrfach, woraus eine noch größere Anzahl an Derivaten resultiert (s. Abb. 3). Allerdings ergibt sich hieraus auch gleichzeitig der Vorteil, dass mehr Analoga eines Naturstoffs mit einem Fütterungsexperiment zugänglich sind.

Vorläufer-dirigierte Biosynthese (A)

Wildtyp
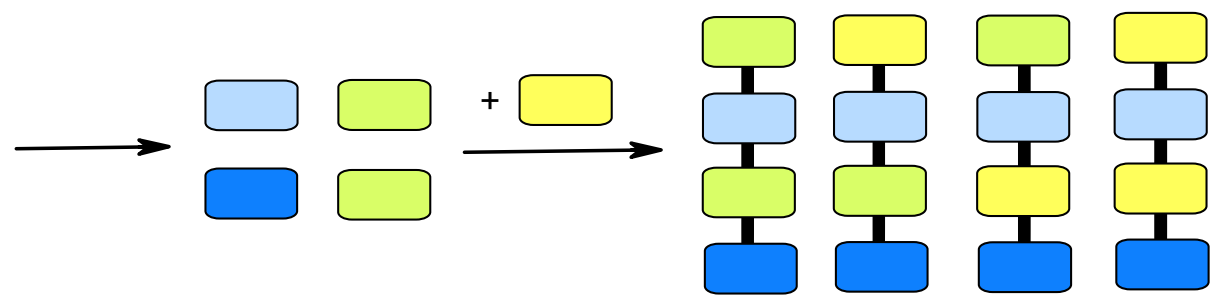

\section{Mutasynthese (B)}

knock-out Mutante
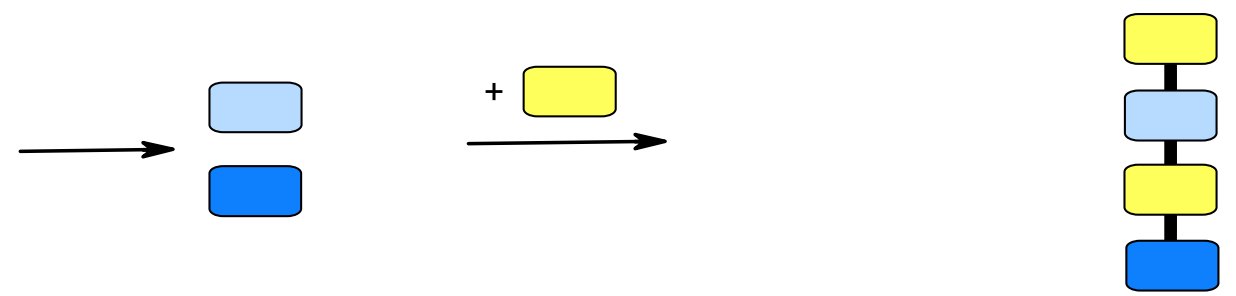

Abb. 3: Vorläufer-dirigierte Biosynthese (A) und Mutasynthese (B) im Vergleich: Die Mutante ist nicht mehr in der Lage den grünen Baustein zu biosynthetisieren, bei Fütterung des „unnatürlichen“ gelben Bausteins resultiert nur ein Derivat (B); der Wildtyp des Naturstoffproduzenten produziert bei Fütterung des gelben Bausteins neben dem Naturstoff drei Analoga (A).

Neben Kenntnissen der Biosynthese eines Sekundärmetaboliten und seiner Vorläufer muss bei den biologischen Derivatisierungen sichergestellt sein, dass die gefütterten Substanzen vom Produzenten toleriert und aufgenommen werden. Für die Variation von Peptiden ist dies zumeist unproblematisch, da in Zellmembranen aktive Transportsysteme für Aminosäuren existieren und somit im Gegensatz zu vielen Polyketidvorläufern (s. Kap. 4.3, S. 100) die Verfügbarkeit am Ort der Sekundärmetabolitenbiosynthese sichergestellt ist.

Weiterhin erscheinen Peptide ideal für den Einsatz in der PDB, da ihre Biosyntheseenzyme häufig eine relativ geringe Substratspezifität aufweisen. ${ }^{84}$ Diese Beobachtung ist allerdings nicht zu verallgemeinern, schon innerhalb ein und desselben NRPS-Komplexes können sehr spezifische neben scheinbar unspezifischen Modulen existieren, wie am Beispiel des 
Immunsuppressivums Cyclosporin gezeigt werden konnte. ${ }^{85,86}$ Generell gilt jedoch, dass Enzyme des Sekundärmetabolismus eine geringere Substratspezifität als solche des Primärmetabolismus zeigen. ${ }^{87}$

\subsection{Vorläufer-dirigierte Biosynthese mit Streptomyces griseoflavus (Stamm W 384)}

In der vorliegenden Dissertation sollten neue Hormaomycine mit der Technik der Vorläuferdirigierten Biosynthese (PDB) dargestellt werden. Hierfür wurden die Kultivierungen in $1 \mathrm{~L}-$ Biostat M-Fermentern durchgeführt, ein Scale-up auf 5-50 L zur Vergrößerung der Ausbeute führte trotz Belüftungs- und Rührgeschwindigkeitsvariationen ebenso wie der Versuch einer Kultivierung in Schüttelkulturen zu einem totalen Ausfall der Hormaomycin-Biosynthese. Die verwendeten Vorläufer wurden wie bei der $1 \mathrm{~L}$-Standardfermentation ab der 20. Stunde über einen Zeitraum von $10 \mathrm{~h}$ im continous flow-Verfahren zu der Kulturbrühe gepumpt.

\subsubsection{Variation der 3-(2'-Nitrocyclopropyl)alanin-Einheiten ${ }^{\mathrm{a}}$}

Die strukturell interessanteste nicht-proteinogene Aminosäure des Hormaomycins (16) ist das 3-(2'-Nitrocyclopropyl)alanin [(3-Ncp)Ala]. An diesem Baustein wurden schon erste Versuche zur Vorläufer-dirigierten Biosynthese durchgeführt, wobei eine allgemeine Substratflexibilität der Hormaomycin-NRPS zu beobachten war. ${ }^{66}$ Cyclopropylalanine, an denen die Nitrogruppe durch einen Carbonsäurerest substituiert war, wurden von dem Multienzymkomplex als Substrate akzeptiert. Bei diesem Fütterungsexperiment kamen die unnatürlichen Aminosäuren 3-(2'-Methoxycarbonylcyclopropyl)alanin [(3-Mcp)Ala] sowie 3-(2'-Carboxycyclopropyl)alanin [(3-Ccp)Ala] zum Einsatz, die beide bevorzugt eingebaut wurden. Es entstand in beiden Ansätzen nur das neue Hormaomycin C (20), d.h. die freien Carboxylgruppen werden im Verlauf der Biosynthese methyliert. Natives Hormaomycin (16) oder solches mit einmaligem Einbau konnte nicht nachgewiesen werden. Ein elektronenziehender Rest ist für die Erkennung der Aminosäure durch den Multienzymkomplex allerdings notwendig, wie die negativen Resultate von Fütterungen mit 3-Cyclopropylalanin und 3-(2'-Aminocyclopropyl)alanin zeigten.

\footnotetext{
a Großer Dank für die Synthese der in Kap. 2.3.1 verwendeten Aminosäuren gilt Herrn DR. B.D. ZLATOPOlskiY und Herrn PROF. Dr. A. DE MeIJERE.
} 


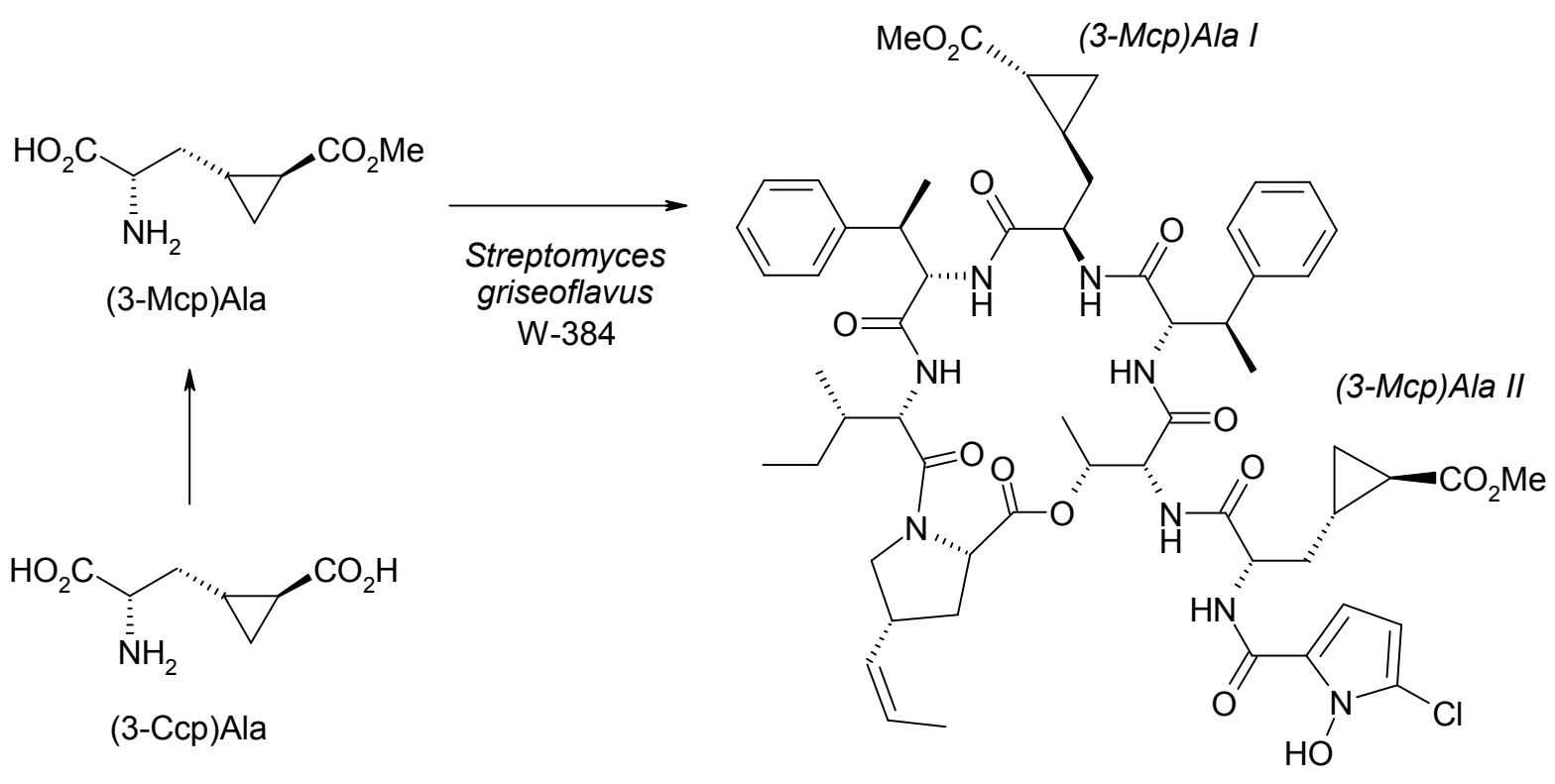

20

Abb. 4: $\quad$ Vorläufer-dirigierte Biosynthese an Streptomyces griseoflavus Stamm W 384.

Diese Ergebnisse zeigen eine Toleranz der Hormaomycin-NRPS gegenüber Cyclopropylalaninen mit einem elektronenziehenden Substituenten am Cyclopropanring. Durch Fütterung von Aminosäuren ohne Cyclopropylring sollten die Erkenntnisse über die Spezifitäten der Biosyntheseenzyme ausgeweitet werden.

\subsubsection{Fütterung von 5-Nitronorvalin}

Das 5-Nitronorvalin [ $\left.\left(\mathrm{NO}_{2}\right) \mathrm{Nva}\right]$ ist eine nicht proteinogene Aminosäure, welche sich vom (3-Ncp)Ala durch das Fehlen der Methylengruppe des Rings unterscheidet. Der Abstand zwischen den funktionellen Gruppen gleicht hingegen dem des natürlichen Substrats der Hormaomycin Biosynthese. Die Fütterungen wurden mit den enantiomerenreinen D- und L$\left(\mathrm{NO}_{2}\right) \mathrm{Nva}$ wie auch dem racemischen Gemisch durchgeführt.<smiles>N[C@@H](CCC[N+](=O)[O-])C(=O)O</smiles>

$\left(\mathrm{NO}_{2}\right) \mathrm{Nva}$<smiles>N[C@@H](C[C@@H]1CC1[N+](=O)[O-])C(=O)O</smiles>

(3-Ncp)Ala 


\section{Fütterung von L-5-Nitronorvalin}

Die Fütterungen wurden unter den Standardfermentationsbedingungen mit 1.0 und $2.0 \mathrm{mM}$ Endkonzentrationen durchgeführt. Die unterschiedlichen Konzentrationen hatten keinen Einfluss auf Ausbeuten und Einbauverhältnisse der gewonnenen Hormaomycine.

Nach einmaliger Chromatographie an Kieselgel zeigte das ESI-Massenspektrum der Hormaomycin-haltigen Fraktion neben dem Peak für Hormaomycin (16) bei $\mathrm{m} / \mathrm{z}=1151$ $[\mathrm{M}+\mathrm{Na}]^{+}$zwei weitere Peaks bei $\mathrm{m} / \mathrm{z}=1139$ sowie 1127 jeweils $[\mathrm{M}+\mathrm{Na}]^{+}$, die in einem Verhältnis von $1.0: 4.0: 3.5$ (16:1139:1127) stehen. Die erhaltenen Molmassen zeigen das Fehlen von einem bzw. zwei Kohlenstoffatomen (Massenunterschied 12) im Vergleich zu 16 an. Die Trennung der Derivate gelang mit semipräparativer HPLC, wobei drei Fraktionen $(A-C)$ gewonnen werden konnten, die sich in ihrem UV-Spektrum glichen.

Das ESI-Massenspektrum der mit einer Ausbeute von $1.5 \mathrm{mg}$ gewonnenen Substanz C $\left(R_{t}=23.9\right)$ weist einen Peak bei $\mathrm{m} / \mathrm{z}=1116[\mathrm{M}+\mathrm{H}]^{+}$auf, dessen Hochauflösung die Summenformel $\mathrm{C}_{54} \mathrm{H}_{69} \mathrm{~N}_{10} \mathrm{O}_{14} \mathrm{Cl}$ ergibt, was für einen einfachen Einbau des zugefütterten $\left(\mathrm{NO}_{2}\right) \mathrm{Nva}$ spricht. Im Protonenspektrum der Substanz fehlen die vier charakteristischen Signale von 3'- $\mathrm{H}_{\mathrm{a}}, 3-\mathrm{H}_{\mathrm{a}}, 1$ '- $\mathrm{H}$ und 3- $\mathrm{H}_{\mathrm{b}}$ der (3-Ncp)Ala I-Einheit (im Ring von 16) im Bereich zwischen $\delta_{H}=-0.72$ und 0.55. Die Resonanz des $\alpha-H$ Atoms dieser Aminosäureeinheit erfährt mit einer chemischen Verschiebung von $\delta_{H}=3.23-3.33 \mathrm{im}$ Vergleich zu 16 einen Hochfeldshift um $\Delta \delta_{H} \approx 0.30$. Ein weiteres Signal von zwei Protonen, welche nach einem HSQC-Spektrum an ein Kohlenstoffatom der Verschiebung $\delta_{C}=74.4$ gebunden sind, erscheint bei $\delta_{H}=3.43-3.52$ und ist somit der endständigen Methylengruppe des $\left(\mathrm{NO}_{2}\right) \mathrm{Nva}$ I zuzuordnen. Im ${ }^{13} \mathrm{C}$-NMR-Spektrum sind bei $\delta_{\mathrm{C}}=31.9$ und 21.7 zwei weitere Signale zu erkennen, die eine Verschiebung gegenüber 16 aufweisen und mit einem phasensensitiven HSQC-Spektrum als tertiäre Kohlenstoffe identifiziert werden können. Die zugehörigen Protonen dieser Kohlenstoffatome finden sich in den Bereichen von $\delta_{H}=0.15-0.21$ sowie 0.22-0.30 und können in Verbindung mit den spektroskopischen Daten der freien Aminosäure $^{88}$ (s. Abb. 5, S. 25) als 3- und 4- $\mathrm{H}_{2}$ identifiziert werden. Die Verschiebungen anderer Kohlenstoffatome und Protonen des Moleküls weisen keine großen Veränderungen gegenüber 16 auf. Da in diesem Fütterungsexperiment das enantiomerenreine L- $\left(\mathrm{NO}_{2}\right) \mathrm{Nva}$ gefüttert wurde und im Ringteil von 16 das D-(3-Ncp)Ala zu finden ist, musste zusätzlich die Stereochemie der in Substanz $C$ enthaltenen Aminosäuren analysiert werden. Hierzu wurde

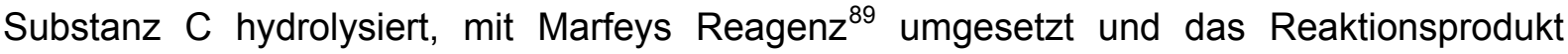
HPLC-analytisch untersucht. Der Vergleich mit synthetischem L- und D- $\left(\mathrm{NO}_{2}\right) \mathrm{Nva}$ ergab, dass Substanz $C$ nur das D-Epimer enthält und demzufolge eindeutig als Hormaomycin $D_{1}$ (21a) mit der gezeigten Stereochemie identifiziert werden kann. 
Im ESI-Massenspektrum der in einer Ausbeute von $2.3 \mathrm{mg}$ als Reinsubstanz gewonnenen Substanz A $\left(R_{t}=20.9\right)$ ist ein Peak bei $\mathrm{m} / \mathrm{z}=1105[\mathrm{M}+\mathrm{H}]^{+}$zu erkennen. Aus der Hochauflösung lässt sich die Summenformel $\mathrm{C}_{53} \mathrm{H}_{69} \mathrm{~N}_{10} \mathrm{O}_{14} \mathrm{Cl}$ ableiten, was einem doppelten Einbau des zugefütterten $\left(\mathrm{NO}_{2}\right) \mathrm{Nva}$ entspricht. Die für Hormaomycin $\mathrm{D}_{1}(\mathbf{2 1 a})$ beschriebenen Signale für die $\left(\mathrm{NO}_{2}\right) \mathrm{Nva}$ l-Einheit (im Ring des Moleküls) finden sich mit nur geringen Abweichungen im Protonen- wie auch Kohlenstoffspektrum von Substanz A wieder. Im Bereich der (3-Ncp)Ala II-Einheit des Hormaomycins erscheinen wie erwartet Veränderungen. So erfährt auch hier das $\alpha-\mathrm{H}$ Atom der Seitenkettenaminosäure verglichen zu Hormaomycin mit $\delta_{H}=5.00$ einen Hochfeldshift um $\Delta \delta_{H}=0.12$. Zusätzlich ist eine Methylengruppe bei $\delta_{H}=4.34 \mathrm{zu}$ erkennen, welche $\mathrm{zu}$ einem Triplett aufspaltet. In Kombination mit ${ }^{13} \mathrm{C}$ - und HSQC-Korrelationsspektrum kann diese einem Kohlenstoffatom mit der chemischen Verschiebung von $\delta_{C}=75.0$, welche für eine Bindung an eine Nitrogruppe spricht, zugeordnet werden. Durch ein phasensensitives HSQC-Spektrum sind zwei weitere Methylengruppen zwischen $\delta_{H}=1.68-1.77 \quad\left(\delta_{C}=29.4\right)$ sowie $1.75-1.92$ $\left(\delta_{C}=21.8\right)$ identifizierbar, welche aber durch weitere Signale anderer Protonen überlagert werden. Die Zuordnung aller neuen Signale in den Resonanzspektren von Substanz A durch Kombination von ${ }^{1} \mathrm{H}-,{ }^{13} \mathrm{C}$ - und HSQC-Spektrum sowie Vergleich mit Spektren des freien $\left(\mathrm{NO}_{2}\right)$ Nva zu zwei $\left(\mathrm{NO}_{2}\right)$ Nva-Einheiten bestätigt die Vermutung, dass in diesem Fall die gefütterte Aminosäure erfolgreich beide (3-Ncp)Ala Einheiten des Hormaomycins ersetzt hat und Substanz $A$ als Hormaomycin $D_{3}(21 c)$ identifiziert ist.

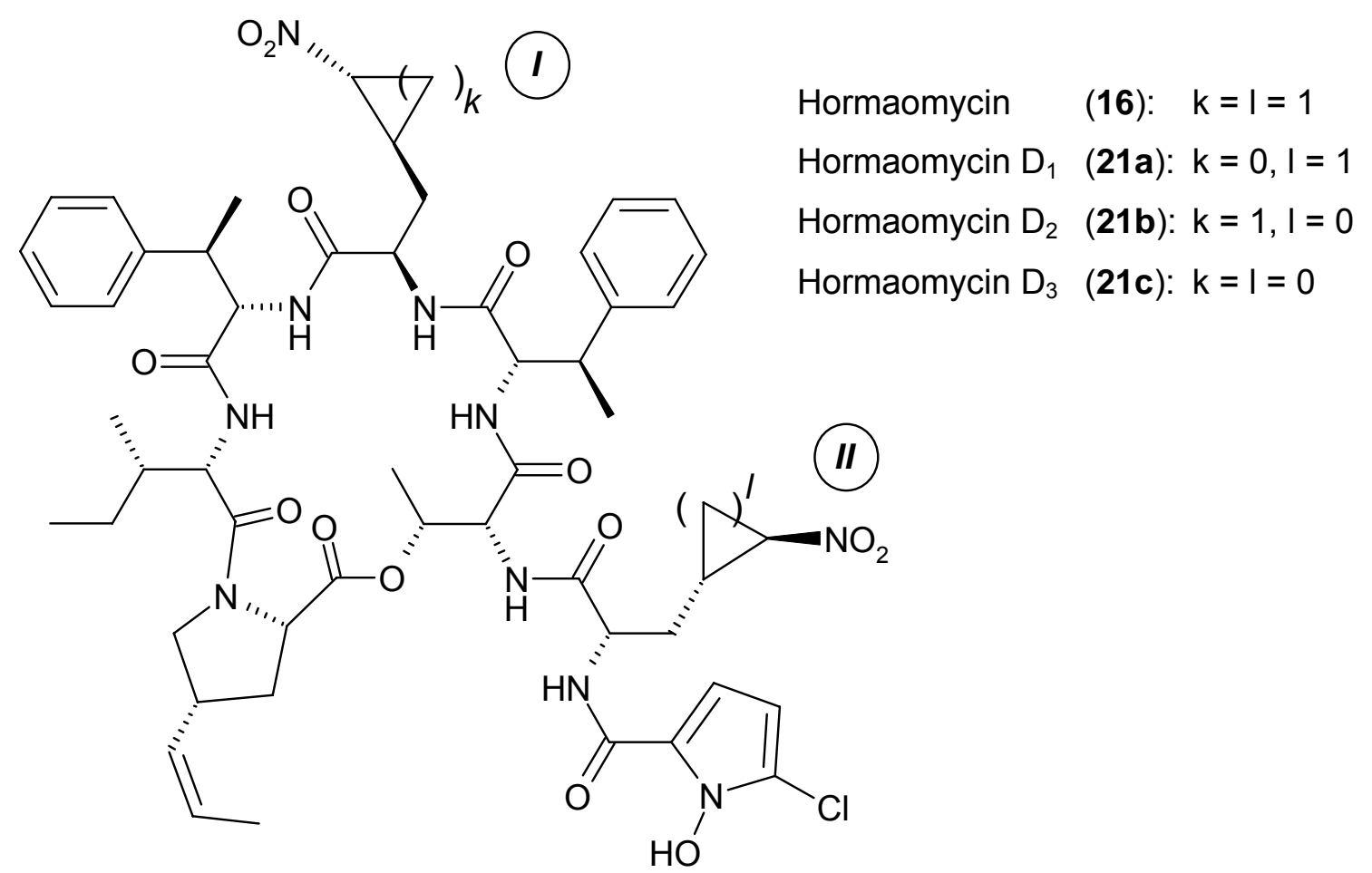


Die Fraktion $B\left(R_{t}=21.9\right)$ der chromatographischen Aufreinigung enthielt $0.2 \mathrm{mg}$ eines Gemisches aus zwei Substanzen, welches aufgrund der geringen Substanzmenge nicht weiter getrennt werden konnte. Das ESI-Massenspektrum der Mischfraktion zeigte Peaks bei $\mathrm{m} / \mathrm{z}=1117$ und 1105 (jeweils $[\mathrm{M}+\mathrm{H}]^{+}$). Nach erfolgreicher Strukturaufklärung von 21a und 21c war davon auszugehen, das in der Mischfraktion neben 21c das dritte denkbare Derivat, Hormaomycin $D_{2}(\mathbf{2 1} \mathbf{b})$, enthalten ist. Um diese Annahme zu verifizieren, wurde $\mathbf{2 1 b}$ von B.D. ZLATOPOLSKIY totalsynthetisch hergestellt. ${ }^{67}$ Die ${ }^{1} \mathrm{H}-$ und ${ }^{13} \mathrm{C}-N M R-D a t e n ~ d e r$ $\left(\mathrm{NO}_{2}\right) \mathrm{Nva}$ II-Einheit von 21b stehen in Übereinstimmung mit denen von 21c. Eine HPLCanalytische Untersuchung bestätigte, dass es sich bei der in Fraktion B neben Hormaomycin $D_{3}(21 c)$ enthaltenen Substanz um Hormaomycin $D_{2}(21 b)$ handelt.

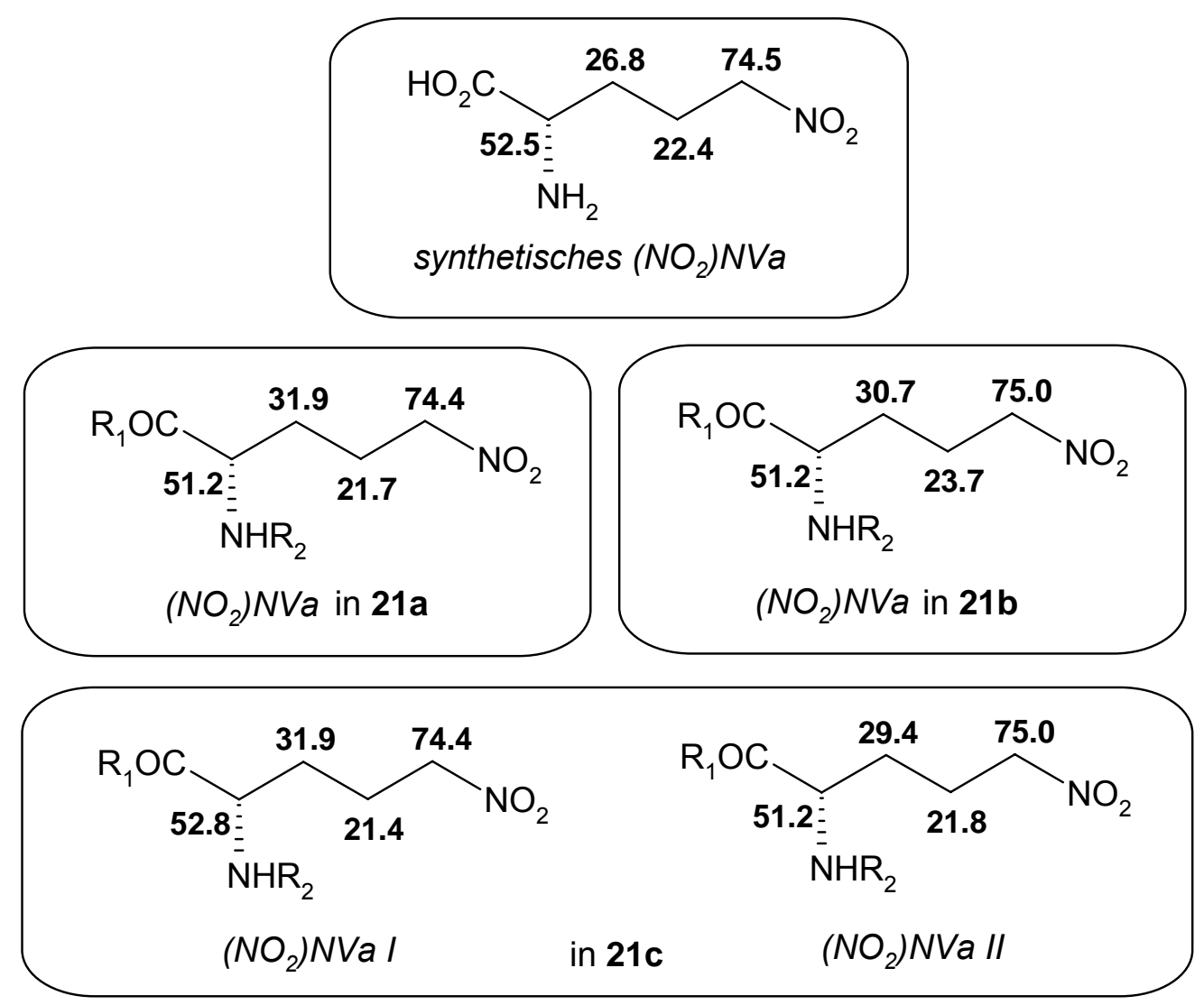

Abb. 5: Gute Übereinstimmung der ${ }^{13} \mathrm{C}-\mathrm{NMR}$ Verschiebungen des $\left(\mathrm{NO}_{2}\right) \mathrm{Nva}$ als freie Aminosäure sowie als Baustein der Hormaomycine $D_{1-3}(21 a-c)$ [synthetisches $\left(\mathrm{NO}_{2}\right) \mathrm{Nva}: 50.3 \mathrm{MHz}$ in $\mathrm{D}_{2} \mathrm{O}^{67}$; 21a-c: $150.8 \mathrm{MHz}$ in $\mathrm{CDCl}_{3}$ ]. 


\section{Fütterung von D-5-Nitronorvalin}

Die Fütterung des $\mathrm{D}-\left(\mathrm{NO}_{2}\right) \mathrm{Nva}$ sollte Aufschluss darüber geben, ob es möglich ist, die Ausbeute von Hormaomycin $D_{1}$ (21a) gegenüber den anderen Derivaten zu steigern. Dies sollte der Fall sein, wenn eine externe Racemase das L-Epimer vor Bindung an den Synthetasekomplex epimerisieren muss, wie z.B. für das D-Alanin in Cyclosporin gezeigt werden konnte. ${ }^{90}$ Ist hingegen eine interne Epimerase für diese stereochemische Transformation der Aminosäure verantwortlich, müsste die Spezifität der Binderegion im Multienzymkomplex die Aufnahme des D-Epimers vollständig verhindern.

Die Fütterungen wurden unter den Standardfermentationsbedingungen mit 1.0 und $2.0 \mathrm{mM}$ Endkonzentrationen durchgeführt. In beiden Experimenten konnte nur Hormaomycin (16) in schlechten Ausbeuten isoliert werden $(\approx 5 \mathrm{mg})$.

\section{Fütterung von rac-5-Nitronorvalin}

Die Ergebnisse der ersten Fütterungsexperimente ließen den Schluss zu, dass die Fütterung des racemischen Gemisches des $\left(\mathrm{NO}_{2}\right) \mathrm{Nva}$ die gleichen Ergebnisse wie die Fütterung von $\mathrm{L}-\left(\mathrm{NO}_{2}\right) \mathrm{Nva}$ ergeben sollte. Der Vorteil ist hierbei die einfachere synthetische Darstellung der Aminosäure.

Das Epimerengemisch wurde unter Standardbedingungen gefüttert (2 mM Endkonzentration nach $34 \mathrm{~h}$ ). Der Rohextrakt wurde an Kieselgel und semipräparativer HPLC chromatographiert. Die Hormaomycinanaloga 21a-c konnten in ähnlichen Ausbeuten wie bei Fütterung von enantiomerenreinem L- $\left(\mathrm{NO}_{2}\right) \mathrm{Nva}$ gewonnen werden.

\subsubsection{Fütterung von L-Ornithin}

Als Vorläufer für die Biosynthese des (3-Ncp)Ala-Bausteins wurde bereits von GeERS die proteinogene Aminosäure Lysin identifiziert. ${ }^{71}$ Zudem hatte ALVERMANN versucht, durch die Fütterung von L-Ornithin die Bildung 2-(2'-Nitrocyclopropyl)glycin [(2-Ncp)Gly] zu erreichen (s. Abb. 6, S. 27). Bei diesem Experiment war im ESI-MS-Spektrum der Hormaomycinhaltigen Fraktion ein Peak bei $\mathrm{m} / \mathrm{z}=1137[\mathrm{M}+\mathrm{Na}]^{+}$gefunden worden, was einem einfachen Einbau des (2-Ncp)Gly entsprechen würde. Die für eine Isolierung und Identifizierung notwendige Substanzmenge konnte zum damaligen Zeitpunkt nicht erreicht werden, weshalb erneut L-Ornithin gefüttert wurde.

Die Fütterung und Aufarbeitung erfolgten unter Standardbedingungen und ergaben ca. $7 \mathrm{mg}$ eines Hormaomycingemisches. Im ESI-Massenspektrum ist erneut ein Peak bei $\mathrm{m} / \mathrm{z}=1137$ $[\mathrm{M}+\mathrm{Na}]^{+}$zu erkennen. Dieser steht jedoch im Verhältnis 1:20 zum Hormaomycinsignal bei $\mathrm{m} / \mathrm{z}=1151[\mathrm{M}+\mathrm{Na}]^{+}$. Eine Isolierung der Komponente war nicht möglich. 
a)<smiles>NCCCC[C@H](N)C(=O)O</smiles>

L-Lysin

b)<smiles>NCCC[C@H](N)C(=O)O</smiles>

L-Ornithin<smiles>N[C@@H](C[C@@H]1C[C@H]1[N+](=O)[O-])C(=O)O</smiles>

(3-Ncp)Ala<smiles>N[C@H](C(=O)O)C1C[C@H]1[N+](=O)[O-]</smiles>

$(2-N c p) G l y$

Abb. 6: a) Biosynthese von 3-(2'-Nitrocyclopropyl)alanin aus Lysin, b) Postulierte Biosynthese von 2-(2'-Nitrocyclopropyl)glycin aus Ornithin.

\subsubsection{Fütterung von rac-2-(2'-Nitrocyclopropyl)glycin}

ALVERMANN $^{66}$ gelang bei diesem Experiment die Isolierung von drei Substanzen, welche vermeintlich dem Einbau von (2-Ncp)Gly in Hormaomycin (16) entsprachen und als Hormaomycin $\mathrm{B}_{1 \mathrm{a}, \mathrm{b}}$ und $\mathrm{B}_{2}(\mathbf{2 2 a}-\mathbf{c})$ bezeichnet wurden. Die ESI-Massenspektren zeigten Peaks bei $\mathrm{m} / \mathrm{z}=1105[\mathrm{M}+\mathrm{H}]^{+}$(für 22c) und $1117[\mathrm{M}+\mathrm{H}]^{+}$(für 22a,b), die korrekten Molmassen müssten jedoch $1100\left(\mathbf{2 2 c}, \mathrm{C}_{53} \mathrm{H}_{65} \mathrm{~N}_{10} \mathrm{O}_{14} \mathrm{Cl}\right)$ und $1114\left(\mathbf{2 2 a}, \mathbf{b}, \mathrm{C}_{54} \mathrm{H}_{67} \mathrm{~N}_{10} \mathrm{O}_{14} \mathrm{Cl}\right)$ betragen. Hier lag ein Widerspruch vor. Die ${ }^{1} \mathrm{H}$ - und ${ }^{13} \mathrm{C}-\mathrm{NMR}$-Daten für die isolierten Substanzen wiesen trotz einer vermeintlichen Zuordnung der Signale zu (2-Ncp)GlyEinheiten teils nicht erklärbare Beobachtungen auf. So konnten für die C-2' Kohlenstoffatome von 22c chemische Verschiebungen von $\delta_{C}=74.5$ und 75.9 gefunden werden, während C-2' der synthetischen Aminosäure HO$\cdot(2-\mathrm{Ncp}) \mathrm{Gly} \cdot \mathrm{NH}_{2}$ mit $\delta_{\mathrm{C}}=59.5$ hierzu deutlich ins Hochfeld verschoben ist. In Hinblick auf die an dieses Kohlenstoffatom gebundene Nitrogruppe sind Verschiebungen von $\delta_{C} \approx 75.0$ nur an einer Alkylkette wie bei Nitropropan o.ä. zu erwarten. ${ }^{91}$ Beim Vergleich der spektroskopischen Daten der hier beschriebenen Analoga mit den in Kap. 2.3.1.1 charakterisierten Hormaomycinen $D_{1-3}(21 a-c)$ (siehe auch Abb. 5, S. 25) fallen große Übereinstimmungen auf. Um zu verifizieren, ob durch Fütterung von (2-Ncp)Gly die Nitronorvalinderivate 21a-c gewonnen werden, wurden ALVERMANN's Experimente wiederholt. 


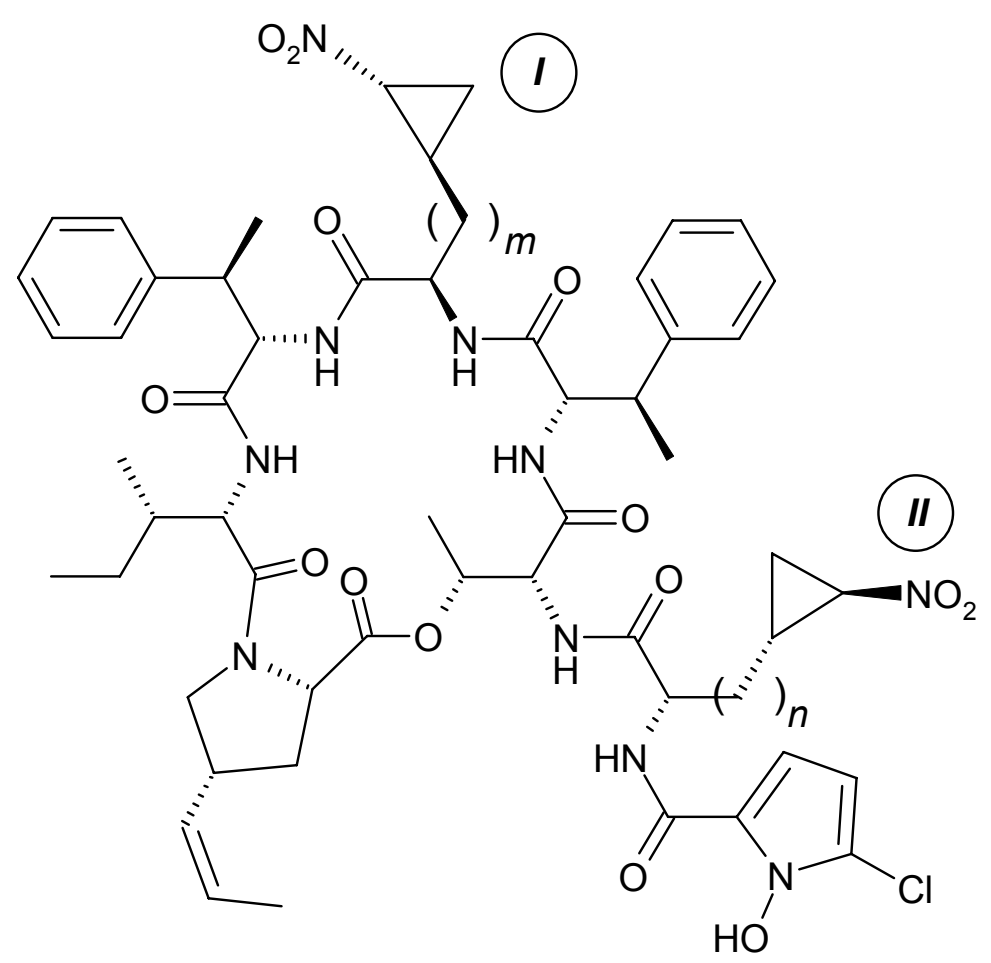

16: $m=n=1$

22a: $m=0, n=1$

22b: $m=1, n=0$

22c: $\quad m=n=0$

Abb. 7: Vermeintliche Hormaomycinanaloga $B_{1 a, b+2}$ (22a-c) mit (2-Ncp)Gly-Einheiten nach ALVERMANN. ${ }^{66}$

Die Zufütterung von rac-2-(2'-Nitrocyclopropyl)glycin erfolgte unter den Standardfermentationsbedingungen in 1 und $2 \mathrm{mM}$ Konzentration. Das Rohprodukt wurde einmal an Kieselgel chromatographiert und die so erhaltene Hormaomycin-Fraktion (ca. $6 \mathrm{mg}$ ) massenspektrometrisch und durch HPLC-Analyse untersucht. Die Fraktion enthielt neben 16 ein Hormaomycin-Analogon mit $\mathrm{m} / \mathrm{z}=1117[\mathrm{M}+\mathrm{H}]^{+}$, dessen Ausbeute für eine Isolierung jedoch zu gering war. Die Retentionszeit des Analogons $\left(R_{t}=16.2 \mathrm{~min}\right)$ entspricht der von Hormaomycin $D_{2}$ (21b), Abb. 8 (S. 29) zeigt die Übereinstimmung der Protonenspektren. 


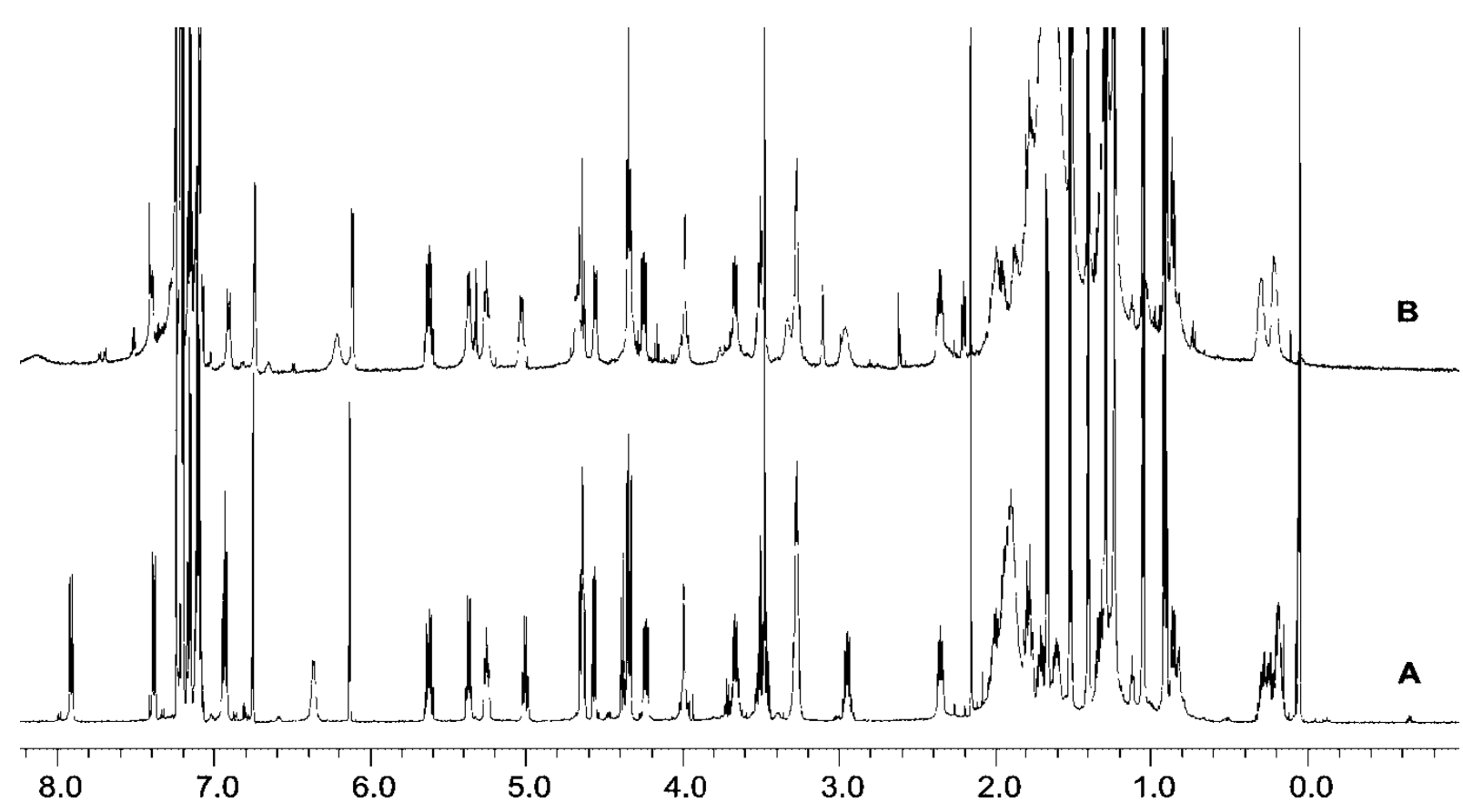

Abb. 8: Identische Protonenspektren von A) Hormaomycin $D_{3}$ [21c, doppelter Einbau des $\left(\mathrm{NO}_{2}\right) \mathrm{Nva}$, $\left.\left(600 \mathrm{MHz}, \mathrm{CDCl}_{3}\right)\right]$ und $\left.\mathrm{B}\right)$ „Hormaomycin $\mathrm{B}_{2}$ “ $\left(500 \mathrm{MHz}, \mathrm{CDCl}_{3}\right)$ beweisen die Identität beider Substanzen.

Überlegungen zur Ringöffnung von (2-Ncp)Gly

Die Beobachtung, dass bei Fütterung von (2-Ncp)Gly eine Ringöffnung der Aminosäure unter Bildung von 5-Nitronorvalin eintritt, ist durch die ausgesprochene Empfindlichkeit des (2'-Nitrocyclopropyl)methylfragments zu erklären. Dieses ist, wie in Abb. 9 gezeigt, in der Lage, eine Umlagerung unter Ringöffnung einzugehen, welche über ein radikalisches ${ }^{92,93}$ oder anionisches ${ }^{94,95}$ Intermediat verläuft. Wahrscheinlich beginnt die Reaktionsfolge mit einer Deprotonierung an C-2, einer für Racemasen charakteristischen Reaktion. ${ }^{96}$ So könnte ein intermediär gebildetes Enolat eine Cyclopropylcarbinyl-Homoallyl-Umlagerung eingehen, um nach anschließender Protonierung die 2-Amino-3-(2'-Nitroethyl)acrylsäure (23) zu ergeben. Eine anschließende enzymatische Reduktion führt zum 5-Nitronorvalin. 


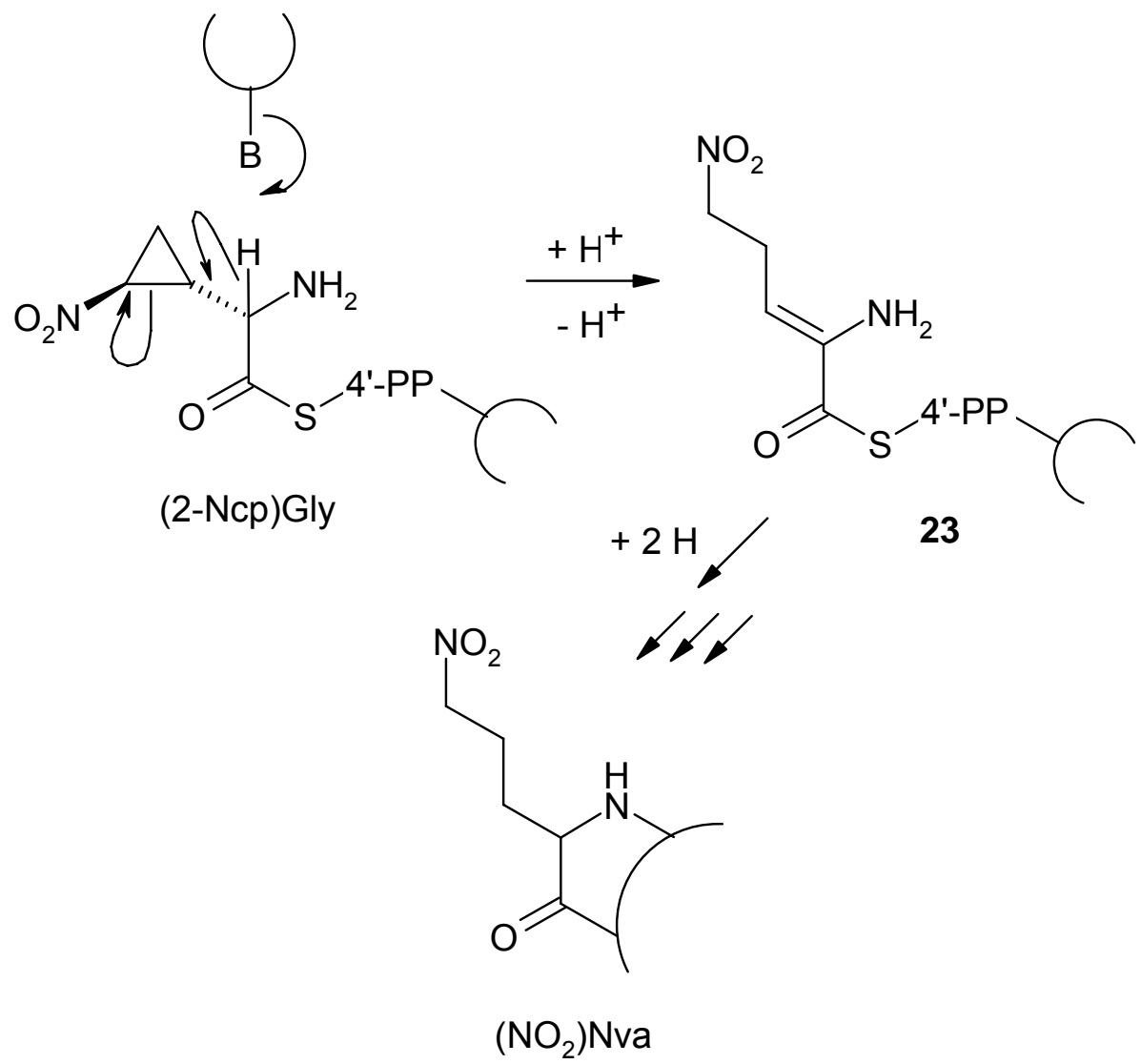

Abb. 9: Postulierter Mechanismus der Umlagerung von (2-Ncp)Gly zu 5-Nitronorvalin.

Ähnliches konnte von LIU et al. für Hypoglycin A [(2S,1'R)-Methylencyclopropylalanin, (24)] ${ }^{97}$ gezeigt werden. Dieses wird in zwei Schritten zu Methylencyclopropanessigsäure (25) metabolisiert. Anschließend erfolgt eine enzymatische C-2-Deprotonierung von 25, woran sich eine FADH-abhängige Ringöffnung über radikalische oder anionischen Zwischenstufen anschließt. $^{98,99}$ Das Coenzym A Derivat von 25 ist ein Inhibitor der Acyl-CoA Dehydrogenase ${ }^{100}$, wodurch der Verzehr unreifer, Hypoglycin A (24) haltiger Akipflaumen lebensbedrohliche Hypoglykämie hervorrufen kann. ${ }^{101}$

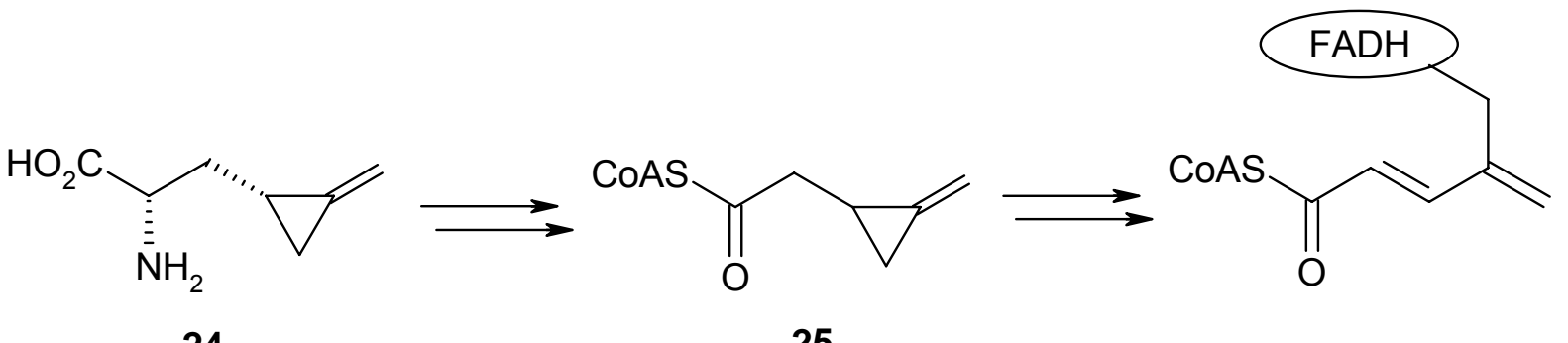

24 25

Abb. 10: Mechanismus der Ringöffnung von Hypoglycin A (24). 


\subsubsection{Fütterung von 6-Nitronorleucin}

Durch die erfolgreichen Fütterungen von $\left(\mathrm{NO}_{2}\right) \mathrm{Nva}$ ist gezeigt worden, dass die (3-Ncp)AlaModule der Hormaomycin-Synthetase die Cyclopropyleinheit für die Erkennung nicht benötigen. In einem Experiment mit der gegenüber $\left(\mathrm{NO}_{2}\right) \mathrm{Nva}$ um eine Methylengruppe verlängerten Aminosäure 6-Nitronorleucin $\left[\left(\mathrm{NO}_{2}\right) \mathrm{Nle}\right]$ sollte die Spezifität gegenüber dem Abstand der funktionellen Gruppen getestet werden.

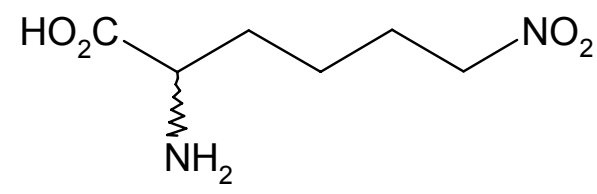

$\left(\mathrm{NO}_{2}\right) \mathrm{Nle}$<smiles>N[C@@H](C[C@@H]1C[C@H]1[N+](=O)[O-])C(=O)O</smiles>

(3-Ncp)Ala

\section{Fütterung von rac- und L-6-Nitronorleucin}

Die Kultivierungen unter Zusatz von 1 und $2 \mathrm{mmol}$ racemischem wie auch enantiomerenreinem L-( $\left(\mathrm{NO}_{2}\right) \mathrm{Nle}$ ergaben nach einer Chromatographie an Kieselgel vergleichbare Ausbeuten eines Hormaomycin-Gemisches von vier Komponenten. Das ESIMassenspektrum des Gemisches zeigt drei Peaks bei m/z $=1151[\mathrm{M}+\mathrm{Na}]^{+}, 1153[\mathrm{M}+\mathrm{Na}]^{+}$ bzw. $1155[\mathrm{M}+\mathrm{Na}]^{+}$. Diese Massen sprechen für einen erfolgreichen einfachen und doppelten Einbau sowie die Produktion von nativem Hormaomycin (16). Die Aufreinigung des Gemisches durch HPLC ergab $1.0 \mathrm{mg}$ Substanz A $\left(R_{t}=43.0 \mathrm{~min}\right), 4.9 \mathrm{mg}$ Fraktion $B$ $\left(R_{t}=45.1 \mathrm{~min}\right)$ sowie $1.9 \mathrm{mg}$ Substanz $C\left(R_{t}=48.4 \mathrm{~min}\right)$.

Aus dem hochauflösenden ESI-Massenspektrum von Substanz A lässt sich die Summenformel $\mathrm{C}_{55} \mathrm{H}_{71} \mathrm{~N}_{10} \mathrm{O}_{14} \mathrm{Cl}$ ableiten, somit enthält die Substanz zwei Protonen mehr als Hormaomycin (16), was einem einfachen Einbau von $\left(\mathrm{NO}_{2}\right) \mathrm{Nle}$ entspricht. Im Protonenspektrum sind die charakteristischen Signale der (3-Ncp)Ala I-Einheit im Ringteil von 16 bei $\delta_{H}=-0.65,-0.13,0.29$ und 0.51 weiterhin zu erkennen, so dass ein Einbau in die Seitenkette anzunehmen ist. Ein zusätzliches Signal mit einer zwei Protonen entsprechenden Intensität bei $\delta_{H}=4.36$ spaltet zu einem Triplett auf und zeigt im HSQCKorrelationsspektrum eine Kopplung zu einem Kohlenstoffatom mit der Verschiebung $\delta_{C}=75.1$, was auf eine Bindung zu einer Nitrogruppe schließen lässt. Das C-2 dieser Aminosäure-Einheit erfährt im Vergleich zur (3-Ncp)Ala II-Einheit von 16 mit $\delta_{C}=51.7$ nur eine geringe Verschiebung im Gegensatz zu 2-H, welches mit $\delta_{H}=4.95$ einen Hochfeldshift von $\Delta \delta_{H}=0.17$ aufweist. Das phasensensitive HSQC-Spektrum lässt Signale von drei Methylengruppen bei $\delta_{C}=22.3,27.2$ und 29.7 erkennen, die an Protonen der chemischen Verschiebungen $\delta_{\mathrm{H}}=1.33-1.37,1.28-1.30$ und $1.94-1.98$ gebunden sind. Aus dem ${ }^{1} \mathrm{H}-{ }^{1} \mathrm{H}-$ COSY Spektrum lässt sich eine Verknüpfung der $\mathrm{CH}_{2}$-Gruppen ableiten, deren endständige Protonen mit 2-H bzw. 6- $\mathrm{H}_{2}$ koppeln. 
Ein HR-ESI-MS/MS-Spektrum unterstützt die Zuordnung aus den NMR-Spektren. Die Hochauflösung des Peaks bei $\mathrm{m} / \mathrm{z}=401[\mathrm{M}+\mathrm{H}]^{+}$ergibt die Summenformel $\mathrm{C}_{22} \mathrm{H}_{25} \mathrm{~N}_{4} \mathrm{O}_{5}$, welche einem (3-Ncp)Ala I-( $\beta$ Me)Phe II-Thr-Bruchstück entspricht, so dass die Veränderung nicht den Ring sondern die Seitenkette betrifft. Zudem lässt sich von $\mathrm{m} / \mathrm{z}=830[\mathrm{M}+\mathrm{H}]^{+}$die Summenformel der Ringeinheit ableiten $\left(\mathrm{C}_{45} \mathrm{H}_{58} \mathrm{~N}_{7} \mathrm{O}_{10}\right)$, dieser Peak ist auch für das Hormaomycin (16) typisch. Substanz A, als Hormaomycin $E_{2}$ bezeichnet, besitzt die Struktur 26b.

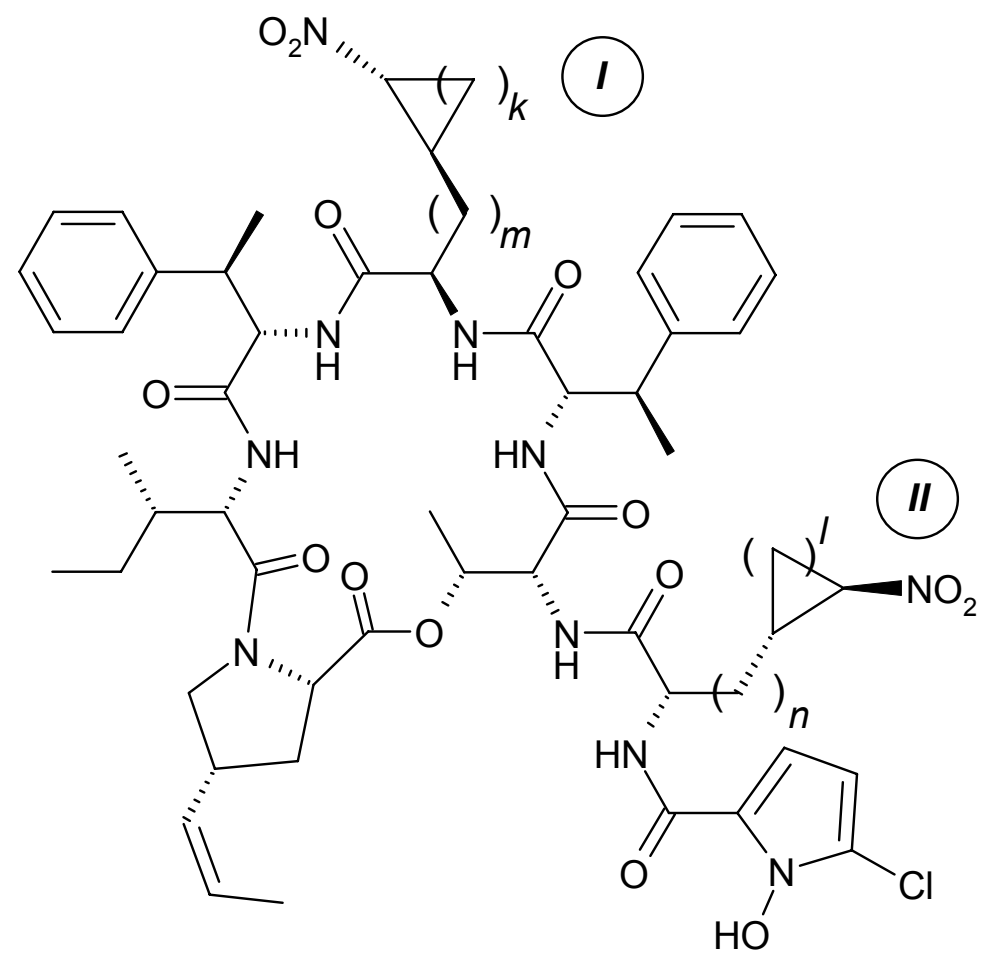

$$
\begin{array}{ll}
\text { Hormaomycin } E_{1}(\mathbf{2 6 a}): & k=0, I=n=1, m=2 \\
\text { Hormaomycin } E_{2}(\mathbf{2 6 b}): & I=0, k=m=1, n=2 \\
\text { Hormaomycin } E_{3}(\mathbf{2 6 c}): & k=I=0, m=n=2
\end{array}
$$

Substanz C, dessen Summenformel zu $\mathrm{C}_{55} \mathrm{H}_{71} \mathrm{~N}_{10} \mathrm{O}_{14} \mathrm{Cl}$ bestimmt wurde, zeigt im Gegensatz zu 26b große Veränderungen in dem konservierten Bereich des Protonenspektrums bei $\delta_{H}<0.60$. Die Protonen der (3-Ncp)Ala I-Einheit des Hormaomycins (16) fehlen, zusätzliche Signale bei $\delta_{H}=-0.29$ und 0.12 jeweils für $2 \mathrm{H}$ lassen auf zwei Methylengruppen schließen. Aus einem HSQC-Korrelationsspektrum lässt sich ihre Bindung an Kohlenstoffatome, deren Signale bei $\delta_{\mathrm{C}}=20.4$ und $32.2 \mathrm{im}$ Kohlenstoffspektrum erscheinen, ableiten. Eine dritte Methylengruppe ist durch Signale bei $\delta_{H}=1.15-1.20$ und $\delta_{C}=26.8 \mathrm{zu}$ erkennen. Auch in den Spektren von Substanz C wird ein Signal für C-6 mit der, durch die Bindung an die Nitrogruppe verursachten, charakteristischen chemischen Verschiebung von $\delta_{C}=74.6$ detektiert. Die an dieses tertiäre Kohlenstoffatom gebundenen Protonen sind durch ein 
Signal bei $\delta_{H}=3.83 \mathrm{im}{ }^{1} \mathrm{H}-\mathrm{NMR}$ charakterisiert. Das $\alpha-\mathrm{H}$-Atom der neuen Aminosäure in Substanz C erfährt im Vergleich zu 16 mit $\delta_{H}=3.25-3.29$ einen Hochfeldshift, wohingegen das Signal von C-2 mit $\delta_{C}=53.0$ kaum Veränderungen aufweist. Die Zuordnung der Protonen zu den Positionen in einer $\left(\mathrm{NO}_{2}\right) \mathrm{Nle}$-Kette ist wie für 26b mit einem ${ }^{1} \mathrm{H}-{ }^{1} \mathrm{H}-\mathrm{COSY}$ Spektrum möglich (Abb. 11). Eine Auswirkung des $\left(\mathrm{NO}_{2}\right) \mathrm{Nle}$-Einbaus auf die chemischen Verschiebungen benachbarter Aminosäuren ist der Tieffeldshift des $\alpha$-H-Atoms der $(B M e)$ Phe I-Einheit auf $\delta_{H}=4.64$.

Auch bei dieser Substanz eignet sich ein HR-ESI-MS/MS-Spektrum für die sichere Zuordnung. Für das Bruchstück des Rings lässt sich in diesem Fall eine Summenformel von $\mathrm{C}_{22} \mathrm{H}_{27} \mathrm{~N}_{4} \mathrm{O}_{5}$ ableiten, es trägt somit zwei Protonen mehr als bei 26b bzw. 16 und entspricht somit einer $\left(\mathrm{NO}_{2}\right) \mathrm{Nle}-(\beta \mathrm{Me})$ Phe II-Thr-Einheit. Eine um zwei Protonen reichere Summenformel findet sich auch für die Ringeinheit bei $\mathrm{m} / \mathrm{z}=832\left(\mathrm{C}_{45} \mathrm{H}_{60} \mathrm{~N}_{7} \mathrm{O}_{10}\right)$. Substanz $\mathrm{C}$ kann somit eindeutig als Hormaomycin $\mathrm{E}_{1}(\mathbf{2 6 a})$ identifiziert werden.

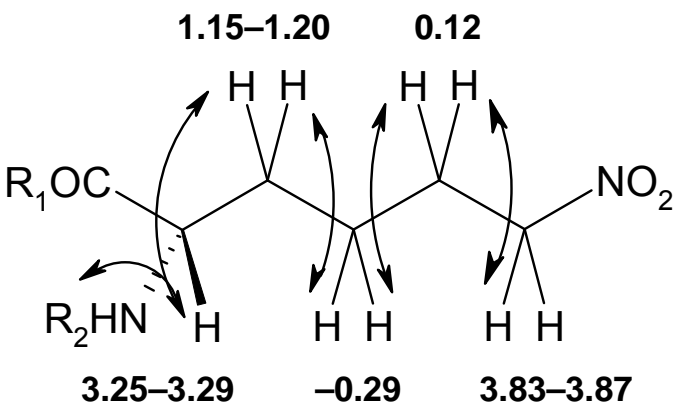

$\left(\mathrm{NO}_{2}\right) \mathrm{Nle} /$ in $\mathbf{2 6 a}$

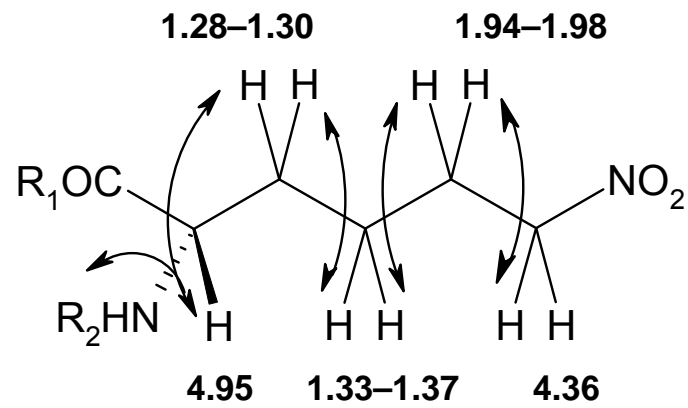

$\left(\mathrm{NO}_{2}\right) \mathrm{Nle} / /$ in $\mathbf{2 6 b}$

Abb. 11: ${ }^{1} \mathrm{H}-{ }^{1} \mathrm{H}$-Kopplungen und ${ }^{1} \mathrm{H}$-chemische Verschiebungen der $\left(\mathrm{NO}_{2}\right) \mathrm{Nle}$-Einheiten in Hormaomycin $\mathrm{E}_{1,2}(\mathbf{2 6 a}, \mathbf{b})\left(600 \mathrm{MHz}, \mathrm{CDCl}_{3}\right)$.

Fraktion B bestand aus zwei Substanzen im Verhältnis 8:5, die sich nicht trennen ließen. Ein ESI-MS ergab zwei Molekülpeaks bei $\mathrm{m} / \mathrm{z}=1129[\mathrm{M}+\mathrm{H}]^{+}$und $1133[\mathrm{M}+\mathrm{H}]^{+}$. Obwohl wegen Überlagerung dieser Signale keine Hochauflösung zu erhalten war, ließ diese Zusammensetzung auf ein Gemisch aus Hormaomycin (16) und Substanz B, die scheinbar zwei $\left(\mathrm{NO}_{2}\right)$ Nle-Einheiten trägt, schließen. Ein Protonenspektrum des Gemisches (s. Abb. 12, S. 35) zeigt neben den Hormaomycin-Signalen die zusätzlichen Signale von zwei $\left(\mathrm{NO}_{2}\right) \mathrm{Nle}$ Einheiten, die sich durch den Intensitätsunterschied eindeutig Substanz B zuordnen lassen. Die chemischen Verschiebungen dieser Resonanzen sind nahezu identisch mit denen der äquivalenten Signale von 26a bzw. 26b, welche einen einfachen Einbau des $\left(\mathrm{NO}_{2}\right) \mathrm{Nle}$ aufweisen. So lassen sich die Hochfeldverschiebungen der $\alpha-H$-Atome $z u \delta_{H}=4.95$ für $\left(\mathrm{NO}_{2}\right) \mathrm{Nle}$ II sowie $\delta_{\mathrm{H}}=3.25-3.29$ für $\left(\mathrm{NO}_{2}\right) \mathrm{Nle}$ I ebenso wie die Tieffeldverschiebung des 
a-H-Atoms der (ßMe)Phe I-Einheit bei 26a beobachten. Dadurch gelingt die

Strukturaufklärung aus dem Gemisch von Fraktion B zu 16 und Hormaomycin $E_{3}(26 c)$.

Fütterung von D-6-Nitronorleucin

Bei der Kultivierung unter Zusatz von D-Nitronorleucin war nach Aufreinigung des Rohprodukts massenspektrometrisch kein Hormaomycin-Analogon nachweisbar. Die Ausbeuten an Hormaomycin (16, ca. $3 \mathrm{mg}$ ) waren zudem geringer als in gewöhnlichen Fermentationen. 


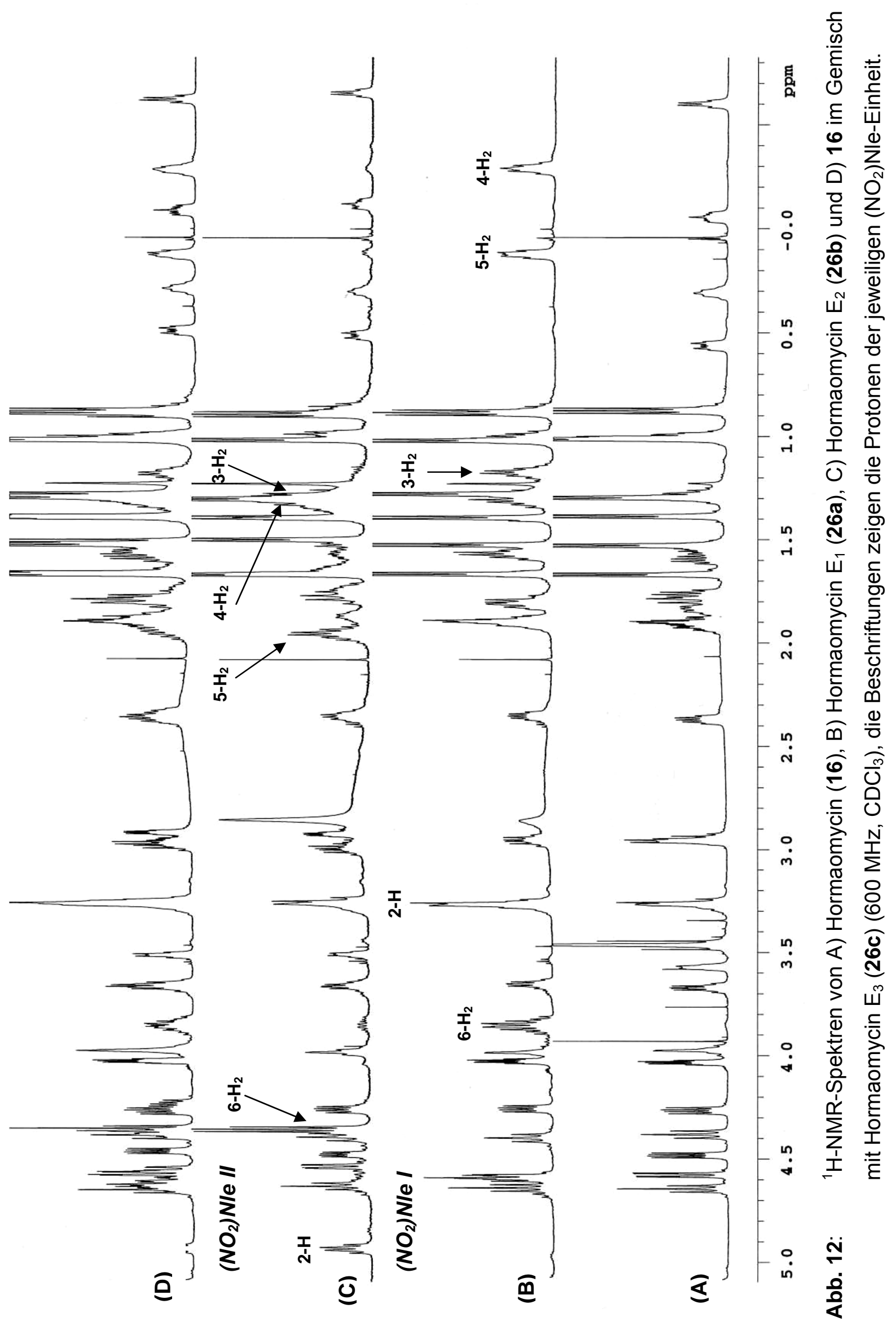




\subsubsection{Fütterung von L-5-Nitro-4-thianorvalin (27)}

Die Fermentation von Streptomyces griseoflavus (Stamm W 384) unter Zusatz von L-5-Nitro-4-thianorvalin (27) sollte zeigen, ob die Hormaomycin-Synthetase weitergehende Modifikationen in der 5-Nitronorvalin-Kette akzeptiert. Ein grundlegendes Problem bei der Fütterung<smiles>N[C@@H](CSC[N+](=O)[O-])C(=O)O</smiles>

27

der Aminosäure $\mathbf{2 7}$ stellt allerdings ihre Instabilität dar. So zeigt sie Zersetzungserscheinungen in Wasser und vor allem an Luft. ${ }^{67}$ Deswegen wurde 27 in fünf 0.4 mmol-Portionen gefüttert, welche erst kurz zuvor angelöst worden waren. Nach Standardaufarbeitung und einmaliger Chromatographie an Kieselgel konnte nur 16 (6.5 mg) isoliert werden. Ob das negative Ergebnis auf der Instabilität von 27 beruht, oder ob die Hormaomycin-Synthetase es nicht akzeptiert, muss offen bleiben.

\subsubsection{Fütterung von L-ortho-Nitrophenylalanin}<smiles>N[C@@H](Cc1ccccc1[N+](=O)[O-])C(=O)O</smiles>

28<smiles>N[C@@H](C[C@@H]1C[C@H]1[N+](=O)[O-])C(=O)O</smiles>

(3-Ncp)Ala

Durch die Fütterung von L-orthoNitrophenylalanin (28) sollte die Spezifität der HormaomycinSynthetase weiter ausgelotet werden. Das Phenylalaninderivat 28 besitzt einen ähnlichen Abstand zwischen Carbonsäure-, Amino- und Nitrogruppe wie auch (3-Ncp)Ala. Die Fütterung des Nitrophenylalanins erfolgte unter Standardbedingungen, die Hormaomycinhaltige Fraktion zeigt nach Aufreinigung des Rohprodukts allerdings keine neuen Derivate. 


\subsubsection{Variation der 3-Methylphenylalanin-Einheiten}

Die C-methylierte Aminosäure 3-Methylphenylalanin [( $\beta \mathrm{Me}) \mathrm{Phe}]$ ist im Gegensatz zu den (3-Ncp)Ala-Einheiten auch in anderen Naturstoffen wie dem bicyclischen Glykopeptidlactam Theonegramid ${ }^{102}$, dem Cyclopeptid Bottromycin ${ }^{103}$ oder AK Toxin I (29) ${ }^{104,105}$ enthalten.

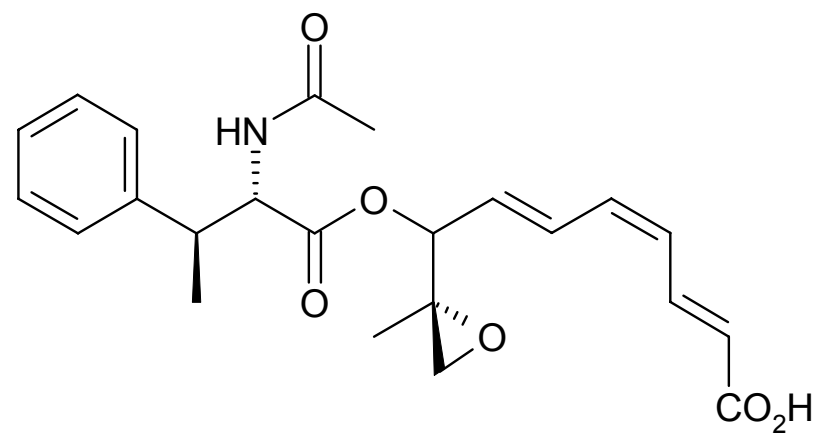

29

Die Biogenese dieses dennoch ungewöhnlichen Bausteins konnte zum Teil von GEERS aufgeklärt werden (s. Kap. 2.4.3, S. 49). ${ }^{71}$ Als Vorläufer ist Phenylalanin identifiziert worden, welches durch Methionin methyliert wird. Bei der Fütterung von Phenylalaninderivaten ist also nicht nur die Spezifität der Hormaomycin-NRPS sondern auch die der Methyltransferase entscheidend. Versuche von ALVERMANN, durch Zufütterung von Ethylmethionin die Methylgegen eine Ethylgruppe auszutauschen, schlugen fehl. ${ }^{66}$

\subsubsection{Fütterung von fluorierten Phenylalanin-Derivaten}

Während chlorierte Naturstoffe [wie auch das Hormaomycin (16) selbst] weit verbreitet sind, existieren lediglich 13 fluorierte Naturstoffe. ${ }^{106}$ Da die Einführung von Fluor in eine Substanz oftmals zu besserer Bioverfügbarkeit, Aktivität und Stabilität führt, ${ }^{107}$ ist das Fluor für die Modifikation biologisch aktiver Naturstoffe interessant. Die ähnliche Größe des Fluors im Vergleich zu Wasserstoff ist für die biologische Derivatisierung von Vorteil, die Erkennung des Substrats durch die Biosyntheseenzyme wird erleichtert, wie erfolgreiche Arbeiten an verschiedenen Sekundärmetaboliten zeigen. ${ }^{108}$

Fütterung von rac-ortho- und rac-meta-Fluorphenylalanin

Die Fütterungen erfolgten unter den Standardfermentationsbedingungen in $2 \mathrm{mM}$ Konzentration. Nach einmaliger Chromatographie an Kieselgel erhielt man ein Substanzgemisch mit Ausbeuten von $7.7 \mathrm{mg}$ (Fütterung von o-Fluorphenylalanin) bzw. $17.8 \mathrm{mg}$ (Fütterung von $m$-Fluorphenylalanin), welches sich nicht weiter aufreinigen ließ. Den Daten liegt das jeweilige Gemisch zugrunde. 
In beiden Fällen sind im ESI-Massenspektrum neben Hormaomycin (16) zwei Peaks bei $\mathrm{m} / \mathrm{z}=1145$ und $1163[\mathrm{M}-\mathrm{H}]^{-}$zu erkennen, aus deren Hochauflösung sich Summenformeln von $\mathrm{C}_{55} \mathrm{H}_{68} \mathrm{~N}_{10} \mathrm{O}_{14} \mathrm{FCl}$ und $\mathrm{C}_{55} \mathrm{H}_{67} \mathrm{~N}_{10} \mathrm{O}_{14} \mathrm{~F}_{2} \mathrm{Cl}$ ableiten lassen. Im Falle der o-Fluorphenylalanin-Fütterung ergibt sich aus den massenspektrometrischen Messungen ein Verhältnis von $1.0: 0.7: 1.4$ [16, Hormaomycin $F_{1,2}(30 a, b)$, Hormaomycin $F_{3}(30 c)$ ], bei der $m$-Fluorphenylalanin-Fütterung betrug es 1.0:1.4:2.0 [16, Hormaomycin $\mathbf{G}_{1,2}(\mathbf{3 1 a}, \mathbf{b})$, Hormaomycin $G_{3}(31 c)$ ]. Ob diese Verteilung den realen Verhältnissen entspricht, ist nicht klar, da durch die Einführung von Fluor die lonisierbarkeit verändert wird. Die erhaltenen Daten sprechen somit für einen einfachen und doppelten Einbau der gefütterten Aminosäuren. Der beobachtete doppelte Einbau legt auch die Produktion beider denkbaren einfach derivatisierten Hormaomycinen $\mathbf{3 0 a}, \mathbf{b}$ und $\mathbf{3 1 a}, \mathbf{b}$ nahe.
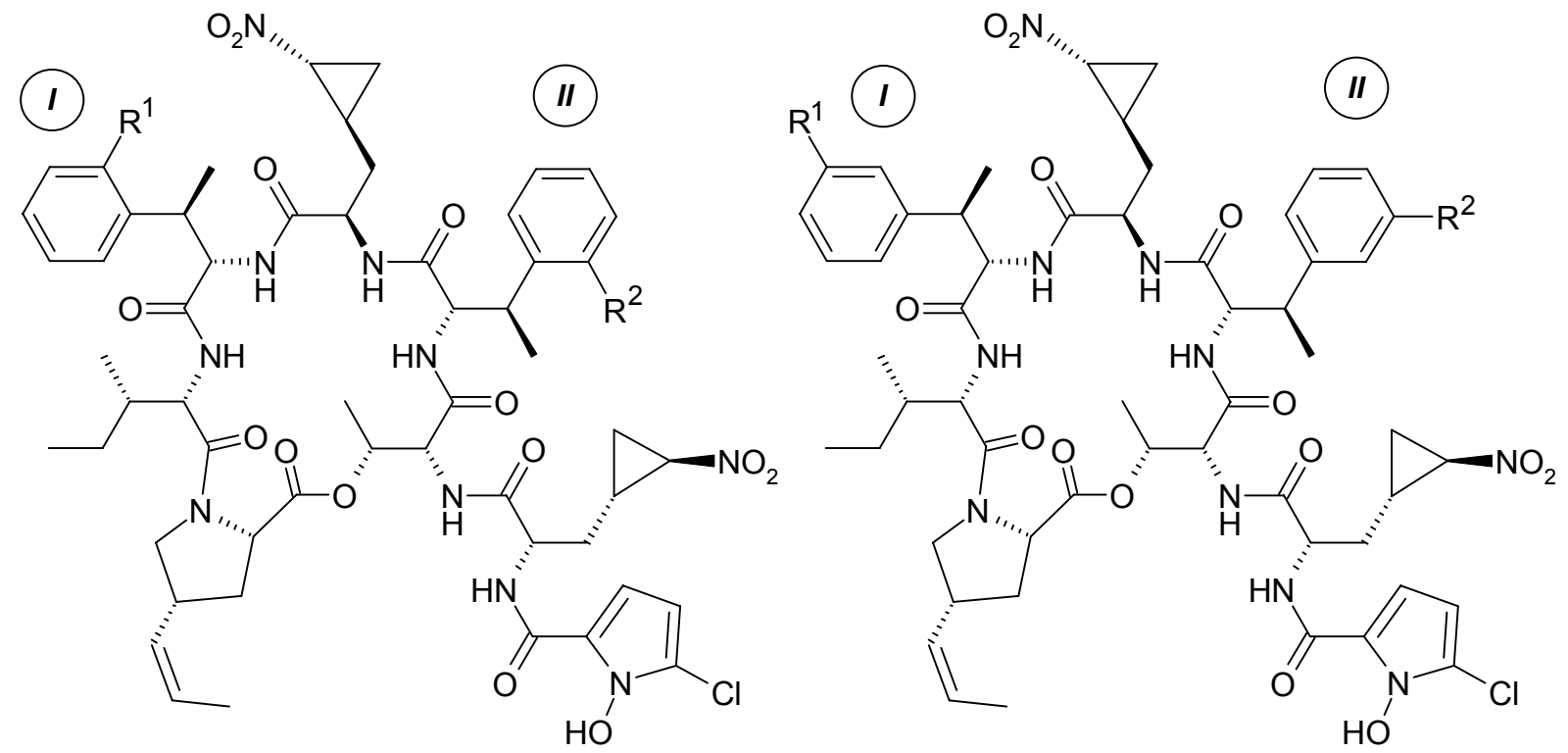

Hormaomycin $F_{1}(\mathbf{3 0 a}): \mathrm{R}^{1}=\mathrm{F}, \mathrm{R}^{2}=\mathrm{H}$ Hormaomycin $\mathrm{G}_{1}(\mathbf{3 1 a}): \mathrm{R}^{1}=\mathrm{F}, \mathrm{R}^{2}=\mathrm{H}$ Hormaomycin $F_{2}(30 b): R^{1}=H, R^{2}=F$ Hormaomycin $\mathrm{G}_{2}(\mathbf{3 1 b}): \mathrm{R}^{1}=\mathrm{H}, \mathrm{R}^{2}=\mathrm{F}$ Hormaomycin $F_{3}(30 c): R^{1}=R^{2}=F$ Hormaomycin $\mathrm{G}_{3}(\mathbf{3 1} \mathrm{c}): \mathrm{R}^{1}=\mathrm{R}^{2}=\mathrm{F}$

\section{Fütterung von rac-para-Fluorphenylalanin}

Die Fermentation erfolgte auch bei dem para-substituierten Derivat unter den Standardfermentationsbedingungen in $2 \mathrm{mM}$ Konzentration. Das Substanzgemisch konnte nach einmaliger Chromatographie an Kieselgel in einer Ausbeute von $11 \mathrm{mg} / \mathrm{L}$ gewonnen werden. Das ESI-MS-Spektrum zeigt neben den erwarteten Peaks von $16(\mathrm{~m} / \mathrm{z}=1151$ $[\mathrm{M}+\mathrm{Na}]^{+}$) und dem Derivat (bzw. den Derivaten) mit einfachem Einbau der gefütterten Aminosäure bei $\mathrm{m} / \mathrm{z}=1168[\mathrm{M}+\mathrm{Na}]^{+}$[Hormaomycin $\left.\mathrm{H}_{1,2}(\mathbf{3 2 a}, \mathbf{b})\right]$ einen weiteren bei $\mathrm{m} / \mathrm{z}=1137[\mathrm{M}+\mathrm{Na}]^{+}$, wohingegen der doppelte Einbau zu Hormaomycin $\mathrm{H}_{3}$ (32c) nicht $z u$ 
beobachten war. Eine HPLC-analytische Untersuchung führt zu dem Ergebnis, dass es sich bei dem neuen 1137-Peak um zwei Substanzen handelt, deren Strukturaufklärung im nächsten Absatz beschrieben wird.

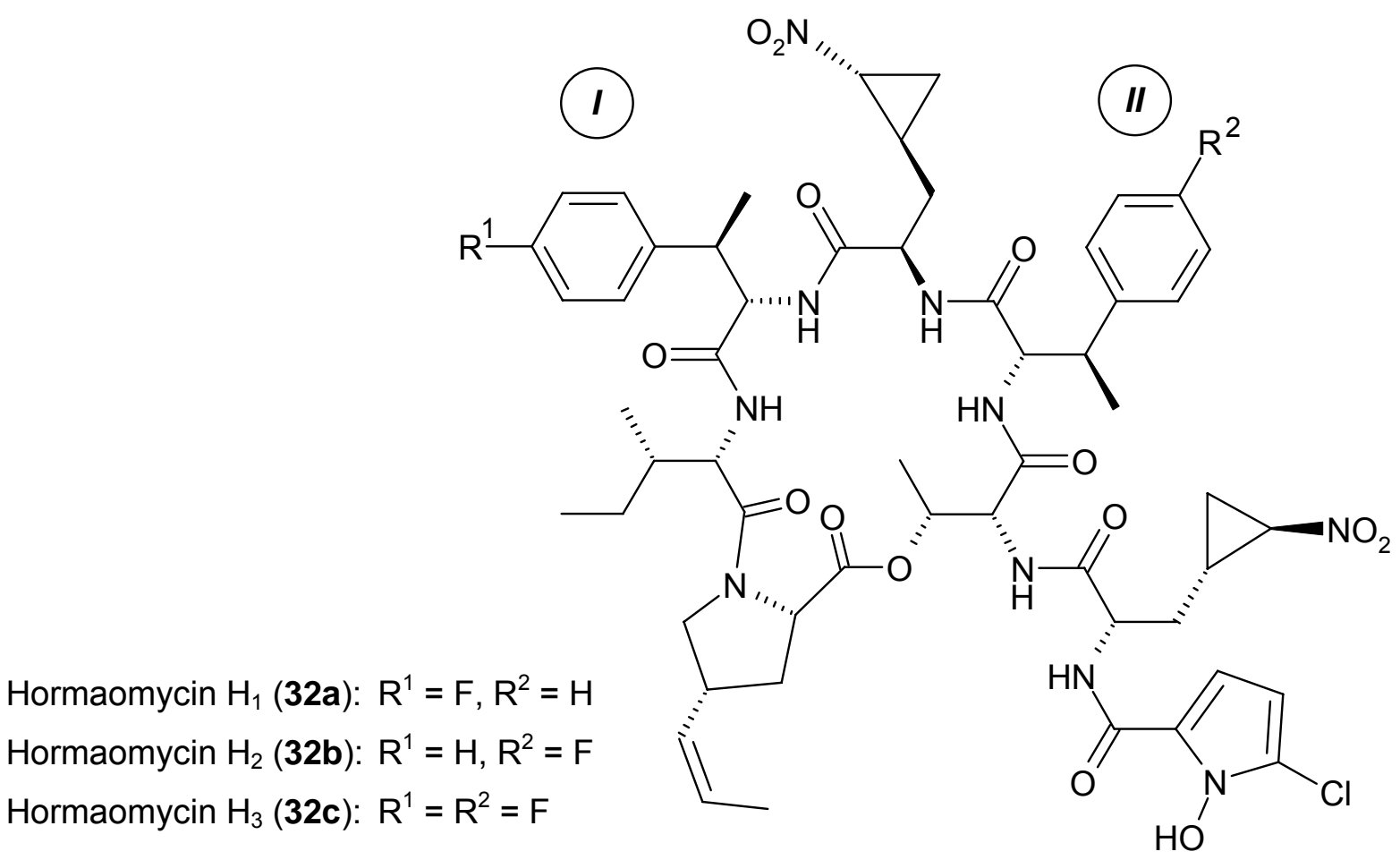

\subsubsection{Fütterung von rac-para-Chlorphenylalanin}

Nach Fermentation und Aufreinigung unter Standardbedingungen erhielt man ein Gemisch von Hormaomycinderivaten, welche im ESI-Massenspektrum Peaks bei $\mathrm{m} / \mathrm{z}=1099,1113$ und $1127[\mathrm{M}-\mathrm{H}]^{-}$ergaben. Die erwarteten Molmassen von 1162 sowie $1196 \mathrm{~g} / \mathrm{mol}$ für den einfachen und doppelten Einbau des methylierten para-Chlorphenylalanins waren nicht zu beobachten. Die HPLC-Aufreinigung des Gemisches ergab neben Hormaomycin (16) drei neue Metaboliten, in Ausbeuten von $1.2 \mathrm{mg}$ (Substanz $\mathrm{A}, \mathrm{R}_{\mathrm{t}}=14.9 \mathrm{~min}$ ), $1.4 \mathrm{mg}$ (Substanz $B, R_{t}=16.2 \mathrm{~min}$ ) und $1.4 \mathrm{mg}$ (Substanz $C, R_{t}=18.5 \mathrm{~min}$ ).

Die Hochauflösung des ESI-MS-Signals von Substanz B bei $\mathrm{m} / \mathrm{z}=1132\left[\mathrm{M}+\mathrm{NH}_{4}\right]^{+}$führt $\mathrm{zu}$ der Summenformel $\mathrm{C}_{54} \mathrm{H}_{67} \mathrm{~N}_{10} \mathrm{O}_{14} \mathrm{Cl}$, was formal dem Verlust einer Methylgruppe (M-14) entspricht. Im Einklang mit diesem Ergebnis fällt im Protonenspektrum sofort das Fehlen der Signale bei $\delta_{H}=1.39$ und 3.68, welche der Methylgruppe und dem 3-H der ( $\beta$ Me)Phe IEinheit in 16 zuzuordnen sind, auf. Das ${ }^{13} \mathrm{C}-\mathrm{NMR}$-Spektrum hingegen zeigt nur das Fehlen der Methylgruppe bei $\delta_{C}=13.0$, das $C-3$ des $(\beta M e)$ Phe I findet sich nur gering ins Hochfeld verschoben bei $\delta_{C}=38.2$. Ein Vergleich mit dem Protonenspektrum des Naturstoffs zeigt Substanz B zudem eine Veränderung im Kopplungsmuster des $\alpha$-H-Atoms von $(\beta M e) P h e ~ I$ bei $\delta_{H}=4.47$. Im Naturstoff ist hier eine Aufspaltung zum Dublett vom Dublett (Kopplung zu 
3-H und -NH) zu erkennen, Substanz B weist hier ein zusätzliches Dublett auf. Die Kopplungspartner dieses Protons sind zwei Signale bei $\delta_{H}=2.80$ und 3.37, die dem Kohlenstoffatom bei $\delta_{C}=38.2$ zuzuordnen sind und eine Kopplungskonstante von $J=14.5 \mathrm{~Hz}$ zueinander sowie von $J=11.0 \mathrm{bzw}$. $4.5 \mathrm{~Hz}$ zu dem $\alpha-\mathrm{H}$-Atom aufweisen, womit gezeigt ist, dass die Methylgruppe der $(\beta M e)$ Phe l-Einheit gegen ein Wasserstoffatom ausgetauscht wurde. Die Signale der aromatischen Protonen des Spektrums weisen nur geringfügige Veränderungen im Vergleich mit dem Naturstoff $\mathbf{1 6}$ auf. Hierdurch ist bewiesen, dass die Zufütterung des chlorierten Phenylalanins zu einem Einbau von natürlichem

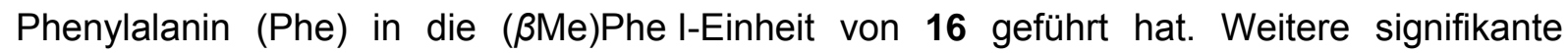
Veränderungen im Spektrum sind lediglich für die Verschiebungen der Protonen der (3-Ncp)Ala I-Einheit zu beobachten, welche einen starken Tieffeldshift von bis zu $\Delta \delta_{H}=0.36$ erfahren (s. Tab. 1). Für Substanz B ergibt sich somit die Struktur 33a (Hormaomycin $J_{1}$ ).

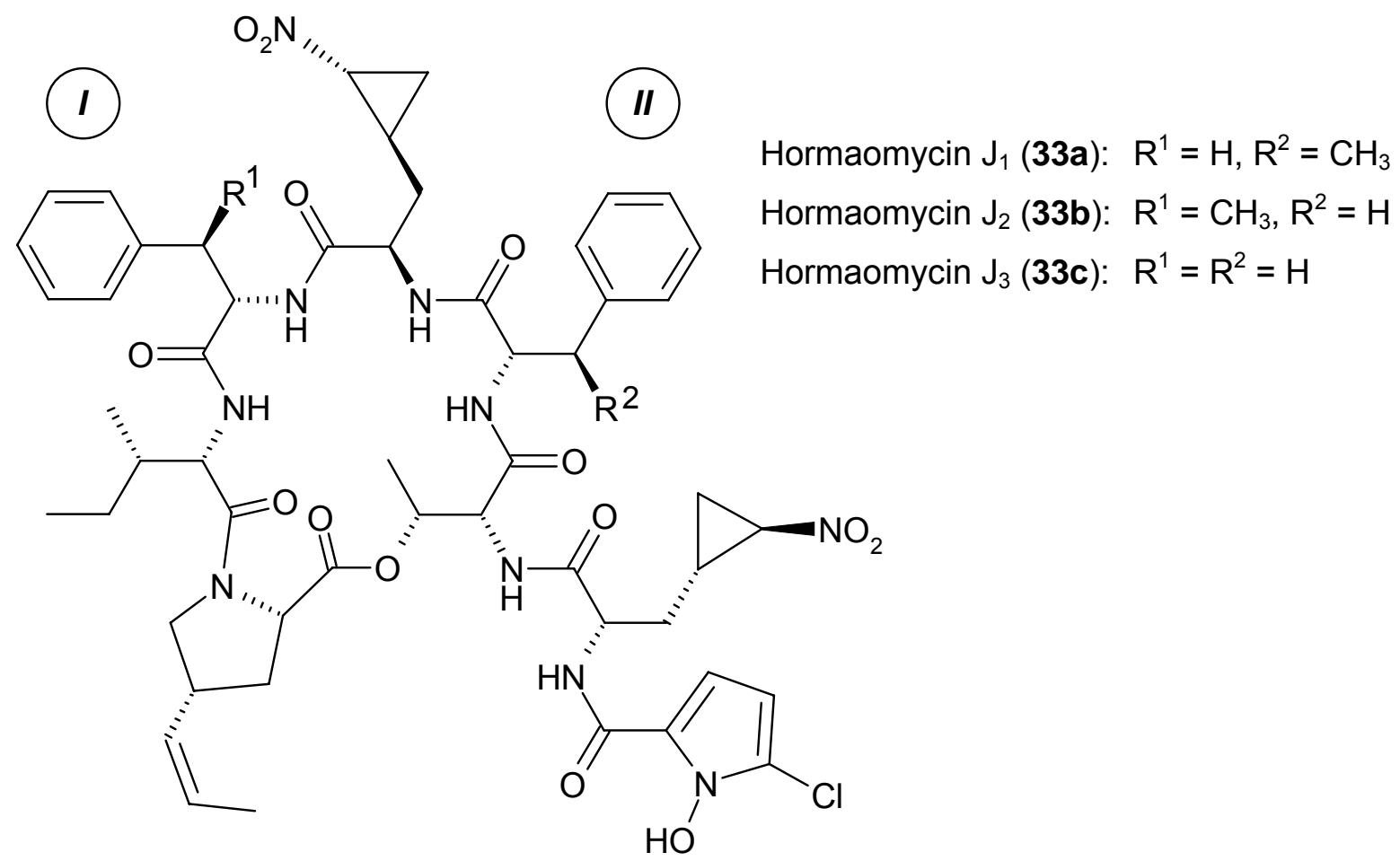

Für Substanz C lässt sich nach Hochauflösung des ESI-MS-Peaks die gleiche Summenformel wie für 33a ableiten, auch hier scheint eine Methylgruppe durch ein Proton ersetzt worden zu sein. So ist im Protonenspektrum der Substanz eine Methylengruppe bei $\delta_{H}=2.88$ und $2.96 \mathrm{zu}$ erkennen, welche das gleiche Kopplungsmuster wie bei 33a aufweist, wobei die Kopplungskonstanten in diesem Fall ${ }^{3} \mathrm{~J}=11.0 \mathrm{~Hz}\left(3-\mathrm{H}_{\mathrm{a}}\right)$ und $5.0 \mathrm{~Hz}\left(3-\mathrm{H}_{\mathrm{b}}\right)$ betragen. Als Kopplungspartner dieser Protonen kann mit Hilfe eines ${ }^{1} \mathrm{H}-{ }^{1} \mathrm{H}-\mathrm{COSY}$ Korrelationsspektrums ein Proton bei $\delta_{H}=4.61-4.66$ identifiziert werden, welches von dem $2-\mathrm{H}$ der Isoleucin-Einheit überlagert wird. Die Methylgruppe der $(\beta \mathrm{Me})$ Phe II-Einheit bei $\delta_{H}=1.29$ in $\mathbf{1 6}$ kann bei Substanz $C$ nicht detektiert werden, so dass der Einbau von Phenylalanin (Phe) in die ( $\beta \mathrm{Me})$ Phe II-Einheit von 16 nachgewiesen und somit nur die 
Struktur 33b für Hormaomycin $J_{2}$ in Frage kommt. Auch bei $\mathbf{3 3 b}$ fallen die Tieffeldverschiebungen der (3-Ncp)Ala I-Einheit auf, welche zum Teil größer als bei 33a sind (s. Tab. 1). Für 33b konnten, obwohl die Ausbeuten vergleichbar mit denen von 33a schienen, keine ${ }^{13} \mathrm{C}-\mathrm{NMR}-\mathrm{Spektren}$ gewonnen werden.

\begin{tabular}{|c|c|c|c|c|}
\hline & $\begin{array}{l}\text { Hormaomycin } \\
\text { (16) }\end{array}$ & $\begin{array}{c}\text { Hormaomycin } \mathrm{J}_{1} \\
\text { (33a) }\end{array}$ & $\begin{array}{c}\text { Hormaomycin } \mathrm{J}_{2} \\
(\mathbf{3} \mathbf{3} \mathbf{b})\end{array}$ \\
\hline & & \multicolumn{3}{|c|}{$\delta_{H}[p p m]$} \\
\hline \multirow{7}{*}{ 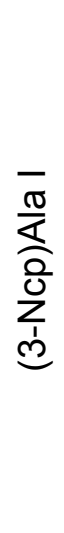 } & $2-\mathrm{H}$ & 3.53 & 3.46 & 3.65 \\
\hline & $3-\mathrm{H}_{a}$ & -0.09 & 0.05 & 0.24 \\
\hline & $3-\mathrm{H}_{b}$ & 0.58 & 0.60 & 0.78 \\
\hline & $1^{\prime}-\mathrm{H}$ & 0.29 & 0.55 & 0.68 \\
\hline & 2'-H & 2.96 & 3.08 & 3.10 \\
\hline & $3^{\prime}-\mathrm{H}_{\mathrm{a}}$ & -0.62 & -0.26 & -0.20 \\
\hline & $3^{\prime}-\mathrm{H}_{\mathrm{b}}$ & 0.99 & 1.10 & 0.95 \\
\hline
\end{tabular}

Tab. 1: ${ }^{1} \mathrm{H}$-chemische Verschiebungen der (3-Ncp)Ala I Einheit in Hormaomycin (16) und in den Desmethylhormaomycinen Hormaomycin $\mathrm{J}_{1,2}(\mathbf{3} \mathbf{3} \mathbf{a}, \mathbf{b})$.

Nach Zuordnung der Molmasse 1114 zu den Hormaomycinen $J_{1,2}(\mathbf{3 3 a}, \mathbf{b})$ musste Substanz A die geringste Molmasse besitzen. Durch die Hochauflösung des Peaks bei $\mathrm{m} / \mathrm{z}=1118$ $\left[\mathrm{M}+\mathrm{NH}_{4}\right]^{+}$ergibt sich die Summenformel $\mathrm{C}_{53} \mathrm{H}_{65} \mathrm{~N}_{10} \mathrm{O}_{14} \mathrm{Cl}$. Folglich ist bei Substanz $\mathrm{A}$ von einem doppelten Einbau des Phenylalanins in die $(\beta M e) P h e-E i n h e i t e n$ des Hormaomycins auszugehen. Ein Protonenspektrum der Substanz bestätigte diese Vermutung, trotz schlechter Qualität des Spektrums aus Substanzmangel und weiterhin enthaltenen Verunreinigungen ist zu erkennen, dass beide Methylgruppen nicht mehr vorhanden sind. Zudem sind die Signale für $3-\mathrm{H}_{\mathrm{a}, \mathrm{b}}$ der Phe I-Einheit bei $\delta_{\mathrm{H}} \approx 2.82$ und 3.35 sowie die der Phe II-Einheit bei $\delta_{H} \approx 2.85$ und $3.05 \mathrm{zu}$ erkennen. Die geringe Qualität der Spektren ermöglicht jedoch keine sichere Identifizierung der $\alpha-\mathrm{H}$-Atome der ausgetauschten Einheiten und anderer Protonen. Mit den vorhandenen Daten kann jedoch davon ausgegangen werden, dass es sich bei Substanz A um Hormaomycin $J_{3}(\mathbf{3 3} \mathrm{c})$ handelt.

Durch einen HPLC-Vergleich der bei Fütterung von para-Fluorphenylalanin entstandenen Metaboliten mit 33a-c konnte gezeigt werden, dass in diesem Experiment neben den fluorierten Hormaomycinen $\mathrm{H}_{1,2}(\mathbf{3 2 a}, \mathbf{b})$ die Hormaomycine $\mathrm{J}_{1,2}(\mathbf{3} \mathbf{3} \mathbf{a}, \mathbf{b})$ produziert wurden, also eine ähnliche Hemmung der Methyltranferase induziert wurde. 


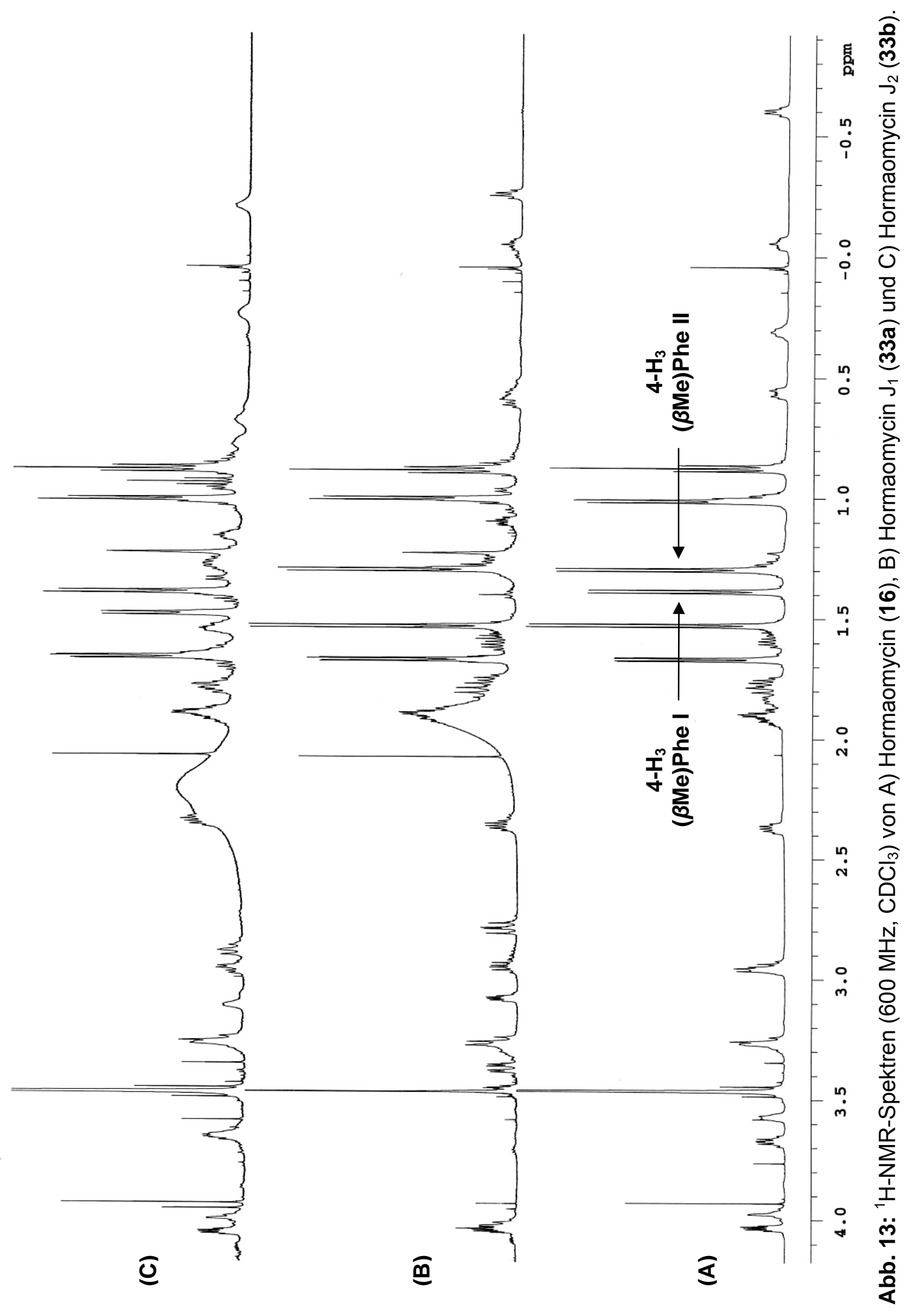




\subsubsection{Fütterung von rac-para-Brom- und Nitrophenylalanin}

Die Fermentationen von Streptomyces griseoflavus (Stamm W 384) unter Zusatz von racpara-Bromphenylalanin ergab nach Chromatographie des Rohprodukts an Kieselgel ein Substanzgemisch mit einer Ausbeute von $9.7 \mathrm{mg}$. Im ESI-Massenspektrum waren erneut die Hormaomycine $J_{1-3} \quad(33 a-c) \quad z u$ erkennen. Die Fütterung des nitrosubstituierten Phenylalanins hingegen ergab eine Ausbeute von $13.4 \mathrm{mg}$, das doppelt derivatisierte Hormaomycin $J_{3}$ (32c) war in diesem Fall nicht nachzuweisen. Die relativen Ausbeuten der Fütterungsexperimente sind in Tab. 2 dargestellt.

\begin{tabular}{ccccc}
\hline Gefütterte Substanz & $\mathbf{3 3 a}$ & $\mathbf{3 3 b}$ & $\mathbf{3 3 c}$ & $\mathbf{1 6}$ \\
\hline D-/L-p-F-Phe & 39 & 39 & 0 & 100 \\
D-/L- $p-\mathrm{Cl}-\mathrm{Phe}$ & 45 & 45 & 34 & 100 \\
D-/L- $p-\mathrm{Br}-\mathrm{Phe}$ & 21 & 21 & 3 & 100 \\
D-/L- $p-\mathrm{NO}_{2}-\mathrm{Phe}$ & 24 & 24 & 0 & 100 \\
\hline
\end{tabular}

Tab. 2: Relative Ausbeuten [\%] der Desmethylhormaomycine Hormaomycin $\mathrm{J}_{1-3}$ (33a-c) im Vergleich zu Hormaomycin (16) aus Fütterungsexperimenten mit unterschiedlich substituierten para-Phenylalaninen.

\subsubsection{Fütterung von L-Tyrosin}

Da unnatürliche Aminosäuren wie die para-halogenierten Phenylalanine eine Methylierung von Phenylalanin verhindern und es so zum Einbau der natürlichen Aminosäure in das Peptid kommt, sollte untersucht werden, ob auch Tyrosin hierzu in der Lage ist. Nach Fütterung in $2 \mathrm{mM}$ Konzentration und Aufarbeitung unter Standardbedingungen fiel in diesem Fall jedoch nur natives Hormaomycin (16) an. Diese Beobachtung kann jedoch nicht endgültig klären, ob Tyrosin prinzipiell auch zu einer Inhibierung der Methylierung in der Lage ist, da diese Aminosäure vom Primärstoffwechsel des Organismus metabolisiert werden kann und so eventuell nicht in ausreichender Konzentration vorliegt.

\subsubsection{Fütterung von rac-Phenylglycin}

Die für den Einbau der $(\beta M e)$ Phe-Einheiten verantwortlichen Module der HormaomycinNRPS haben, wie in Kap. 2.3 .2 (S.37) beschrieben, eine allgemeine Substrattoleranz gezeigt. Durch Fütterung von Phenylglycin sollte versucht werden, diese Aussage mit der 
Verkürzung der Kettenlänge zu überprüfen. Die Fütterung von $2 \mathrm{mmol}$ rac-Phenylglycin zu der wachsenden Kultur unter Standardbedingungen ergab nach einmaliger Chromatographie an Kieselgel eine Hormaomycin-haltige Fraktion in einer Ausbeute von $13.5 \mathrm{mg}$. Im ESIMassenspektrum zeigte sich jedoch nur der Peak für Hormaomycin (16), Derivate waren nicht nachweisbar.

\subsubsection{Variation der 5-Chlor-N-hydroxypyrrolcarbonsäure-Startereinheit}

Schon von GEERS wurde postuliert, dass die 5-Chlor-N-hydroxypyrrolcarbonsäure (Chpca) die Startereinheit der Hormaomycin-Biosynthese ist (s. Kap. 2.4, S. 47). In ihren Arbeiten identifizierte sie zudem die Aminosäure L-Prolin als Vorläufer dieser ungewöhnlichen Carbonsäure. $^{71}$ Ein vermutliches Intermediat in der Biosynthese der Chpca, die 2-Pyrrolcarbonsäure (2-PCA), kommt frei im Kulturfiltrat von Streptomyces griseoflavus vor und kann in Ausbeuten von ca. $10 \mathrm{mg} / \mathrm{L}$ isoliert werden. Ziel der Fütterungen von zu der 2-PCA verwandten Vorläufern war somit neue Erkenntnisse zur Biosynthese zu erlangen. Weiterhin sollten sich Hinweise auf die Spezifität des ersten Moduls in der HormaomycinNRPS sowie vorgeschalteter Enzyme, die für Chlorierung und Hydroxylierung verantwortlich sind, ergeben.

Alle Fermentationen wurden unter Standardbedingungen durchgeführt und die Vorläufer in 2 mM Konzentration gefüttert.<smiles>O=C(O)C1CCCO1</smiles>

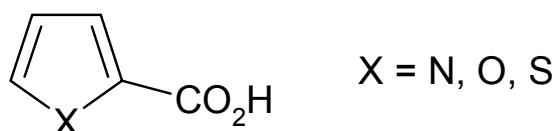<smiles>O=C(O)C1CCCCN1</smiles><smiles>O=C(O)c1ccccn1</smiles><smiles>O=C(O)c1cccc(Cl)c1O</smiles>

Abb. 14: Vorläufer für Fütterungsexperimente zur Variation der Chpca-Startereinheit.

In den Fütterungsexperimenten mit Furan-, Tetrahydrofuran- und Thiophen-2-carbonsäure sowie Picolin-, Pipecolin- und 3-Chlorsalicylsäure (s. Abb. 14) war nach Standardaufarbeitung lediglich Hormaomycin (16) in Ausbeuten von 8-15 mg zu isolieren. Die isolierten Mengen entsprechen somit Fermentationen ohne Zusatz von Vorläufern. Die Zugabe von 2 mmol 2-Pyrrolcarbonsäure bewirkte eine Steigerung der Ausbeute von 16 (bis zu $45 \mathrm{mg} / \mathrm{L}$ ), was dem vierfachen einer durchschnittlichen Fermentation ohne Zusatz 
dieses Vorläufers entspricht. Durch diese Fütterung scheint also ein bottle-neck in der

Biosynthese von 16 gefunden $\mathrm{zu}$ sein. Die Fütterung von 2-PCA in 4 und $8 \mathrm{mM}$ Konzentration führt zu keiner weiteren Erhöhung der Ausbeute, Zusatz von $1 \mathrm{mmol}$ ergibt 16 in einer Ausbeute von $21 \mathrm{mg} / \mathrm{L}$.

\subsubsection{Diskussion der Ergebnisse}

Durch die Experimente zur Vorläufer-dirigierten Biosynthese (PDB) am HormaomycinProduzenten Streptomyces griseoflavus (Stamm W 384) ist ersichtlich geworden, dass die unterschiedlichen Module der Peptidsynthetase unterschiedliche Substratspezifität besitzen. So konnte ALVERMANN zeigen, dass scheinbar keine Substrattoleranz in den allo-Threonin und den Isoleucin-Einheiten besteht, die Fütterungsexperimente bezüglich der Startereinheit zeigen auch hier eine geringe Toleranz. Im Gegensatz hierzu konnte durch die erzielten Ergebnisse eine große Toleranz der Hormaomycin-Synthetase am (3-Ncp)Ala- wie auch am $(\beta \mathrm{Me})$ Phe-Modul nachgewiesen werden.

\section{Die (3-Ncp)Ala-Einheiten}

Durch den erfolgreichen Einbau der offenkettigen Aminosäuren 5-Nitronorvalin und 6-Nitronorleucin [ $\left.\left(\mathrm{NO}_{2}\right) \mathrm{Nle}\right]$ und die daraus resultierende Bildung der Hormaomycine $\mathrm{D}_{1-3}$ $(21 a-c)$ und $E_{1-3}(26 a-c)$ konnte gezeigt werden, dass der Cyclopropylring für die ModulErkennung nicht notwendig ist. Auch spielt der Abstand der funktionellen Gruppen nur eine untergeordnete Rolle, im $\left(\mathrm{NO}_{2}\right) \mathrm{Nle}$ ist dieser im Vergleich zum (3-Ncp)Ala vergrößert. Grenzen der Substrattoleranz werden durch die Misserfolge bei der Fütterung von 5-Nitro-4thianorvalin (27) und ortho-Nitrophenylalanin (28) aufgezeigt. Ob die Verkürzung der Aminosäurekette um eine Methylengruppe im Fall des 2-(2'-Nitrocyclopropyl)glycins von dem Modul akzeptiert wird, kann aufgrund der (enzymatischen) Umwandlung der Substanz zu 5-Nitronorvalin nicht gesagt werden. Die Hormaomycine $\mathrm{B}_{1 \mathrm{a}, \mathrm{b}+2}(\mathbf{2 2 a}-\mathbf{c})$ scheinen mit diesem Fütterungsexperiment nicht zugänglich zu sein. Auch die Fütterung von Ornithin brachte keinen Erfolg, die Hormaomycine $B_{1 a, b}(\mathbf{2 1 a}, \mathbf{b})$ sind höchstens in Spuren nachweisbar.

\section{Die ( $\beta M e)$ Phe-Einheiten}

Die in ortho- und meta-Position fluorierten Phenylalaninderivate sind als Substrate für die Methyltransferase wie auch das NRPS-Module gut geeignet und treten in methylierter Form auf, wobei sich die Hormaomycine $F_{1-3}(30 a-c)$ und $G_{1-3}(31 a-c)$ nicht vom Hormaomycin (16) trennen lassen. Das para-Fluorphenylalanin wird auch von beiden Enzymen als Substrat erkannt [Hormaomycine $\mathrm{H}_{1,2}(\mathbf{3 2 a}, \mathbf{b})$ ], scheint aber, wie auch die in gleicher Position chlorierten, bromierten und nitrierten Phenylalanine, als Inhibitor der Methyltransferase zu wirken. Dies lässt sich an dem Einbau von Phenylalanin in das Peptid erkennen, welcher zur 
Bildung der Desmethylhormaomycine $J_{1-3}(33 a-c)$ führt. Der Abstand der funktionellen Gruppen zum Phenylring ist für die Erkennung wichtig, wie durch den Misserfolg der Phenylglycinfütterung gezeigt werden konnte.

Die Fütterungsexperimente und die gewonnenen Derivate liefern zudem weitere Erkenntnisse zur Biosynthese des Hormaomycins (16), auf die im nächsten Kapitel eingegangen werden soll. Die Biologischen Aktivitäten der neuen Hormaomycine werden in Kap. 2.6 (S. 61) besprochen. 


\subsection{Die Biosynthese des Hormaomycins}

\subsubsection{Die frühe Biosynthese nichtribosomaler Peptide}

Die Aminosäuren nichtribosomal aufgebauter Peptide zeigen eine wesentlich größere strukturelle Vielfalt als Peptide ribosomalen Ursprungs. Die benötigten Aminosäuren werden zumeist vor der Bindung an einen Multienzymkomplex, der die eigentliche Peptidbiosynthese katalysiert, aus dem Pool der proteinogenen Aminosäuren aufgebaut.

Ein Beispiel für die strukturelle Vielfalt sind Cyclopropylgruppen tragende Aminosäuren wie die Coronaminsäure, einer 2,3-Methanoaminosäure aus dem Peptid-Polyketid-Hybrid Coronatin (34), deren Biosynthese von WALSH et al. aufgeklärt werden konnte. ${ }^{109,110} \mathrm{Da}$ Fütterungsexperimente mit isotopenmarkierten L-allo-Isoleucinen den Vorläufer, nicht aber den Mechanismus der Bildung der Coronaminsäure aufzeigen konnten, ${ }^{111,112}$ wurden molekularbiologische Methoden angewandt. Nach Aufklärung des Biosynthesegenclusters von $34^{113}$ gelang die Isolierung der Biosyntheseenzyme CmaA-E, ${ }^{114}$ die genaue Untersuchungen aller Intermediate ermöglichten. Dies führte zu dem Ergebnis, dass der Cyclopropanring nach Aktivierung einer Methylgruppe durch Chlor entsteht.<smiles>CC[C@H](C)C(N)C(=O)O</smiles><smiles>SCCc1cccc2ccccc12</smiles>

CmaA

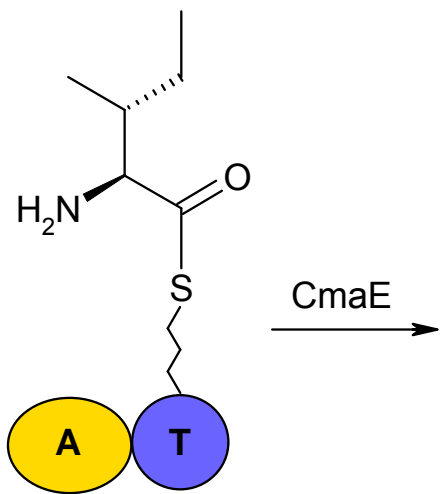

$\mathrm{CmaA}$<smiles>CC[C@H](C)[C@H](N)C(=O)SCCc1ccccc1</smiles>

CmaD<smiles>CC[C@H]1CC(C(=O)N[C@]2(C(=O)O)C[C@H]2CC)[C@H]2CCC(=O)[C@H]2C1</smiles>

34
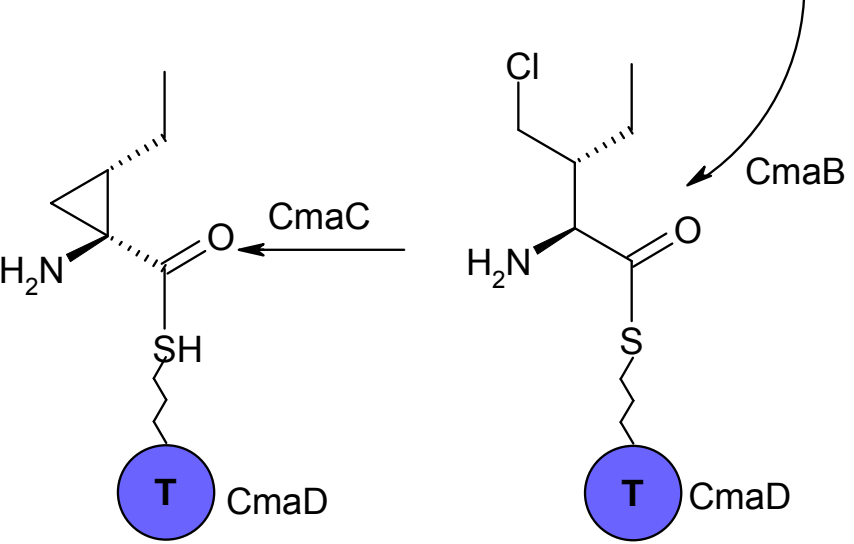

Abb. 15: Darstellung der Biosynthese der Coronaminsäure im Coronatin (34). ${ }^{109-113}$ 
Die Einführung des Chlors übernimmt eine Nicht-Häm-Eisen-Oxygenase, in deren Zentrum hochreaktives Eisen (IV) vorliegt. In einem radikalischen Mechanismus wird dabei das Halogen in eine reaktionsträge Methylgruppe eingeführt. Ein ähnlicher Mechanismus eines solchen Enzyms ist vor kurzem für die Biosynthese von 4-Chlorthreonin, einer Aminosäure des Peptidlactons Syringomycin E, nachgewiesen worden. ${ }^{115}$ Untersuchungen an $\mathrm{FADH}_{2}$ Oxygenasen hingegen zeigen, dass diese Halogene nur für die Halogenierung von ungesättigten Systemen aktivieren können. Die Ergebnisse für Coronatin sind somit ein eindrucksvolles Beispiel dafür, wie gut die Natur die Reaktivität von Enzymen den Substraten anpasst.

\subsubsection{Der Mechanismus der (3-Ncp)Ala-Biosynthese}

Neben der Möglichkeit, Dreiringe durch intramolekularen Ringschluss zu bilden, wird für andere Naturstoffe die Methylierung einer Doppelbindung angenommen. ${ }^{116}$ Dieser Mechanismus konnte für Hormaomycin (16) durch Fütterungsversuche mit isotopenmarkierten Aminosäuren von GEERS ausgeschlossen werden. ${ }^{68,71}$ So ist L-Lysin der Ausgangspunkt für die Biosynthese des 3-(2'-Nitrocyclopropyl)alanins, alle Kohlenstoffe und der Stickstoff der endständigen Nitrogruppe stammen aus dieser proteinogenen Aminosäure. Die Kenntnis dieses Vorläufers war die Grundlage für die Untersuchungen von ALVERMANN ${ }^{66}$ zum genauen Mechanismus der Biosynthese dieser außergewöhnlichen 4,5-Methanoaminosäure. Die Fütterung Deuterium-markierter Lysine und die Bestimmung ihrer Einbauraten in 16 führte zu der Erkenntnis, das mit [6,6- $\left.{ }^{2} \mathrm{H}_{2}\right]$ Lysin die Markierung verloren geht, was z.B. durch eine intermediäre $\mathrm{sp}^{2}$-Hybridisierung des Kohlenstoffs erklärt werden

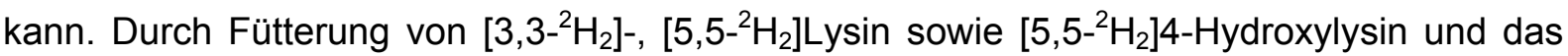
Auffinden von jeweils zwei Markierungen in den (3-Ncp)Ala-Einheiten hingegen konnte bewiesen werden, dass an diesen Stellen kein Protonenaustausch stattfindet. In der 4-Position wurde durch Fütterung von $\left[4,4-{ }^{2} \mathrm{H}_{2}\right]$ Lysin lediglich ein Deuteriumatom gefunden, was ein Cyclisierungsmechanismus berücksichtigen muss.

Durch den in Kap. 2.3.1.4 (S. 31) beschriebenen erfolgreichen Einbau von 6-Nitronorleucin und die Isolierung der daraus resultierenden Hormaomycine $E_{1-3}(26 a-c)$ kann weiterhin die vollständige Oxidation der Aminogruppe vor dem Ringschluss ausgeschlossen werden. Die erfolglosen Fütterungsexperimente mit den D-Epimeren der eingebauten Aminosäuren L-5-Nitronorvalin und L-6-Nitronorleucin lässt, wie schon zuvor vermutet, die Beteiligung einer externen Racemase an der Biosynthese des (3-Ncp)Ala I unwahrscheinlich erscheinen. Mit diesen zusätzlichen Informationen kann nun ein neuer Mechanismus für die Biosynthese dieser ungewöhnlichen Cyclopropylaminosäure vorgeschlagen werden (s. Abb. 16, S. 49). Im ersten Reaktionsschritt kommt es dabei zur oxidativen Hydroxylierung von Lysin (35) zu 
4-Hydroxylysin (36). Das offenkettige Hydroxylysin liegt im Gleichgewicht mit der thermodynamisch begünstigten Lactonform (37) vor, aus welcher sich durch Oxidation am Stickstoff das Nitrosamin (38) bildet. Dieses liegt in einem tautomeren Gleichgewicht vor, welches den Deuteriumaustausch bei Fütterung von $\left[6,6-{ }^{2} \mathrm{H}_{2}\right]$ Lysin erklärt. Ausgehend vom Hydroxylamin (39) kommt es zur Cyclisierung unter Bildung des (2S,1'R)-3-(2'Nitrosocyclopropyl)alanin (40), welches durch Oxidation zum (2S,1'R,2'R)-3-(2'Nitrocyclopropyl)alanin [(3-Ncp)Ala)] umgesetzt wird.<smiles>NCCCC[C@H](N)C(=O)OCCCN</smiles>

35

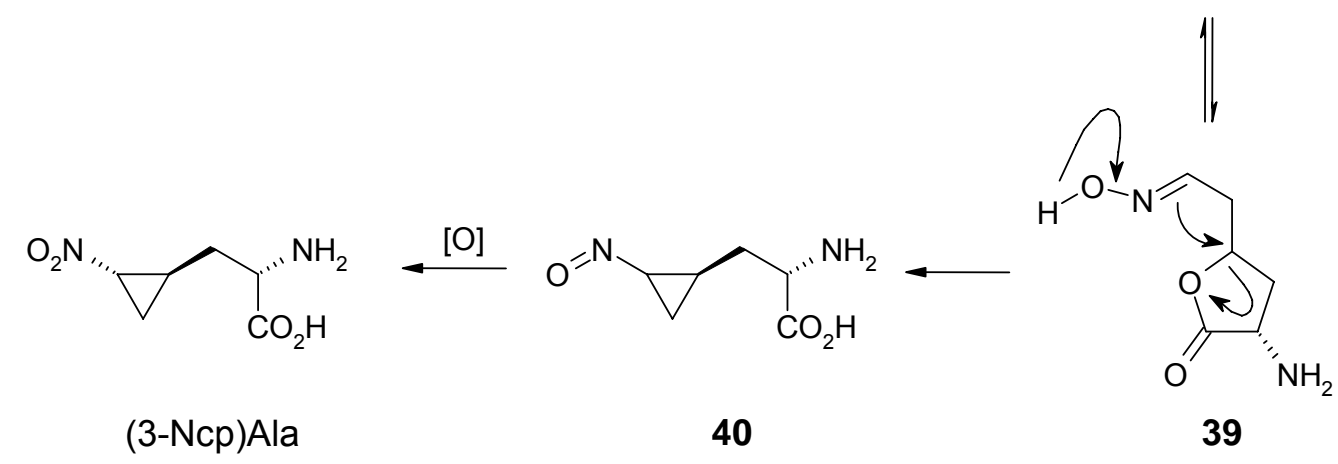

Abb. 16: Vermuteter Mechanismus der Biosynthese von (3-Ncp)Ala in der frühen Biosynthese des Hormaomycins (16).

\subsubsection{Genetische Untersuchungen zur Biosynthese des Hormaomycins}

Schon GEERS ${ }^{71}$ hatte nach Auffinden aller Vorläufer des Peptidlactons 16 eine nichtribosomale Peptidsynthetase (NRPS) postuliert. Um den zugehörenden Biosynthesegencluster zu finden, wurde Streptomyces griseoflavus W 384 in der Arbeitsgruppe PIEL ${ }^{b}$ auf entsprechende NRPS-Gene gescreent. Hierbei wurden zwei NRPSGencluster gefunden, von denen einer der Hormaomycin-Biosynthese zugeordnet werden konnte. Der Cluster trägt wie erwartet Gene für sieben Module mit Kondensations-, Adenylierungs- und PCP-(Peptidyl Carrier Protein, auch: Thionylierungs-) Domänen, sowie eine Adenylierungs- und PCP-Domäne für die Aufnahme der Chpca-Startereinheit am Anfang des Mutlienzymkomplexes.

\footnotetext{
Herrn Prof. DR. J. PIEL (Kekulé-Institut für Organische Chemie und Biochemie, Universität Bonn) danke ich für die Überlassung der Informationen aus seinen molekulargenetischen Untersuchungen der HormaomycinSynthetase.
} 


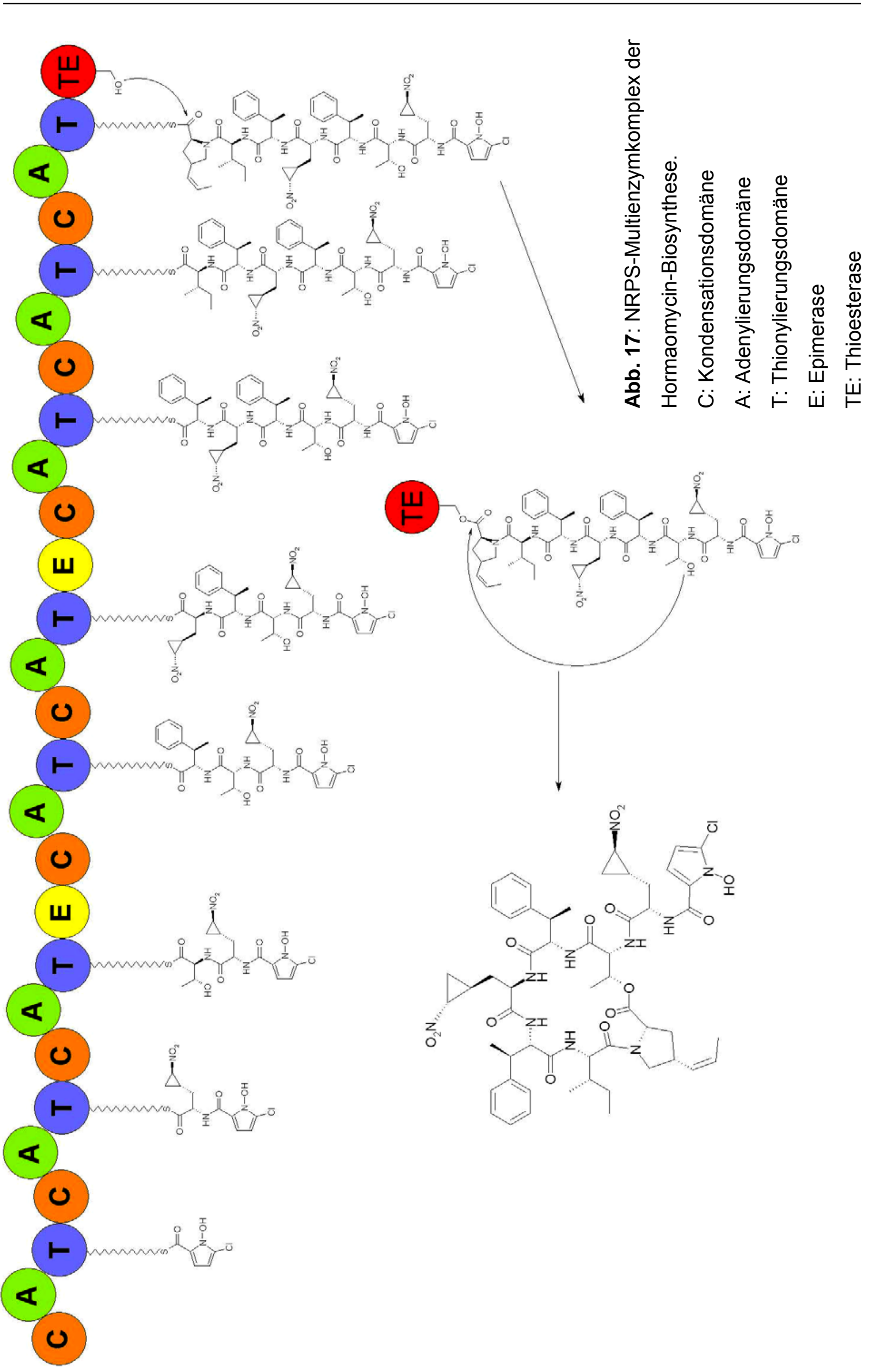


Im zweiten und vierten Modul sind zudem Epimerase-Domänen nachgewiesen worden, welche die Bildung von D-Thr und D-(3-Ncp)Ala I katalysieren. Am Schluss des Komplexes befindet sich wie vorhergesagt eine Thioesterase, die für die Cyclisierung des linearen Peptids zum Peptidlacton 16 notwendig ist. In dem konservierten Bereich des Clusters sind weitere Gene zu finden, welche für die frühe Biosynthese, also den Aufbau der Aminosäuren, von 16 codieren. Durch Homologie dieser Gene mit bekannten Genen anderer Gencluster können die Vorläufer Prolin, Threonin, Isoleucin und Tyrosin [für Chpca, Thr, Ile und (4-Pe)Pro] bestätigt werden. Für die (3-Ncp)Ala und die ( $\beta \mathrm{Me})$ Phe-Einheiten ist keine genaue Zuordnung möglich, da keine Daten über vergleichbare Biosynthesewege existieren. Daher wurden die unbekannten Gene, $h r m \mathrm{l}, \mathrm{J}$ für die (3-Ncp)Ala und $h r m S$ für die ( $\beta \mathrm{Me})$ PheBiosynthese, jeweils heterolog in Escherichia coli exprimiert. ${ }^{117}$ Durch Zufütterung geeigneter Vorläufer sollten die beiden Aminosäuren entstehen, deren Nachweis den Beweis für die richtige Zuordnung des Clusters zur Hormaomycin-Biosynthese erbringen würde.

\section{Escherichia coli pKZ72 ${ }^{\mathrm{C}}$}

Die Mutante enthält mit hrmS ein Gen, welches große Übereinstimmungen mit einem Gen einer Methyltransferase aus Streptomyces lincolnensis zeigt und daher vermutlich für die Methylierung von Phenylalanin zu $(\beta \mathrm{Me})$ Phe verantwortlich ist. ${ }^{118}$ Trotz bewiesener Herkunft des $\mathrm{C}_{1}$-Fragments aus Methionin ist bisher unklar, ob die Methylierung von Phenylalanin direkt geschieht oder eine Aktivierung hierfür nötig ist, da die Deprotonierung an C-3 aufgrund der geringen Acidität der Methylengruppe im Phenylalanin $\left(\mathrm{pK}_{\mathrm{a}}>40\right)^{119} \mathrm{sehr}$ erschwert ist. Eine mögliche Zwischenstufe ist das Phenylpyruvat, dessen Methylengruppe mit $\mathrm{pK}_{\mathrm{a}} \approx 19^{119}$ wesentlich reaktiver ist. Phenylpyruvat könnte unter Beteiligung einer Transaminase direkt aus Phenylalanin entstehen.

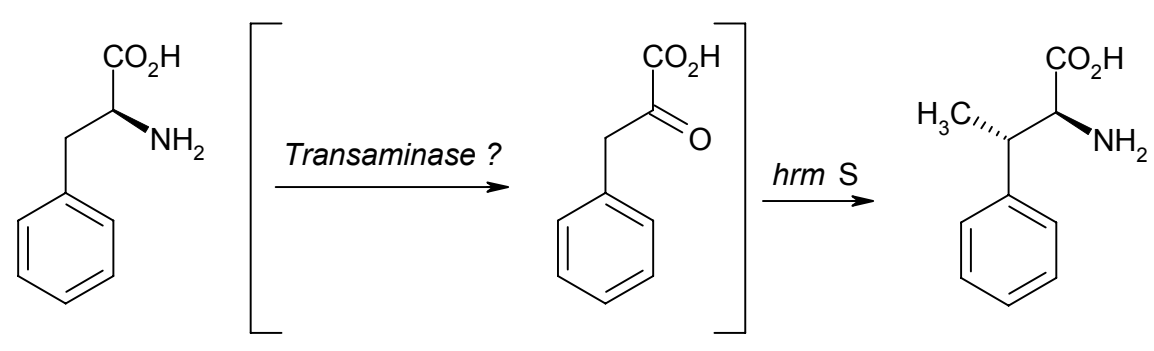

Abb. 18: Die Methylierung von Phenylalanin oder Phenylpyruvat führt zu $(\beta M e) P h e$.

Da beide Vorläufer vorstellbar sind, wurde die Mutante unter Zusatz von Phenylpyruvat und Phenylalanin kultiviert. Zur Induktion der Expression wurde zum gleichen Zeitpunkt $m$-Toluylsäure in unterschiedlichen Konzentrationen gefüttert. Die $m$-Toluylsäure ist hierbei

c Für die Überlassung der E. coli-Mutanten gilt mein besonderer Dank Herrn PrOF. DR. J. PIEL (Universität Bonn) sowie Frau K. ZIMMERMANN. 
für die Aktivierung des vor die Biosynthesegene geschalteten Pm-Promotors verantwortlich. In den HPLC-MS-Chromatogrammen der Kulturextrakte waren im Vergleich zur Blindprobe keine neuen Metaboliten nachweisbar.

\section{Escherichia coli pKZ73}

Die Gene $h r m l$ und $h r m J$ mit unbekannter Funktion sind die zwei letzten Gene des Clusters die für Enzyme der (3-Ncp)Ala-Biosynthese codieren können. Die Kultivierungen erfolgten wie bei der pKZ72-Mutante, als Vorläufer wurde hier Lysin gefüttert. Erneut waren in den Extrakten keine neuen Metaboliten nachweisbar.

Warum die Mutanten nicht die erwarteten Metaboliten produzieren bleibt ungeklärt, eventuell würde schon eine Temperaturänderung zum Erfolg führen. Denkbar wäre jedoch auch, dass die heterologe Expression von hrml,J und hrmS aus systemischen Gründen im E. coliWirtsstamm nicht funktioniert. Zum jetzigen Zeitpunkt wird die heterologe Expression der beiden Gene in Pseudomonas sp. im Arbeitskreis von PROF. PIEL untersucht. 


\subsection{Die Struktur des Hormaomycins}

\subsubsection{Die Struktur von Hormaomycin in Lösung}

Im Arbeitskreis von PROF. GRIESINGER ${ }^{d}$ wurden die Raumstrukturen des fermentativ gewonnenen Hormaomycins (16) sowie einiger synthetischer Derivate in DMSO ${ }^{120,121}$ und Chloroform ${ }^{122}$ durch NMR-Spektroskopie bestimmt. Hierzu wurden aus NOE-(Nuclear Overhauser Effect) Kopplungen Strukturen mit minimaler Energie errechnet und mit RD(Residual-Dipolar) Kopplungskonstanten verfeinert. Es zeigte sich, dass die Ringstruktur sowohl in DMSO als auch in Chloroform zwei $\beta$-turns zwischen (4-Pe)Pro und a-Thr sowie (3-Ncp)Ala I und ( $\beta \mathrm{Me})$ Phe I aufweist. Die Anordnung der Seitenkette ist in den verwendeten Lösungsmitteln jedoch unterschiedlich. In Chloroform ist eine sehr starre Konformation auszumachen, worauf schon der große Unterschied in den chemischen Verschiebungen zwischen den verschiedenen $\alpha$ - und $\mathrm{N}-\mathrm{H}$-Atomen schließen lässt, diese Signale sind in DMSO in einem sehr viel kleineren Bereich zu finden. Zudem treten in Chloroform unerwartete NOE-Fernkopplungen von der Chpca- zu der $(\beta M e) P h e$ I-Einheit auf. Hieraus ergibt sich für die Struktur in Chloroform eine Interaktion der drei aromatischen Ringe von 16, die Seitenkette ist über den Ring „gebogen“. Dieser Effekt ist in DMSO nicht zu beobachten, die Seitenkette interagiert scheinbar überhaupt nicht mehr mit den Phenylringen.
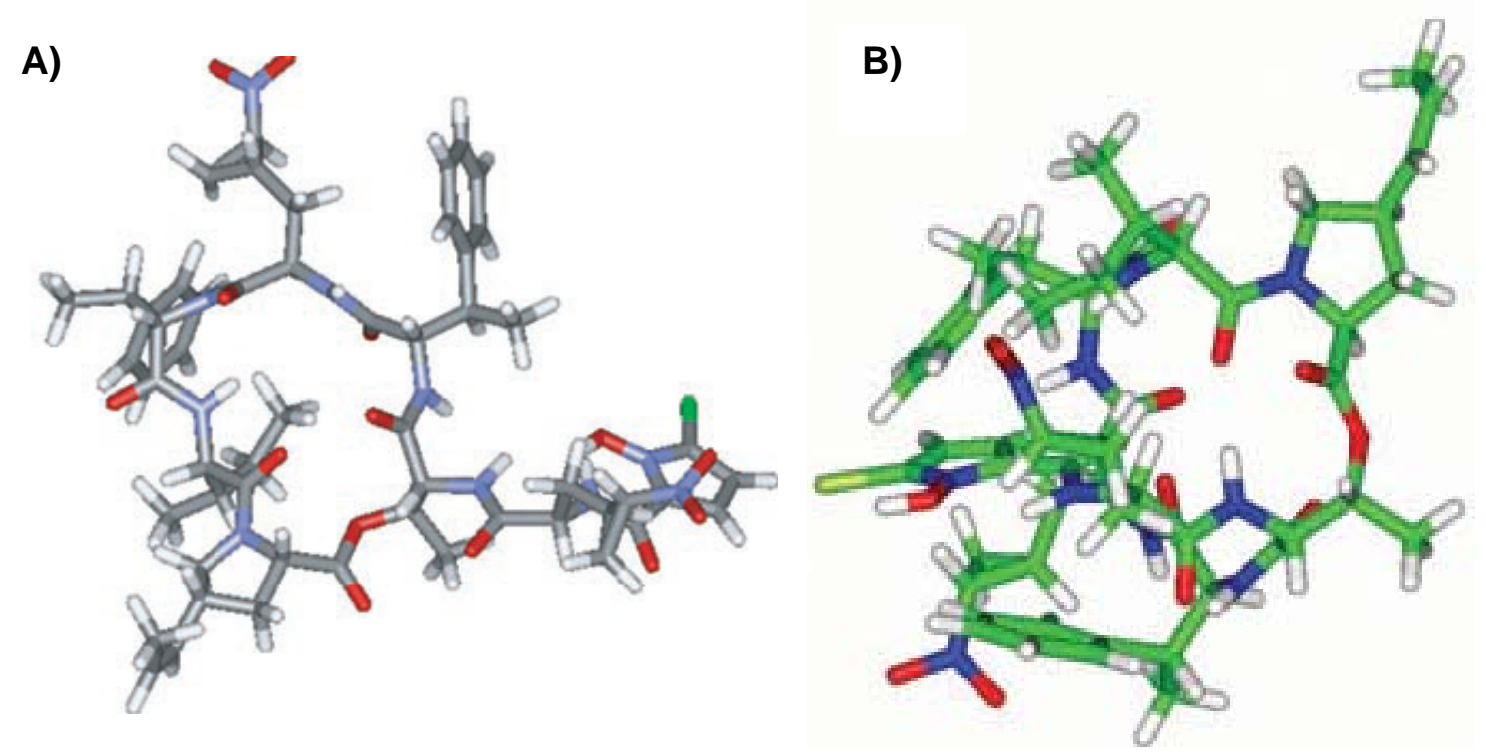

Abb. 19: NMR-Lösungstruktur von Hormaomycin (16), A) in $\left.\mathrm{DMSO}^{120}, \mathrm{~B}\right)$ in Chloroform ${ }^{122}$.

d Für die NMR-Messungen und die Abbildungen gilt mein besonderer Dank DR. U.M. REINSCHEID, J. FARJon, P. HABERz sowie PRof. Dr. C. Griesinger (Max-Planck-Institut für Biophysikalische Chemie, Göttingen). 


\subsubsection{Die Kristallstruktur des Hormaomycins}

Nach intensiven Kristallisationsversuchen ist es der Arbeitsgruppe SHELDRICK ${ }^{e}$ gelungen, Hormaomycinkristalle aus wässrigem Ethanol in Gegenwart von 2-Methyl-2,4-pentandiol und $\mathrm{MgCl}_{2}$ zu züchten. Die gewonnene Röntgenstruktur zeigt überraschenderweise eine dimere Anordnung des Peptidlactons 16 im Kristall. Es besteht eine enge Bindung der beiden Monomereinheiten an ein zentrales Kation über die Carbonylsauerstoffe von 3-Nitrocyclopropylalanin I, Isoleucin und Threonin. Da die Auflösung der Röntgenstrukturanalyse zu gering ist, kann noch keine sichere Aussage über die Art des Zentralions gemacht werden. Erstaunlich ist zudem, dass die kürzlich geglückte Röntgenstruktur von synthetischem 16 keine dimere Anordnung aufweist.

Die Raumstruktur der Monomereinheit zeigt zudem große Differenzen zu den Lösungsstrukturen der NMR-Experimente. Am ehesten vergleichbar scheint die Struktur mit der DMSO-Struktur, da in beiden Fällen die Seitenkette nicht über den Ringteil gebogen ist, sondern vom Ring wegzeigt. Der Grund für die Unterschiede kann in der Befähigung unterschiedlicher Lösungsmittel Wasserstoffbrückenbindungen auszubilden liegen. So ist Chloroform ein schwacher Donor und Akzeptor, DMSO hat starke Akzeptoreigenschaften und beim verwendeten Ethanol/ Wasser Kristallisationsmedium sind sowohl Akzeptor- als auch Donoreigenschaften stark. Eine Verwechslung intramolekularer NOE- mit intermolekularen ROE-Korrelationen bei Erstellung der Lösungsstrukturen konnte ausgeschlossen werden.

e Großer Dank für die kristallographischen Untersuchungen und die Abbildungen gilt Herrn DR. T. GRÜNE und Herrn PROF. DR. G.M. SHELDRICK (Institut für Anorganische Chemie, Universität Göttingen). 
(A)

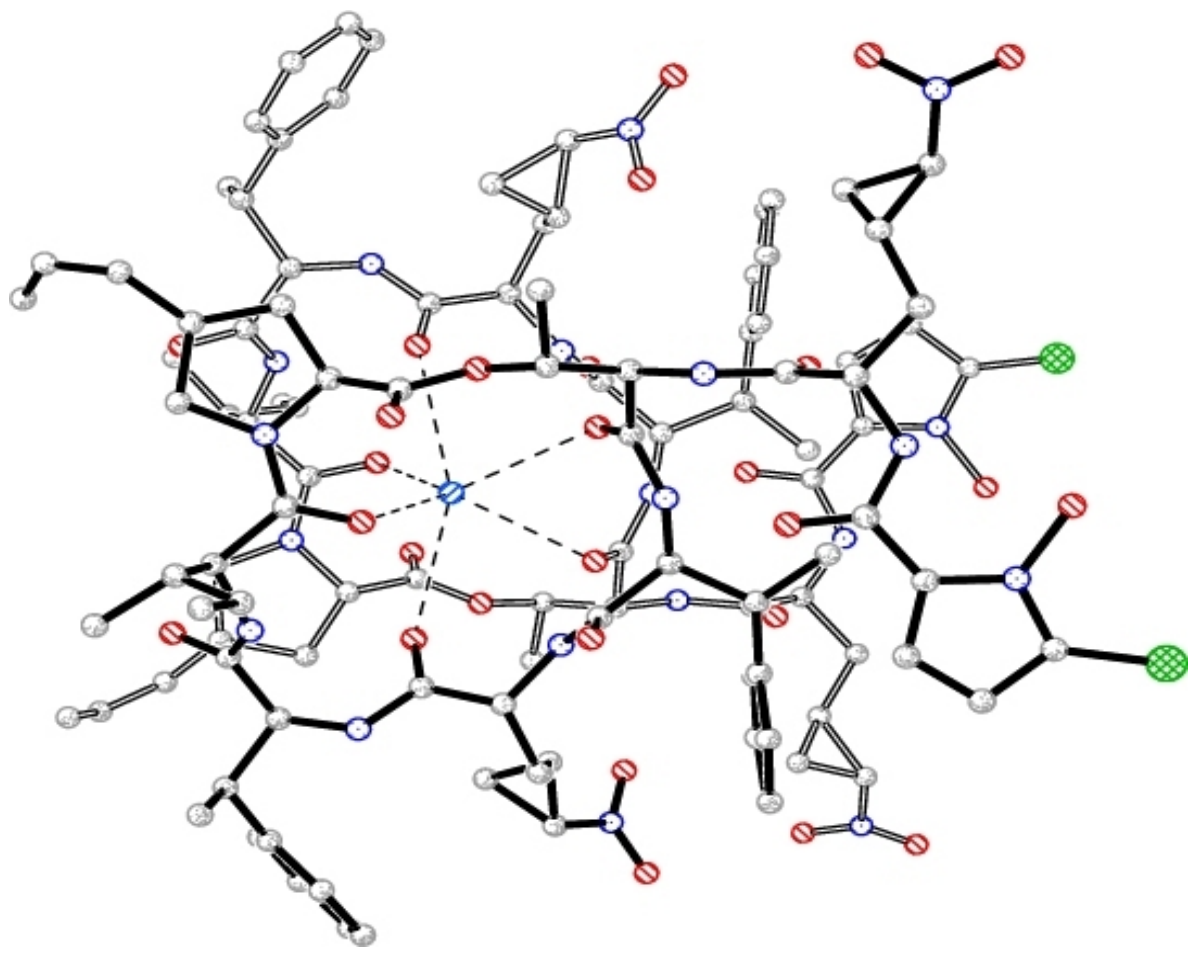

B)

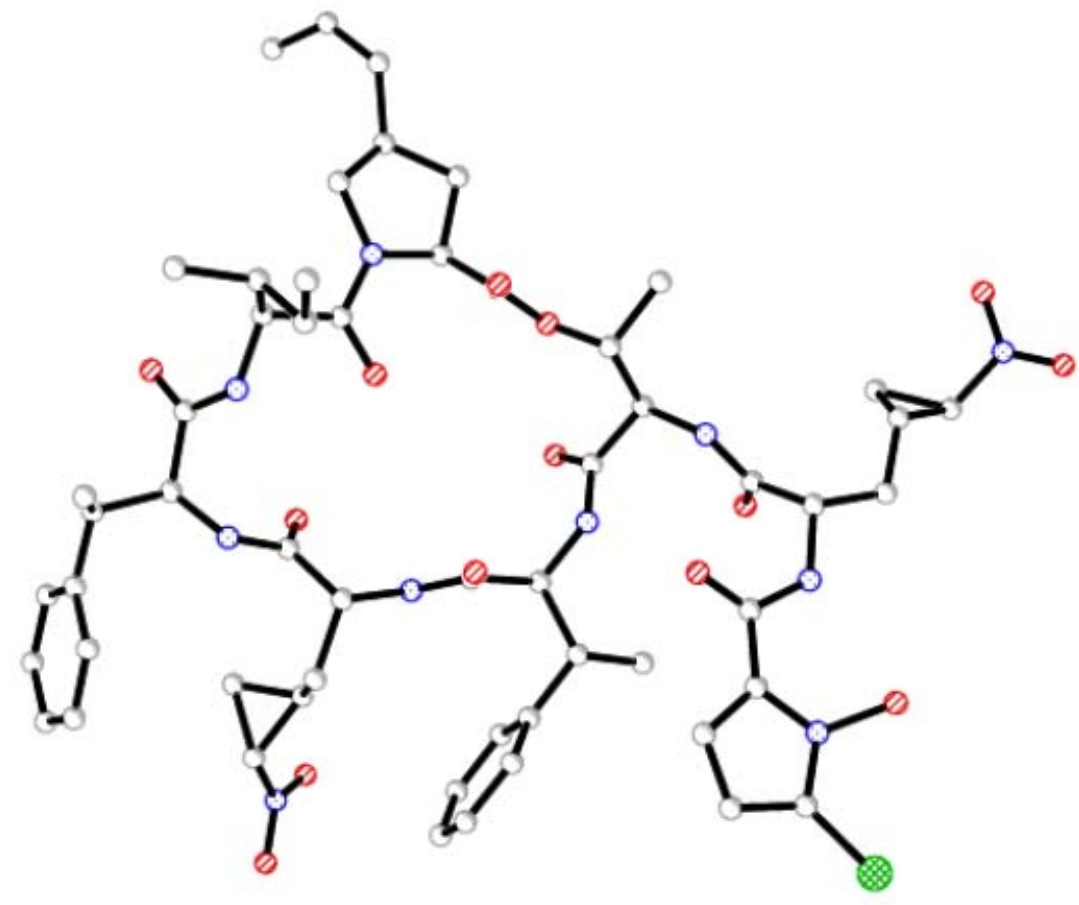

Abb. 20: Kristallstruktur des Hormaomycins (16), A) Die Dimereinheit der HormaomycinKristallstruktur (das obere Monomer mit ausgefüllten, das untere mit offenen Bindungen, gestrichelte Linien zeigen die Bindung zum Zentralion an); B) Monomereinheit von 16 (Bindungen zum Zentralion aus Übersichtsgründen nicht dargestellt). 


\subsubsection{Untersuchung zum Zentralion im Hormaomycin}

Die im Kristall aufgefundene dimere Struktur von Hormaomycin (16) zeigt die koordinative Bindung von zwei Peptideinheiten an ein Zentralion. Die Kation-Carbonylsauerstoff-Abstände sprechen dabei am ehesten für die Bindung von $\mathrm{K}^{+}, \mathrm{Na}^{+}$oder $\mathrm{NH}_{4}{ }^{+}$. Da im Kristallisationsmedium keine Kationen außer $\mathrm{Mg}^{2+}$ vorliegen, muss eine Bindung während der Fermentation oder bei der Aufarbeitung erfolgen.

Die Hochauflösung eines ESI-MS-Peaks der Masse m/z = 2295 führt zu der Summenformel $\mathrm{C}_{110} \mathrm{H}_{138} \mathrm{~N}_{20} \mathrm{O}_{28} \mathrm{Cl}_{2} \mathrm{~K}$ und entspricht somit einem $\mathrm{K}^{+}$-Hormaomycin-Dimer. Der beobachtete Peak ist aufgrund seiner Intensität nicht als einfaches Addukt zu bewerten, allerdings kann mit dieser Methode keine Quantifizierung vorgenommen werden. Um eine quantitative Bestimmung zu ermöglichen, wurde 16 einer ICP-MS (Inductively-coupled plasma mass spectrometry) Untersuchung unterzogen. Hierzu wird 16 oxidativ aufgeschlossen und die Rückstände in der Gasphase untersucht. Bezogen auf 5.0 mg 16 enthielt die Probe lediglich $10 \mathrm{ng} \mathrm{K}$, was $0.2 \%$ des Hormaomycin-Dimers entsprechen würde. In höheren Anteilen konnten $\mathrm{Na}^{+}, \mathrm{Zn}^{2+}$ und $\mathrm{Ca}^{2+}$ nachgewiesen werden (s. Tab. 3), wobei $\mathrm{Ca}^{2+}$ aufgrund ähnlicher Molmassen durch Rückstände der Hydrolyse wie $\mathrm{CO}_{2}$ oder $\mathrm{CNO}$ vorgetäuscht sein kann.

\begin{tabular}{cccc}
\hline & $\begin{array}{c}\text { Masse } \\
{[\mu \mathrm{g}]}\end{array}$ & $\begin{array}{c}\text { Stoffmenge } \\
{[\mathrm{nmol}]}\end{array}$ & $\begin{array}{c}\text { Verhältnis pro } \\
\text { 16-Dimer [mol\%] }\end{array}$ \\
\hline $\mathrm{Na}$ & 9.585 & 416.92 & 18.4 \\
$\mathrm{~K}$ & 0.090 & 2.30 & 0.2 \\
$\mathrm{Ca}$ & 1.212 & 30.31 & 1.4 \\
$\mathrm{Fe}$ & 0.068 & 1.21 & $<0.1$ \\
$\mathrm{Cu}$ & 0.090 & 1.42 & $<0.1$ \\
$\mathrm{Zn}$ & 2.610 & 39.93 & 1.8 \\
$\mathrm{Sn}$ & 0.045 & 0.38 & $<0.1$ \\
\hline
\end{tabular}

Tab. 3: Anteile verschiedener Metallionen in $5 \mathrm{mg}(4.4 \mathrm{nmol})$ Hormaomycin (16). 


\subsubsection{Austausch des Zentralions im Hormaomycin}

Schon in frühen Arbeiten waren Unterschiede in den Protonenspektren des Hormaomycins (16) bei Isolierung des Naturstoffs aus unterschiedlichen Fermentationsansätzen aufgefallen. Auch der Beweis, dass es sich bei Takaokamycin und 16 um identische Substanzen handelt, konnte aufgrund dieser Differenzen erst spät erbracht werden. ${ }^{53}$ Weiterhin zeigte auch das Syntheseprodukt deutliche Unterschiede der ${ }^{1} \mathrm{H}-\mathrm{NMR}-S p e k t r e n$ im Vergleich zum Naturstoff, wobei in allen Fällen die größten Unterschiede in der (3-Ncp)Ala I-Einheit auszumachen waren.

Die chemischen Verschiebungen einiger Protonen in diesem Teil des Moleküls zeigen zudem die Besonderheit, dass sie in einem Bereich $\delta_{H}=-0.62$ bis +0.60 liegen, was durch die Lage dieser Protonen in den Anisotropiekegeln der Phenylringe erklärt werden kann. Dies wird durch die starken Unterschiede der chemischen Verschiebungen der (3-Ncp)Ala I-Einheit in den Desmethylhormaomycinen $J_{1-3}$ (33a-c; vgl. Tab. 1, S. 41) im Vergleich zum Naturstoff bestätigt. Bei keiner anderen Aminosäureeinheit des Peptidlactons zeigen die Variationen benachbarter Aminosäuren so große Einflüsse auf die Resonanzspektren. Es muss also festgehalten werden, dass in diesem Bereich des Moleküls kleinste konformative oder konstitutionelle Variationen deutliche Auswirkungen auf die ${ }^{1} \mathrm{H}$ chemischen Verschiebungen haben können, die in der Größenordnung bis 0.4 ppm liegen.

Um zu verifizieren, ob die Unterschiede in den Protonenspektren durch das in der Röntgenstruktur beobachtete koordinativ gebundene Zentralion begründet sind, wurde der Naturstoff an einem lonenaustauscherharz chromatographiert. Das Protonenspektrum der so erhaltenen Substanz zeigt im Vergleich zum Naturstoff starke Veränderungen im Bereich $\delta_{H}=-0.62$ bis +0.60 und 2.90-3.00 (s. Abb. 21, S. 60 und Tab. 4, S. 59), aber große Übereinstimmungen zum Syntheseprodukt ${ }^{\mathrm{f}}$. Diese Beobachtung spricht für eine koordinative Bindung von Teilen der Hormaomycin-Moleküle an Metallionen auch in Lösung, die in den Untersuchungen von GRIESINGER et al. nicht gefunden werden konnte.

Die Fermentation zur Gewinnung von 16 erfolgt in einem synthetischen Nährmedium, welches die Metalle $\mathrm{Na}^{+}, \mathrm{K}^{+}, \mathrm{Ca}^{2+}, \mathrm{Cu}^{2+}, \mathrm{Mn}^{2+}, \mathrm{Fe}^{3+}$ und $\mathrm{Zn}^{2+}$ enthält. Dementsprechend kommen diese lonen während der Kultivierung mit $\mathbf{1 6}$ in Berührung und können je nach Affinität koordinativ gebunden werden, was sich auf die NMR-Spektren auswirkt. Um solche Effekte zu untersuchen, wurde der deionisierte Naturstoff in Chloroform gelöst und mit verschiedenen Salzlösungen der Metalle vorbehandelt (s. Kap. B.2.2.1, S. 115). Um den Zusatz von NMR-aktiven Eisen zu vermeiden, wurde die mögliche Bindung in diesem Fall durch Zusatz einer Gallium(III)-nitratlösung simuliert. Gallium(III) ist aufgrund ähnlicher lonengröße als Ersatz für Eisen(III) gut geeignet. ${ }^{123}$

\footnotetext{
f Ich danke Herrn DR. V. RaEV und Herrn PROF. DR. A. DE MeIJeRE für die Überlassung des
} Syntheseproduktes. 
Beim Vergleich der ${ }^{1} \mathrm{H}-\mathrm{NMR}$-Spektren der so erhaltenen Substanzen sind Unterschiede in der Lage einzelner Signale zu erkennen. Nach der Zuordnung der Signale fällt auf, dass sich die vorbehandelten Hormaomycine in zwei Gruppen unterteilen lassen, deren Protonen in entgegengesetzter Richtung relativ zum Naturstoff verschoben sind. Zudem sind die Tiefund Hochfeldverschiebungen einzig auf den Bereich der (3-Ncp)Ala I- sowie die Protonen in 2- und 3-Position der ( $\beta \mathrm{Me})$ Phe-Einheiten beschränkt.

Zur ersten Gruppe gehören $16 \cdot \mathrm{K}^{+;}$g und $16 \cdot \mathrm{Ga}^{3+;}$ g, ihre Protonenspektren sind vergleichbar mit denen des deionisierten Hormaomycins. Bei dieser Gruppe weisen alle Protonen der (3-Ncp)Ala I- und die $\alpha-\mathrm{H}$-Atome der $(\beta \mathrm{Me})$ Phe-Einheiten Hochfeldverschiebungen auf, während das $3-\mathrm{H}$ der $(\beta \mathrm{Me})$ Phe II-Einheit ins Tieffeld verschoben ist. Die einzelnen Verschiebungen sind Tab. 4 (S. 59) zu entnehmen.

Im Gegensatz hierzu stehen die Beobachtungen nach Vorbehandlung des deionisierten Hormaomycins mit einer Kupfer(II)-chloridlösung. In diesem Fall erfahren die Protonen des (3-Ncp)Ala und die $\alpha-\mathrm{H}$-Atome der ( $\beta \mathrm{Me})$ Phe Verschiebungen ins Tieffeld. Das $3-\mathrm{H}$ des $(\beta \mathrm{Me})$ Phe II ist mit $\delta_{H}=2.91$ ins Hochfeld verschoben. Die Beobachtungen sprechen somit für konformative Änderungen des Moleküls bei Bindung an ein Metallion. Die Verschiebungen der Kohlenstoffatome hingegen weisen keine Veränderungen auf, alle so gewonnenen Hormaomycine haben gleiche ${ }^{13} \mathrm{C}-\mathrm{NMR}-\mathrm{Daten}$. Weiterhin reicht die konformative Änderung nicht aus, um auch die CD- und UV-Spektren zu beeinflussen, auch hier ist bei den vorbehandelten Hormaomycinen kein Unterschied zum Naturstoff auszumachen.

g 16·X:deionisiertes Hormaomycin mit Metallsalz $(X)$ angereichert. 


\begin{tabular}{|c|c|c|c|c|c|c|}
\hline & & 16 & 16.De & $16 \cdot \mathrm{K}^{+}$ & $16 \cdot \mathrm{Ga}^{3+}$ & $16 \cdot \mathrm{Cu}^{2+}$ \\
\hline \multirow{2}{*}{ 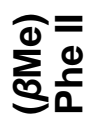 } & $2-\mathrm{H}$ & 4.38 & 4.36 & 4.36 & 4.38 & 4.39 \\
\hline & $3-\mathrm{H}$ & 2.94 & 3.01 & 3.00 & 2.99 & 2.91 \\
\hline \multirow{7}{*}{ 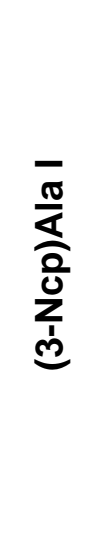 } & $2-\mathrm{H}$ & 3.57 & 3.46 & 3.48 & 3.48 & 3.62 \\
\hline & $3-\mathrm{H}_{\mathrm{a}}$ & -0.06 & -0.16 & -0.14 & -0.11 & -0.02 \\
\hline & $3-H_{b}$ & 0.56 & 0.50 & 0.54 & 0.50 & 0.59 \\
\hline & $1 '-H$ & 0.31 & 0.26 & 0.26 & 0.28 & 0.36 \\
\hline & 2'-H & 2.96 & 2.89 & 2.90 & 2.90 & 2.92 \\
\hline & $3^{\prime}-\mathrm{H}_{\mathrm{a}}$ & -0.60 & -0.71 & -0.69 & -0.64 & -0.55 \\
\hline & $3^{\prime}-\mathrm{H}_{b}$ & 1.01 & 0.98 & 0.98 & 0.99 & 1.01 \\
\hline \multirow{2}{*}{$\sum_{S}^{\infty} \frac{\Phi}{\alpha}$} & $2-\mathrm{H}$ & 4.48 & 4.45 & 4.45 & 4.46 & 4.51 \\
\hline & 3-H & 3.68 & 3.67 & 3.67 & 3.67 & 3.69 \\
\hline
\end{tabular}

Tab. 4: $\delta$-Werte in den ${ }^{1} \mathrm{H}-\mathrm{NMR}$-Spektren $\left(600 \mathrm{MHz}, \mathrm{CDCl}_{3}\right.$ ) für die (3-Ncp)Ala I und $(\beta \mathrm{Me})$ Phe-Einheiten in verschieden vorbehandelten Hormaomycinen (rot: Hochfeldverschiebung, blau: Tieffeldverschiebung).

Die Beschränkungen der Verschiebungen der vorbehandelten Hormaomycine auf einen bestimmten Abschnitt des Moleküls sind außergewöhnlich und nicht literaturbekannt. Möglicherweise ist diese Eigenschaft durch eine schwach ionophore Eigenschaft von $16 \mathrm{zu}$ erklären. Für verschiedene lonophore wie z.B. Salinomycin ${ }^{124}$ oder das für die Entstehung von Alzheimer mitverantwortliche Amyloid- $\beta(1-16)^{125,126}$ sind ähnliche Beobachtungen publiziert. Im Fall des Amyloid- $\beta(1-16)$ verändern sich nach Bindung an Zink oder Cadmium jedoch nicht nur die ${ }^{1} \mathrm{H}-\mathrm{NMR}$-Verschiebungen, es treten zeitgleich sehr große Unterschiede der CD- und UV-Spektren auf, was bei vorbehandelten Hormaomycinen nicht beobachtet werden konnten. 


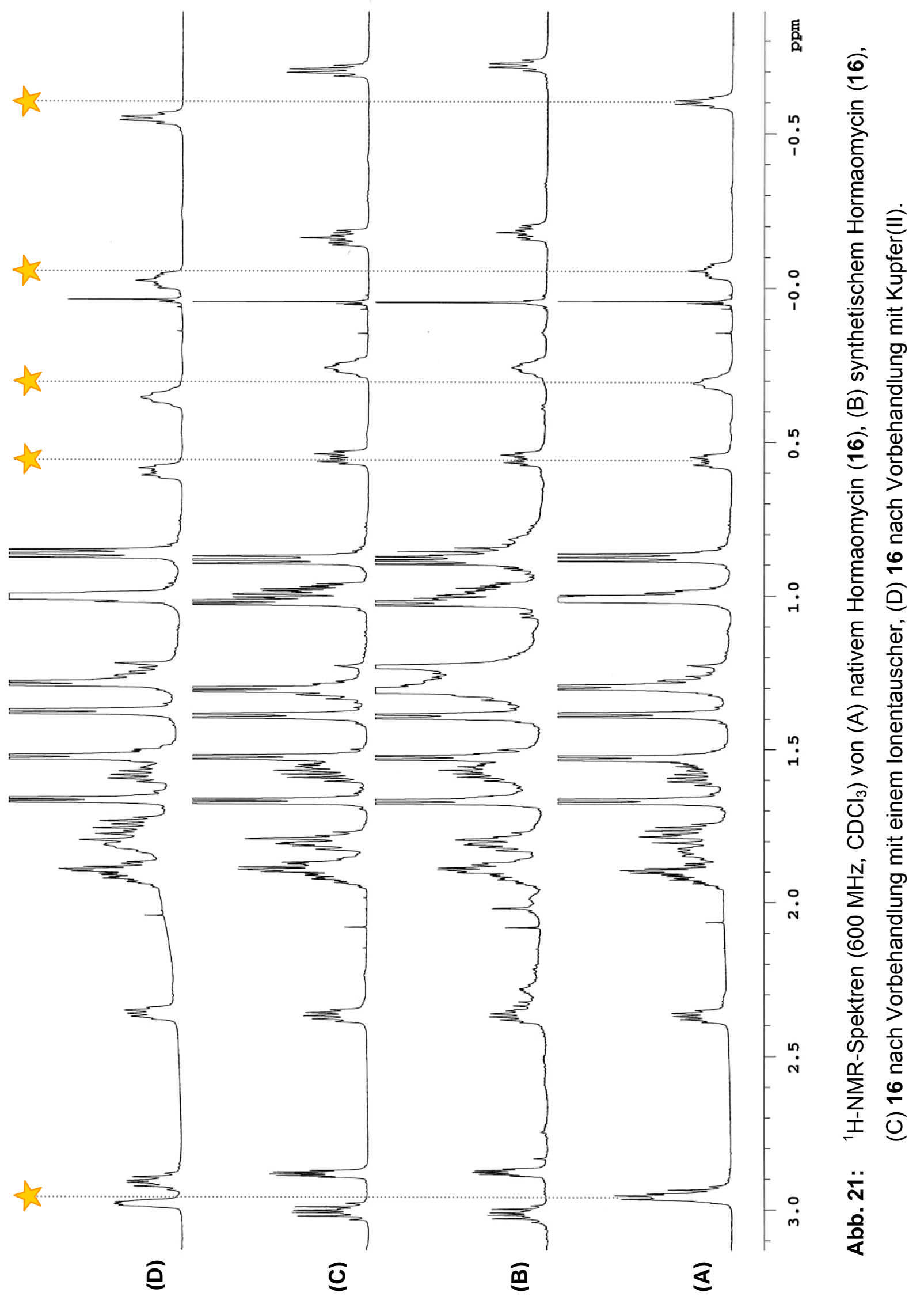




\subsection{Biologische Aktivitäten}

\subsubsection{Antibakterielle und antimykotische Aktivitäten}

Die aus der Vorläufer-dirigierten Biosynthese gewonnenen neuen Hormaomycine wurden im Plattendiffusionstest gegen Escherichia coli, Bacillus subtilis, Staphylococcus aureus, Candida albicans, Arthrobacter oxydans und Arthrobacter crystallopoites getestet. Alle getesteten Substanzen besaßen dem Hormaomycin (16) vergleichbare Aktivitäten gegen die coryneformen Arthrobacter sp.. Die Werte hierfür sind in Tab. 5 relativ zum Naturstoff 16 (= $100 \%)$ zusammengefasst. Zudem zeigte sich, dass weder Derivate noch der Naturstoff selbst gegen Escherichia coli, Bacillus subtilis und Staphylococcus aureus aktiv sind.

\begin{tabular}{lccc}
\hline & \multicolumn{2}{c}{ Substanzmenge [mg] pro Filterplättchen } & \\
& $1.5 \times 10^{-2}$ & $1.5 \times 10^{-3}$ & $1.5 \times 10^{-4}$ \\
\hline Hormaomycin (16) & 100 & 72 & 44 \\
Penicillin $\mathrm{G}$ & 78 & 0 & 0 \\
Hormaomycin $\mathrm{D}_{1}(\mathbf{2 1 a})$ & 57 & 53 & 33 \\
Hormaomycin $\mathrm{D}_{2}(\mathbf{2 1 b})$ & $90^{\mathrm{a}}$ & $84^{\mathrm{a}}$ & $58^{\mathrm{a}}$ \\
Hormaomycin $\mathrm{D}_{3}(\mathbf{2 1 c})$ & 87 & 83 & 57 \\
Hormaomycin $\mathrm{E}_{1}(\mathbf{2 6 a})$ & 97 & - & - \\
Hormaomycin $\mathrm{E}_{2}(\mathbf{2 6 b})$ & 94 & - & - \\
Hormaomycin $\mathrm{E}_{3}(\mathbf{2 6 c})$ & $97^{\mathrm{b}}$ & - & - \\
Hormoamycin $\mathrm{F}_{1-3}(\mathbf{3 0 a}-\mathbf{c})$ & $100^{\mathrm{c}}$ & $95^{\mathrm{c}}$ & $70^{\mathrm{c}}$ \\
Hormaomycin $\mathrm{G}_{1-3}(\mathbf{3 1 a}-\mathbf{c})$ & $100^{\mathrm{c}}$ & $95^{\mathrm{c}}$ & $70^{\mathrm{c}}$ \\
Hormaomycin $\mathrm{H}_{1-3}(\mathbf{3 2 a}-\mathbf{c})$ & $100^{\mathrm{c}}$ & $95^{\mathrm{c}}$ & $70^{\mathrm{c}}$ \\
Hormaomycin $\mathrm{J}_{1}(\mathbf{3 3 a})$ & 100 & 93 & 78 \\
Hormaomycin $\mathrm{J}_{2}(\mathbf{3 3 b})$ & 100 & 83 & 65 \\
Hormaomycin $\mathrm{J}_{3}(\mathbf{3 3} \mathbf{c})$ & 93 & 78 & 75 \\
\hline
\end{tabular}

Tab. 5: Relative antibakterielle Aktivitäten [\%] der Hormaomycin-Derivate im Plattendiffusiontest gegen Arthrobacter oxydans (Stamm 20119) im Vergleich zum Naturstoff und Penicillin G. [a) Getestet gegen Arthrobacter crystallopoites (Stamm 20117); b) Getestet im Gemisch mit Hormaomycin (ca. 5:8); c) Getestet als Gemisch.]

Überraschenderweise zeigte Hormaomycin $D_{2}(\mathbf{2 1 b})$ gegen Candida albicans mit einem Hemmhofdurchmesser von 21 und $13 \mathrm{~mm}\left(1.5 \times 10^{-2}\right.$ und $1.5 \times 10^{-3} \mathrm{mg}$ pro Filterplättchen $)$ eine Aktivität ähnlich dem zum Vergleich eingesetzten Antimykotikum Nystatin. Der 
Naturstoff 16 und alle anderen getesteten Derivate hemmten diesen Pilz nicht in seinem Wachstum.

Zusammen mit Testergebnissen für Derivate von RITZAU ${ }^{64}$ und weiteren HormaomycinAnaloga aus der Synthese ${ }^{88}$ ließen sich bereits erste Erkenntnisse über StrukturWirkungsbeziehungen des Hormaomycins (16) gewinnen. Hierzu zählt, das die $\mathrm{N}$-Hydroxygruppe der Pyrrolcarbonsäure für eine antibakterielle Aktivität gegen Arthrobacter sp. notwendig ist. Die durch Vorläufer-dirigierte Biosynthese gewonnenen Analoga können zu diesen Erkenntnisen nicht beitragen, da ihre Aktivität der von 16 in fast allen Fällen entspricht.

\subsubsection{Antiparasitäre Aktivitäten}

Die neuen Hormaomycine wurden gegen Trypanosoma brucei rhodesiense ${ }^{127}$, Trypanosoma cruzi, Leishmania donovanii ${ }^{128}$ sowie Plasmodium falciparum ${ }^{129}$ gestestet. $^{\text {h }}$

In vitro Aktivitäten gegen Plasmodium falciparum K1

In Tab. 6 (S. 63) sind die $\mathrm{IC}_{50}$-Werte für Hormaomycin (16) und seine Analoga gegen Plasmodium falciparum K1 und für die Cytotoxizität angeben. Zusätzlich ist das Verhältnis der beiden Konzentrationen als ein Maß für die therapeutische Breite aufgeführt.

Wie von OMURA ${ }^{53}$ berichtet besitzt 16 gegen den Erreger der Malaria tropica eine Aktivität gleicher Größenordnung wie das Kombinationspräparat Chloroquin/ Artemisinin. Zudem kann eine geringe Toxizität festgestellt werden, woraus ein gutes Verhältnis der $I_{5}{ }_{50}$-Werte resultiert. Die Analoga von 16 besitzen eine ähnlich gute Aktivität wie der Naturstoff selbst. Auffällig ist, dass größere strukturelle Veränderungen im Ring wie bei Hormaomycin $E_{1,3}$ $(26 a, c)$ und $J_{1,3} \quad(33 a, c)$ zu einem Aktivitätsverlust führen, der bei den Desmethylhormaomycin 33a,c am stärksten ausgeprägt ist. Veränderungen in der Seitenkette [Hormaomycin $D_{2}(21 b), E_{2}(26 b)$ und $J_{2}(33 b)$ ] zeigen hingegen keinen großen Einfluss auf die Aktivität. Die fluorierten Derivate Hormaomycin $F_{1-3}(30 a-c), G_{1-3}(31 a-c)$ und $\mathrm{H}_{1,2}(\mathbf{3 2 a}, \mathbf{b})$ besitzen ähnliche Aktivitäten wie der Naturstoff 16 selbst. Erstaunlich ist die Abhängigkeit der therapeutischen Breite von den enthaltenen Zentralionen. Während die antiparasitäre Wirkung dieser Analoga keine großen Unterschiede zu 16 aufweist, sind die Toxizitäten bis um den Faktor 10 größer.

Diese Erkenntnisse zu Struktur-Wirkungsbeziehungen von 16 lassen sich durch von ZLATOPOLSKIY synthetisierte Analoga erweitern. So zeigte sich, dass Peptidlactamanaloga eine noch größere Aktivität gegen Plasmodien als der Naturstoff besitzen und das Ersetzen

\footnotetext{
h Ich danke Herrn PROF. DR. M. KAISER (Swiss Tropical Institute, Basel) für die Durchführung der
} Tests auf antiparasitäre Aktivitäten. 
der Seitenkette durch eine $p$-MeZ-Schutzgruppe zu einer Verringerung der Toxizität führt. Die Substanz BDZ 251-1 (41), in welcher das Threonin durch 2,3-Diaminopropionsäure und die HO-(3-Ncp)Ala-Chpca-Seitenkette durch die MeZ-Schutzgruppe ersetzt sind, hat von diesen Substanzen die größte therapeutische Breite $\left(>1500 ; I_{50}: K_{1}=0.0605\right.$, L6 > 90). Mit vorhandener Seitenkette und ausgetauschter Threonin-Einheit (BDZ 255, 42) wird hingegen die beste Aktivität erreicht $\left(>438 ; \mathrm{IC}_{50}: \mathrm{K} 1=0.02285\right.$, L6 > 10)

\begin{tabular}{|c|c|c|c|}
\hline & \multicolumn{2}{|c|}{$\mathrm{IC}_{50}[\mu \mathrm{g} / \mathrm{mL}]$} & \multirow{2}{*}{ Verhältnis $^{\mathrm{a})}$} \\
\hline & P. falc. K $1^{\mathrm{a})}$ & Cytotox. $L 6$ & \\
\hline Hormaomycin (16) & 0.0835 & 47.20 & 565 \\
\hline Chloroquin/Artemisinin & 0.045 & 0.005 & - \\
\hline Hormaomycin·K $(\mathbf{1 6} \cdot \mathrm{K})$ & 0.171 & 15.11 & 88 \\
\hline Hormaomycin·Cu $(\mathbf{1 6} \cdot \mathrm{Cu})$ & 0.132 & 11.13 & 84 \\
\hline Hormaomycin·De (16·De) & 0.124 & 3.32 & 27 \\
\hline Hormaomycin $D_{1}(21 a)$ & - & - & - \\
\hline Hormaomycin $\mathrm{D}_{2}(\mathbf{2 1} \mathbf{b})$ & 0.0925 & $>10$ & $>108$ \\
\hline Hormaomycin $D_{3}(21 c)$ & - & - & - \\
\hline Hormaomycin $E_{1}(22 a)$ & 0.340 & 16.49 & 49 \\
\hline Hormaomycin $E_{2}(22 b)$ & 0.198 & 16.81 & 85 \\
\hline Hormaomycin $E_{3}(22 c)$ & 0.374 & 53.62 & 143 \\
\hline Hormaomycin $\mathrm{F}_{1-3}(30 \mathrm{a}-\mathrm{c})$ & 0.263 & 41.97 & 160 \\
\hline Hormaomycin $\mathrm{G}_{1-3}(\mathbf{3 1} \mathbf{a}-\mathbf{c})$ & 0.181 & 16.55 & 92 \\
\hline Hormaomycin $\mathrm{H}_{1-2}(\mathbf{3 2 a} \mathbf{a}-\mathbf{c})$ & 0.433 & 36.59 & 85 \\
\hline Hormaomycin $\mathrm{J}_{1}(\mathbf{3} 3 \mathbf{a})$ & 1.295 & 36.95 & 29 \\
\hline Hormaomycin $\mathrm{J}_{2}$ (33b) & 0.373 & 30.84 & 83 \\
\hline Hormaomycin $\mathrm{J}_{3}(33 \mathrm{c})$ & 1.660 & 41.88 & 25 \\
\hline
\end{tabular}

Tab. 6: In vitro Aktivitäten gegen Plasmodium falciparum K1 sowie Cytotoxizität der Hormaomycine, a) IEF-Stadium.

In vivo Test gegen Plasmodium berghei

Für die in vivo Experimente wurden natives Hormaomycin (16) sowie die synthetischen Derivate $\mathbf{4 1}$ und $\mathbf{4 2}$ im Mausmodell getestet. Nach viermaliger intraperitonealer Injektion von 
25 mg/kg einer DMSO/Wasser-Lösung der Substanzen konnte keine Lebensverlängerung gegenüber der Kontrollgruppe festgestellt werden (0\% Aktivität).

Warum die getesteten Hormaomycine keine in vivo-Aktivität besitzen, kann nicht eindeutig beantwortet werden. Denkbar ist eine Ringöffnung (z.B. am Lacton bzw. Lactam), welche nach den vorliegenden Ergebnissen einen Totalverlust an Aktivität zur Folge hätte. Eventuell ist die intraperitoneale Injektionsform hierfür verantwortlich. Weitere in vivo Tests sollten durch intravenöse Gabe erfolgen, um enzymatische Öffnungen des Rings zu vermeiden.

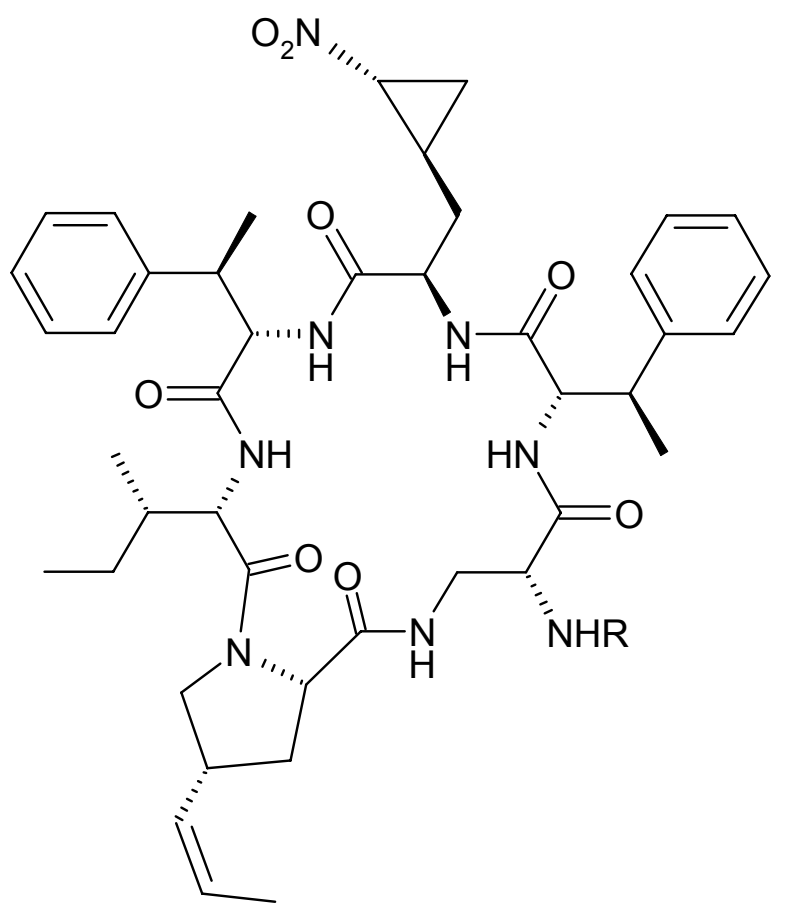

41: $R=M e Z$

42:<smiles>[R][IH]C(=O)[C@H](C[C@@H]1C[C@H]1[N+](=O)[O-])NC(=O)c1ccc(Cl)n1O</smiles>

\section{Aktivitäten gegen Leishmania donovanii}

Die Ergebnisse der Tests gegen Leishmania donovanii, den Erreger der Kala-Azar (Hindi: schwarze Krankheit) sind in Tab. 7 (S. 65) wiedergegeben. Verwendet wurden ein axenischer sowie ein Makrophagen-Assay, das Verhältnis stellt erneut den Quotienten zwischen $\mathrm{IC}_{50}$ und Cytotoxizität dar.

Hormaomycin (16) und die Analoga zeigen im Vergleich zum Referenzpräparat Miltefosin im axenischen Assay gegen diesen Parasiten eine vergleichbare und im Falle des $\mathbf{1 6} \cdot \mathbf{K}$ leicht erhöhte Aktivität. Erneut ist zu beobachten, dass die strukturellen Veränderungen im Ring [Hormaomycin $\mathrm{E}_{1,3}(\mathbf{2 6 a}, \mathbf{c})$ und $\mathrm{J}_{1,3}(33 \mathrm{a}, \mathbf{c})$ ] zu einer Aktivitätsminderung führen, welche bei Veränderungen in der Seitenkette [Hormaomycin $D_{2}$ (21b), $E_{2}(26 b)$ und $J_{2}(33 b)$ ] nicht ins Gewicht fallen. Im Vergleich zu den Struktur-Wirkungsbeziehungen der anti-plasmodialen Aktivität ist dieser Effekt aber deutlich geringer ausgeprägt. 
Die synthetischen Derivate von ZLATOPOLSKIY zeigen zudem, dass die Seitenkette für die Inhibierung der Leishmania-Protozoen wichtig ist, Substanzen ohne die Seitenkette haben eine 10-100fach geringere Aktivität als 16. Das Azahormaomycin (17) zeigt mit $I_{50}=0.11 \mu \mathrm{g} / \mathrm{mL}$ eine geringfügig höhere Aktivität als die Substanzen aus der Vorläuferdirigierten Biosynthese und den lonenaustauschexperimenten.

\begin{tabular}{|c|c|c|c|}
\hline & $\begin{array}{c}\mathrm{IC}_{50}[\mu \mathrm{g} / \mathrm{mL}] \\
\text { L. don. axen.. }\end{array}$ & Verhältnis ${ }^{\mathrm{a})}$ & $\begin{array}{c}\mathrm{IC}_{50}[\mu \mathrm{g} / \mathrm{mL}] \\
\text { L. don. macr. }^{\text {a) }}\end{array}$ \\
\hline Hormaomycin (16) & 0.17 & 278 & $>10$ \\
\hline Miltefosin & 0.14 & - & 0.41 \\
\hline Hormaomycin·K $(\mathbf{1 6} \cdot \mathrm{K})$ & 0.13 & 116 & $>10$ \\
\hline Hormaomycin·Cu $(\mathbf{1 6} \cdot \mathrm{Cu})$ & 0.14 & 80 & $>10$ \\
\hline Hormaomycin·De (16·De) & 0.22 & 15 & Tox. \\
\hline Hormaomycin $D_{1}(21 a)$ & - & - & - \\
\hline Hormaomycin $\mathrm{D}_{2}(\mathbf{2 1 b})$ & 0.28 & $>36$ & $>10$ \\
\hline Hormaomycin $\mathrm{D}_{3}(\mathbf{2 1 c})$ & - & - & - \\
\hline Hormaomycin $E_{1}(22 a)$ & 0.58 & 28 & - \\
\hline Hormaomycin $E_{2}(\mathbf{2 2 b})$ & 0.20 & 84 & $>10$ \\
\hline Hormaomycin $\mathrm{E}_{3}(22 \mathrm{c})$ & 0.59 & 91 & - \\
\hline Hormaomycin $\mathrm{F}_{1-3}(30 \mathrm{a}-\mathrm{c})$ & 0.15 & 280 & $>10$ \\
\hline Hormaomycin $\mathrm{G}_{1-3}(\mathbf{3 1 a - c})$ & 0.17 & 97 & $>10$ \\
\hline Hormaomycin $\mathrm{H}_{1-2}(\mathbf{3 2 a}-\mathbf{c})$ & 0.44 & 83 & $>10$ \\
\hline Hormaomycin $\mathrm{J}_{1}(\mathbf{3} 3 \mathrm{a})$ & 0.64 & 57 & - \\
\hline Hormaomycin $\mathrm{J}_{2}(33 \mathrm{~b})$ & 0.43 & 43 & - \\
\hline Hormaomycin $\mathrm{J}_{3}$ (33c) & 0.71 & 97 & $>10$ \\
\hline
\end{tabular}

Tab. 7: In vitro Aktivitäten gegen Leishmania donovanii im axenischen und MakrophagenAssay sowie das Verhältnis zwischen $\mathrm{IC}_{50}$ axen. $/ \mathrm{IC}_{50}$ cyt der Hormaomycine, a) Amastigoten-Stadium.

Der Markophagen-Assay hingegen offenbart, dass der Naturstoff 16 und die in Tab. 7 aufgelisteten Analoga nicht in der Lage sind, Parasiten in Ruhephasen zu bekämpfen. Das deionisierte Hormaomycin (16.De) zeigt den Makrophagen gegenüber sogar toxische Eigenschaften. Auffällig ist jedoch, dass zwei synthetische Peptidlactame, BDZ 252 (43) und 
255 (42) mit hohen $\mathrm{IC}_{50}$-Werten (1.8 und $4.8 \mu \mathrm{g} / \mathrm{mL}$ ), zu einer Inhibierung der Parasiten in diesem Stadium befähigt sind. Die geringe Aktivität in diesem Assay kann wahrscheinlich auf eine schlechte Membrangängigkeit von 16 und seinen Derivaten zurückgeführt werden.

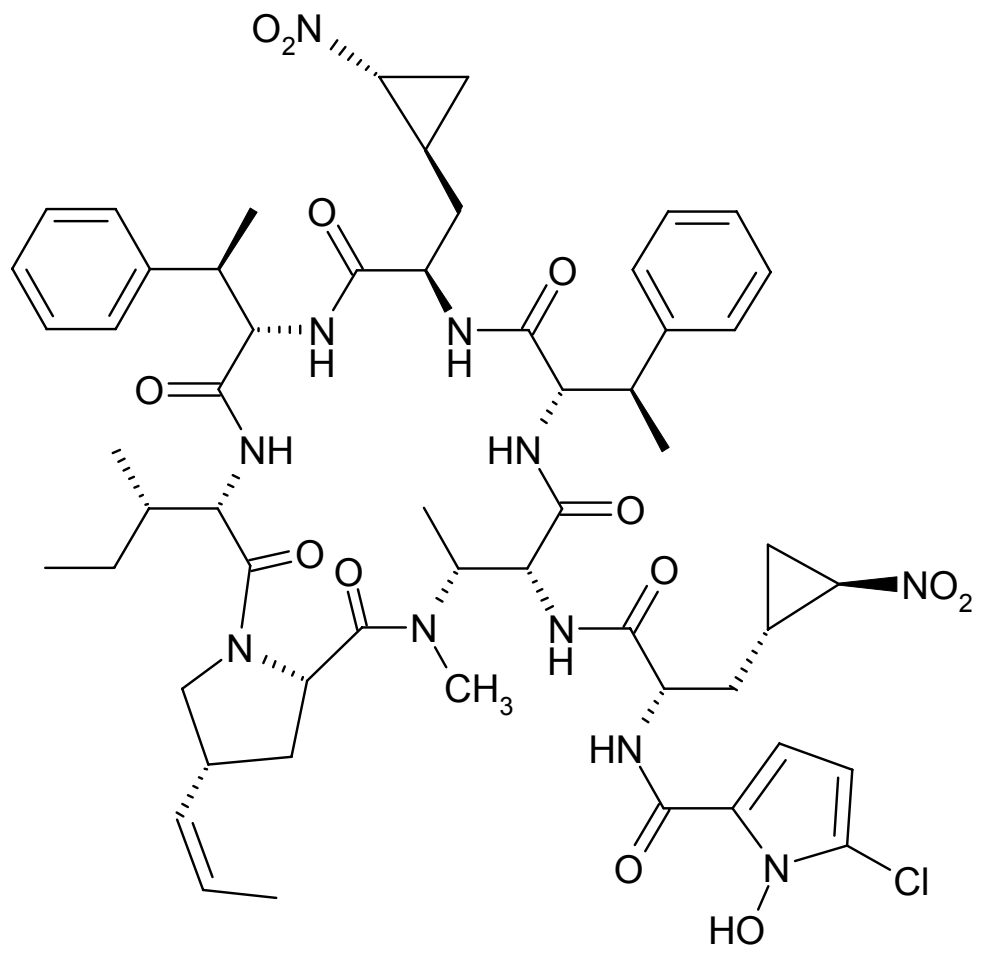

43 
Aktivitäten gegen Trypanosoma sp.

Die in Tab. 8 dargestellten $I_{50}$-Werte des Hormaomycins (16) und seiner Analoga gegen die zwei Schraubengeißling-Arten zeigen moderate Aktivitäten, welche allerdings um den Faktor 100-1000 geringer als die der Standardpräparate zur Behandlung der Schlafkrankheit (Melarsoprol) und der Chagaskrankheit (Benznidazol) sind. Struktur-Wirkungsbeziehungen sind in diesem Fall weder aus den Analoga der Vorläufer-dirigierten Biosynthese noch den totalsynthetisch gewonnenen Hormaomycinen abzuleiten.

\begin{tabular}{|c|c|c|c|}
\hline & \multicolumn{3}{|c|}{$\mathrm{IC}_{50}[\mu \mathrm{g} / \mathrm{mL}]$} \\
\hline & T. b. rhod. ${ }^{\text {a) }}$ & T. cruzi ${ }^{\text {b) }}$ & Cytotox. L6 \\
\hline Hormaomycin (16) & 17.70 & 12.90 & 47.20 \\
\hline Referenz $z^{i)}$ & 0.004 & 0.19 & 0.005 \\
\hline Hormaomycin·K (16·K) & 10.50 & 20.03 & 15.11 \\
\hline Hormaomycin·Cu $(\mathbf{1 6} \cdot \mathrm{Cu})$ & 9.24 & 18.07 & 11.13 \\
\hline Hormaomycin·De (16·De) & 7.63 & 18.95 & 3.32 \\
\hline Hormaomycin $D_{1}(21 a)$ & - & - & - \\
\hline Hormaomycin $\mathrm{D}_{2}$ (21b) & 5.30 & $>10$ & $>10$ \\
\hline Hormaomycin $\mathrm{D}_{3}(21 \mathrm{c})$ & - & - & - \\
\hline Hormaomycin $E_{1}(22 a)$ & 7.51 & 18.26 & 16.49 \\
\hline Hormaomycin $\mathrm{E}_{2}(\mathbf{2 2 b})$ & 8.57 & 17.21 & 16.81 \\
\hline Hormaomycin $\mathrm{E}_{3}(\mathbf{2 2 c})$ & 10.45 & 28.00 & 53.62 \\
\hline Hormaomycin $\mathrm{F}_{1-3}(30 \mathrm{a}-\mathrm{c})$ & 13.55 & 5.60 & 41.97 \\
\hline Hormaomycin $\mathrm{G}_{1-3}(\mathbf{3 1 a - c})$ & 5.45 & 20.75 & 16.55 \\
\hline Hormaomycin $\mathrm{H}_{1-2}(\mathbf{3 2 a} \mathbf{a})$ & 14.97 & $>30$ & 36.59 \\
\hline Hormaomycin $\mathrm{J}_{1}(\mathbf{3} 3 \mathbf{a})$ & 11.16 & 20.41 & 36.95 \\
\hline Hormaomycin $\mathrm{J}_{2}$ (33b) & 15.64 & $>30$ & 30.84 \\
\hline Hormaomycin $\mathrm{J}_{3}$ (33c) & 11.08 & 22.46 & 41.88 \\
\hline
\end{tabular}

Tab. 8: Aktivitäten gegen Trypanosoma brucei rhodesiense ( $T$. b. rhod.) und Trypanosoma cruzi (T. cruzi) sowie Cytotoxizität von Hormaomycin und Analoga. i) Referenzsubstanzen/ parasitäres Stadium; a) T. b. rhod.: Melarsoprol/ Trypomastigoten; b) T. cruzi: Benznidazol/ Amastigoten; Cytotoxizität: Podophyllotoxin. 


\subsubsection{Quorum sensing}

Obwohl Hormaomycin (16) gleich mehrere selektive biologische Wirkungen besitzt, wäre es ohne seine Fähigkeit in anderen Streptomyceten die Luftmycelbidung anzuregen, vielleicht nie entdeckt worden. Für diese morphologische Aktivität ist im Plattendiffusionstest bei Streptomyces griseoflavus (Stamm Tü 1306) schon eine Konzentration von $0.1 \mu \mathrm{g}$ pro Filterplättchen ausreichend. Da der Hormaomycin-Produzent Streptomyces griseoflavus (Stamm W 384) das Peptidlacton ohne Kultivierungsoptimierung nur in geringen Mengen produziert, ist ein Screening mit solch hoher Sensitivität für ein positives Ergebnis Voraussetzung.

Das Luftmycel in Actinomyceten bildet sich nach dem Substratmycel in Phasen der Nährstoffarmut und dient dem Fortbestehen der Art. Dies geschieht über eine Differenzierung in Luftmycel und Sporen, welche vermutlich gleichzeitig mit dem Einsetzen des Sekundärmetabolismus stattfindet. Da 16 in der Lage ist, auch die Antibiotikaproduktion anderer Mikroorganismen zu beeinflussen, scheint $\mathbf{1 6}$ direkt an der Schnittstelle zwischen beiden Prozessen einzugreifen.

Um auch für diese biologische Aktivität von 16 Struktur-Wirkungsbeziehungen ableiten zu können, sollte der Test auf Differenzierungsaktivität an Streptomyces griseoflavus (Stamm Tü 1306) wiederholt werden. Der in Göttingen vorhandene Stamm wie auch ein Isolat des DSMZ (Deutsche Sammlung von Mikroorganismen und Zellkulturen $\mathrm{GmbH}$, Braunschweig) zeigten jedoch ein schlechtes Wachstum auf dem verwendeten nährstoffarmen NSAAgarmedium. Da schon von GEERS und ANDRES bei 15 aus insgesamt 73 Actinomycetenstämmen eine morphologische Aktivität nachgewiesen werden konnte, sollten weitere Stämme mit dieser Qualität gesucht werden.

Hierfür wurde jeweils ein Stamm am Rand einer M2-Agarplatte in Wellenform ausgestrichen und auf die andere Seite ein Filterplättchen gelegt, welches mit 16 (c=1.0 mg/mL) getränkt war. Hierbei wirkte Hormaomycin auf 12 Stämme antibiotisch oder schwach wachstumshemmend, bei acht Stämmen war eine schwache morphologische Aktivität mit leichter Steigerung der Luftmycelbildung zu erkennen, ein weiterer Stamm (Streptomyces sp. Stamm F1/11) bildete ein blaues Pigment. Die Ausprägung morphologischer Aktivitäten war jedoch äußerst gering, so dass diese Stämme nicht für ein Testsystem geeignet erscheinen. Auch die Bildung des blauen Farbstoffs konnte bei Wiederholung der Versuche nicht sicher angeregt werden. Eine Kultivierung von Streptomyces sp. Stamm F1/11 in Schüttelkulturen ergab eine Bildung des Farbstoffs auch ohne Zusatz von 16. Die blaue Substanz ist in organischen Lösungsmitteln und Wasser vollkommen unlöslich, während die Zugabe von konz. $\mathrm{H}_{2} \mathrm{SO}_{4}$ eine Lösung intensiv grüner Farbe ergab. Dies könnte dafür sprechen, dass es sich bei der Substanz um einen Indigofarbstoff handelt. ${ }^{130}$ 


\section{Strukturaufklärung von Sekundärmetaboliten}

Die in diesem Kapitel charakterisierten Sekundärmetaboliten stammen aus vier verschiedenen Actinomyceten unterschiedlicher Herkunft. Zwei dieser Mikroorganismen (Actinomyces sp. Stamm P4 und Stamm M4-1) fielen im chemischen Screening auf. Streptomyces sp. (Stamm Tü 6319 und Stamm Tü 2561) hingegen gingen aus einem HPLCDAD-Screening ${ }^{131}$ im Arbeitskreis FIEDLER (Mikrobiologisches Institut, Universität Tübingen) als potente Naturstoffproduzenten hervor.

\subsection{Chemisches Screening von Actinomyceten}

Die im Rahmen des chemischen Screenings untersuchten Mikroorganismen stammen aus Erdproben von der Algarve (Portugal) und aus der Mongolei. Es handelt sich um taxonomisch nicht weiter bestimmte Actinomyceten.

Die Kultivierung von vier Stämmen aus Portugal (P1-P4) und von drei Stämmen aus der Mongolei (M4-1, M4-2 und M8-1) erfolgte in vier verschiedenen Nährmedien (Hafer, M2, SGG und SM). Die Extrakte von Kulturfiltrat und Mycel wurden einem von UMEZAWA et al. begründeten und ZÄHNER ${ }^{132}$ und ZEECK ${ }^{133,134}$ weiterentwickelten chemischen Screening ${ }^{135}$ unterzogen. Hierbei bestimmt die Zonenbildung im Dünnschichtchromatogramm und das Anfärbeverhalten gegenüber Sprühreagenzien (Anisaldehyd, Ehrlich, Orcin) die Auswahl der Stämme, die für die Isolierung auffälliger Metaboliten in größeren Maßstab kultiviert werden. Actinomyces sp. (Stamm P4) und Actinomyces sp. (Stamm M4-1) fielen durch ihre Metabolitenproduktion auf. Nach Kultivierung im $1 \mathrm{~L}-$ Maßstab gelang die Isolierung von insgesamt vier literaturbekannten Metaboliten [Chartreusin (44), Genistein (45), Daidzein (12a) und Borrelidin (15)]. Die säulenchromatographische Aufreinigung der Metaboliten ist in Kap. B.3.1.3 (S. 143) und Kap. B.3.1.4 (S. 145) beschrieben. 


\subsubsection{Actinomyces sp. Stamm P4}

\subsubsection{Chartreusin (44)}

Kulturfiltrat- und Mycelextrakte lieferten im Dünnschichtchromatogramm eine Zone intensiv gelber Eigenfarbe mit blauer Fluoreszenz bei $R_{f}=0.4$ (Chloroform/Methanol 9:1). Die zugehörige Substanz konnte mit einer Ausbeute von $35 \mathrm{mg} / \mathrm{L}$ aus dem Kulturfiltrat und mit $45 \mathrm{mg} / \mathrm{L}$ aus dem Mycel isoliert werden. Sie zeigt eine mäßige Löslichkeit in Methanol, löst sich in Pyridin und DMSO hingegen gut.

Das ESI-Massenspektrum des Metaboliten lieferte einen Peak bei $\mathrm{m} / \mathrm{z}=663[\mathrm{M}+\mathrm{Na}]^{+}$, aus dessen Hochauflösung sich die Summenformel $\mathrm{C}_{32} \mathrm{H}_{32} \mathrm{O}_{14}$ ergab. Aus dem ${ }^{1} \mathrm{H}-\mathrm{NMR}$ Spektrum in DMSO- $d_{6}$ lassen sich zwei 6-Desoxyzucker ableiten, deren anomere Kohlenstoffe unter Berücksichtigung der $\alpha-\mathrm{H}$-Kopplungskonstanten von ${ }^{3} \mathrm{~J}=4.0 \mathrm{bzw} .8 .0 \mathrm{~Hz}$ $\alpha-$ und eine $\beta$-Konfiguration besitzen. Weiterhin sind im Protonenspektrum jeweils ein aromatisches ABC- und AB-Spinsystem, sowie zwei Methylgruppen bei $\delta_{H}=2.82$ und 3.16 zu erkennen. Eine Antibase-Datenbanksuche ${ }^{136}$ mit diesen Informationen führt zum Chartreusin (44), ein Abgleich der NMR-Daten mit Literaturwerten ${ }^{137}$ zeigt jedoch im Bereich der Zuckerresonanzen Differenzen. Die Identität der isolierten Substanz mit $\mathbf{4 4}$ konnte durch ein ${ }^{1} \mathrm{H}-\mathrm{NMR}$-Spektrum in Pyridin ${ }^{138}$, CD-Wert und einen HPLC-Vergleich bewiesen werden. Wichtig ist jedoch anzumerken, dass Protonenspektren von $\mathbf{4 4}$ in DMSO gegenüber anderen Lösungsmitteln Differenzen aufweisen, deren Ursache unklar ist.

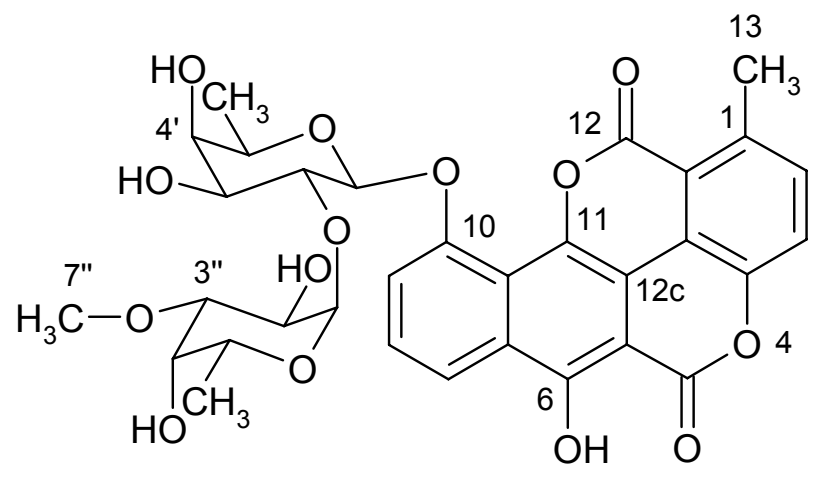

44

Das stark antibakteriell wirkende $\mathbf{4 4}$ ist erstmals 1953 aus Streptomyces chartreusis isoliert worden, ${ }^{139}$ eine Strukturaufklärung gelang durch Derivatisierungs- und Abbaureaktionen. ${ }^{140,141}$ Die Biosynthese erfolgt durch Cyclisierung einer Undecaketidkette zu einem Benzpyrenderivat, welches nach Bindungsspaltung und Decarboxylierung das Aglykon von 44, das Chartrarin ergibt. ${ }^{142}$ Durch Hemmung der Topoisomerase I inhibiert 44 die Biosynthese der $\mathrm{DNA}^{143}$ und induziert Doppelstrangbrüche in Verbindung mit 
reduzierenden Agentien ${ }^{144}$. Diese Aktivität ist der Grund für eine sehr hohe Aktivität gegen Tumorzellen, wobei eine schlechte Bioverfügbarkeit und eine schnelle Metabolisierung einen klinischen Einsatz von $\mathbf{4 4}$ verhindern. ${ }^{145}$

\subsubsection{Actinomyces sp. Stamm M4-1}

Im chemischen Screening fiel der Stamm M4-1 nach Kultivierung im Soja-Mannit-Medium durch drei bei 254 nm UV-löschende Zonen auf. Während die beiden polaren Komponenten im Dünnschichtchromatogramm in Chloroform/Methanol 9:1 bei $R_{f}=0.14$ (Genistein, 45) und 0.31 (Daidzein, 12a) nur eine sehr schwache Färbung mit Orcin zeigten, färbte die dritte Substanz (Borrelidin, 15) $\left(R_{f}=0.5\right.$, Chloroform/Methanol 9:1) mit Anisaldehyd braun an. Die Isolierung der Metaboliten ist in Kap. B.3.1.4 (S.145) beschrieben.

\subsubsection{Isoflavone}

Für die farblosen Feststoffe 12a und 45 lassen sich aus einem HRESI-Massenspektrum Summenformeln von $\mathrm{C}_{15} \mathrm{H}_{10} \mathrm{O}_{4}$ und $\mathrm{C}_{15} \mathrm{H}_{10} \mathrm{O}_{5}$ ableiten. Im Protonenspektrum sind acht (12a) bzw. sieben (45) Signale im aromatischen Bereich zu erkennen, von denen in beiden Fällen zwei, mit einer Gesamtintensität vier Protonen entsprechend, einem $A_{2} B_{2}$-Spinsystem zugeordnet werden können. Für beide Substanzen ist ein weiteres aromatisches Ringsystem zu erkennen, welches für 12a mono- und für 45 disubstituiert ist. Eine AntibaseDatenbanksuche ${ }^{136}$ mit den gefundenen Strukturfragmenten und den Summenformeln führt zu Daidzein (12a) und Genistein (45). Ein Vergleich der spektroskopischen Daten ${ }^{146}$ bestätigt diese Zuordnung.

Isoflavone wie $\mathbf{1 2 a}$ und $\mathbf{4 5}$ besitzen neben antimikrobiellen, insektiziden und cytotoxischen Aktivitäten auch eine östrogene Wirkung (s. auch Kap. 1.1). ${ }^{147}$ Sie sind Pflanzenmetaboliten, welche vor allem in Soja und Baumwollsamen stark angereichert werden. Obwohl in zahlreichen Publikationen von der Isolierung aus Mikroorganismen berichtet wird, ${ }^{148}$ muss angenommen werden, dass Isoflavone Artefakte aus den Nährmedien sind. Darauf weist auch die Beobachtung von RosAzZA et al. hin, dass der Gehalt an isolierten Isoflavonen aus Streptomyces griseus sp. direkt proportional zu dem Anteil an Sojamehl im Nährmedium ist. $^{149}$<smiles>[R]c1cc(O)cc2occ(-c3ccc(O)cc3)c(=O)c12</smiles>

12a: $\mathrm{R}=\mathrm{H}$ 


\subsubsection{Borrelidin (15)}

Die dritte aus Actinomyces sp Stamm M4-1 isolierte, ebenfalls farblose Substanz liefert im ESI-Massenspektrum einen Peak bei $\mathrm{m} / \mathrm{z}=488[\mathrm{M}-\mathrm{H}]^{-}$, woraus nach der Stickstoffregel auf eine ungerade Zahl an Stickstoffatomen geschlossen werden kann. In Übereinstimmung damit führt die Hochauflösung des Peaks zu einer Summenformel von $\mathrm{C}_{28} \mathrm{H}_{43} \mathrm{NO}_{6}$. Das IRSpektrum der Substanz zeigt eine starke Absorption bei $\widetilde{v}=2213$ und $1709 \mathrm{~cm}^{-1}$, was auf eine Nitrilgruppe und einen Ester (bzw. Lacton) schließen lässt. Im ${ }^{13} \mathrm{C}-N M R-S p e k t r u m$ können Signale bei $\delta_{C}=173.2$ und 180.7 beobachtet werden, ihre chemische Verschiebung ist für Ester bzw. Carbonsäuren typisch. Weiterhin sind bei $\delta_{C}=117.4,119.9,129.0,140.2$ und 145.5 fünf Signale für olefinische C-Atome $\mathrm{zu}$ beobachten. Aus einem HSQCKorrelationsspektrum ergibt sich nur für die drei am weitesten ins Hochfeld verschobenen Resonanzen eine Bindung an Protonen, während die restlichen zwei quartären Kohlenstoffatomen zuzuordnen sind. Das HSQC-Spektrum zeigt weiterhin vier Methylgruppen bei $\delta_{C}=15.4,18.7,19.1$ und 20.9, acht Methylen- sowie neun Methingruppen. Drei dieser Methingruppen tragen Sauerstoffatome, was die ${ }^{13} \mathrm{C}$-Daten $\left(\delta_{C}=72.9,73.1\right.$ und 77.4$)$ belegen. Die Verknüpfung der beschriebenen Gruppen zu zwei Fragmenten (s. Abb. 22, S. 73) gelingt nach Zuordnung der Signale des Protonenspektrums mit einem COSY-Korrelationsspektrum. Die trans-Isomerie der C-14/C-15 Doppelbindung wird durch die Kopplungskonstante von ${ }^{3} \mathrm{~J}=15.0 \mathrm{~Hz}$ bestätigt.

Eine Datenbanksuche ${ }^{150}$ mit den Fragmenten ergibt als einzigen Treffer Borrelidin (15). Durch den Vergleich der NMR-Daten mit Literaturwerten ${ }^{151}$ kann die isolierte Substanz eindeutig als 15 identifiziert werden. 


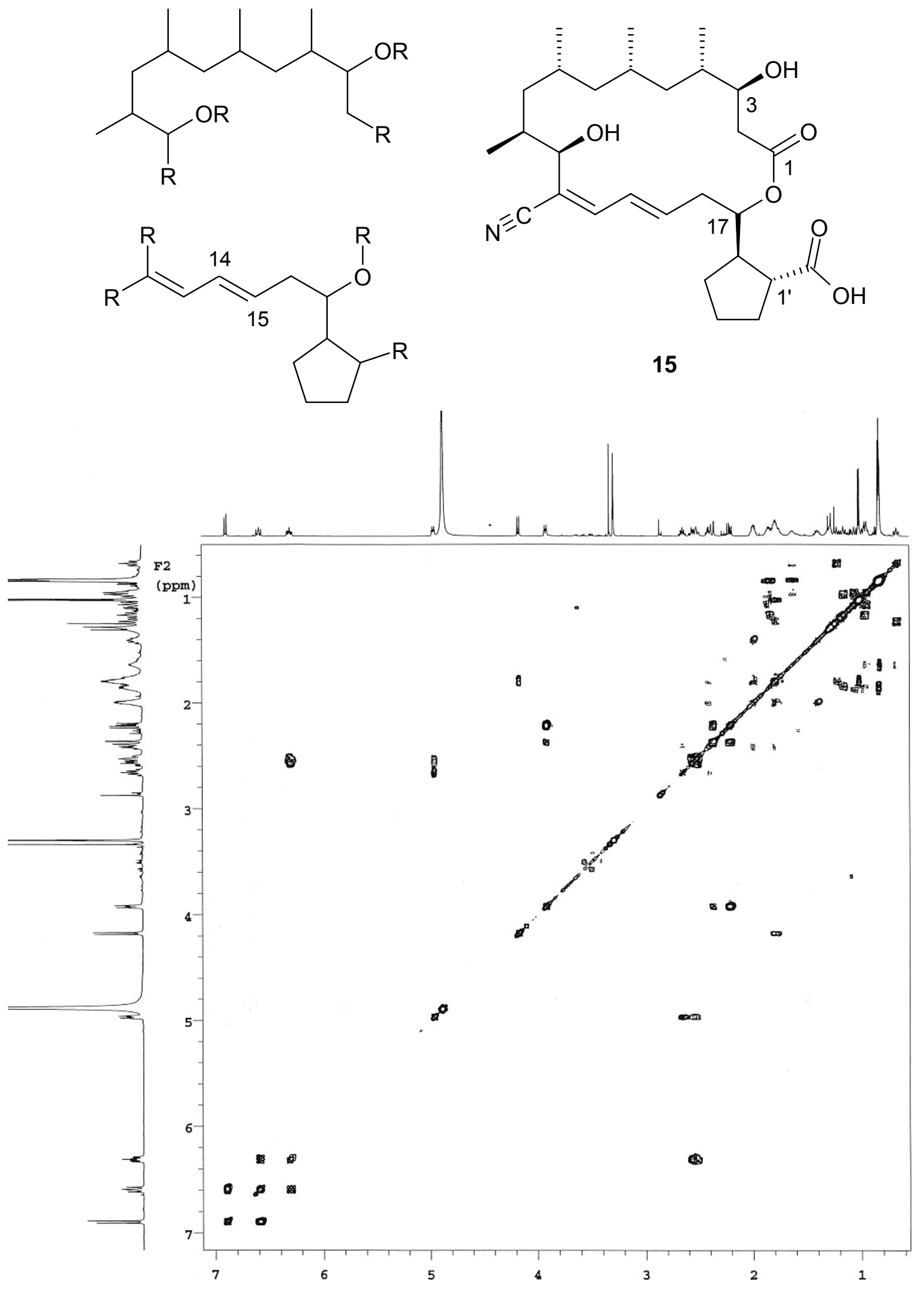

Abb. 22: $\quad{ }^{1} \mathrm{H}-{ }^{1} \mathrm{H}-\mathrm{COSY}-K o r r e l a t i o n s s p e k t r u m$ von Borrelidin (15) und daraus abgeleitete Strukturfragmente $\left(600 \mathrm{MHz}, \mathrm{CD}_{3} \mathrm{OD}\right)$. 


\subsection{HPLC-DAD Screening}

Für eine effiziente Naturstoffforschung ist die frühe Identifizierung bekannter Substanzen notwendig. Hierfür sind Techniken, die eine Charakterisierung der Metaboliten aus den Rohextrakten erlauben, vorteilhaft. Beim HPLC-DAD-Screening ${ }^{131}$ werden Retentionszeit und UV-Spektrum verbunden, wodurch eine schnelle Identifizierung von in einer Datenbank gespeicherten Substanzen möglich ist. In Zusammenarbeit mit dem Arbeitskreis FIEDLER ${ }^{i}$ wurden Streptomyces sp. Tü 6319 und Tü 2561 auf ihre Sekundärmetabolitenproduktion untersucht. Da ein Screening der Stämme in Schüttelkulturen keine Übereinstimmungen mit den 834 in der HPLC/UV-Vis-Datenbank gespeicherten Substanzen ergab, wurde ein Scaleup vorgenommen, um die Metaboliten zu isolieren.

\subsubsection{Streptomyces sp. Stamm Tü 6319}

Die chemotaxonomische Untersuchung des aus einer mit Industrieabfällen kontaminierten Erdprobe aus Fogaras (Rumänien) isolierten Stammes ergab aufgrund des LL-Diaminopimelinsäure-Gehalts der Peptidoglycanschicht eine Zuordnung zur Gattung Streptomyces, was die phänomenologische Charakterisierung bestätigte. Weiterhin zeigte Stamm Tü 6319 große Übereinstimmung der $16 S$ rRNA-Gensequenz mit den eng verwandten Stämmen Streptomyces coelescens DSM 40421, S. violaceolatus DSM 40438 und S. violaceoruber DSM 40049.

Die Fermentationen erfolgten in einem $10 \mathrm{~L}$ New Brunswick Blattrührfermenter in Hafermedium (2\% Hafermehl in Leitungswasser, pH 7.3, 27 ${ }^{\circ} \mathrm{C}, 0.5 \mathrm{vvm}, 200 \mathrm{rpm}, 168 \mathrm{~h}$ Kultivierungsdauer), wobei ein Zusatz von $3 \%$ DMSO zum Nährmedium zu einer leicht gesteigerten Ausbeute der Metaboliten führte.

Das Kulturfiltrat wurde an XAD-16 aufgereinigt, die Metaboliten in der $40 \% \mathrm{MeOH}$ Fraktion aufgefangen. Die Fraktion wurde in vacuo eingeengt, auf $\mathrm{pH} 2$ eingestellt und mit Ethylacetat extrahiert. Dieses Rohprodukt wurde an LiChroprep Diol $\left(\mathrm{CH}_{2} \mathrm{Cl}_{2} \rightarrow 5 \% \mathrm{MeOH}\right)$, Sephadex LH-20 (MeOH) und Fraktogel TSK HW-40 (MeOH) aufgereinigt. Insgesamt konnten auf diese Weise sechs Substanzen erhalten werden, von denen sich mit Fogacin (46) eine als neu erwies. Vier weitere Metaboliten [SEK4b (47, $1 \mathrm{mg} / \mathrm{L})$, anhydroSEK4b (48, $0.5 \mathrm{mg} / \mathrm{L})$, Germicidin A (49, $0.4 \mathrm{mg} / \mathrm{L})$ und Germicidin B (50, $0.3 \mathrm{mg} / \mathrm{L})$ sind literaturbekannte Sekundärmetaboliten, bei der sechsten Substanz (Ferulasäure, $0.8 \mathrm{mg} / \mathrm{L}$ ) handelt es sich wahrscheinlich um einen Nährmedienbestandteil.

Ich danke Herrn PROF. DR. H.-P. FIEDLER sowie Frau DR. N. ANTAL (Mikrobiologisches Institut, Universität Tübingen) für die Isolierung der Substanzen und die gute Zusammenarbeit. 


\subsubsection{Germicidin A (49) und B (50)}

Die unpolaren $\left(R_{f} \approx 0.8\right.$, Chloroform/Methanol 9:1) öligen Substanzen färben mit Anisaldehyd in der Wärme leicht braun an und zeigen auf Kieselgelplatten bei $254 \mathrm{~nm}$ schwache UVLöschung. Aus der Hochauflösung der El-MS-Peaks lassen sich Summenformeln von $\mathrm{C}_{11} \mathrm{H}_{16} \mathrm{O}_{3}$ (49) und $\mathrm{C}_{10} \mathrm{H}_{14} \mathrm{O}_{3}(50)$ ableiten. Bei beiden Substanzen ist im ${ }^{1} \mathrm{H}-N M R$-Spektrum bei $\delta_{H} \approx 1.00$ eine mit $J=7.5 \mathrm{~Hz}$ zum Triplett aufgespaltene Methylgruppe zu erkennen, die zu einer Methylengruppe bei $\delta_{H} \approx 2.40$ koppelt. Substanz 49 zeigt weitere Signale im aliphatischen Bereich für zwei Methylgruppen $\left(\delta_{H}=0.89,1.19\right)$, eine Methylengruppe bei $\delta_{H}=1.54$ und 1.67 und eine Methingruppe $\left(\delta_{H}=2.45\right)$ welche einer sekundären Butyleinheit zugeordnet werden können. Für Substanz $\mathbf{5 0}$ ist analog ein iso-Propylrest abzuleiten. Die ${ }^{13} \mathrm{C}$-NMR-Spektren von 49 und 50 zeigen mit $\delta_{C} \approx 170,169,168,105$ und 102 Signale, die in Verbindung mit den Summenformeln ein 4-Hydroxypyran-2-on erkennen lassen.

Eine Datenbanksuche ${ }^{136}$ führt zu Germicidin A (49) und Germicidin B (50), alle spektroskopischen Daten stimmen mit den Literaturwerten überein. ${ }^{152}$

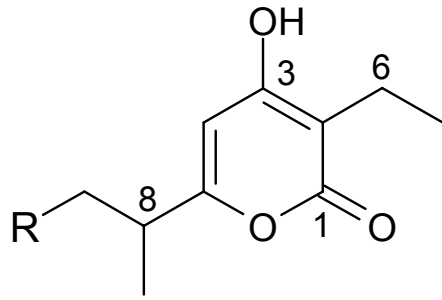
49: $\mathrm{R}=\mathrm{CH}_{3}$
50: $\mathrm{R}=\mathrm{H}$

\subsubsection{SEK4b (47) und AnhydroSEK4b (48)}

Die farblosen Substanzen $\mathbf{4 7}$ und $\mathbf{4 8}$ zeigen im ESI-Massenspektrum jeweils einen Peak bei $\mathrm{m} / \mathrm{z}=299$ (47) und 281 (48) $[\mathrm{M}-\mathrm{H}]^{-}$, aus deren Hochauflösung sich Summenformeln von $\mathrm{C}_{16} \mathrm{H}_{14} \mathrm{O}_{7}(47)$ und $\mathrm{C}_{16} \mathrm{H}_{12} \mathrm{O}_{6}(48)$ ableiten lassen.

Das Protonenspektrum von Substanz 47 zeigt zum Dublett aufgespaltene Signale bei $\delta_{H}=6.18$ und 6.30 , deren Kopplungskonstante mit $J=2.5 \mathrm{~Hz}$ auf eine meta-Kopplung eines Aromaten schließen lässt. Dem Aromaten können mit einem HMBC-Spektrum Kohlenstoffsignale mit chemischen Verschiebungen von $\delta_{C}=101.6,111.9,112.7,142.4$, 160.9 und 162.7 sowie ein Carbonyl- und ein Methylsubstituent zugeordnet werden. Zusätzlich weisen die chemischen Verschiebungen auf zwei Sauerstoffreste hin. Methingruppen bei $\delta_{C}=88.9$ und 103.5 sind durch HMBC-Korrelationen zu $\delta_{C}=160.4,163.9$ und 170.6 einem 2-Hydroxypyran-4-on-Ringsystem zuzuordnen. Im Protonenspektrum ist weiterhin eine Methylengruppen bei $\delta_{H}=2.98-3.14 \mathrm{zu}$ erkennen, aus deren HMBCKorrelationen sich ihre Bindung an die Pyranoneinheit und ein Halbacetal $\left(\delta_{C}=100.1\right)$ ergibt. Zusätzlich zeigt sie Kopplungen zu einer zweiten Methylengruppe bei $\delta_{H}=2.58$ und 2.95, die 
ihrerseits zu dem Carbonyl-Kohlenstoff bei $\delta_{C}=190.2$ benachbart ist und somit die Verknüpfung der Fragmente ermöglicht. In Verbindung mit der Summenformel ist nur die gezeigte Strukturformel (SEK4b, 47) denkbar und kann durch Vergleich mit Literaturdaten ${ }^{153}$ verifiziert werden. Obwohl an C-2 ein Chiralitätszentrum vorhanden ist, beträgt der Drehwert $0^{\circ}, 47$ liegt also offensichtlich als racemisches Gemisch vor (s. Kap. 3.2.1.5, S. 81).

In einem ${ }^{13} \mathrm{C}-N M R$-Spektrum von Substanz 48 sind wie bei 4713 Signale eines methylierten, zweifach mit Sauerstoff substituierten Aromaten sowie eines Hydroxypyranons, welches eine Methylengruppe trägt, zu finden. Im olefinischen Bereich tauchen zwei neue Signale auf, während das Halbacetal und die C-3 Methylengruppe von 47 nicht mehr vorhanden sind, was auf eine Wasserabspaltung aus 47 schließen lässt. Spektroskopische Vergleichsdaten ${ }^{154}$ bestätigen die ermittelte Strukturformel (anhydroSEK4b, 48).<smiles>Cc1c[Z7](O)cc2c1C(=O)C[C@@](O)(Cc1cc(=O)cc(O)o1)O2</smiles>

47<smiles>Cc1cc(O)cc2oc(Cc3cc(=O)cc(O)o3)cc(=O)c12</smiles>

48

Der Pyranonring in $\mathbf{4 7}$ und $\mathbf{4 8}$ erlaubt die Formulierung einer Tautomerie zwischen 6'-OH und 4'-O (52 und 53). Da in den NMR-Spektren keine Effekte dieser Art nachgewiesen werden konnten, wurden die experimentell bestimmten ${ }^{13} \mathrm{C}-\mathrm{NMR}$ chemischen Verschiebungen der beiden Substanzen $\mathbf{4 7}$ und $\mathbf{4 8}$ mit berechneten Daten ${ }^{155}$ verglichen. Die Berechnung der Verschiebungen beider Tautomere ergibt für C-2' keine guten Übereinstimmungen (s. Tab. 9, S. 77), zeigt jedoch an C-3' und C-4', dass wahrscheinlich die 6'-Hydroxypyran-4'-on-Form vorliegt. Bestätigt wird dies durch die in 47 und 48 gefundenen HMBC-Kopplungen von C-1', C-2', C-4' und C-5' zu 3'-H sowie C-3', C-4' und C6' zu 5-H. Die von MOORE et al. publizierte Struktur ${ }^{154}$ muss dementsprechend revidiert werden. 
<smiles>[R][X]c1cc(=O)cc(O)o1</smiles>

51<smiles>[R]Cc1cc(O)cc(=O)o1</smiles>

52

\begin{tabular}{ccccc}
\hline \multicolumn{5}{c}{$\delta_{\mathrm{C}}[\mathrm{ppm}]$} \\
\hline C-2' & $\mathbf{5 1}$ & $\mathbf{5 2}^{\mathbf{a}}$ & $\mathbf{4 7}$ & $\mathbf{4 8}$ \\
C-3' & 170.0 & 150.8 & 160.4 & 160.0 \\
C-4' & $\mathbf{9 8 . 5}$ & $\mathbf{1 1 1 . 1}$ & $\mathbf{1 0 3 . 5}$ & $\mathbf{1 0 2 . 0}$ \\
C-5' & $\mathbf{1 7 0 . 9}$ & $\mathbf{1 6 6 . 8}$ & $\mathbf{1 7 0 . 6}$ & $\mathbf{1 7 0 . 3}$ \\
C-6' & 88.2 & 89.8 & 88.9 & 89.1 \\
\hline${ }^{2}$ Die Nummerierung der Kohlenstoffatome erfolgt aus Übersichtsgründen \\
\hline \multicolumn{5}{c}{ wie bei 47 und 48. } \\
\hline \multicolumn{5}{c}{} \\
\hline
\end{tabular}

Tab. 9: Berechnete (51 und 52) und experimentell bestimmte ${ }^{13} \mathrm{C}$-Chemische Verschiebungen für die Pyranoneinheit in $\mathbf{4 7}$ und $\mathbf{4 8 .}$

\subsubsection{Fogacin (46)}

Der farblosen mit Anisaldehyd in der Wärme bräunlich anfärbenden Substanz hoher Polarität $\left(R_{f}=0.1\right.$, Chloroform/Methanol 9:1) kann durch das ${ }^{13} \mathrm{C}-N M R-S p e k t r u m$ in Kombination mit einem HRESI-Massenspektrum die Summenformel $\mathrm{C}_{16} \mathrm{H}_{19} \mathrm{O}_{6}$ zugeordnet werden. Aus dem 2D-NMR-Datensatz ergeben sich eine Methylgruppe $\left(\delta_{C}=19.3\right)$, vier Methylengruppen $\left(\delta_{C}=32.5,35.4,35.8\right.$ und 42.9), drei oxygenierte aliphatische $\left(\delta_{C}=65.4,68.1\right.$ und 69.3$)$ und eine aromatische $\left(\delta_{C}=119.1\right)$ Methingruppen sowie sieben quartäre Kohlenstoffatome. Von den quartären Signalen steht eines für ein Keton $\left(\delta_{C}=206.1\right)$ und eines für eine Carboxylgruppe $\left(\delta_{C}=176.0\right)$, die weiteren fünf Signale legen unter Berücksichtigung der aromatischen Methingruppe mit Verschiebungen von $\delta_{C}=114.2,127.8,144.1,145.9$ und 159.7 ein Phenol nahe. Die Methylengruppen können durch ein ${ }^{1} \mathrm{H}-{ }^{1} \mathrm{H}-\mathrm{COSY}-S p e k t r u m$ zwei Spinsystemen zugeordnet werden. Das erste dieser beiden Systeme zeigt eine Methingruppe bei $\delta_{H}=4.43$ zwischen zwei $\mathrm{CH}_{2}$-Gruppen $\left(\delta_{H}=2.52-2.60\right.$ sowie $\left.2.68,2.85\right)$. Die zweite Partialstruktur lässt sich ausgehend von einer Methylengruppe bei $\delta_{H}=2.10$ und 2.29 ableiten, welche Kopplungen zu einer Methingruppe bei $\delta_{H}=4.81$ sowie einer weiteren $\mathrm{CH}_{2}$-Gruppe $\left(\delta_{\mathrm{H}}=2.65,2.89\right)$ aufweist. Ein weiteres Strukturelement des farblosen Feststoffs ergibt sich durch die Aufspaltung des Signals der Methylgruppe $\left(\delta_{H}=1.55,{ }^{3} \mathrm{~J}=6.5 \mathrm{~Hz}\right)$, welche der eines zum Quartett aufgespaltenen Signals einer Methingruppe bei $\delta_{H}=5.06$ entspricht. Aus dem HMBC-Spektrum ist die Verknüpfung der drei aliphatischen Partialstrukturen untereinander und mit dem Aromaten erkennbar, zudem gelingt die 
Zuordnung der Carbonsäure (s. Abb. 23, S. 79). Die Ketogruppe weist mit $\delta_{C}=206.1$ eine ausgesprochen starke Tieffeldverschiebung auf, welche auf den ersten Blick gegen die Stellung in 9-Position, direkt benachbart dem Phenol, spricht. Obwohl die erwartete Verschiebung in diesem Fall $\delta_{C} \approx 190^{91}$ betragen würde, ist die Struktur von 46 durch die Kopplung der Protonen (6-H/ 7- $\left.\mathrm{H}_{\mathrm{a}, \mathrm{b}} / 8-\mathrm{H}_{\mathrm{a}, \mathrm{b}}\right)$ sowie die HMBC-Kopplung zwischen C-6 und $5-\mathrm{H}$ eindeutig bewiesen und wird zusätzlich durch Berechnungen der ${ }^{13} \mathrm{C}$-chemischen Verschiebungen unterstützt. 


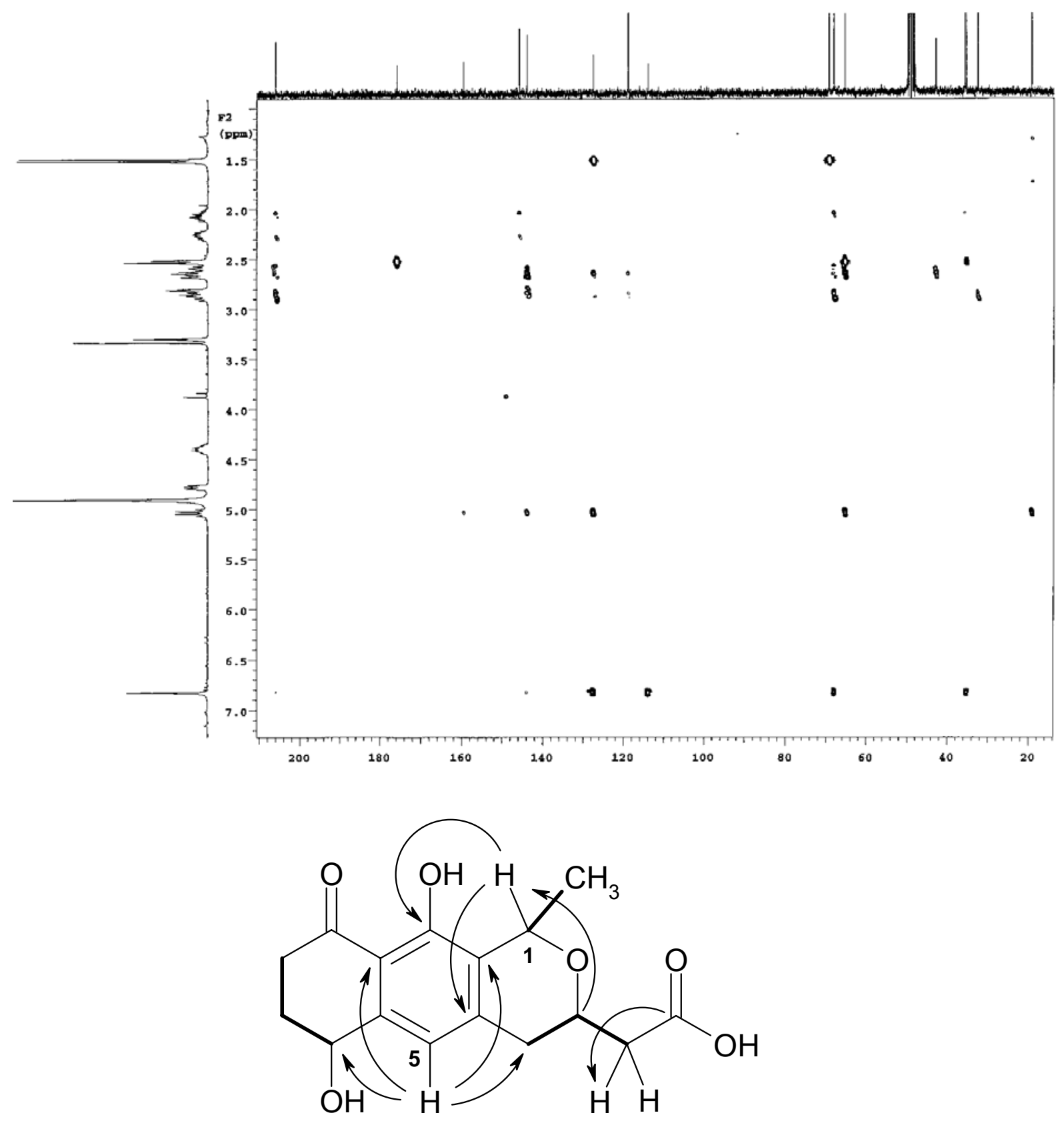

57

Abb. 23: HMBC-Spektrum (600 MHz, $\left.\mathrm{CD}_{3} \mathrm{OD}\right)$ und wichtige HMBC-Kopplungen von Fogacin (46) sowie die daraus abgeleitete Verknüpfung der aus einem COSYSpektrum gewonnenen Strukturfragmente (fett).

Zur Bestimmung der relativen Stereochemie von 46 wurde ein eindimensionales NOESYSpektrum aufgenommen. Hierbei ergibt die selektive Anregung der Methylgruppe Kopplungen $\mathrm{zu} 1-\mathrm{H}$ und $3-\mathrm{H}$, woraus geschlossen werden kann, dass die Methyl- und Carboxymethylengruppe trans zueinander stehen. Somit sind die in Abb. 24 gezeigten 
Stereoisomere denkbar. Die Kopplungskonstante zwischen $3-\mathrm{H}$ und $4-\mathrm{H}_{\mathrm{a}}$ beträgt ${ }^{3} \mathrm{~J}=11.0 \mathrm{~Hz}$, zu $4-\mathrm{H}_{\mathrm{b}}$ ist sie entsprechend kleiner $\left({ }^{3} \mathrm{~J}=3.0 \mathrm{~Hz}\right)$.
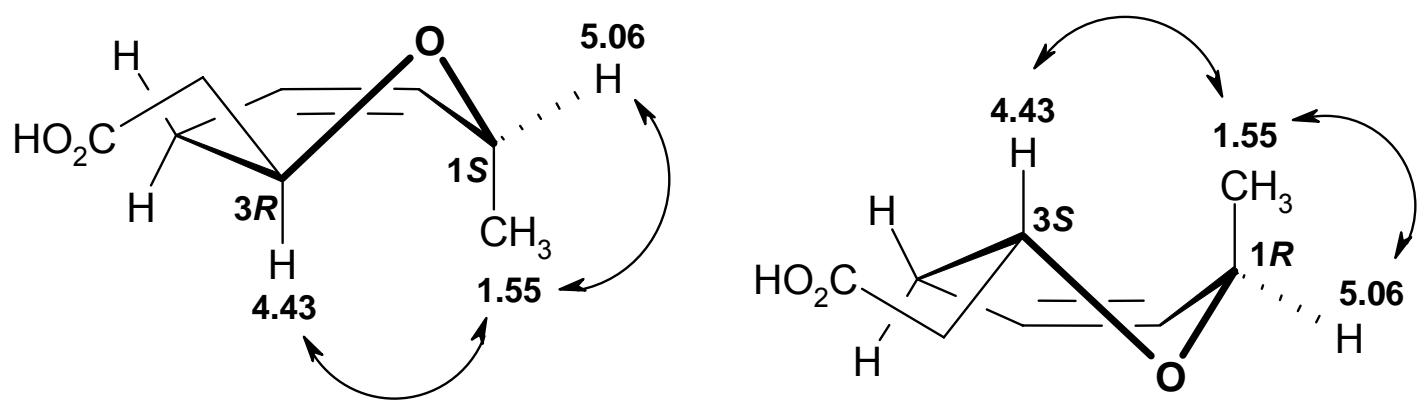

Abb. 24: NOE-Kopplungen bei selektiver Anregung der Methylgruppe können zur Ableitung der relativen Stereochemie von Ring A des Fogacins (46) genutzt werden.

Ergänzend können aus den vicinalen Kopplungskonstanten unter Berücksichtigung der Karplus-Kurve die Diederwinkel und somit die Konformation des Cyclohexanonrings bestimmt werden. 6-H zeigt eine Aufspaltung zum Dublett vom Dublett mit Kopplungskonstanten von ${ }^{3} \mathrm{~J}=8.5$ und $3.5 \mathrm{~Hz}$ was auf eine pseudoaxiale Stellung schließen lässt. Die vicinalen Kopplungen von $8-\mathrm{H}_{\mathrm{a}}$ betragen ${ }^{3} \mathrm{~J}=9.0$ und $4.5 \mathrm{~Hz}$ und sind in ihrem Betrag denen von $8-\mathrm{H}_{\mathrm{b}}$ mit ${ }^{3} \mathrm{~J}=8.0$ und $4.5 \mathrm{~Hz}$ sehr ähnlich, was für eine Wannenform bei Ring C spricht (s. Abb. 25).

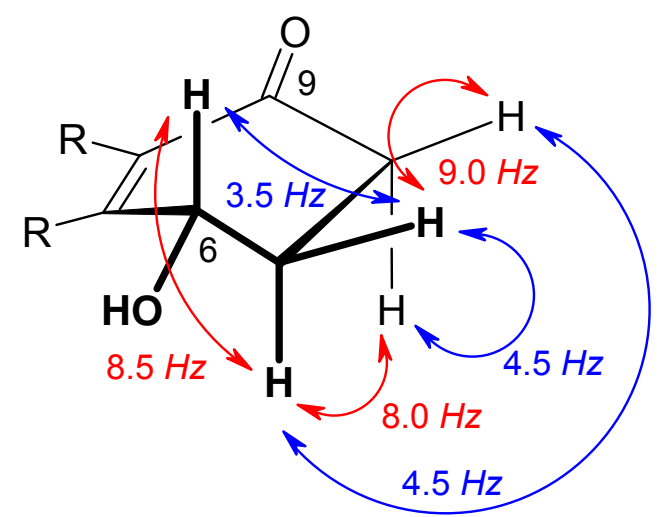

Abb. 25: ${ }^{3} \mathrm{~J}-K o p p l u n g e n$ der Protonen an Ring C von 46 (blau: pseudo-axial-äquatoriale Kopplung, rot: pseudo-axial-axiale Kopplung).

Die Bestimmung der absoluten Stereochemie der drei Chiraltitätszentren in $\mathbf{4 6}$ wäre an C-6 durch die Helmchen-Methode möglich. Für Ring A könnten CD-Berechnungen diese Frage lösen. Ein Vergleich der CD-Werte von 46 mit denen bekannter Octaketide (wie den 
Nanaomycinen, o.a.) ist nicht möglich, da keine ähnlichen Substanzen mit einem aromatischen Ring B und einem weiteren Stereozentrum in Ring C bekannt sind.

Datenbankvergleiche ${ }^{136,150}$ ergaben, dass die gezeigte Struktur 46 nicht literaturbekannt ist. Substanz 46 wurde in Anlehnung an die Herkunft der Erdprobe, aus welcher Streptomyces sp. Stamm Tü 6319 isoliert wurde, Fogacin genannt. ${ }^{156}$

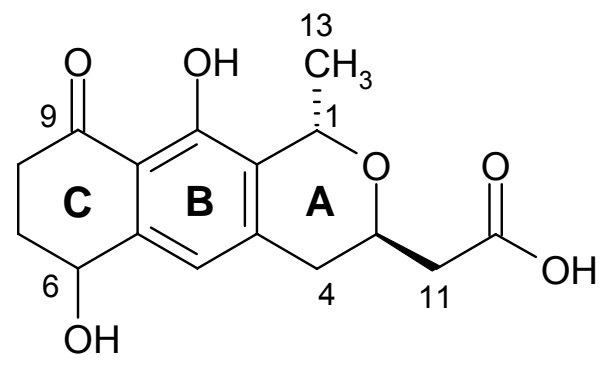

46

\subsubsection{Biologische Aktivitäten der Metaboliten}

Die isolierten Metaboliten 46-50 wurden im Plattendiffusionstest $\left(1.5 \times 10^{-2} \mathrm{mg}\right.$ pro Filterplättchen) auf antimikrobielle Aktivität gegen Escherichia coli, Bacillus subtilis, Staphylococcus aureus und Candida albicans untersucht. Die Substanzen zeigten keine antibakterielle oder antimykotische Aktivität. In Tübingen hingegen wies anhydroSEK4b (48) mit Hemmhöfen von 11 und $16 \mathrm{~mm}$ bei einer Konzentration von $1 \mathrm{mg} / \mathrm{mL}$ eine moderate Aktivität gegen Bacillus subtitlis DSM 10 und Streptomyces viridochromogenes Tü 57 auf.

Weitergehend wurden 46-50 im Arbeitskreis BEIL gegen die Krebszellinien HepG2 (Lebercarcinom), HM02 (Magenadenocarcinom) sowie MCF7 (Mammacarcinom) getestet. Bis zu einer Konzentration von $10 \mu \mathrm{g} / \mathrm{mL}$ war keine Aktivität nachzuweisen.

\subsubsection{Zur Biosynthese der Octaketide 46, 47 und 48}

Die aus Streptomyces sp. Tü 6319 isolierten Polyketide SEK4b (47) und anhydroSEK4b (48) sind literaturbekannte "Shuntmetaboliten“ von Mutanten des Actinorhodin-Produzenten Streptomyces coelicolor A3(2). ${ }^{157,158}$ Eine $\mathrm{C}_{16}$-Einheit des dimeren Octaketids Actinorhodin (53) wird durch eine Typ-II-Polyketidsynthase (PKS II) aus einer Acetat und sieben Malonateinheiten aufgebaut. Der für die Produktion von 53 codierende Gencluster beinhaltet einen Abschnitt für die sogenannte „minimale PKS“ („minPKS“) sowie weitere, für die regiound stereospezifische Cyclisierung, Reduktion, Oxygenierung etc. verantwortliche Gene. Die „minPKS“ besteht aus einem Acyl-Carrier-Protein und zwei $\beta$-Ketoacylsynthasen $\left(\mathrm{KS}_{\alpha}\right.$ und $\mathrm{KS}_{\beta}{ }^{159}$ ) und ist in der Lage $\mathrm{C}_{16}$-Polyketide wie 47 und 48 in vivo ${ }^{160}$ und in vitro ${ }^{161}$ zu bilden. Bei der heterologen Expression des „minPKS“-Gens werden dabei ebenso wie bei Arbeiten 
mit den aufgereinigten „minPKS“-Enzymen neben 47 und 48 Metabolite wie SEK4 (54) und anhydro SEK4 (55) ${ }^{162}$ produziert (s. Abb. 26, S. 83), die zwar ein $\mathrm{C}_{16}$-Grundgerüst aufweisen, aber nicht selektiv cyclisiert und reduziert wurden. Wenn die „minPKS“ hingegen mit zusätzlichen Genen für Cyclisierung oder Reduktion exprimiert wird oder einzelne Gene der späten Actinorhodin-Biosynthese im Wildstamm inaktiviert werden, können weitere Metaboliten, wie die teilweise kontrolliert cyclisierten Aloesaponarin $\|^{163}$, (S)-DNPA, DMAC $^{164}$ oder $(S)-\mathrm{NHAB}^{165}$, erhalten werden (nicht dargestellt). Bei der heterologen Expression konnte zudem gezeigt werden, das Gene, welche für die Cyclisierung von Decaketiden wie Tetracenomycin verantwortlich sind, die Fähigkeit haben eine kontrollierte späte Biosynthese von Octaketidketten durchzuführen. ${ }^{154,166}$

In Streptomyces sp. Tü 6319 liegen demnach die Enzyme für die vollständige Biosynthese eines Octaketids wie $\mathbf{4 6}$ vor, zeitgleich werden mit $\mathbf{4 7}$ und $\mathbf{4 8}$ Shuntmetabolite produziert, die über eine nichtenzymatische Cyclisierung entstehen. Die Frage, warum auch die Natur Shuntmetabolite bildet, ist nicht einfach zu beantworten. Denkbar ist, dass in dem vorliegenden Fall ein nicht abgeschlossener evolutionärer Prozess in Streptomyces sp. Tü $6319 \mathrm{zu}$ beobachten ist, der einen neuen, aktiven Sekundärmetaboliten hervorbringen könnte. Weiterhin ist der umgekehrte Prozess eines biologisch inaktiven Sekundärmetaboliten $\mathbf{4 6}$ denkbar, dessen Biosynthesegene aufgrund fehlenden Nutzens für den Organismus schrittweise deletiert werden. In der Literatur ist eine ähnliche Beobachtung nur für Streptomyces Stamm P6417 beschrieben, der neben dem „echten“ Decaketid Balmoralmycin die zuvor von Fu et al. ${ }^{167}$ beschriebenen Shuntmetaboliten SEK15 und 8-DeshydroxySEK15 produziert. ${ }^{168}$ 
$\stackrel{\mathrm{H}}{\mathrm{SCOA}}^{+} 7 \mathrm{HO}_{2} \mathrm{C} \stackrel{\mathrm{SCoA}}{\mathrm{SCO}}^{\mathrm{O}}$

act 'min' PKS $\mid-7 \mathrm{CO}_{2}$

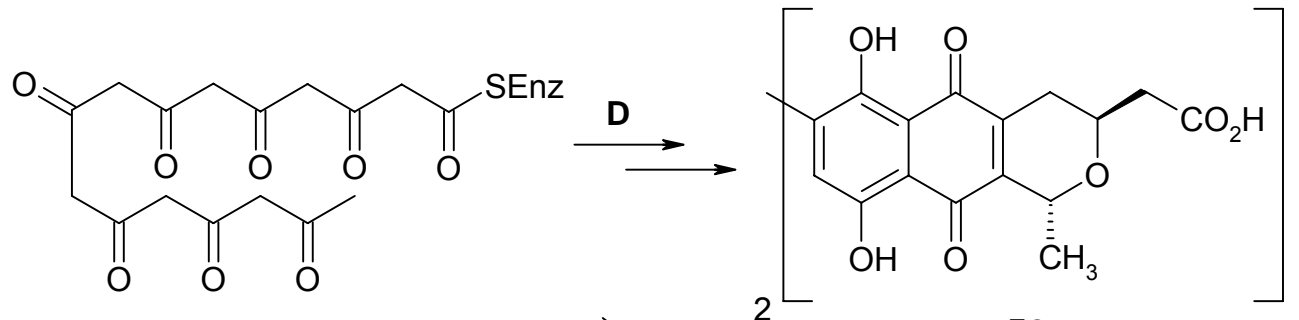

53<smiles>CCOC(=O)CC(=O)CC(=O)CC(=O)CC(=O)CC(=O)CC(=O)CC(C)=O</smiles><smiles>[B][13CH2]OCCC(=O)CC(=O)CC(=O)CC(=O)CC(=O)CC(=O)CC(C)=O</smiles>

C<smiles>CC1O[C@H](CC(=O)O)Cc2cc3c(c(O)c21)C(=O)CCC3O</smiles>

46<smiles>Cc1cc(O)cc2c1C(=O)CC(O)(Cc1cc(=O)cc(O)o1)O2</smiles>

47

54<smiles>CC1(O)CC(=O)c2c(Cc3cc(=O)cc(O)o3)cc(O)cc2O1</smiles>

$\downarrow-\mathrm{H}_{2} \mathrm{O}$<smiles></smiles><smiles>Cc1cc(O)cc2oc(Cc3cc(=O)cc(O)o3)cc(=O)c12</smiles>

48<smiles>Cc1cc(=O)c2c(Cc3cc(=O)cc(O)o3)cc(O)cc2o1</smiles>

Abb. 26: Typ II Polyketid-Biosynthese verschiedener Octaketide durch spontane Cyclisierung oder enzymatische Umsetzung der Kette (A: knock-out Mutanten und Streptomyces sp. Tü 6319, B: knock-out Mutanten, C: Streptomyces sp. Tü 6319, D: Streptomyces coelicolor A3(2). 


\subsubsection{Streptomyces sp. Stamm Tü 2561}

Die Fermentationen erfolgten in einem $10 \mathrm{~L}$ New Brunswick Blattrührfermenter in Hafermedium (2\% Hafermehl in Leitungswasser, $\mathrm{pH} 7.3,27^{\circ} \mathrm{C}, 0.5 \mathrm{vvm}, 200 \mathrm{rpm}, 168 \mathrm{~h}$ Kultivierungsdauer)

Das Kulturfiltrat wurde mit Ethylacetat extrahiert und der Extrakt in vacuo eingeengt. Die weitere Aufreinigung erfolgte an Kieselgel $\left(\mathrm{CH}_{2} \mathrm{Cl}_{2} \rightarrow 10 \% \mathrm{MeOH}\right)$ und zweimalig an Sephadex LH-20 (MeOH). Substanz 2561-1 (56) fiel in einer Ausbeute von $4.8 \mathrm{mg} / \mathrm{L}$ an.

Der farblose Feststoff ist in in Chloroform, Methanol, Benzol und Pyridin gut löslich und zeigt auf dem Dünnschichtchromatogramm mit Anisaldehyd in der Wärme eine braune Färbung. Das ESI-Massenspektrum der bei $254 \mathrm{~nm}$ UV-löschenden Substanz mittlerer Polarität $\left(R_{f}=0.35\right.$, Chloroform/ Methanol 9:1) ergibt einen Peak bei $\mathrm{m} / \mathrm{z}=1209[\mathrm{M}+\mathrm{Na}]^{+}$, aus dessen Hochauflösung sich mit einer Genauigkeit von $\Delta<0.05 \mathrm{ppm}$ eine Summenformel von $\mathrm{C}_{73} \mathrm{H}_{86} \mathrm{O}_{14}$ ableiten lässt. Die Hochauflösung des Ammoniumadduktsignals bei $\mathrm{m} / \mathrm{z}=1204$ kann diese Summenformel nicht unterstützen, ergibt jedoch auch keine Alternative hinreichender Genauigkeit. Eine hochauflösende MS/MS-Untersuchung zeigt Peaks, die zu Summenformeln von $\left[\mathrm{C}_{7} \mathrm{H}_{12} \mathrm{O}_{3}\right]^{+},\left[\mathrm{C}_{13} \mathrm{H}_{22} \mathrm{O}_{6}\right]^{+}$und $\left[\mathrm{C}_{19} \mathrm{H}_{32} \mathrm{O}_{9}\right]^{+}$führen.

Das ${ }^{13} \mathrm{C}-N M R-S p e k t r u m$ lässt insgesamt ca. 70 Signale erkennen, die genaue Anzahl ist aufgrund von Überlagerungen nicht zu ermitteln. Von den Resonanzen liegen ca. $60 \mathrm{im}$ aliphatischen Bereich unter $\delta_{C} \approx 100$. Signale bei $\delta_{C}=201.6$ und 206.3 lassen auf zwei Ketogruppen, weitere bei $\delta_{C}=157.4,167.1$ und 180.9 auf zwei Ester sowie eine Carbonsäure schließen. Weiterhin sind vier Doppelbindungen zu erkennen $\left(\delta_{C}=119.1-\right.$ 141.3), denen in Verbindung mit einem HSQC-Spektrum fünf Protonen $\left(\delta_{H}=5.14-5.73\right)$ zuzuordnen sind. Im aliphatischen Bereich sind vier Signale bei $\delta_{C}=91.0,96.8,97.9$ und 98.2 auszumachen, deren chemische Verschiebung eine Acetalstruktur nahelegt. Durch HSQC-Korrelationen ist ihre Bindung an vier Protonen im Bereich von $\delta_{C}=4.46-5.13$ belegt. Aus den COSY-Kopplungen dieser Wasserstoffatome wird die Ableitung von zwei vollständigen 2,6-Didesoxyzuckern (Zucker A und B) sowie zwei 2,6-DidesoxyzuckerPartialstrukturen (Zucker C und D) möglich (s. Tab. 10, S. 85; Abb. 27, S. 86), ihre Strukturen werden durch HMBC- und NOESY-Korrelationsspektren gestützt. Durch HMBCKorrelationen von $1-\mathrm{H}$ sowie $4-\mathrm{H}$ ist für Zucker $\mathrm{A}$ weiterhin die Verknüpfung zu Zucker B (1,4-glykosidisch) sowie zu einer Methylgruppe $\left(4 \mathrm{~A}-\mathrm{OCH}_{3}\right)$ bewiesen. In gleicher Weise gelingt die Verbindung von Zucker B zu dem Zuckerfragment C (1,3-glykosidisch). Mit diesen Informationen können den in der HR-ESI-MS/MS Untersuchung gefundenen Summenformeln ein methylierter Didesoxyzucker (Zucker $A, \mathrm{C}_{7} \mathrm{H}_{12} \mathrm{O}_{3}$ ), ein Disaccharid (Zucker $A+B, C_{13} \mathrm{H}_{22} \mathrm{O}_{6}$ ) und ein Trisaccharid (Zucker $A+B+C, \mathrm{C}_{19} \mathrm{H}_{32} \mathrm{O}_{9}$ ) zugeordnet werden. Allerdings legt eine HMBC-Kopplung von $3 \mathrm{C}-\mathrm{H}$ zu $\delta_{C}=157.4$ eine oxidative Öffnung dieses Rings nahe (s. Abb. 27, S. 86), was gegen die Beobachtung des Trisaccharids in der Masse 
spricht. Aus den ${ }^{3} \mathrm{~J}$-Kopplungskonstanten lässt sich weiterhin die relative Stereochemie einzelner Zucker ableiten. So betragen die Konstanten der anomeren Protonen $1 \mathrm{~A}-\mathrm{H}$ und $1 \mathrm{C}-\mathrm{H}$ jeweils ${ }^{3} \mathrm{~J}=9.5$ und $1.5 \mathrm{~Hz}$, was für eine axiale Position spricht, während für $1 \mathrm{~B}-\mathrm{H}$ und $1 \mathrm{D}-\mathrm{H}$ die Konstanten $\left({ }^{3} \mathrm{~J} \approx 4.0 \mathrm{~Hz}\right.$ ) für eine äquatoriale Stellung von $1-\mathrm{H}$ charakteristisch sind. Nach dem gleichen Prinzip ergibt sich die Stereochemie für 3-H, 4-H und 5-H der Zucker A und $B$.

\begin{tabular}{ccccc}
\hline & \multicolumn{4}{c}{$\delta_{\mathrm{C}} / \delta_{\mathrm{H}}[\mathrm{ppm}]$} \\
& $\mathrm{A}$ & $\mathrm{B}$ & $\mathrm{C}$ & $\mathrm{D}$ \\
\hline 1 & $98.2 / 4.92$ & $90.9 / 5.12$ & $97.9 / 4.77$ & $96.8 / 4.46$ \\
2 & $36.7 / 1.68,2.15$ & $34.1 / 1.90,2.12$ & $29.9 / 1.70,2.36$ & $35.6 / 1.60,2.79$ \\
3 & $63.9 / 4.27$ & $64.9 / 4.23$ & $66.9 / 4.02$ & $53.6 / 4.39$ \\
4 & $82.08 / 2.85$ & $82.13 / 3.25$ & - & - \\
5 & $68.3 / 3.77$ & $62.0 / 4.00$ & $65.0 / 4.02$ & $69.0 / 3.46$ \\
6 & $18.3 / 1.24$ & $18.3 / 1.14$ & $17.7 / 1.21$ & $16.9 / 1.10$ \\
$4-\mathrm{OCH}_{3}$ & $57.3 / 3.42$ & - & - & - \\
\hline
\end{tabular}

Tab. 10: ${ }^{1} \mathrm{H}$ - und ${ }^{13} \mathrm{C}$-chemische Verschiebungen der Zucker A-D in Substanz 2561-1 (56)

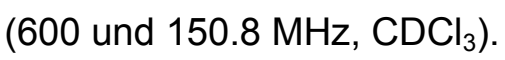

Aus COSY- und HMBC-Spektren ist die Ableitung einer Kohlenstoffkette mit olefinischen und aliphatischen Segmenten möglich, welche insgesamt aus 13 Atomen besteht. Diese Kette trägt an C-4, C-10 und C-12 Methylgruppen, an C-9 einen Propionoylrest, an C-13 Zucker D und muss an C-1, C-5, C-8 und C-13 weitere, bisher nicht identifizierte, Reste aufweisen. Für die C-6/C-7-Doppelbindung ist durch die gefundene Kopplungskonstante von ${ }^{3} \mathrm{~J}=10.0 \mathrm{~Hz}$

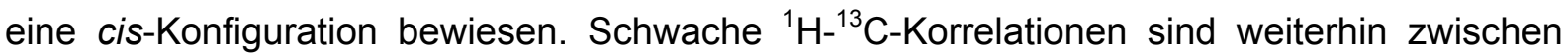
5-H der Kette und der Methylgruppe des C-9-Restes vorhanden, eine Ringverknüpfung an dieser Stelle ist denkbar.

Eine zweite Kohlenstoffkette kann ausgehend von den zwei restlichen olefinischen Protonen durch HMBC-Kopplungen konstruiert werden. So ergibt sich ein konjugiertes System von zwei Doppelbindungen, welches an einen Propylrest grenzt. Eine Verknüpfung dieses Systems mit dem großen Gerüst ist durch eine schwache HMBC-Kopplung von 1-H zu C-4"' wahrscheinlich, für einen Beweis scheint dies aber unzureichend. Die chemischen Verschiebungen aller beschriebenen Strukturelemente sind in den Tabellen 10-12 (S. 85, S. 87) zu finden. 


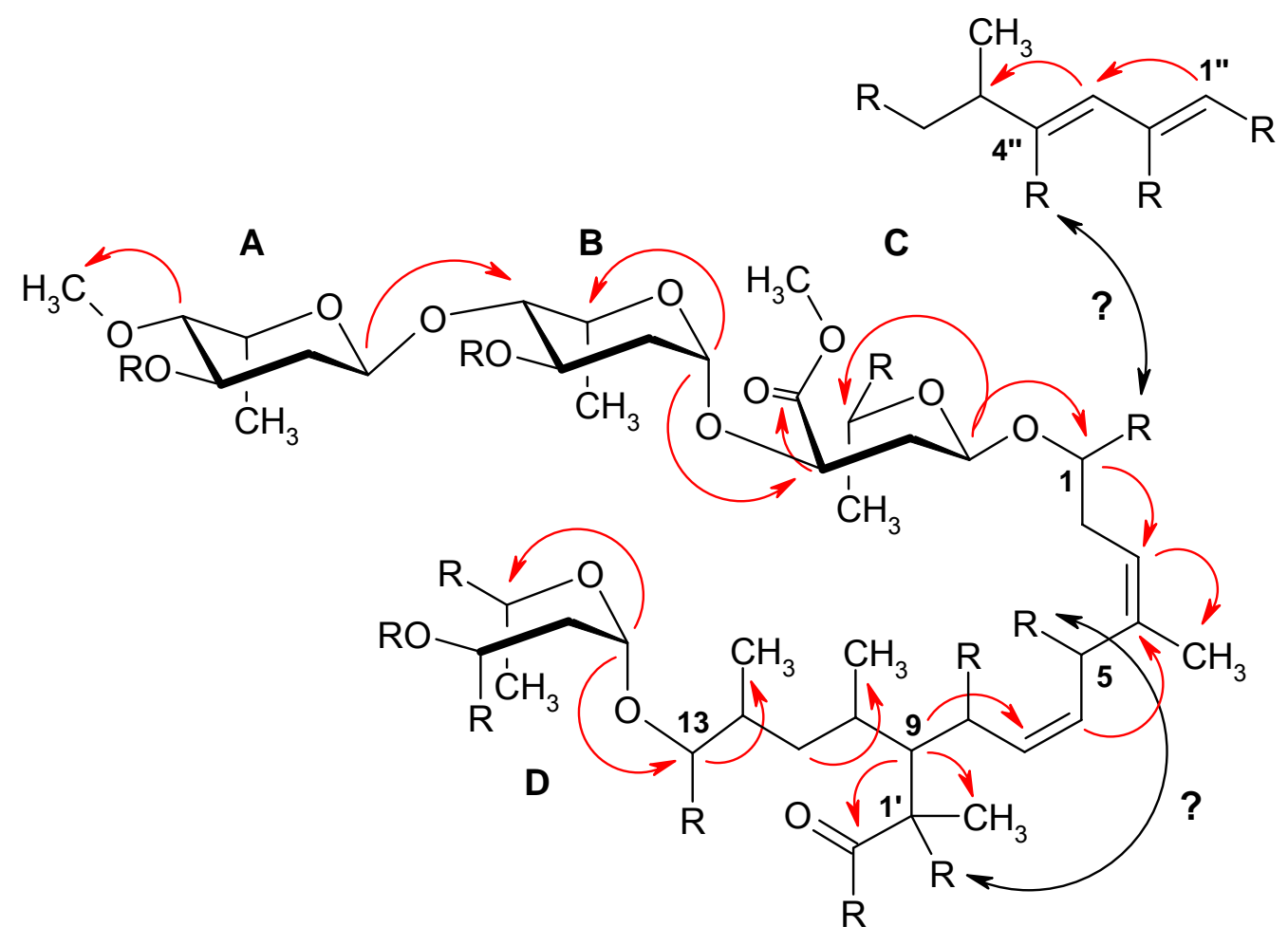

Abb. 27: Wichtige HMBC-Kopplungen (rot) und daraus abgeleitete Partialstruktur der Substanz 2561-1 (56); schwarze Pfeile zeigen mögliche, aber nicht eindeutig bewiesene Verknüpfungen.

Die bisher ermittelten Fragmente ergeben die Bruttoformel $\mathrm{C}_{52} \mathrm{H}_{78} \mathrm{O}_{15}$, d.h. gegenüber der ermittelten Summenformel $\mathrm{C}_{73} \mathrm{H}_{86} \mathrm{O}_{14}$ fehlen noch über $20 \mathrm{C}$-Atome. Selbst wenn einzelne Hydroxygruppen der Zucker verbrückt sind, scheint die Summenformel eventuell falsch zu sein. So führt die Berechnung der Doppelbindungsäquivalente (DBE) für $\mathrm{C}_{73} \mathrm{H}_{86} \mathrm{O}_{14} \mathrm{zu}$ insgesamt 31. Unter Berücksichtigung der aus den NMR-Experimenten ersichtlichen Doppelbindungen (neun) und Zucker (vier) müssten in Substanz 2561-1 (56) demnach 18 (!) weitere Ringe vorhanden sein, was schwer vorstellbar ist.

Ein großes Problem bei der Strukturaufklärung von 56 ist die Überlagerung vieler aliphatischer Signale in den Protonenspektren, welche durch Lösungsmittelwechsel (von Chloroform zu Pyridin, Benzol, Methanol) nicht aufzuheben ist. Der Einsatz von EuropiumVerschiebungsreagenzien führt zwar zu einer Separierung einzelner Signale, eine größere Signalbreite macht diesen Vorteil allerdings zunichte. Wahrscheinlich sind die verbleibenden Fragen durch ein INADEQUATE-Korrelationsspektrum zu lösen, Versuche der Messung dieser ${ }^{13} \mathrm{C}-{ }^{13} \mathrm{C}$-Korrelationen scheiterten bisher jedoch.

Das ${ }^{13} \mathrm{C}-\mathrm{NMR}$ - wie auch ein IR-Spektrum zeigen, dass es sich bei der Substanz um ein Makrolid handeln könnte. Makrolide von ähnlicher Größe wie 56, z.B. die Quinolidomycine ${ }^{169}$ besitzen größere Ringe (bis zu 59 C-Atome), als die gefundenen Substanz. Auffällig ist bei 
56 zudem der hohe Anteil an reduzierten, aber nicht olefinisches Strukturteilen und die damit einhergehende niedrige Anzahl an Heteroatomen. Wie erste Fütterungsversuche mit $\left[1,2-{ }^{13} \mathrm{C}_{2}\right]$ Acetat zeigen, handelt es sich bei 56 um ein mehrfach glykosyliertes Polyketid (wahrscheinlich vom PKS I-Typ). Die Verbindung ist nach Datenbankrecherchen mit den bisherigen Informationen neu und zeichnet sich durch eine bemerkenswerte antibakterielle Wirkung aus. Die Struktur konnte aus zeitlichen Gründen nicht vollständig aufgeklärt werden.

\begin{tabular}{|cc|cc|cc|}
\hline & $\delta_{\mathrm{C}}[\mathrm{ppm}]$ & & $\delta_{\mathrm{C}}[\mathrm{ppm}]$ & & $\delta_{\mathrm{C}}[\mathrm{ppm}]$ \\
\hline $\mathrm{C}-1$ & 78.2 & $\mathrm{C}-10$ & 31.2 & 1'-CH $^{3}$ & 15.0 \\
$\mathrm{C}-2$ & 30.9 & $\mathrm{C}-11$ & 41.6 & $\mathrm{C}-1{ }^{\prime \prime}$ & 119.1 \\
$\mathrm{C}-3$ & 123.3 & $\mathrm{C}-12$ & 34.3 & $\mathrm{C}-2{ }^{\prime \prime}$ & 137.0 \\
$\mathrm{C}-4$ & 135.7 & $\mathrm{C}-13$ & 83.9 & $\mathrm{C}-3{ }^{\prime \prime}$ & 121.4 \\
$\mathrm{C}-5$ & 53.1 & $4-\mathrm{CH}_{3}$ & 13.7 & $\mathrm{C}-4{ }^{\prime \prime}$ & 141.3 \\
$\mathrm{C}-6$ & 126.3 & $10-\mathrm{CH}_{3}$ & 22.2 & $\mathrm{C}-5{ }^{\prime \prime}$ & 27.9 \\
$\mathrm{C}-7$ & 125.9 & $12-\mathrm{CH}_{3}$ & 14.1 & $\mathrm{C}-6{ }^{\prime \prime}$ & 35.3 \\
$\mathrm{C}-8$ & 38.4 & $\mathrm{C}-1{ }^{\prime}$ & $?$ & $5^{\prime \prime}-\mathrm{CH}_{3}$ & 20.1 \\
$\mathrm{C}-9$ & 43.0 & $\mathrm{C}-2{ }^{\prime}$ & 206.3 & & \\
\hline
\end{tabular}

Tab. 11: ${ }^{13} \mathrm{C}$-chemische Verschiebungen der Aglykon-Partialstruktur von Substanz 2561-1 (56) $\left(150.8 \mathrm{MHz}, \mathrm{CDCl}_{3}\right)$.

\begin{tabular}{|cc|cc|cc|}
\hline & $\delta_{\mathrm{H}}[\mathrm{ppm}]$ & & $\delta_{\mathrm{H}}[\mathrm{ppm}]$ & & $\delta_{\mathrm{H}}[\mathrm{ppm}]$ \\
\hline $1-\mathrm{H}$ & 4.18 & $9-\mathrm{H}$ & 2.00 & $12-\mathrm{CH}_{3}$ & 1.11 \\
$2-\mathrm{H}_{2}$ & $2.25,2.36$ & $10-\mathrm{H}$ & 1.60 & $1 '-\mathrm{CH}_{3}$ & 1.62 \\
$3-\mathrm{H}$ & 5.17 & $11-\mathrm{H}_{2}$ & $1.51,1.62$ & $1{ }^{\prime \prime}-\mathrm{H}$ & 5.14 \\
$5-\mathrm{H}$ & 3.48 & $12-\mathrm{H}$ & 2.21 & $3{ }^{\prime \prime}-\mathrm{H}$ & 5.52 \\
$6-\mathrm{H}$ & 5.38 & $13-\mathrm{H}$ & 3.42 & $5 " \cdot-\mathrm{H}$ & 2.69 \\
$7-\mathrm{H}$ & 5.73 & $4-\mathrm{CH}_{3}$ & 1.32 & $6{ }^{\prime \prime}-\mathrm{H}_{2}$ & $1.85,2.40$ \\
$8-\mathrm{H}$ & 2.10 & $10-\mathrm{CH}_{3}$ & 0.65 & $5{ }^{\prime \prime}-\mathrm{CH}_{3}$ & 1.33 \\
\hline
\end{tabular}

Tab. 12: ${ }^{1} \mathrm{H}$-chemische Verschiebungen der Aglykon-Partialstruktur von Substanz 2561-1 (56) $\left(600 \mathrm{MHz}, \mathrm{CDCl}_{3}\right)$. 


\section{Borrelidin}

\subsection{Allgemeines}

Das Makrolid Borrelidin (15) wurde aufgrund seiner antibakteriellen Aktivität gegen verschiedene Borrelia-Arten 1949 von BERGER et al. entdeckt. ${ }^{170}$ Erste Untersuchungen zur Struktur des Moleküls gelangen 1965, ${ }^{171}$ kurze Zeit später erfolgte die vollständige Strukturaufklärung. ${ }^{172}$ Neben einem nicht glykosylierten $\mathrm{C}_{18}$-Ring besitzt das Polyketid eine in Naturstoffen seltene Nitrilgruppe ${ }^{173}$ und eine einzigartige trans-1,2-Cyclopentandicarbonsäure (CPDA).

Der antibakteriellen Wirkung von $15^{174}$ liegt eine selektive Inhibierung der Threonyl-tRNASynthetase zugrunde. ${ }^{175}$ Die insgesamt 20 bekannten Aminoacyl-tRNA-Synthetasen ${ }^{176}$, sind bei Pro- und Eukaryonten ausreichend differenziert, um einen selektiven Angriff auf diese bakteriellen Enzyme zu ermöglichen. Sie sind aufgrund ihrer universellen Verbreitung zudem als hervorragende Targets für Breitspektrumantibiotika geeignet. Ein weiterer Vorteil ihrer Inhibierung ist die Blockade eines in nahezu allen Bakterien vollständig vorhandenen Biosyntheseweges über 20 einzelne Targets, welche unabhängig voneinander angegriffen werden können. ${ }^{177}$ Das erste Antibiotikum dieser Art im klinischen Einsatz ist der IsoleucyltRNA-Synthetaseinhibitor Mupirocin, ${ }^{178}$ der gute Aktivitäten gegen Methicillin-resistente Staphylococcus aureus (MRSA) aufweist. ${ }^{179}$ Der breite klinische Einsatz hat jedoch, wie bei vielen anderen Antibiotika zuvor, zu ersten Resistenzen geführt. ${ }^{180}$

Die wohl interessanteste Aktivität von 15 ist die Fähigkeit, die Angiogenese und Proliferation von Zellen zu inhibieren. ${ }^{181}$ Die Blutgefässbildung wird durch eine beim Tumorwachstum häufig auftretende Hypoxie stimuliert und ist somit für die Krebstherapie ein aussichtreiches Target. Der Vorteil ist hierbei das Vermeiden von Resistenzen, da Zellzyklen im Wirt und nicht in der Tumorzelle inhibiert werden. ${ }^{182}$ Lange Zeit wurde angenommen, dass die Angiogenese-inhibierende Wirkung von 15 wie die antibakterielle Wirkung auf die Thr-tRNAInhibierung zurückzuführen ist. Jüngste Untersuchungen zeigen jedoch, dass das Makrolid 15 auch bei Zusatz von hohen Threoninkonzentrationen nur einen geringen Teil seiner Aktivität verliert. Es konnte gezeigt werden, dass 15 zusätzlich die Proteasen Caspase-3 und -8 aktiviert und somit den programmierten Zelltod, die Apoptose, auslöst. ${ }^{183}$ Weitere biologische Aktivitäten des Naturstoffs 15 sind die Inhibierung der Cyclin-abhängigen Kinase in Saccharomyces cereviseae, eine antivirale sowie eine antiplasmodiale Aktivität (s. auch Kap. 1.3). ${ }^{184}$ Die umfassenden biologischen Aktivitäten von 15 zeigen, wie sinnvoll es ist, die evolutionäre Entwicklung von Naturstoffen als Basis für neue Wirkstoffe zu nutzen. Gleichwohl muss für das Makrolid 15 die Einschränkung gemacht werden, dass die Vielzahl an Aktivitäten den Einsatz als Wirkstoff in der Klinik aufgrund zu geringer Selektivität 
verhindert. Allerdings können Substanzen dieser Art gut als Leitstrukturen in der Arzneimittelforschung Verwendung finden.

\subsection{Die Biosynthese des Borrelidins}

Makrolide wie das Borrelidin (15) werden durch modulare „Typ I“-Polyketidsynthasen (PKS I) aufgebaut. Nach dem Kolinearitätsprinzip katalysiert in diesen Enzymen jeweils ein Modul einen Kettenverlängerungsschritt und reduziert in direktem Anschluss („in situ“) die $\beta$-Ketogegebenenfalls zur Hydroxygruppe, die weiter modifiziert werden kann. Die Bausteine eines PKS I-Polyketids sind Acetat oder Propionat, welche aus Malonat oder Methylmalonat hervorgehen. ${ }^{185}$ Auf einem PKS-I-Biosynthesegencluster eines Bakteriums befinden sich im Einklang mit dieser Theorie gerade so viele Gene wie für die Kettenverlängerung notwendig sind.

Das Polyketid 15 wird von Streptomyces parvulus Tü 4055 wahrscheinlich aus drei Acetatund fünf Propionateinheiten aufgebaut, welche an die Startereinheit (trans-1,2Cyclopentandicarbonsäure, s.u.) kondensiert werden. Hiernach müssten also die Gene für eine ,loading domain' und für acht Module zur Kettenverlängerung bereitstehen. LEADLAY und SALAS et al. konnten jedoch zeigen, dass im Gencluster borPKS lediglich die Information für sechs Module vorhanden ist. ${ }^{186}$ Insgesamt sind im Cluster die PKS-Gene borA1-6 zu finden, wobei die Expression von borA3 zu dem Enzym BorA3 führt, welches aus zwei Modulen besteht (s. Abb. 28, S. 90). ${ }^{187}$ BorA5 weist hingegen nur ein Modul auf, welches aber drei Kettenverlängerungsschritte katalysiert.

Ein ähnliches Prinzip wird für den Lankacidin-Produzenten Streptomyces rochei erwartet, dessen Gencluster nur fünf anstatt der erwarteten acht Kettenverlängerungsmodule trägt. ${ }^{188}$ Das dritte Beispiel dieser Art ist der Stigmatellin-Gencluster aus Stigmatella aurantiaca, welcher nur neun Module für eine Undecaketidproduktion aufweist. ${ }^{189}$ Diese drei, in mindestens einem Modul iterativ arbeitenden PKS I-Cluster, sind die ersten Beispiele ihrer Art. Dieser iterative Einsatz einzelner Module wurde bisher als evolutionäre Resteigenschaft bewertet, da sich bei einzelnen Makrolidbildnern Nebenprodukte entsprechender Art finden, z.B. zwei Oktaketide aus dem Erythronolid-Produzenten Saccharopolyspora erythrea. ${ }^{190}$ Dieser Vorgang wird als "Stottern“ bezeichnet. Das Paradigma einer rein linear funktionierenden PKS I muss also aufgrund der beschriebenen Ausnahmen aufgehoben werden, was als weiteres Beispiel gelten kann, das im Sekundärstoffwechsel variable Wege existieren, um Strukturdiversität zu erreichen. 


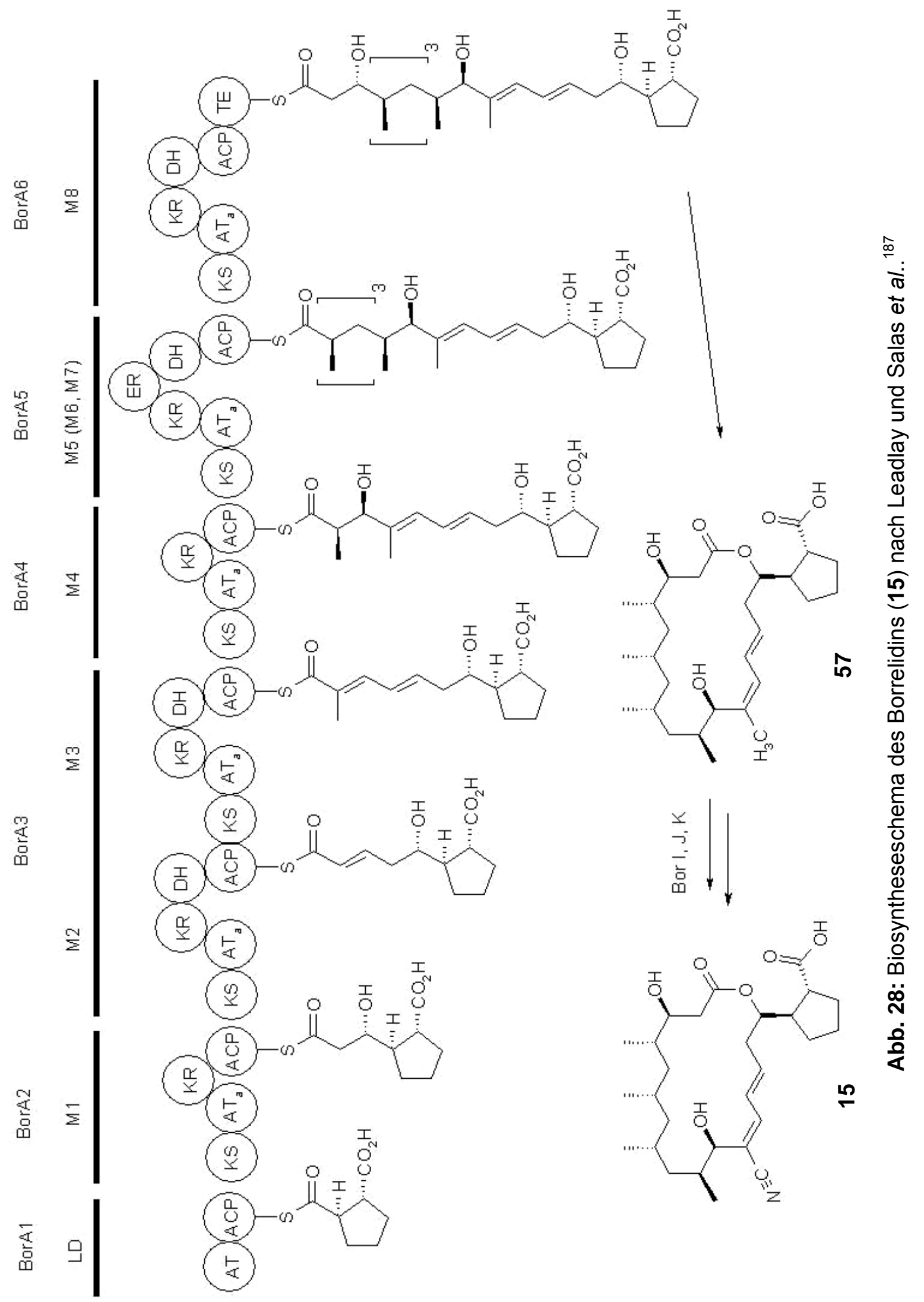


Obwohl über 120 Naturstoffe mit Nitrilgruppen aus zumeist pflanzlichen Quellen bekannt sind, ist ihre Biosynthese wenig untersucht. Als Vorläufer dieser ungewöhnlichen funktionellen Gruppe konnten bisher anorganisches Cyanid oder Aminosäuren identifiziert werden. Bei der Umwandlung von Aminosäuren bildet sich nach Hydroxylierung und Decarboxylierung ein Aldoxim, das unter Wasserabspaltung das Nitril liefert. ${ }^{173,191}$

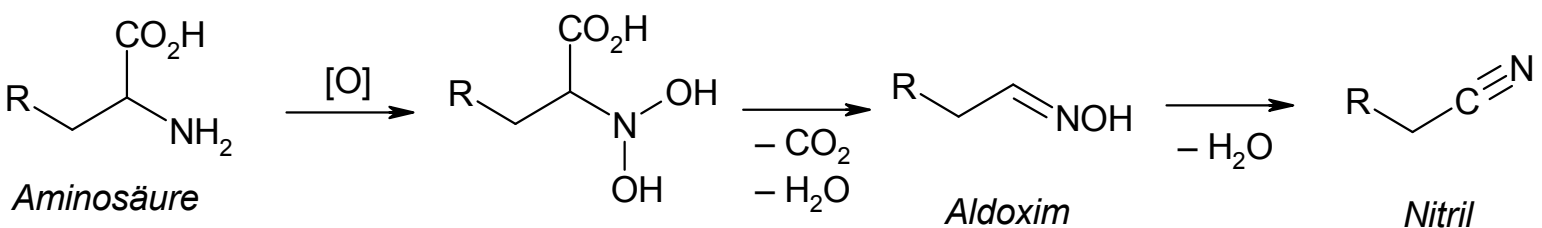

Abb. 29: Biosynthese von Nitrilen aus Aminosäuren.

Durch Analyse des Biosynthesegenclusters Streptomyces parvulus Tü 4055 und aus Fütterungsexperimenten mit uniform ${ }^{13} \mathrm{C}$-markiertem Propionat konnte für die Nitrilgruppe des Borrelidins die Herkunft des Kohlenstoffs aus Propionat bewiesen werden. ${ }^{192}$ Die Gene borl-K sind hierbei für die Transformation verantwortlich. Der knock-out von borl führt zur Bildung von 12-Desnitril-12-methylborrelidin (57), während die Kultivierung der Mutante ohne borJ-Gen die Produktion von 12-Desnitril-12-carboxylborrelidin (58) ergibt. Diese Beobachtungen führen zu dem in Abb. 30 dargestellten Mechanismus der NitrilgruppenBiosynthese. Die Dicarbonsäure 58 ist schon früher als Nebenprodukt aus BorrelidinProduzenten isoliert worden. ${ }^{193}$

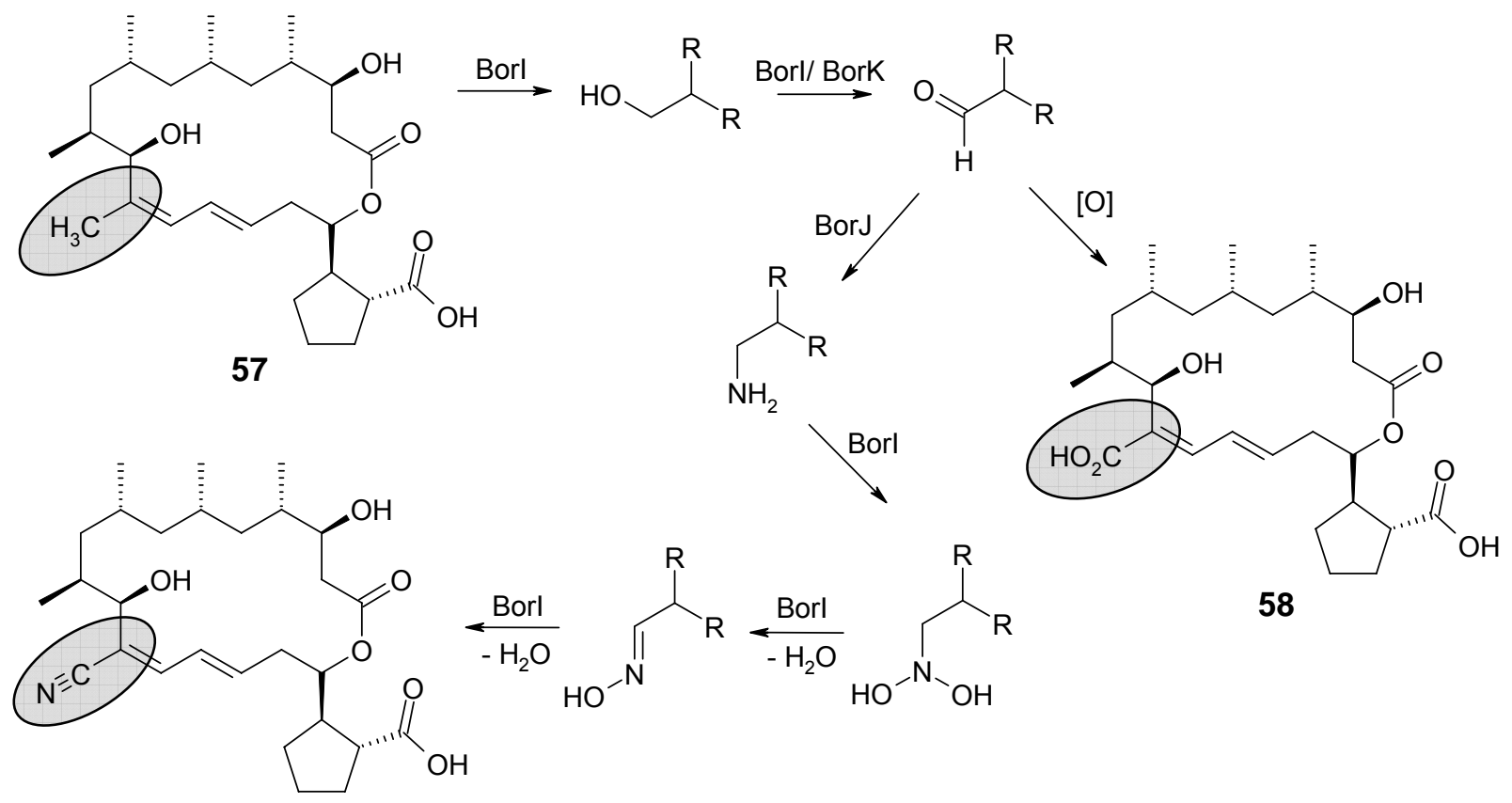
15

Abb. 30: Postulierter Mechanismus für die Biosynthese der Nitrilguppe von Borrelidin (15). 
Den Arbeitsgruppen von LEADLAY und SALAS gelang zudem die Zuordnung von insgesamt zehn Genen, deren Enzyme in die Biosynthese der Startereinheit involviert sind. Der Beweis wurde auch hier über knock-out Mutanten geführt, die nur unter Zusatz von transCyclopentan-(1R,2R)-dicarbonsäure (CPDA) in der Lage waren, Borrelidin (15) zu produzieren. Vorläufer der CPDA wurden bisher nicht gefunden, aus Gen-Homologien ergaben sich Hinweise, dass mit 5-Oxo-pent-3-en-1,2,5-tricarbonsäure ein Produkt des Tyrosinkatabolismus $^{194}$ ein Ausgangspunkt sein könnte. Der entscheidende Schritt dieses Biosyntheseweges ist die Cyclisierung einer Pentan-1,5-dicarbonsäure. Dieser Schritt wird demnach durch das borE-Enzym katalysiert, welches Ähnlichkeit zur Chloromuconat Cycloisomerase aus Bacillus subtilis zeigt. Cycloisomerasen gehören zur Superfamilie der Enolasen, welche zur Stabilisierung eines Anions in a-Position einer Carboxylgruppe befähigt sind. Der potentielle Mechanismus für die CPDA-Biosynthese ist in Abb. 35 (S. 99) dargestellt.

In der vorliegenden Arbeit sollten die genetischen Untersuchungen zur Biosynthese des Borrelidins (15) durch Fütterung isotopenmarkierter Verbindungen verifiziert werden. Aufgrund höherer Ausbeuten wurden die Fütterungsexperimente mit dem zweiten in der Abteilung ZEECK vorhandenen Borrelidin-Produzenten, Streptomyces sp. S 1495, durchgeführt. 


\subsubsection{Fermentationskurve}

Um Fütterungsexperimente optimal durchführen zu können, muss man den Zeitpunkt kennen, zu dem bei einer Kultivierung die Sekundärmetabolitenproduktion einsetzt. Nur so kann vermieden werden, dass ein gefütterter Vorläufer in den Primärstoffwechsel eingeht, was geringe Anreicherung im Sekundärstoff zur Folge hätte.

Zur Erstellung der Fermentationskurve wurden aus einem Kultivierungsansatz des Stammes S 1495 in Schüttelkulturen zu jeder 12. Stunde zwei Kolben entnommen, standardisiert aufgearbeitet und mit Hilfe der HPLC analysiert (s. Kap. B.4.1, S. 153). Durch Vergleich der Absorption der Proben bei $280 \mathrm{~nm}$ mit denen einer Eichkurve ergab sich die Ausbeute an Borrelidin (15), wie in Abb. 26 dargestellt. Die tatsächliche Ausbeute an 15 liegt aufgrund von Verlusten bei der Aufreinigung bei ca. $70 \%$.

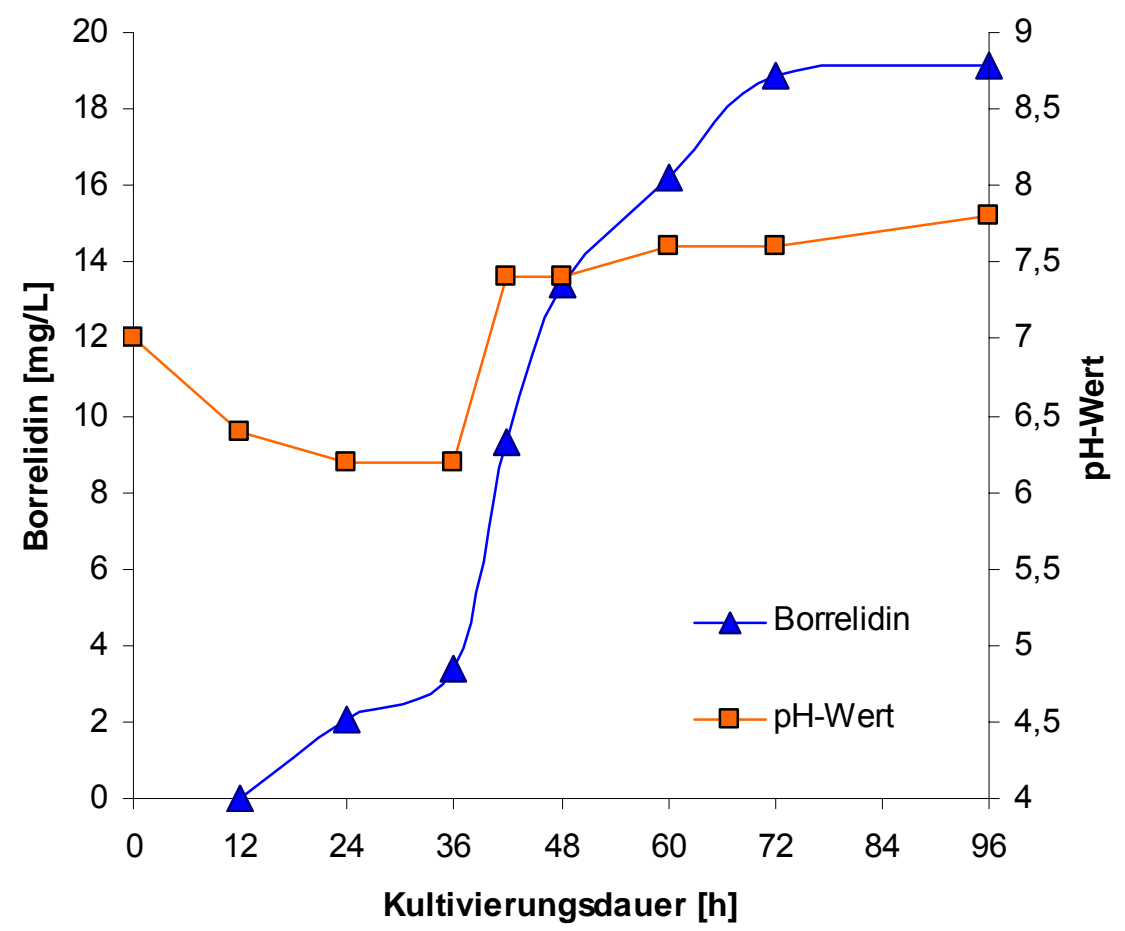

Abb. 31: Fermentationskurve von Borrelidin (15) aus Streptomyces sp. S 1495.

Die Kurve zeigt, dass die Biosynthese von 15 zwischen der 12. und 24. Stunde einsetzt und die Borrelidin-Konzentration nach der 36. Stunde stark ansteigt. Nach 72 Stunden ist das Produktionsmaximum erreicht, von der 96. bis zur 168. Stunde (nicht dargestellt) ist ein leichtes Absinken des Borrelidin-Gehaltes zu erkennen. Bemerkenswert ist die Beobachtung eines mit der Produktion von 15 nahezu zeitgleich einsetzenden pH-Anstiegs in der Kulturbrühe.

Die Fütterung markierter Verbindungen erfolgte dementsprechend zur 36., 42 . und 48. Stunde der Kultivierung. Die Kulturen ( $1 \mathrm{~L}$ verteilt auf 10 Schüttelkolben) wurden nach 60 Stunden aufgearbeitet. 


\subsubsection{Fütterung von $\left[1-{ }^{13} \mathrm{C}\right]$ Acetat}

Zur Überprüfung der in Kap. 4.2 vorgestellten Biosynthese von Borrelidin (15) wurde $\left[1-{ }^{13} \mathrm{C}\right]$ Acetat gefüttert. Nach der Aufarbeitung konnte mit $1.3 \mathrm{mg}$ vergleichsweise wenig (Standardausbeute ca. $15 \mathrm{mg}) 15$ isoliert werden. Ein ${ }^{13} \mathrm{C}-\mathrm{NMR}$ Spektrum der Substanz zeigte leichte Intensitätserhöhungen für C-1, C-13, C-15, C-3', C-5' sowie 1'-COOH. Unter Berücksichtigung der natürlichen Häufigkeit des ${ }^{13} \mathrm{C}$-Isotops lassen sich die Anreicherung und der spezifische Einbau nach

$$
\begin{gathered}
\text { Anreicherung }[\%]=1.1 \% \times \frac{\text { Intensität des Signals der markierten Verbindung }}{\text { Intensität des Signals der unmarkierten Verbindung }}-1.1 \% \\
\text { spezifischer Einbau }=\frac{\text { Anreicherung }[\%] \times 100}{\text { Anreicherung des Vorläufers [\%] }} \text { bestimmen. }
\end{gathered}
$$

Ein Einbau gilt als erfolgreich, wenn die Signalintensität verdoppelt und der spezifische Einbau somit größer eins ist. Für die $\left[1{ }^{13} \mathrm{C}\right]$ Acetat-Fütterung sind die Einbauraten in Tab. 13, bei Referenzierung auf den Mittelwert der C-4, C-6 und C-8 Methylgruppen wiedergegeben. Die Polyketid-Biosynthese lässt sich durch den Einbau an C-1, C-13 und C-15 bestätigen, auffällig ist jedoch, dass auch die Startereinheit Markierungen aufweist. Während 1'-COOH eine Anreicherung wie die Acetateinheiten des Rings zeigt, entspricht diese für C-3' und C-5' nur etwa der Hälfte. Diese Beobachtung könnte für ein symmetrisches Intermediat in der Biosynthese der Startereinheit sprechen. Eine Tabelle mit den Einbauraten aller Kohlenstoffe ist in Kap. B.4.2 (Tab. 21, S. 154) zu finden.

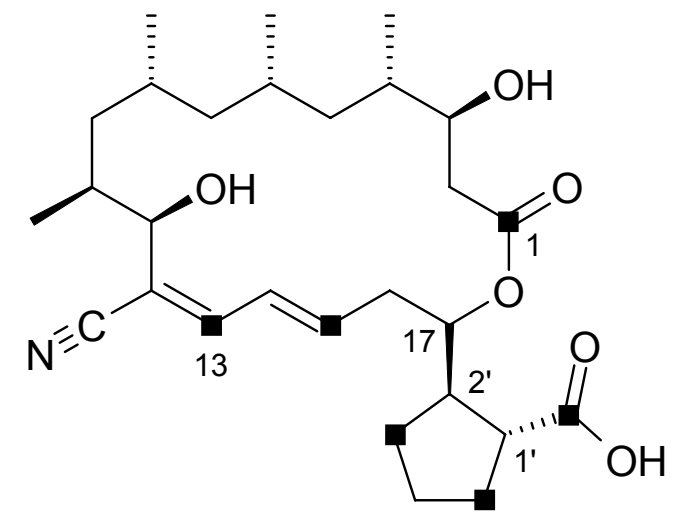

15

\begin{tabular}{ccc}
\hline & $\delta$ [ppm] & Spez. Einbau \\
\hline C-1 & 173.2 & 2.39 \\
C-13 & 145.5 & 2.39 \\
C-15 & 140.2 & 2.31 \\
C-3' & 30.5 & 1.22 \\
C-5' & 32.5 & 1.09 \\
1'-COOH & 180.7 & 2.13 \\
\hline
\end{tabular}

Tab. 13: Spezifische Einbauraten in Borrelidin (15) für markierte Kohlenstoffatome nach $\left[1-{ }^{13} \mathrm{C}\right]$ Acetat-Fütterung. 


\subsubsection{Fütterung von $\left[1-{ }^{13} \mathrm{C}\right]$ Propionat}

Nach Fütterung von $\left[1-{ }^{13} \mathrm{C}\right]$ Propionat unter Standardbedingungen konnten $6.6 \mathrm{mg}$ Borrelidin (15) isoliert werden. Ein ${ }^{13} \mathrm{C}-\mathrm{NMR}$-Spektrum zeigt mit 9.3-13.2 hohe spezifische Einbauraten für C-3, C-5, C-7, C-9 sowie C-11. Dieser Einbau bestätigt somit die Biosynthese des Rings wie von SALAS und LEADLAY vorausgesagt.

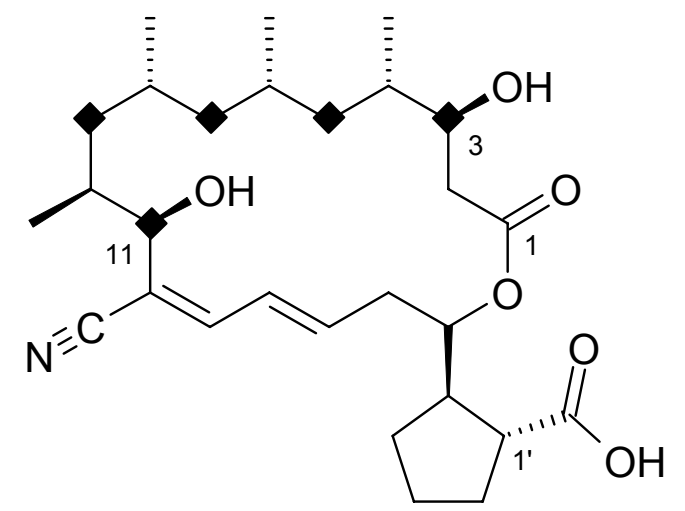

\begin{tabular}{ccc}
\hline & $\delta[\mathrm{ppm}]$ & Spez. Einbau \\
\hline C-3 & 72.9 & 9.45 \\
C-5 & 44.6 & 11.10 \\
C-7 & 49.4 & 10.11 \\
C-9 & 39.0 & 9.30 \\
C-11 & 73.0 & 13.19 \\
\hline
\end{tabular}

Tab. 14: Spezifische Einbauraten für markierte Kohlenstoffatome in Borrelidin (15) nach $\left[1-{ }^{13} \mathrm{C}\right]$ Propionat-Fütterung.

C)
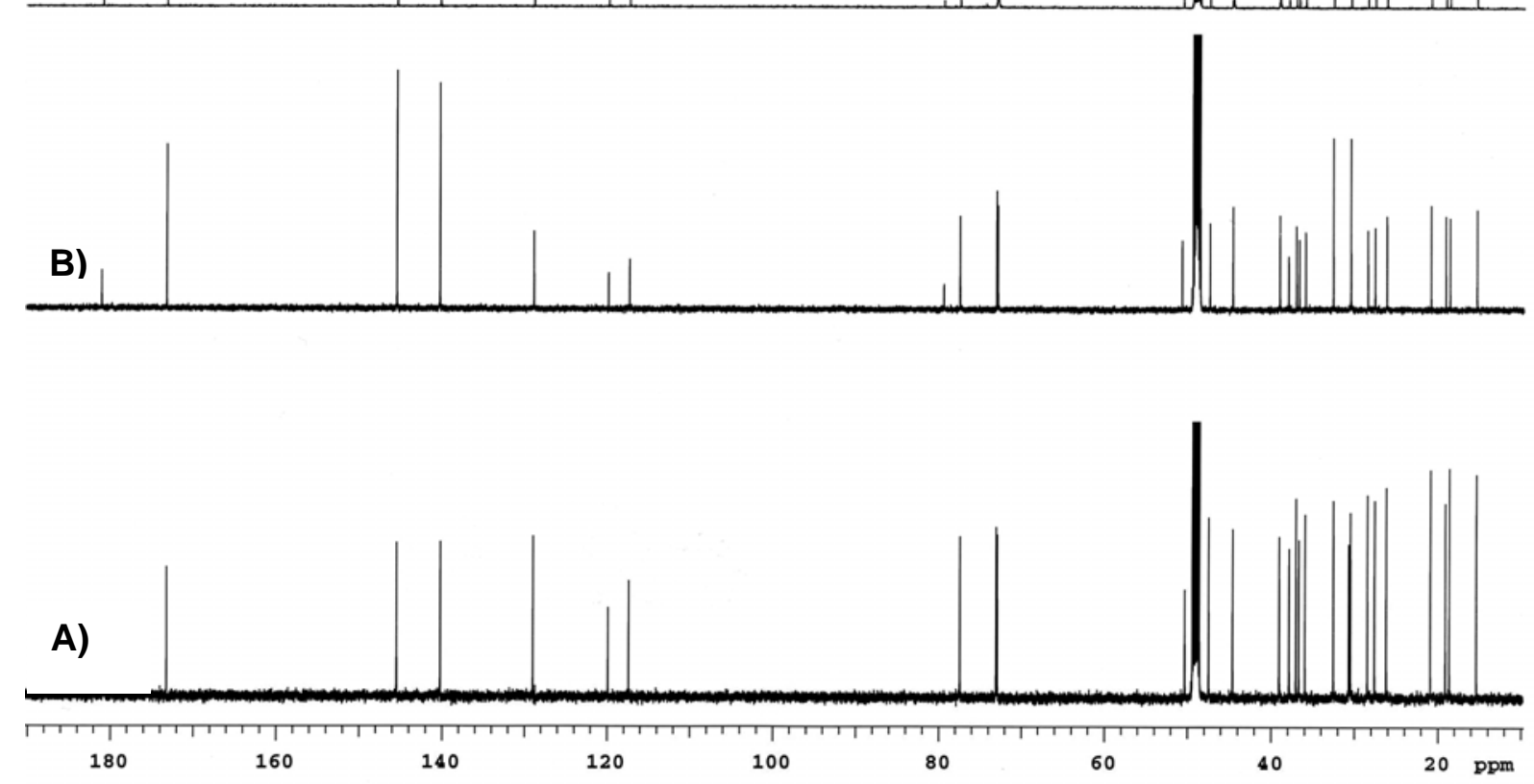

Abb. 32: ${ }^{13} \mathrm{C}-\mathrm{NMR}-S p e k t r e n\left(150.8 \mathrm{MHz}, \mathrm{CD}_{3} \mathrm{OD}\right)$ von 15 aus verschiedenen Fütterungen: A) Referenz, B) $\left[1-{ }^{13} \mathrm{C}\right]$ Acetat, C) $\left[1-{ }^{13} \mathrm{C}\right]$ Propionat. 


\subsubsection{Fütterung von $\left[1,2-{ }^{13} \mathrm{C}_{2}\right]$ Acetat}

Nach dem erfolgreichen Einbau von $\left[1-{ }^{13} \mathrm{C}\right]$ Acetat dient die Fütterung der doppelt markierten Substanz der Bestimmung intakter Acetateinheiten. Nach Fütterung von $\left[1,2-{ }^{13} \mathrm{C}\right]$ Acetat wurden $15 \mathrm{mg}$ Borrelidin (15) erhalten. Im ${ }^{13} \mathrm{C}$-Spektrum sind für alle Kohlenstoffatome Kopplungen zu erkennen, welche für Anreicherungen benachbarter Kohlenstoffatome sprechen. Hierbei muss zwischen statistischen Kopplungen und solchen eines intakten Einbaus des doppelt markierten Vorläufers unterschieden werde. Im ersten Fall entstehen verglichen zu einer intakten Acetateinheit Dubletts weit geringerer Intensität. Ein Beispiel hierfür ist die Propionateinheit C-5/ C-6/ 6- $\mathrm{CH}_{3}$. Die Methylgruppe zeigt eine Kopplung zu C-6, welches seinerseits noch zur Methylengruppe koppelt. Dieses Kopplungsmuster spricht aufgrund seiner Intensität für einen Einbau des Acetats in die Propionateinheiten nachdem es im Citratcyclus metabolisiert wurde.

Für alle Kohlenstoffatome der Startereinheit von 15 sind Kopplungen zu beobachten, welche leicht höhere Intensitäten als die statistischen Kopplungen der Propionateinheiten aufweisen. Für C-3', C-4' und C-5' ist hierbei der stärkste Einbau zu erkennen. Da C-3' und C-5' wie bei Fütterung von $\left[1-{ }^{13} \mathrm{C}\right]$ Acetat ca. die Hälfte an Intensitätserhöhung des Dubletts verglichen mit den Acetateinheiten des Rings aufweisen, ist ein symmetrisches Intermediat in der Biosynthese von 15 wahrscheinlich. Ob jedoch intakte Acetateinheiten (C-4'/C-5' bzw. C-4'/C-3') vorhanden sind, lässt sich, wie auch für die übrigen C-Atome des Cyclopentanrings, nicht abschließend beweisen (Abb. 34, S. 97).

\subsubsection{Fütterung von $\left[\mathrm{U}_{-}{ }^{13} \mathrm{C}_{3}\right] \mathrm{Glycerin}$}

Die Anreicherungen der C-3'/C-4'/C-5'-Kohlenstoffatome aus den in Kap. 4.2.2 und 4.2.4 beschriebenen Experimenten sprechen für ein symmetrisches Intermediat oder den Einbau von Acetat in Glycerin, welches dort bei Fütterung von $\left[1-{ }^{13} \mathrm{C}\right]$ Acetat eine $1,3-{ }^{13} \mathrm{C}_{2^{-}}$ Markierung hervorrufen würde. Die Fütterung von $\left[\mathrm{U}-{ }^{13} \mathrm{C}_{3}\right]$ Glycerin ergab einen Einbau in die Acetateinheiten des Rings wie auch in alle Kohlenstoffatome der Startereinheit. Bemerkenswert ist die Markierung von C-17 und C-2', welche hier deutlich ausgeprägter als bei Fütterung von $\left[1,2-{ }^{13} \mathrm{C}_{2}\right]$ Acetat ist. Das Scrambling war im Vergleich zur Fütterung von doppelt markiertem Acetat geringer ausgeprägt. Wie in Abb. 34 (S. 97) dargestellt, kann davon ausgegangen werden, dass $\mathrm{C}_{2}$-Einheiten aus Glycerin in die Startereinheit eingebaut werden (C-17/C-2' und C-1'/1'-COOH). Die Signale von C-3'/C-5' weisen im Vergleich mit den anderen Resonanzen eine leichte Verbreiterung auf. Ob dies für eine ${ }^{2} \mathrm{~J}$-Fernkopplung und somit für den Einbau einer intakten Glycerineinheit spricht konnte nicht geklärt werden. 


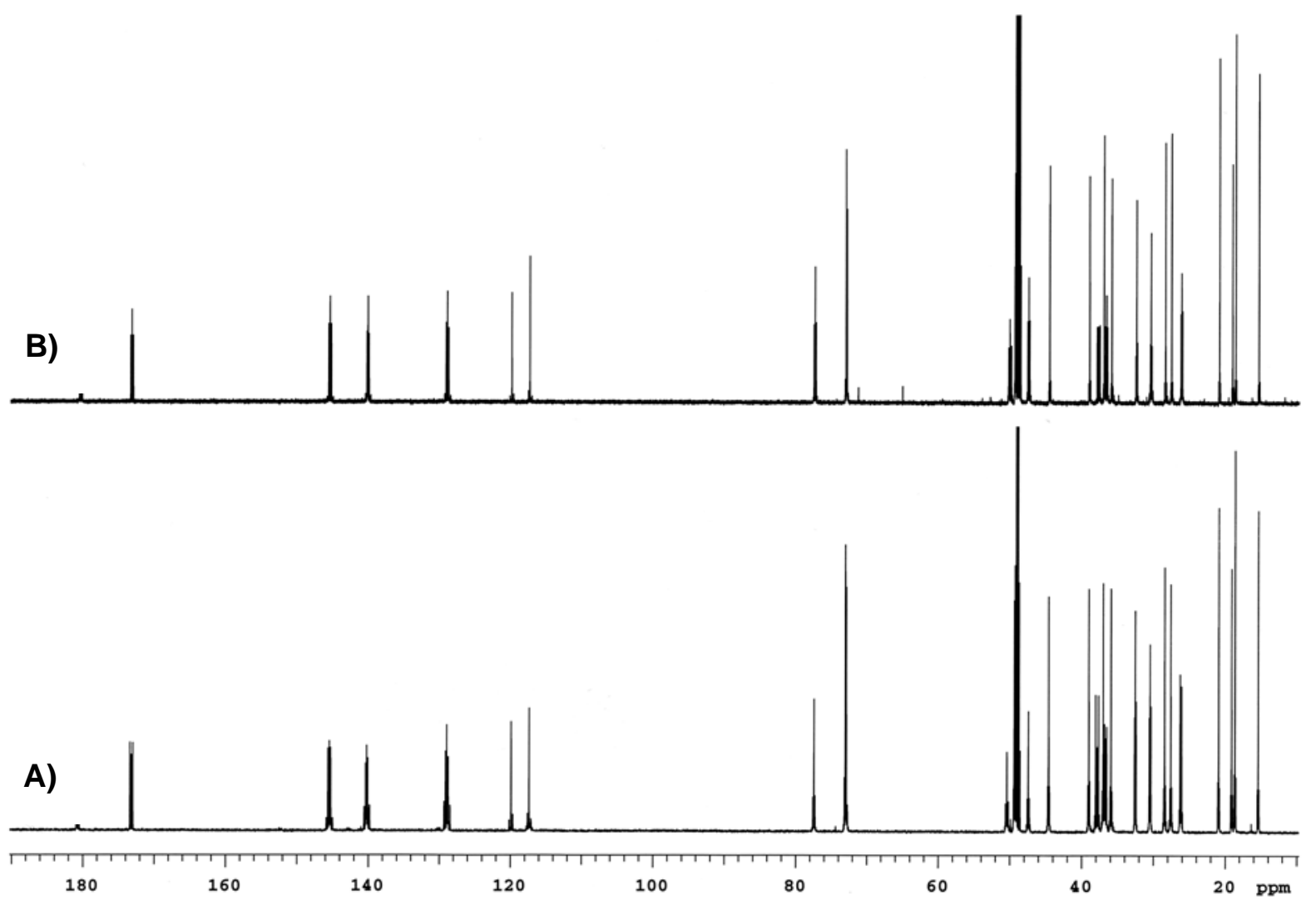

Abb. 33: ${ }^{13} \mathrm{C}-\mathrm{NMR}-S p e k t r e n$ von Borrelidin (15) $\left(150.8 \mathrm{MHz}, \mathrm{CDCl}_{3}\right.$ ): A) Fütterung von $\left[1,2-{ }^{13} \mathrm{C}_{2}\right]$ Acetat und B) $\left[\mathrm{U}-{ }^{13} \mathrm{C}_{3}\right]$ Glycerin.

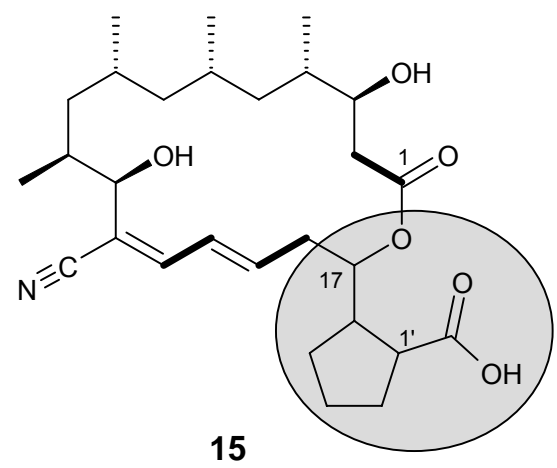

A)

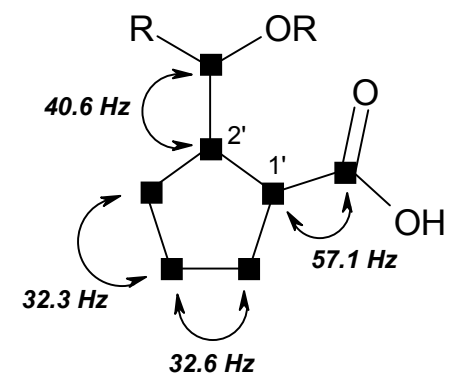

B)

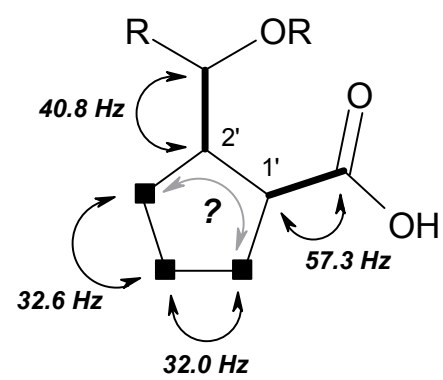

Abb. 34: Einbaumuster von $\left[1,2-{ }^{13} \mathrm{C}_{2}\right]$ Acetat $(A)$ und $\left[U-{ }^{13} C_{3}\right]$ Glycerin $(B)$ in 15. 


\subsubsection{Fütterung von $\left[2-{ }^{13} \mathrm{C}\right]$ Acetat}

Mit der Fütterung von $\left[2-{ }^{13} \mathrm{C}\right]$ Acetat sollte überprüft werden, ob die bisher nicht eindeutig bestimmten Kohlenstoffe der Dicarbonsäureeinheit (C-17, C-1', C-2' und C-4') aus Acetat hervorgehen. Das Kohlenstoffspektrum des so gewonnenen Borrelidins (15) zeigt ein starkes Scrambling mit statistischen Kopplungen für alle Kohlenstoffatome, was für eine schnelle Metabolisierung des Vorläufers im Citratcyclus spricht (für eine statistische Kopplung in einer Propionateinheit muss dieser zweimal durchlaufen werden). Aufgrund dieses Effektes ist eine Bestimmung der Anreicherung einzelner Atome nicht möglich. Eine Wiederholung des Experiments mit niedrigerer Konzentration des Vorläufers konnte bis zum Abschluss der Dissertation aus Zeitgründen nicht mehr durchgeführt werden.

\subsubsection{Fütterung von $\left[2,3,5,6-d_{4}\right]-,\left[1-{ }^{13} C\right]$ Tyrosin und $d_{3}$-Acetat}

Um die Tyrosinhypothese für die Bildung der CPDA (59) zu überprüfen, wurden in weiteren Experimenten $\left[2,3,5,6-d_{4}\right]-$ und $\left[1-{ }^{13} \mathrm{C}\right]$ Tyrosin gefüttert. Weiterhin wurde eine Kultivierung unter Zugabe von $d_{3}$-Acetat durchgeführt, um den Einbau von Acetat in 59 verifizieren zu können. Bei der Fütterung von $\left[1-{ }^{13} \mathrm{C}\right]$ Tyrosin zeigt das isolierte 15 keine Markierung (wie auch beim Tyrosinkatabolismus zu erwarten). Unter Verwendung der deuterierten Vorläufer zeigen die Protonenspektren von 15 bei keinem Signal eine Intensitätserniedrigung, was bei einem erfolgreichen Einbau zu erwarten gewesen wäre. Dieses Ergebnis ist jedoch nicht hinreichend aussagekräftig, weil beim pH-Wert der Kulturlösung am Ende des Experiments $(\mathrm{pH}=7.8)$ ein Protonenaustausch möglich ist.

\subsubsection{Diskussion der Biosynthese}

Die Ergebnisse dieser Arbeit bestätigen die von LEADLAY und SALAS nach genetischen Experimenten vorausgesagte Biosynthese des Makrolidrings von 15. Der von den gleichen Autoren postulierte Mechanismus für die Biosynthese der trans-Cyclopentan-(1R,2R)dicarbonsäure (CPDA, 59) muss jedoch nach den vorliegenden Ergebnissen in Frage gestellt werden. Wie in Abb. 35 (S. 99) gezeigt, kann Acetat über den Citratcyclus über Bernsteinsäure (60) und Phosphoenolpyruvat (61) in den Shikimatweg [Shikimisäure (62), Chorisminsäure (63)] eingebracht werden. Dies führt zu einem Einbau von $\left[1-{ }^{13} \mathrm{C}\right]$ Acetat in Tyrosin (64) an C-1. Die anschließende Decarboxylierung zu 4-Hydroxyphenylessigsäure (65) hätte einen Totalverlust der Markierung zur Folge. Die zweite Möglichkeit eines Einbaus von Acetat kann hypothetisch über eine Markierung von Erythrose (66) erfolgen. Hierbei muss Acetat über mehrere Stufen in Glycerin überführt werden, welches anschließend über 
den Pentosephosphatweg eine Markierung in 15 hervorrufen könnte (nicht dargestellt). Das Markierungsmuster der Startereinheit CPDA (59) von 15 stimmt hiermit jedoch nicht überein, zudem müsste der spezifische Einbau in 1'- $\mathrm{COOH}$ in diesem Fall wesentlich niedriger als in den Acetateinheiten des Makrolidrings sein. Mit den vorliegenden Daten ist eine Aussage über den genauen Mechanismus der Biosynthese von 59 nicht möglich.

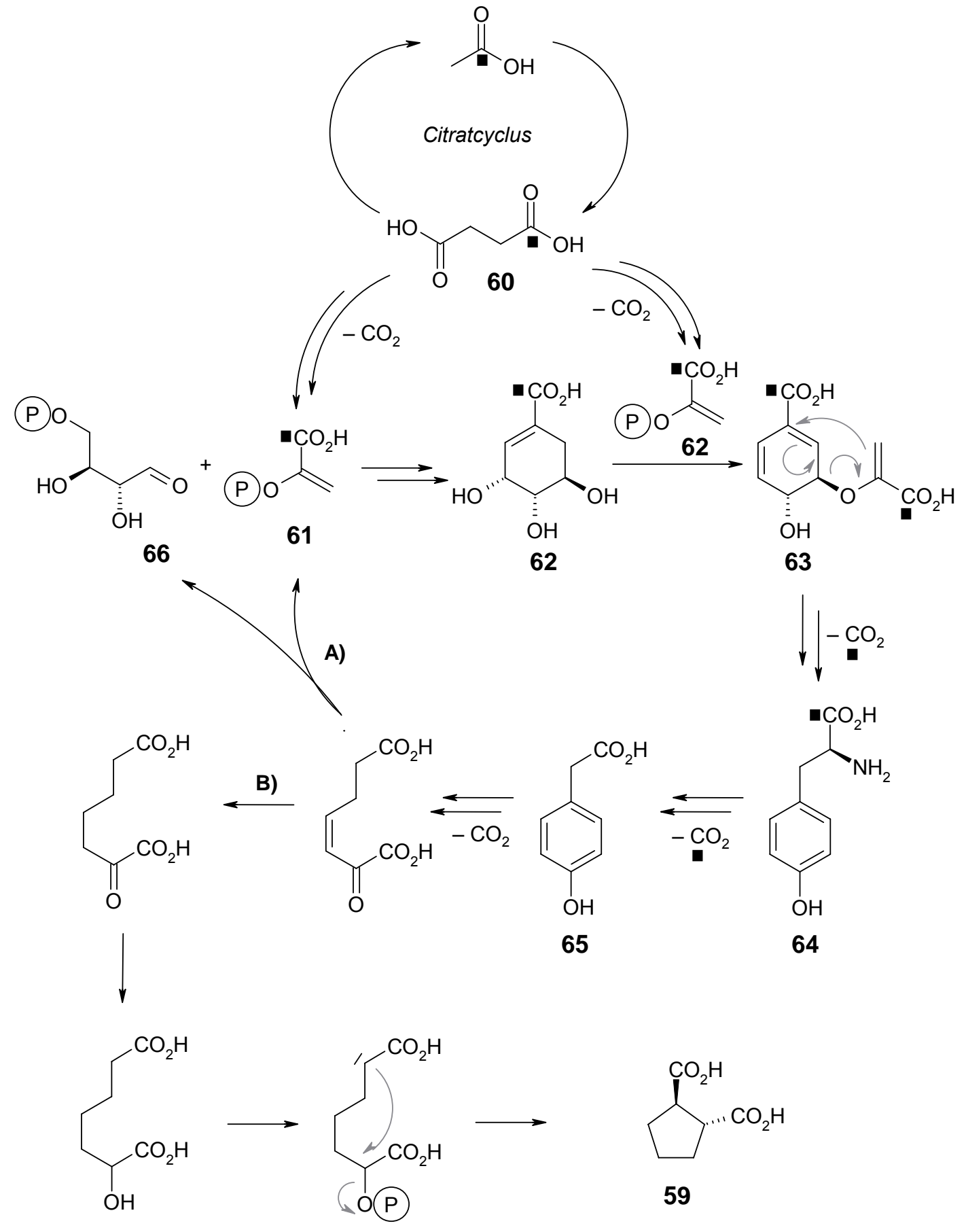

Abb. 35: Der Biosynthesemechanismus für die trans-Cyclopentan-(1R,2R)-dicarbonsäure (59) nach LEADLAY und SALAS ${ }^{186}$ zeigt, dass kein Einbau von $\left[1-{ }^{13} \mathrm{C}\right]$ Acetat in die Startereinheit zu erwarten wäre [A] Tyrosinkatabolismus in E. coli ATCC 11105, B) Biosynthese der Startereinheit in Streptomyces parvulus Tü 4055]. 


\subsection{Vorläufer-dirigierte Biosynthese am Borrelidin}

\subsubsection{Allgemeines}

Während für die Kettenverlängerungsschritte in der Biosynthese von Polyketiden mit Acetat und Propionat lediglich zwei verschiedene Bausteine zur Verfügung stehen, existiert eine wesentlich größere Substratbreite zu Beginn der Biosynthese. Einige unter vielen Beispielen ungewöhnlicher Startereinheiten sind Isovaleriat im PKS/NRPS-Hybrid ${ }^{195}$ Myxothiazol ${ }^{196}$, Cyclohexancarboxylat in Asukamycin ${ }^{197}$ und Phoslactomycin $\mathrm{B}^{198}$ oder Benzoat in Soraphen $A^{199}$. Wie in den vorangehenden Kapiteln beschrieben gehört auch Borrelidin (15), mit der als Startereinheit einmaligen trans-1,2-Cyclopentandicarbonsäure (59) in die Gruppe von Polyketiden, deren Biosynthese mit einem ungewöhnlichen Baustein beginnt.

Bei der Vorläufer-dirigierten Biosynthese von Polyketiden lassen sich ungewöhnliche Startereinheiten nutzen, die anstelle der natürlichen in die Substanz eingebaut werden. Im Vergleich mit der Vorläufer-dirigierten Biosynthese an Peptiden (s. Kap. 2.2, S. 17) muss die zugefütterte Einheit von einer größeren Zahl an Enzymen toleriert werden. So ist eine Aktivierung von freien Carbonsäuren durch eine Coenzym A-Ligase nötig, weiterhin kann eine geringe Membranpermeabilität verhindern, dass der Vorläufer den Ort der Biosynthese überhaupt erreicht. ${ }^{81}$ Trotzdem gelingt in einer Vielzahl von Fällen die Derivatisierung von Naturstoffen durch die Zufütterung potentieller Startereinheiten. So konnten durch Fütterungsexperimente mit dem Produzenten des Avermectins (67) (Streptomyces avermitilis MA 5502) die stark antihelmintisch und insektizid wirksamen 2-Pentyl- und 2-Hexylavermectine ${ }^{200}$ gewonnen werden. ${ }^{201}$ Eine noch breitere Substrattoleranz der loading domain der Avermectin-PKS wurde durch Verwendung der Mutasynthese verifiziert, wobei die Produktion von insgesamt 140 neuen Avermectinen mit 35 verschiedenen Startereinheiten gelang. ${ }^{202}$ Neben offenkettigen werden auch cyclische (aliphatische und olefinische) Vorläufer, welche teilweise Heteroatome tragen, eingebaut. ${ }^{203}$ Eine ähnlich große Substrattoleranz konnte auch für die loading domain der Erythromycin-PKS nachgewiesen werden. ${ }^{204}$

Da von LEADLAY und SALAS ${ }^{186}$ für die Borrelidin loading domain große Ähnlichkeiten zu denen von 67 und des Erythromycins gezeigt werden konnten, sollte im Rahmen dieser Arbeit die Substrattoleranz von Streptomycessp.S1495 gegenüber unnatürlichen Startereinheiten getestet werden. 
<smiles>[R]CCCC(C)C(=O)O</smiles>

\subsubsection{Vorläufer-dirigierte Biosynthese an Streptomyces sp. S 1495}

Die Kultivierungen wurden in $2 \times 100 \mathrm{~mL}$ Schüttelkulturen unter Standardbedingungen (s. Kap. B.4.3, S. 155) durchgeführt. Für die Fütterungen wurden die Vorläufer in sterilem Wasser unter Zusatz von Natronlauge gelöst und zur 36., 42. und 48. Stunde, bis zu einer Endkonzentration von $2 \mathrm{mmol} / \mathrm{L}$ zugesetzt. Nach 60 Stunden wurden die Kulturbrühen ohne Trennung in Kulturfiltrat und Mycel aufgearbeitet und HPLC-MS analytisch untersucht.

Bei den Fütterungsversuchen mit insgesamt 36 Vorläufern wurden neben Cyclohexancarbonsäure verschiedene Benzoesäuren, Stickstoff-, Sauerstoff- und Schwefelheterocyclen, sowie offenkettige Substanzen gefüttert (s. Tab. 15, S. 102). Die Untersuchung an der HPLC-MS erbrachte keine Hinweise auf neue Metaboliten mit der jeweils erwarteten Masse, wodurch ein Einbau in das Borrelidin (15) bewiesen wäre. Zusätzlich wurden die Extrakte HPLC analytisch untersucht, um auch neue Metaboliten mit schlechten lonisierungseigenschaften detektieren zu können. Einzig bei der Fütterung von 4-Amino-2-hydroxybenzoesäure war ein neuer Metabolit nachweisbar. Die Substanz besitzt ein ähnliches UV-Spektrum wie der Vorläufer und konnte durch eine Masse von $\mathrm{m} / \mathrm{z}=166$ $[\mathrm{M}-\mathrm{H}]^{-}$sowie ein Protonenspektrum als 4-Amino-2-hydroxybenzoesäuremethylester identifiziert werden. 


\begin{tabular}{|c|c|c|c|}
\hline Pipecolinsäure & $\begin{array}{l}\text { 2,6-Pyridinium- } \\
\text { dicarbonsäureoxid }\end{array}$ & $\begin{array}{l}\text { 4-Amino-2-hydroxy- } \\
\text { benzoesäure }\end{array}$ & $\begin{array}{l}\text { 3-Amino-2-methyl- } \\
\text { benzoesäure }\end{array}$ \\
\hline 2-Picolinsäure & Adipinsäure & $\begin{array}{l}\text { 1,3,5-Benzol- } \\
\text { tricarbonsäure }\end{array}$ & $\begin{array}{l}\text { 3-Amino-4-methyl- } \\
\text { benzoesäure }\end{array}$ \\
\hline $\begin{array}{l}\text { 2-Furan- } \\
\text { carbonsäure }\end{array}$ & trans-Aconitsäure & $\begin{array}{c}\text { 2-Brom- } \\
\text { benzoeäure }\end{array}$ & $\begin{array}{l}\text { 3,5-Diamino- } \\
\text { benzoesäure }\end{array}$ \\
\hline $\begin{array}{c}\text { 3-Furan- } \\
\text { carbonsäure }\end{array}$ & $\begin{array}{l}\text { Octan- } \\
\text { dicarbonsäure }\end{array}$ & Phthalsäure & $\begin{array}{l}\text { 3,4-Diamino- } \\
\text { benzoesäure }\end{array}$ \\
\hline $\begin{array}{l}\text { 2-Thiophen- } \\
\text { carbonsäure }\end{array}$ & Malonsäure & Benzoesäure & $\begin{array}{l}\text { 5-Amino-2-nitro- } \\
\text { benzoesäure }\end{array}$ \\
\hline $\begin{array}{l}\text { 2,6-Pyridin- } \\
\text { dicarbonsäure }\end{array}$ & $\begin{array}{c}\text { 2,4- } \\
\text { Dihydroxypyrimidin- } \\
\text { 6-carbonsäure }\end{array}$ & $\begin{array}{l}\text { 4-Amino- } \\
\text { benzoesäure }\end{array}$ & $\begin{array}{l}\text { 5-Amino-2-hydroxy- } \\
\text { benzoesäure }\end{array}$ \\
\hline $\begin{array}{l}\text { 2-Tetra- } \\
\text { hydrofuran- } \\
\text { carbonsäure }\end{array}$ & $\begin{array}{l}\text { Cyclohexan- } \\
\text { carbonsäure }\end{array}$ & $\begin{array}{l}\text { 3-Amino- } \\
\text { benzoesäure }\end{array}$ & $\begin{array}{l}\text { 3-Amino-4-hydroxy- } \\
\text { benzoesäure }\end{array}$ \\
\hline Salicylsäure & $\begin{array}{l}\text { 4-Amino-2-hydroxy- } \\
\text { benzoesäure }\end{array}$ & $\begin{array}{l}\text { 5-Amino- } \\
\text { isophthalsäure }\end{array}$ & $\begin{array}{l}\text { 4-Fluor-3-nitro- } \\
\text { benzoesäure }\end{array}$ \\
\hline Acetylsalicylsäure & $\begin{array}{l}\text { 3-Amino-4- } \\
\text { chlorbenzoesäure }\end{array}$ & $\begin{array}{c}\text { 2-Methyl-3,5- } \\
\text { dinitrobenzoesäure }\end{array}$ & $\begin{array}{l}\text { 4-Hydroxy-3-nitro- } \\
\text { benzoesäure }\end{array}$ \\
\hline
\end{tabular}

Tab. 15: Bei der Vorläufer-dirigierten Biosynthese an Streptomyces sp. S 1495 gefütterte Vorläufer.

\subsubsection{Diskussion}

Obwohl eine große Substrattoleranz der Borrelidin-PKS loading domain postuliert wurde, tauchten bei den Fütterungen mit verschiedenen Carbonsäuren (s. Tab. 15) keine neuen Metaboliten auf. Ob die mangelnde Spezifität des Enzyms bei der Bindung der Startereinheit für den Misserfolg verantwortlich ist, muss offen bleiben. Dass die gefütterten Carbonsäuren nicht eingebaut wurden, könnte in zu geringer Membrangängigkeit oder mangelnder Substratflexibilität der Coenzym A-Ligase begründet sein. Dieses Problem kann eventuell durch eine Aktivierung der Substrate als $\mathrm{N}$-Acetylcysteaminthioester umgangen werden. ${ }^{205}$ 


\section{Zusammenfassung der Ergebnisse}

\subsection{Untersuchungen am Hormaomycin-Produzenten Streptomyces griseoflavus (Stamm W 384)}

Produktionsoptimierung

Durch Fütterung von 2-Pyrrolcarbonsäure zu $1 \mathrm{~L}-$ Kulturen von Streptomyces griseoflavus (Stamm W 384) wurde die Ausbeute an Hormaomycin (16) von 15 bis auf $45 \mathrm{mg} / \mathrm{L}$ gesteigert. Ein Scale-up unter Verwendung von größeren Fermentern $(5-50 \mathrm{~L})$ war nicht möglich.

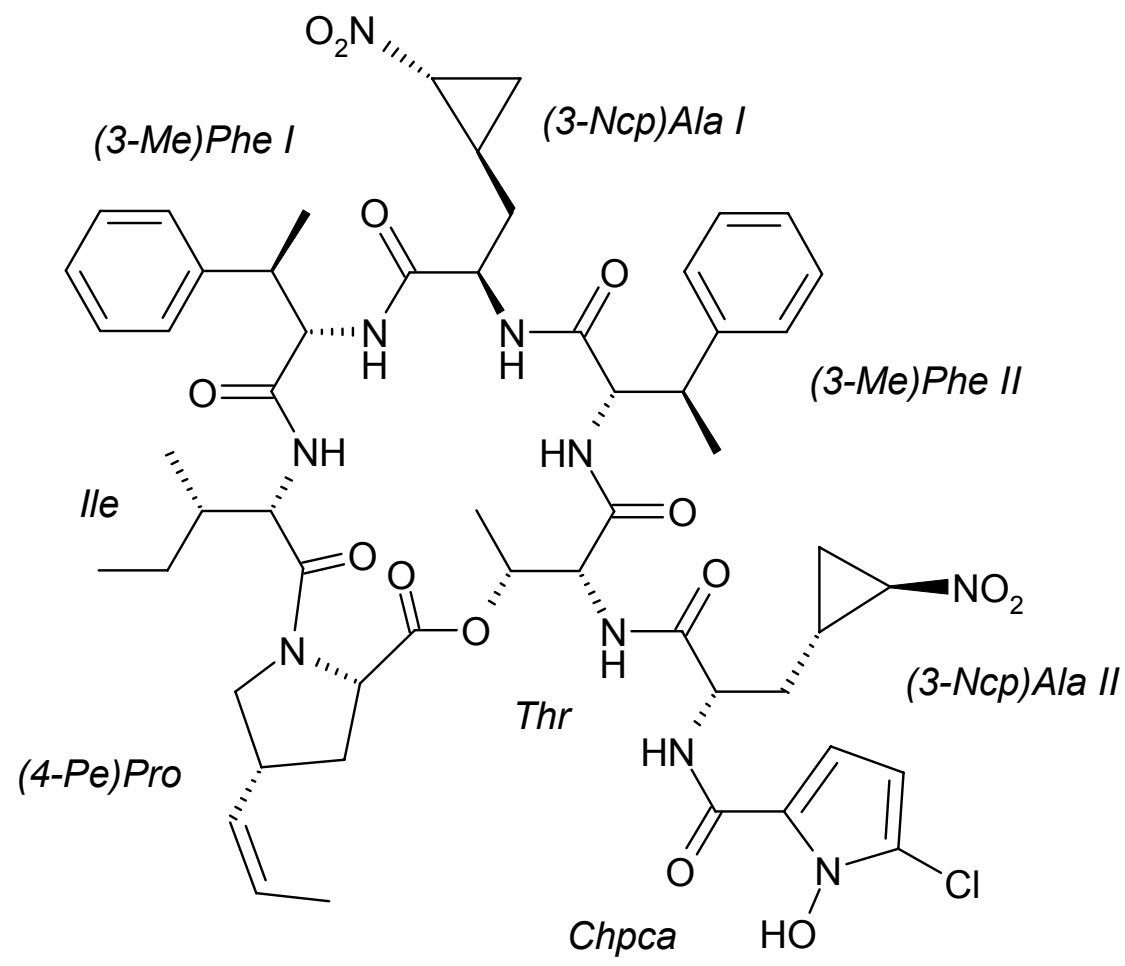

16

Vorläufer-dirigierte Biosynthese

Variation der 3-(2'-Nitrocyclopropyl)alanin [(3-Ncp)Ala]-Einheiten

1. Nach Fütterung von L-5-Nitronorvalin und rac-5-Nitronorvalin konnten die neuen Hormaomycine $D_{1-3}(21 a-c)$ isoliert werden. Die Ausbeute an isolierten Derivaten war nicht proportional zur Konzentration des gefütterten Vorläufers. Die Derivate 21a-c enthalten D-5-Nitronorvalin in der Ringeinheit. Durch Fütterung enantiomerenreinen D-5-Nitronorvalins sank die Ausbeute von 16 auf 5 mg/L, ein Einbau fand nicht statt.

2. Der erwartete Einbau von 2-(2'-Nitrocyclopropyl)glycin [(2-Ncp)Gly] anstelle von (3-Ncp)Ala in $\mathbf{1 6}$ war nach Fütterung von L-Ornithin im Rohextrakt der Kulturlösung durch 
ESI-MS nachweisbar. Eine Isolierung des neuen Derivates gelang wegen seines geringen Gehalts nicht.

3. Die Fütterung von (2-Ncp)Gly ergab keinen Einbau der intakten Aminosäure in das Peptidlacton. Stattdessen enstanden die Derivate 21a-c. Für die Ringöffnung des (2-Ncp)Gly zum 5-Nitronorvalin konnte ein Mechanismus postuliert werden.

4. Bei Fermentationen unter Zugabe von L-6-Nitronorleucin und rac-6-Nitronorleucin entstanden die neuen Hormaomycine $E_{1-3}(26 a-c)$. Durch HR-ESI-MS ${ }^{n}$ konnte ein Fragmentierungsschema gewonnen werden, was die aus NMR-Spektren abgeleiteten Strukturen zusätzlich stützt. Die Fütterung des D-Epimers der nichtproteinogenen Aminosäure führt neben einem Absinken der Hormaomycin-Produktion (3 mg/L) zu keinem der neuen Derivate.

5. L-5-Nitro-4-thianorvalin und L-ortho-Nitrophenylalanin werden von der HormaomycinSynthetase nicht akzeptiert. In beiden Fütterungsexperimenten sinkt die Ausbeute des Naturstoffs 16 unter die der Standardfermentation ohne Zugaben.

\section{Variation der $\beta$-Methylphenylalanin [( $\beta M e)$ Phe]-Einheiten}

1. Nach Fütterung von ortho- und meta-Fluorphenylalanin konnte Hormaomycin (16) im Gemisch mit den fluorierten Hormaomycinen $F_{1-3}(30 a-c)$ bzw. $G_{1-3}(31 a-c)$ isoliert werden.

2. Durch Zugabe von para-Fluorphenylalanin zu Streptomyces griseoflavus (Stamm W 384) konnten neben den mono-Fluorhormaomycinen $\mathrm{H}_{1,2} \quad(\mathbf{3 2 a}, \mathbf{b})$ die Monodesmethylhormaomycine $\mathrm{J}_{1,2}(\mathbf{3} \mathbf{3} \mathbf{a}, \mathbf{b})$ gewonnen werden.

3. Fütterungen von para-Chlor- und para-Bromphenylalanin ergaben neben $\mathbf{3 3} \mathbf{a}, \mathbf{b}$ das Didesmethylhormaomycin $J_{3}(33 c)$ in unterschiedlichen Ausbeuten. Während bei Zusatz von para-Nitrophenylalanin $\mathbf{3 3 a}, \mathbf{b}$ zu beobachten waren, führte die Fütterung von Tyrosin ausschließlich zur Produktion des Naturstoffs 16.

4. Weiterhin konnte gezeigt werden, dass die ( $\beta M e)$ Phe-Domänen der Hormaomycin-NRPS Phenylglycin nicht als Substrat akzeptieren.

Variation der 5-Chlor-N-hydroxypyrrol-2-carbonsäure (Chpca)-Einheit

1. Nach Fütterungen von Furan-, Tetrahydrofuran-, Pyrrol- und Thiophen-2-carbonsäure sowie Picolin-, Pipecolin- und 3-Chlorsalicylsäure konnte immer nur 16 gewonnen werden.

2. Die Zugabe von Pyrrol-2-carbonsäure führte zu einem starken Produktionsanstieg von 16. Bei Zusatz von $2 \mathrm{mmol} / \mathrm{L}$ betrug die Ausbeute bis zu $45 \mathrm{mg} / \mathrm{L}$ (ca. $300 \%$ ), bei $1 \mathrm{mmol} / \mathrm{L}$ $21 \mathrm{mg} / \mathrm{L}$ (ca. $150 \%$ ). Eine Erhöhung der Konzentration bis zu $8 \mathrm{mmol} / \mathrm{L}$ ergab keinen weiteren Produktionsanstieg. 
Die Biosynthese des Hormaomycins

1. Die Ergebnisse der Vorläufer-dirigierten Biosynthese zeigen:

a) 6-Nitronorleucin als Intermediat sowie eine externe Epimerase können für die Biosynthese von (3-Ncp)Ala ausgeschlossen werden;

b) die Methyltransferase in der $(\beta \mathrm{Me})$ Phe-Biosynthese kann durch parahalogenierte und nitrierte Phenylalanine inhibiert werden;

c) Pyrrol-2-carbonsäure ist ein Intermediat der Chpca-Biosynthese. Ihre Verfügbarkeit bestimmt die Ausbeute an 16.

2. Beim HPLC-MS-Screening von Extrakten der Mutanten E. coli pKZ72 und pKZ73, in welchen die Biosyntesegene hrmS und hrml, hrmJ exprimiert wurden, konnten weder $(\beta \mathrm{Me})$ Phe noch (3-Ncp)Ala nachgewiesen werden. Somit fehlt weiterhin der endgültige Beweis, dass der Hormaomycin-Biosynthesegencluster gefunden wurde (AK PIEL, Universität Bonn).

\section{Die Struktur des Hormaomycins}

1. Nach der Gewinnung von Hormaomycin (16) in gut aufgereinigter Form gelang der Arbeitsgruppe SHELDRICK die Kristallisation und eine Röntgenstrukturanalyse, der ein dimerer Metall-Komplex des Naturstoffs zugrunde liegt.

2. Durch eine ICP-MS-Untersuchung konnte gezeigt werden, dass im dimeren 16 mit Natrium, Calcium und Zink ein Gemisch von Metallionen enthalten ist.

3. Durch Ionenaustauschchromatographie und nachfolgende Beladung von 16 mit verschiedenen Metallionen wurden Konformationsänderungen in $\mathbf{1 6}$ erreicht und somit der Grund für die Unterschiede in ${ }^{1} \mathrm{H}-\mathrm{NMR}$-Spektren verschiedener Fermentationsansätze sowie zwischen Syntheseprodukt und Naturstoff aufgeklärt.

\section{Biologische Aktivitäten der Hormaomycinderivate}

1. Die antimikrobiellen Aktivitäten aller Derivate wurden ermittelt und entsprechen gegen Arthrobacter sp. mit 60-100\% der des Naturstoffs. Für Hormaomycin $\mathrm{D}_{2}$ (21b) konnte zusätzlich eine hohe Aktivität gegen Candida albicans nachgewiesen werden, weder 16 noch andere Derivate besitzen antimykotische Aktivitäten.

2. Für alle Derivate konnten gegen Plasmodium falciparum $\left(\mathrm{IC}_{50}=0.08-1.66 \mu \mathrm{g} / \mathrm{mL}\right)$ und Leishmania donovanii $\left(\mathrm{IC}_{50}=0.13-0.71 \mu \mathrm{g} / \mathrm{mL}\right)$ sehr gute, sowie gegen Trypanosoma sp. $\left(\mathrm{IC}_{50}=5.5-17.7 \mu \mathrm{g} / \mathrm{mL}\right)$ moderate in vitro Aktivitäten nachgewiesen werden. Die therapeutische Breite der Peptidlactone gegen Plasmodium falciparum ist aufgrund geringer Cytotoxizität als gut einzustufen. Für 16 verliefen Tests zur in vivo Aktivität gegen Plasmodium berghei negativ. Erkenntnisse zu Struktur-Wirkungsbeziehungen wurden diskutiert. 
3. Die Tests der mit Metallionen angereicherten Hormaomycine zeigen, dass Aktivität und Cytotoxizität vom gebundenen lon abhängen, was für keinen antiparasitären Wirkstoff literaturbekannt ist.

\subsection{Strukturaufklärung von Sekundärmetaboliten}

Sieben Stämme aus Portugal und der Mongolei wurden einem chemischen Screening nach dem OSMAC-Ansatz unterzogen und zwei zur weiteren Bearbeitung ausgewählt.

1. Aus dem Kulturfiltrat- und Mycelextrakt von Actinomyces sp. Stamm P4 konnte der bekannte Metabolit Chartreusin (44) in guten Ausbeuten isoliert werden.

2. Von den drei im chemischen Screening von Actinomyces sp. Stamm M4-1 aufgefallenen Substanzen erwiesen sich mit Genistein (45) und Daidzein (12a) zwei als Nährmedienbestandteile, der dritte Metabolit ist das ebenfalls bekannte Borrelidin (15).

Die als Reinsubstanzen vorliegenden Metaboliten im Kooperationsprojekt mit PROF. DR. H.-P. FIEDLER (Mikrobiologisches Institut, Universität Tübingen) aus Streptomyces sp. Stamm Tü 6319 wurden in ihrer Struktur aufgeklärt. Für die aus Streptomyces sp. Stamm Tü 2561 isolierte Substanz 2561-1 (57) konnten Partialstrukturen ermittelt werden, die auf ein neues, ungewöhnlich großes Makrolid hinweisen. Die Metaboliten wurden aus Kultivierungsansätzen von jeweils $10 \mathrm{~L}$ isoliert.

Aus dem Kulturfiltratextrakt von Stamm Tü 6319 konnten die bekannten Metabolite Germicidin A (49), Germicidin B (50), Ferulasäure, SEK4b (47) und anhydroSEK4b (48) in ihrer Struktur aufgeklärt werden. Weiterhin konnte mit Fogacin (46) ein neues Octaketid isoliert und in seiner Struktur aufgeklärt werden. Die Metaboliten 47 und 48 sind als Shuntmetaboliten aus Actinorhodin-Deletionsmutanten bekannt und konnten erstmals in einem Wildstamm nachgewiesen werden. Ihre und die vermutliche Biosynthese von 46 werden vergleichend diskutiert. Für 48 ließ sich eine moderate Aktivität gegen Bacillus subtitlis DSM 10 und Streptomyces viridochromogenes Tü 57 nachweisen.<smiles>CC(C)CC(C)C[C@@H](C)C[C@@H](C)C[C@@H](C)C(O)CC(=O)OC(C/C=C/C=C(/C#N)C(O)C1CCC[C@@H]1C(=O)O)C1CCC[C@@H]1C</smiles><smiles>C[C@H]1OC(CC(=O)O)Cc2cc3c(c(O)c21)C(=O)CCC3O</smiles>

46 


\subsection{Untersuchungen am Borrelidin-Produzenten Streptomyces sp. S 1495}

1. Die bisherigen molekulargenetischen Untersuchungen zur Biosynthese von Borrelidin (15) wurden diskutiert. Zur Verifizierung der Befunde wurden Fütterungen mit isotopenmarkierten Vorläufern $\quad\left(\left[1-{ }^{13} \mathrm{C}\right]-, \quad\left[2-{ }^{13} \mathrm{C}\right]-, \quad\left[1,2-{ }^{13} \mathrm{C}_{2}\right]-\right.$ und $\mathrm{d}_{3}$-Acetat; $\left[1-{ }^{13} \mathrm{C}\right]$ Propionat; $\left[\mathrm{U}-{ }^{13} \mathrm{C}_{3}\right]$ Glycerin; $\left[1-{ }^{13} \mathrm{C}\right]$ - und 2,3,5,6- $\mathrm{d}_{4}$-Tyrosin) durchgeführt.

2. Während sich die von LEADLAY und SALAS postulierte Biosynthese des BorrelidinMakrolidrings durch die Fütterungen bestätigen ließ, gibt es keine Hinweise darauf, dass die Bildung der trans-Cyclopentan-(1R,2R)-dicarbonsäure (59) von Tyrosin ausgeht. Der erkennbare Einbau von Acetat und Glycerin spricht für einen Aufbau aus Bausteinen des Kohlenhydratpools, bzw. Citratcyclus. Ein Beweis dafür steht noch aus.

3. Erste Versuche zur Vorläufer-dirigierten Biosynthese an Streptomyces sp. S 1495 wurden durchgeführt, eine mangelnde Substratflexibilität der beteiligten Enzyme konnte nachgewiesen werden. 


\section{B EXPERIMENTELLER TEIL}

\section{Allgemeines}

\subsection{Instrumentelle Analytik}

\section{Massenspektren:}

El-MS: Finnigan MAT 95, $70 \mathrm{eV}$, Hochauflösungen wurden mit Perfluorkerosin als Vergleichssubstanz gemessen, die relativen Intensitäten beziehen sich auf den Basispeak (I $=100 \%)$ und sind in Klammern angegeben. DCI-MS: Finnigan MAT 95, $200 \mathrm{eV}$, Reaktandgas $\mathrm{NH}_{3}$. ESI-MS: Finnigan LC-Q. HR-ESI-MS: Bruker Apex-Q III, 7 Tesla. DRCICP-MS: PerkinElmer Elan-DRCII, Probenvorbereitung nach AAV 1, interne Standards: Sc, Y, Ga, In, Bi.

\section{Infrarotspektren (IR):}

Alle IR-Spektren wurden mit einem FT-IR-Spektrometer der Fa. Perkin-Elmer Modell 1600 als $\mathrm{KBr}$-Presslinge gemessen, $\mathrm{sh}=$ Schulter.

\section{Elektronenspektren (UV):}

Alle Elektronenspektren wurden mit einem Spektrometer der Fa. Varian Modell Cary 3E gemessen. Die Wellenlänge $\lambda$ ist in [nm] angegeben, der molare Extinktionskoeffizient $\varepsilon$ hat die Dimension [1000 $\mathrm{cm}^{2} \mathrm{~mol}^{-1}$ ], sh = Schulter; Methanol/HCl bzw. Methanol/NaOH: Zu $2 \mathrm{~mL}$ methanolischer Lösung wurde jeweils ein Tropfen $1 \mathrm{~m} \mathrm{HCl}$ bzw. $1 \mathrm{~m} \mathrm{NaOH}$ gegeben.

\section{Drehwerte:}

Alle Drehwerte wurden mit einem Polarimeter der Fa. Perkin-Elmer Modell 343 bestimmt, die

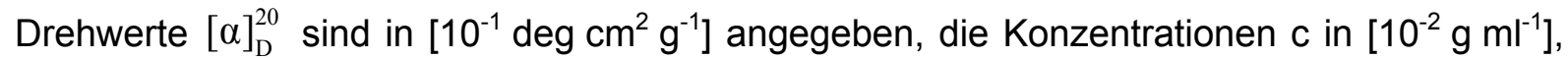
Referenz: Natrium D-Linie (589 nm).

\section{Circulardichroismus-Spektren (CD):} Jasco J 500 mit Jasco IF 500 A/D-Wandler und BMC IF 800 Personalcomputer als Prozessor, die molaren Elliptizitäten $\theta$ sind in $\left[10^{-1} \mathrm{grad} \mathrm{cm}^{2} \mathrm{~mol}^{-1}\right]$ angegeben. 


\section{${ }^{1}$ H-NMR-Spektren:}

Varian Inova-600 (600 MHz), Varian Inova-500 (500 MHz), Varian Mercury-300 (300 MHz), Varian Unity-300 (300 MHz), Bruker AMX 300 (300 MHz). Chemische Verschiebungen in $\delta-$ Werten (ppm) relativ zum jeweiligen Lösungsmittel als internem Standard; Kopplungskonstanten $(J)$ in Hertz $(\mathrm{Hz})$.

Abkürzungen: $s=$ Singulett,$d=$ Dublett, $d d=$ Dublett vom Dublett, $d d d=$ Dublett vom Dublett vom Dublett, $\mathrm{ddt}=$ Dublett vom Dublett vom Triplett, $\mathrm{dt}=$ Dublett vom Triplett, $\mathrm{t}=$ Triplett, $\mathrm{td}=$ Triplett vom Dublett, $\mathrm{q}=$ Quartett, $\mathrm{qd}=$ Quartett vom Dublett, quint $=$ Quintett , sept $=$ Septett, $m=$ Multiplett, $b r=$ breit .

Alle ${ }^{1} \mathrm{H}-\mathrm{NMR}-S p e k t r e n$ wurden näherungsweise als Spektren erster Ordnung interpretiert.

\section{${ }^{13}$ C-NMR-Spektren:}

Varian Inova-600 (150.8 MHz), Varian Mercury-300 (75.5 MHz), Varian Unity-300 $(75.5 \mathrm{MHz})$. Chemische Verschiebungen in $\delta$-Werten (ppm) relativ zum jeweiligen Lösungsmittel als internem Standard.

${ }^{13} \mathrm{C}-{ }^{1} \mathrm{H}$-Multiplizitäten sind aus HSQC-Experimenten ableitbar. Abkürzungen: $\mathrm{s}=$ Singulett, $\mathrm{d}=$ Dublett, $\mathrm{t}=$ Triplett, $\mathrm{q}=$ Quartett.

\section{D-NMR-Spektren:}

${ }^{1} \mathrm{H},{ }^{1} \mathrm{H}$-COSY $\left({ }^{1} \mathrm{H},{ }^{1} \mathrm{H}\right.$-Correlated Spectroscopy), HSQC (Heteronuclear Singular Quantum Coherence), HMBC (Heteronuclear Multiple Bond Connectivity), HMQC (Heteronuclear Multiple Quantum Coherence), NOESY (Nuclear Overhauser Effect Spectroscopy).

\subsection{Chromatographische Methoden}

\section{Dünnschichtchromatographie (DC):}

Merck HPTLC-Fertigplatten Kieselgel $60 \mathrm{~F}_{254}: 10$ × $10 \mathrm{~cm}$, Schichtdicke 0.2 mm; Merck DCAlufolien Kieselgel $60 \mathrm{~F}_{254}: 20 \times 20 \mathrm{~cm}$, Schichtdicke $0.2 \mathrm{~mm}$; Merck DC-Alufolien RP-18 $F_{254 \mathrm{~s}}: 20 \times 20 \mathrm{~cm}$, Schichtdicke $0.2 \mathrm{~mm}$. Angegeben sind $R_{f}-W e r t e$ (Laufhöhe relativ zur Laufmittelfront).

\section{Sprühreagenzien:}

Nach Merck, Anfärbereagenzien für die Dünnschichtchromatographie. ${ }^{206}$ Die DC-Platten wurden nach dem Ansprühen auf ca. $120^{\circ} \mathrm{C}$ erwärmt.

Anisaldehyd (Anis, Nr. 21): $1.0 \mathrm{~mL}$ Anisaldehyd wird in eine Lösung aus $85 \mathrm{~mL}$ Methanol, $10 \mathrm{~mL}$ Eisessig und $5 \mathrm{~mL}$ konz. Schwefelsäure gegeben.

Ehrlichs Reagenz (Ehrlich, Nr. 91): $1 \mathrm{~g}$ 4-Dimethylaminobenzaldehyd wird in einer Mischung von $25 \mathrm{~mL}$ Salzsäure (36 \%) und $75 \mathrm{~mL}$ Methanol gelöst. 
Orcin-Sprühreagenz (Orcin, Nr. 120 - 122): $1 \mathrm{~g}$ Eisen(III)-chlorid wird in $100 \mathrm{~mL}$ Schwefelsäure gelöst und zu gleichen Anteilen mit einer Orcinlösung (6 \% in Ethanol) gemischt.

Vanillin-Schwefelsäure (Vanillin, Nr. 322): $1 \mathrm{~g}$ Vanillin wird in $100 \mathrm{~mL}$ konz. Schwefelsäure gegeben.

Säulen- und Gelchromatographie:

ICN Kieselgel 60 (KG), 32-63 $\mu \mathrm{m}$, Fluka Sephadex ${ }^{\circledR}$ LH-20.

lonenaustauschchromatographie:

Merck Amberlite CG-50 I.

Adsorptionschromatographie:

Serva Amberlite ${ }^{\circledR}$ XAD-2.

High Performance Liquid Chromatography (HPLC):

Analytische HPLC:

Pumpe: Kontron 322; Mischkammer: Kontron HPLC 360; Diode-Array-Detektor: Kontron 440; Autosampler: Kontron 360 mit analytischer Aufgabeschleife; Software: Kontron Kromasystem $2000^{\mathrm{TM}}$ Version 1.60.

Säule A: Jasco Nucleosil $100 \mathrm{C}-18,5 \mu \mathrm{m}, 250 \times 3 \mathrm{~mm}$, Flussrate $0.5 \mathrm{~mL} / \mathrm{min}$.

Säule B: $\quad$ Kromasil $100 \mathrm{C}-18,5 \mu \mathrm{m}, 250 \times 3 \mathrm{~mm}$, Flussrate $0.7 \mathrm{~mL} / \mathrm{min}$.

Säule C: $\quad$ Macherey-Nagel Nucleodur 100-5 C-18 ec, $5 \mu \mathrm{m}, 250 \times 3 \mathrm{~mm}$, Flussrate $0.5 \mathrm{~mL} / \mathrm{min}$.

Programm 1: $15 \%$ Acetonitril auf $100 \%$ Acetonitril in Wasser, $+0.1 \%$ TFA in 20 min.

\section{(Semi-)Präparative HPLC:}

Pumpe: Jasco PU-1587; UV-Detektor: Jasco UV 1575; manuelles Probenaufgabeventil: Rheodyne mit $2.0 \mathrm{~mL}$ Aufgabeschleife; Chromatographiesoftware: Jasco Borwin; Steuersoftware: Jasco Borwin HSS-1500;

Säule D: $\quad$ Jasco Nucleosil $100 \mathrm{C}-18,5 \mu \mathrm{m}, 250 \times 8 \mathrm{~mm}$, Flussrate $3.0 \mathrm{~mL} / \mathrm{min}$.

Säule E: $\quad$ Kromasil, C-18, $5 \mu \mathrm{m}, 250 \times 8 \mathrm{~mm}$, Flussrate $2.5 \mathrm{~mL} / \mathrm{min}$.

Säule F: Kromasil, C-18, $5 \mu \mathrm{m}, 250 \times 21 \mathrm{~mm}$, Flussrate $17.0 \mathrm{~mL} / \mathrm{min}$.

Säule G: $\quad$ Macherey-Nagel Nucleodur 100-5 C-18 ec, $5 \mu \mathrm{m}, 250 \times 21 \mathrm{~mm}$, Flussrate $18.0 \mathrm{~mL} / \mathrm{min}$.

\section{LC-MS:}

Pumpe: Flux Instruments Rheos 4000; Autosampler: Jasco AS-851 (0-100 $\mu \mathrm{L}$ variable Aufgabeschleife); UV-Detektor: Linear UVIS-205; Massendetektor: Finnigan LC-Q; Entgaser: Flux Instruments ERC-3415 $\alpha$; Steuersoftware HPLC: Flux Instruments Janeiro; 
Datensystem: Finnigan Xcalibur; Vorsäule: Grom Supersphere 100 RP-18 endcapped, 4 m, $10 \times 2 \mathrm{~mm}$;

Säule: $\quad$ Grom Supersphere $100 \mathrm{RP}-18$ endcapped, $4 \mu \mathrm{m}, 100 \times 2 \mathrm{~mm}$.

Programm 1: $20 \%$ Methanol auf $100 \%$ Methanol in 20 min, 10 min $100 \%$ Methanol;

Programm 2: 5 \% Methanol auf $100 \%$ Methanol in 20 min, 10 min $100 \%$ Methanol;

Flussrate: $300 \mu \mathrm{L} / \mathrm{min}$; UV-Detektion: $254 \mathrm{~nm}$, Massendetektion: positive und negative lonen.

\section{Lösungsmittel:}

Die Lösungsmittel für die Säulenchromatographie wurden zuvor destilliert. Für die HPLC wurden nur analysenreine Lösungsmittel und bidestilliertes Wasser verwendet. Lösungsmittel für die semipräparative HPLC wurden im Ultraschallbad (10 min) und durch anschließendes Durchleiten von Helium (10 min) entgast.

\subsection{Mikrobiologische Methoden}

\section{Nährmedienbestandteile:}

Malzextrakt, D-Glucose, Stärke, Caseinpepton, Fleischextrakt und $\mathrm{CaCO}_{3}$ wurden von der Fa. Merck bezogen. Hefeextrakt stammt von der Fa. Oxoid, Cornsteep Powder von der Fa. Marcor, D-(-)-Mannit von der Fa. Riedel-deHaën, Haferkleie mit Keim von der Fa. Quickvital, BiTek Agar, Trypton und Casamino Acids von der Fa. Difco, Sojamehl fettarm von der Fa. Henselwerk $\mathrm{GmbH}$, Kanamycinsulfat von der Fa. Roth.

\section{Nährmedien:}

Für alle Nährmedien wurde demineralisiertes Wasser verwendet und der $\mathrm{pH}$-Wert vor dem Autoklavieren mit $0.5 \mathrm{M} \mathrm{NaOH}$ bzw. $0.5 \mathrm{M} \mathrm{HCl}$ eingestellt. Die Nährmedien wurden durch Autoklavieren (feuchte Hitze, $121^{\circ} \mathrm{C}, 1$ bar Überdruck, $30 \mathrm{~min}$ ) sterilisiert. ${ }^{207}$

M2: Malzextrakt (10 g/L), Hefeextrakt (4 g/L), Glucose $(4 \mathrm{~g} / \mathrm{L}), \mathrm{pH}=7.0$; für die Stammhaltung Zusatz von Agar (20 g/L).

M2+: Malzextrakt (10 g/L), Hefeextrakt $(4 \mathrm{~g} / \mathrm{L})$, Glucose $(4 \mathrm{~g} / \mathrm{L}), \mathrm{CaCO}_{3}(0.5 \mathrm{~g} / \mathrm{L})$, $\mathrm{pH}=7.0$; für die Stammhaltung Zusatz von Agar (20 g/L).

SM: $\quad$ Entfettetes Sojamehl (20 g/L), D-(-)-Mannit (20 g/L), $\mathrm{pH}=7.0$.

Ha: $\quad$ Haferkleie $(20 \mathrm{~g} / \mathrm{L}), \mathrm{pH}=7.0$.

SGG: Glucose (10 g/L), Glycerin $(10 \mathrm{~g} / \mathrm{L})$, Stärke $(10 \mathrm{~g} / \mathrm{L})$, Cornsteep Powder $(2.5 \mathrm{~g} / \mathrm{L})$, Caseinpepton $(5 \mathrm{~g} / \mathrm{L})$, Hefeextrakt $(2 \mathrm{~g} / \mathrm{L}), \mathrm{NaCl}(1 \mathrm{~g} / \mathrm{L}), \mathrm{CaCO}_{3}$ (3 g/L), $\mathrm{pH}=7.0$. 
NSA: Hefeextrakt (4 g/L), Stärke (löslich, $20 \mathrm{~g} / \mathrm{L}$ ), Casamino Acids (20 g/L), Agar (20 g/L).

LB $_{\text {Kn50: Trypton }}(10 \mathrm{~g} / \mathrm{L})$, Hefeextrakt $(5 \mathrm{~g} / \mathrm{L}), \quad \mathrm{NaCl}(10 \mathrm{~g} / \mathrm{L}), \quad$ Kanamycinsulfat (50 mg/L), $\mathrm{pH}=7.0$; für die Stammhaltung Zusatz von Agar (15 g/L).

NM6: D-(-)-Mannit (20 g/L), Sojamehl (vollfett, $20 \mathrm{~g} / \mathrm{L})$, Fleischextrakt (20 g/L), NaCl (2 g/L), L-Valin (0.3 g/L), $\mathrm{ZnSO}_{4} \times 6 \mathrm{H}_{2} \mathrm{O}(0.5 \mathrm{~g} / \mathrm{L}), \mathrm{pH}=7.3$.

NM10: D-(-)-Mannit (50 g/L), L-Asparagin $(3 \mathrm{~g} / \mathrm{L}), \mathrm{K}_{2} \mathrm{HPO}_{4}(1 \mathrm{~g} / \mathrm{L}), \quad \mathrm{NaCl}(25 \mathrm{~g} / \mathrm{L})$, $\mathrm{MgSO}_{4} \times 7 \mathrm{H}_{2} \mathrm{O}(50 \mathrm{mg} / \mathrm{L}), \mathrm{CaCl}_{2} \times 2 \mathrm{H}_{2} \mathrm{O}(50 \mathrm{mg} / \mathrm{L}), \mathrm{CH}_{3} \mathrm{COONa}(420 \mathrm{mg} / \mathrm{L})$, meso-Inosit $(100 \mathrm{mg} / \mathrm{L})$, Spurenelementelösung $(10 \mathrm{~mL} / \mathrm{L})$, Vitaminlösung $(1 \mathrm{~mL} / \mathrm{L})$.

Spurenelementelösung: $\quad \mathrm{CaCl}_{2} \times 2 \mathrm{H}_{2} \mathrm{O} \quad(8 \mathrm{~g} / \mathrm{L}), \quad \mathrm{MnCl}_{2} \times 2 \mathrm{H}_{2} \mathrm{O} \quad(5 \mathrm{~g} / \mathrm{L}), \quad \mathrm{ZnCl}_{2}$ (50 mg/L), $\quad \mathrm{CuCl}_{2} \times 2 \mathrm{H}_{2} \mathrm{O} \quad(50 \mathrm{mg} / \mathrm{L}), \quad \mathrm{FeCl}_{3} \times 6 \mathrm{H}_{2} \mathrm{O}$ (50 mg/L).

Vitaminlösung: Thiamin- $\mathrm{HCl}(1 \mathrm{~g} / \mathrm{L})$, Calcium-D-(+)-Pantothenat $(1.2 \mathrm{~g} / \mathrm{L})$, FlavinMononukleotid (1 g/L), Nikotinsäure (2.3 g/L), Pyridoxin-HCl (12 g/L), p-Aminobenzoat $(200 \mathrm{mg} / \mathrm{L})$, Vitamin $B_{12}(100 \mathrm{mg} / \mathrm{L})$, Folsäure (10 mg/L), Biotin (6 mg/L).

\section{Isotopenmarkierte Verbindungen:}

Alle verwendeten Verbindungen waren, soweit nicht anders angegeben, zu $99 \%$ isotopenmarkiert und wurden bezogen von:

Na-[1- $\left.{ }^{13} \mathrm{C}\right]$ Acetat, $\quad\left[\mathrm{U}^{-13} \mathrm{C}_{3}\right]$ Glycerin von Chemotrade $\mathrm{GmbH} ; \quad \mathrm{Na}-\left[2-{ }^{13} \mathrm{C}\right]$ Acetat, $\mathrm{Na}-\left[1,2-{ }^{13} \mathrm{C}_{2}\right]$ Acetat von Deutero $\mathrm{GmbH}$; Na[2- $\left.\mathrm{d}_{3}\right]$ Acetat von Cambridge Isotope Laboratories Inc.; $\left[1-{ }^{13} \mathrm{C}\right]$ Tyrosin, $\left[2,3,5,6-\mathrm{d}_{4}\right]$ Tyrosin $(98 \%)$, Na- $\left[1-{ }^{13} \mathrm{C}\right]$ Propionat von Isotec Inc. .

\section{Schüttler und Fermenter:}

Braun Inkubationsschüttelschrank BS4, Braun Certomat RM, Braun Biostat M (1 L), Braun Biostat B (3 L), Braun Biostat U (50 L).

\section{Plattendiffusionstest:}

Auf die mit den verschiedenen Testkeimen angeimpfte Agarplatte wurden Filterplättchen (Durchmesser: $6 \mathrm{~mm}$, Dicke: $0.5 \mathrm{~mm}$ ) gelegt, die mit $15 \mu \mathrm{L}$ Substanzlösung (in Methanol oder Chloroform gelöst, $c=1 \mathrm{mg} / \mathrm{mL}$ ) getränkt und vor dem Auflegen unter sterilen Bedingungen getrocknet worden waren. Als Testkeime dienten Bacillus subtilis, Escherichia coli, Staphylococcus aureus, und Candida albicans. Die Agarplatten wurden $24 \mathrm{~h}$ bei $25^{\circ} \mathrm{C}$ (C. albicans) bzw. $37^{\circ} \mathrm{C}$ (B. subtilis, E. coli und S. aureus) inkubiert. 


\section{Zusammensetzung der Nährböden für die Plattendiffusionstests:}

Bac. subt. und E. coli: Glucose (5 g/L), Trinatriumcitrat $x 2 \mathrm{H}_{2} \mathrm{O}(0.5 \mathrm{~g} / \mathrm{L}), \mathrm{KH}_{2} \mathrm{PO}_{4}(3 \mathrm{~g} / \mathrm{L})$, $\mathrm{K}_{2} \mathrm{HPO}_{4}(7 \mathrm{~g} / \mathrm{L}), \mathrm{MgSO}_{4} \times 7 \mathrm{H}_{2} \mathrm{O}(0.1 \mathrm{~g} / \mathrm{L}),\left(\mathrm{NH}_{4}\right)_{2} \mathrm{SO}_{4}(1 \mathrm{~g} / \mathrm{L})$ und Agar (15 g/L), keine $\mathrm{pH}$-Einstellung.

Staph. aureus.: $\quad$ Bacto Nutrient Broth $(8 \mathrm{~g} / \mathrm{L}), \mathrm{NaCl}(5 \mathrm{~g} / \mathrm{L})$ und Agar $(15 \mathrm{~g} / \mathrm{L})$, keine $\mathrm{pH}$-Einstellung.

Cand. albicans: $\quad$ Hefeextrakt $(4 \mathrm{~g} / \mathrm{L})$, Malzextrakt $(10 \mathrm{~g} / \mathrm{L})$, Glucose $(4 \mathrm{~g} / \mathrm{L})$ und Agar $(15 \mathrm{~g} / \mathrm{L}), \mathrm{pH}=5.5$.

Zum Ansetzen der Testplatten-Medien wurde demineralisiertes Wasser verwendet. Die Glucose wurde erst nach der 30 minütigen Sterilisation hinzugegeben.

\section{Test auf Differenzierungsaktivität:}

$2 \mathrm{~mL}$ einer mit $\mathrm{NaCl}$-Lösung (0.9\%) hergestellten Sporensuspensionslösung des Stammes Streptomyces griseoflavus Tü 1306 wurden in $200 \mathrm{~mL} 40^{\circ} \mathrm{C}$ warmes NSA-Medium gegeben und als dünne Schichten auf NSA-Agarplatten gegossen. Wie unter den allgemeinen Bedingungen für Plattendiffusiontests beschrieben wurden Filterplättchen aufgelegt und die Platten für $8-10 \mathrm{~d}$ bei $28^{\circ} \mathrm{C}$ inkubiert.

\section{Screening auf Differenzierungsaktivität:}

Auf die M2-Agarplatten wurden Filterplättchen (Durchmesser: $6 \mathrm{~mm}$, Dicke: $0.5 \mathrm{~mm}$ ) gelegt, die mit $15 \mu \mathrm{L}$ Substanzlösung (in Chloroform gelöst, $\mathrm{c}=1 \mathrm{mg} / \mathrm{mL}$ ) getränkt und vor dem Auflegen unter sterilen Bedingungen getrocknet worden waren. Diese Agarplatten wurden an den Rändern mit den Teststämmen angeimpft und für $7 \mathrm{~d}$ bei $28^{\circ} \mathrm{C}$ inkubiert.

\subsection{Allgemeine Arbeitsvorschriften (AAV)}

\section{AAV 1: Aufschluss von Hormaomycin für DRC-ICP-MS}

$2.5 \mathrm{mg}$ Hormaomycin werden in einem Teflongefäß mit $1 \mathrm{~mL} \mathrm{HNO}$ (60\%, ultrapur), $0.5 \mathrm{~mL}$ $\mathrm{H}_{2} \mathrm{O}_{2}(30 \%)$ sowie $0.75 \mathrm{~mL}$ Wasser versetzt und einem Mikrowellenaufschluss unterworfen (Programm: $3 \mathrm{~min} 250 \mathrm{~W}, 1 \mathrm{~min} 0 \mathrm{~W} 4 \mathrm{~min} 250 \mathrm{~W}, 5 \mathrm{~min} 500 \mathrm{~W}, 3 \min 400 \mathrm{~W}, 4 \mathrm{~min}$ $300 \mathrm{~W})$. 


\section{Untersuchungen am Hormaomycin-Produzenten Streptomyces griseoflavus (Stamm W 384)}

\subsection{Stammhaltung}

\subsubsection{Agarplatten}

Die Haltung von Streptomyces griseoflavus (Stamm W 384) erfolgte auf Petrischalen mit $\mathrm{M} 2+-N a ̈ h r m e d i u m$. Sie wurden bei $28^{\circ} \mathrm{C} 7-10$ Tage inkubiert und bei $28^{\circ} \mathrm{C}$ für maximal einen sowie bei $4^{\circ} \mathrm{C}$ maximal drei Monate gelagert.

\subsubsection{Langzeitkonservierung}

Aus einer gut bewachsenen Agarplatte wurden mit einseitig zugeschweißten und mit einem Bleistück beschwerten sterilen Halmen aus Polypropylen Agarstückchen ausgestanzt, bis der Halm gefüllt war. Dieser wurde in einen zweiten äußeren Halm gesteckt, der mit einer ausgeglühten Tiegelzange an beiden Seiten zugeschmolzen wurde. Die Halme wurden in einem Dewar über flüssigem Stickstoff bei $-196^{\circ} \mathrm{C}$ gelagert.

\subsubsection{Kultivierung}

\section{Vorkultur:}

Die Kultivierung erfolgte in $250 \mathrm{~mL}$ Erlenmeyerkolben mit drei Schikanen in $50 \mathrm{~mL}$ NM6, welches mit einem ca. $1 \mathrm{~cm}^{2}$ großen gut bewachsenen Agarstück angeimpft wurde. Die Inkubation erfolgte bei $27^{\circ} \mathrm{C}$ und $180 \mathrm{rpm}$ für ca. $48 \mathrm{~h}$.

\section{Hauptkultur:}

Der Stamm W 384 wurde im Braun $1 \mathrm{~L}$ Biostat M-Fermenter mit NM10 unter Zugabe von $2 \mathrm{~mL}$ NIAX-Entschäumer kultiviert und mit $10 \%$ Vorkultur beimpft. Nach dem Beimpfen erfolgte die Zugabe der Vitaminlösung durch einen Sterilfilter, der pH-Wert wurde auf 6.5 eingestellt und mit $2 \mathrm{M}$ Citronensäure und $0.5 \mathrm{M} \mathrm{NaOH}$ automatisch bei $6.5 \pm 1.0$ gehalten. Die Fermentation erfolgte für $72 \mathrm{~h}$ bei $27^{\circ} \mathrm{C}, 700 \mathrm{rpm}$ und einer Luftzufuhr von $1.6 \mathrm{vvm}$. Zur Ausbeuteerhöhung wurden ab der 24. Stunde über einen Zeitraum von $10 \mathrm{~h} 2 \mathrm{mmol}$ Pyrrol2-carbonsäure (gelöst in $50 \mathrm{~mL}$ sterilem Wasser) zu der Kulturbrühe gepumpt. 


\subsection{Isolierung und Charakterisierung von Hormaomycin (16)}

Die Kulturbrühe wurde durch Zentrifugation in Mycel und Kulturfiltrat getrennt, wobei letzteres aufgrund des sehr geringen Hormaomycin-Gehalts $(<1 \%)$ verworfen wurde. Die Extraktion des Mycels erfolgte nach Gefriertrocknung und Mörsern mit $2 \times 300 \mathrm{~mL}$ Ethylacetat pro Liter Kulturbrühe für 15 min im Ultraschallbad. Die organischen Phasen wurden vereint, das Lösungsmittel in vacuo entfernt. Das Rohprodukt wurde anschließend mit kaltem Pentan gewaschen und an Kieselgel chromatographiert (Trennung A: Aceton/Cyclohexan 2:3; Trennung B: $\mathrm{CH}_{2} \mathrm{Cl}_{2} / \mathrm{MeOH}$ 98:2). Die höchsten Ausbeuten an 16 (bis zu $45 \mathrm{mg}$ ) gelangen durch Fermentationen unter Zugabe von Pyrrol-2-carbonsäure, dem putativen Vorläufer der Startereinheit der Hormaomycin-Biosynthese, ohne Zugabe wurden höchstens 20 mg Ausbeute erreicht.

\subsubsection{Untersuchungen des Hormaomycin-Zentralions}

$10.0 \mathrm{mg} 16$ wurden in Methanol gelöst und an Amberlite CG-50 I-Ionentauscher ( $\mathrm{MeOH}$, $100 \times 5 \mathrm{~mm}$ ) chromatographiert. Anschließend wurde das Lösungsmittel in vacuo entfernt. Die erhaltene deionisierte Form von 16 wurde in Chloroform gelöst ( $c=1.0 \mathrm{mg} / \mathrm{mL}$ ), und mit jeweils gleichem Volumen $0.5 \mathrm{M}$ Metallsalzlösung versetzt. Die organische Phase wurde abgetrennt und das Lösungsmittel entfernt. Die entstandenen Hormaomycin-Analoga gleichen sich bis auf ihre ${ }^{1} \mathrm{H}$-chemischen Verschiebungen in allen spektroskopischen und spektrometrischen Daten.

Hormaomycin (16)

$\mathrm{C}_{55} \mathrm{H}_{69} \mathrm{~N}_{10} \mathrm{O}_{14} \mathrm{Cl}(1128.47)$

farbloser Feststoff

UV-löschend (254 nm)

Anfärbeverhalten: rosa (Ehrlich).

$\mathbf{R}_{\mathbf{f}}: \quad 0.61\left(\mathrm{KG}, \mathrm{CHCl}_{3} / \mathrm{MeOH} 9: 1\right)$;

0.25 (KG, Aceton/Cyclohexan 2:3).

Smp.: $\quad 166-168^{\circ} \mathrm{C}$.

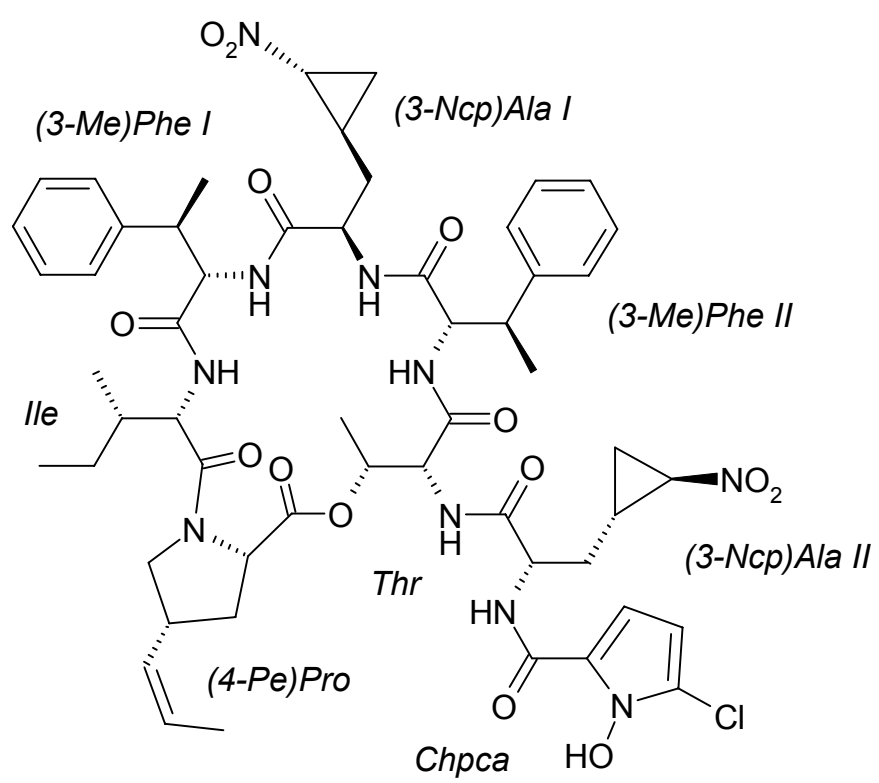


ESI-MS: $\quad$ (pos. Ionen) $\mathrm{m} / \mathrm{z}=1151[\mathrm{M}+\mathrm{Na}]^{+}, 1129[\mathrm{M}+\mathrm{H}]^{+}$.

(neg. lonen) $\mathrm{m} / \mathrm{z}=1127[\mathrm{M}-\mathrm{H}]^{-}$.

HR-ESI-MS: berechnet: $1129.64758[\mathrm{M}+\mathrm{H}]^{+}$.

gefunden: $1129.64755(\Delta=0.03 \mathrm{ppm})$.

DRC-ICP-MS: $\quad \mathrm{Na}(9.2 \mathrm{~mol} \%), \mathrm{Zn}(0.9 \mathrm{~mol} \%)$, $\mathrm{Ca}(0.7 \mathrm{~mol} \%)$.

$\begin{array}{lll}\text { UV } & (\mathrm{MeOH}): & \lambda_{\max }(\lg \varepsilon)=274(4.18) \mathrm{nm} ; \\ & (\mathrm{MeOH}, \mathrm{HCl}): & \lambda_{\max }(\lg \varepsilon)=274(4.18) \mathrm{nm} ; \\ & (\mathrm{MeOH}, \mathrm{NaOH}): & \lambda_{\max }(\lg \varepsilon)=274(4.18) \mathrm{nm} . \\ \text { CD } & (\mathrm{MeOH}): & \lambda_{\max }\left([\Theta]^{20}\right)=275(+27500), 224(-60600), 207(+11500) \mathrm{nm} .\end{array}$

$[\alpha]_{\mathrm{D}}^{20}=+14^{\circ}(\mathrm{c}=0.1, \mathrm{MeOH})$.

IR $(\mathrm{KBr}): \widetilde{\mathbf{v}}=3384(\mathrm{br}), 2928,1742,1628(\mathrm{br}), 1544,1447,1370 \mathrm{~cm}^{-1}$.

\section{Natives Hormaomycin (16)}

${ }^{1} \mathrm{H}-\mathrm{NMR}\left(600 \mathrm{MHz}, \mathrm{CDCl}_{3}\right): \delta=-0.62$ [ddd, $J=7.0,7.0,7.0 \mathrm{~Hz}, 1 \mathrm{H}, 3{ }^{\prime}-\mathrm{H}_{\mathrm{a}}, \quad$ (3-Ncp)Ala I], -0.09 [ddd, $\left.J=14.0,9.0,4.5 \mathrm{~Hz}, 1 \mathrm{H}, 3-\mathrm{H}_{\mathrm{a}},(3-N c p) A l a ~ I\right], 0.29$ [m, $1 \mathrm{H}, 2$ '- H, (3-Ncp)Ala I], 0.58 [ddd, J = 14.0, 6.0, $5.0 \mathrm{~Hz}, 1 \mathrm{H}, 3-\mathrm{H}_{\mathrm{b}},(3-N c p) A l a$ l], 0.89 (t, J = 7.0 Hz, $\left.3 \mathrm{H}, 5-\mathrm{H}, I l e\right)$, 0.99-1.01 [m, 2 H, 3'- $\mathrm{H}_{\mathrm{b}}$, (3-Ncp)Ala I, 3'- $\mathrm{H}_{\mathrm{a}}$, (3-Ncp)Ala II], 1.02 (d, J = 7.0 Hz, 3 H, 1'-H, Ile), $1.29[\mathrm{~d}, J=6.5 \mathrm{~Hz}, 3 \mathrm{H}, 4-\mathrm{H},(\beta M e) P h e I I], 1.30-1.35\left(\mathrm{~m}, 1 \mathrm{H}, 4-\mathrm{H}_{\mathrm{a}}, I l e\right), 1.39$ [d, J = $7.2 \mathrm{~Hz}$, $3 \mathrm{H}, 4-\mathrm{H},(\beta M e) P h e ~], 1.53(\mathrm{~d}, \mathrm{~J}=6.5 \mathrm{~Hz}, 3 \mathrm{H}, \mathrm{a}-T h r), 1.54-1.60$ [m, $2 \mathrm{H}, 3-\mathrm{H}_{\mathrm{a}},(3-N c p) A l a ~ I I$, 4- $\left.\mathrm{H}_{\mathrm{b}}, I l e\right], 1.67$ [dd, J = 7.0, 2.0 Hz, 3 H, 3'-H, (4-Pe)Pro], 1.76-1.84 [m, $2 \mathrm{H}, 3-\mathrm{H}_{\mathrm{b}}$,

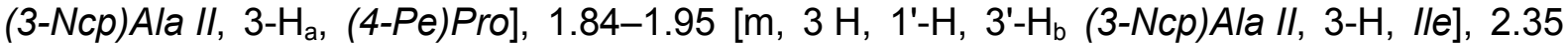
[ddd, $J=13.0,5.5,5.5 \mathrm{~Hz}, 1 \mathrm{H}, 3-\mathrm{H}_{\mathrm{b}},(4-P e) P r o$ ], 2.94 [dq, $J=11.0,6.5 \mathrm{~Hz}, 1 \mathrm{H}, 3-\mathrm{H}$, (BMe)Phe II], 2.96 [ddd, J = 7.0, 3.5, 3.5 Hz, $1 \mathrm{H}, 2$ '-H, (3-Ncp)Ala I], 3.25-3.32 [m, $2 \mathrm{H}, 4-\mathrm{H}$, 5- $\left.\mathrm{H}_{\mathrm{a}},(4-P e) P r o\right], 3.53[\mathrm{~m}, 1 \mathrm{H}, 2-\mathrm{H},(3-N c p) A l a ~ I], 3.68[\mathrm{dq}, J=7.0,4.5 \mathrm{~Hz}, 1 \mathrm{H}, 3-\mathrm{H}$, (BMe)Phe I], 3.96-4.00 [m, $\left.1 \mathrm{H}, 5-\mathrm{H}_{\mathrm{b}},(4-P e) P r o\right], 4.03$ [ddd, J = 7.0, 3.5, 3.5 Hz, $1 \mathrm{H}, 2 '-\mathrm{H}$, (3-Ncp)Ala II], 4.27 [dd, $J=11.5,6.0 \mathrm{~Hz}, 1 \mathrm{H}, 2-\mathrm{H},(4-P e) P r o], 4.40$ [dd, $J=11.0,11.0 \mathrm{~Hz}$, $1 \mathrm{H}, 2-\mathrm{H},(\beta M e) P h e ~ I I], 4.48$ [dd, J = 9.0, $4.5 \mathrm{~Hz}, 1 \mathrm{H}, 2-\mathrm{H},(\beta M e) P h e ~ I], 4.58$ (dd, J = 9.5, $2.5 \mathrm{~Hz}, 1 \mathrm{H}, 2-\mathrm{H}, \mathrm{a}-T h r), 4.65(\mathrm{dd}, J=9.0,9.0 \mathrm{~Hz}, 1 \mathrm{H}, 2-\mathrm{H}, I l e), 5.12[\mathrm{~m}, 1 \mathrm{H}, 2-\mathrm{H}$, (3-Ncp)Ala II], 5.26 [m, $1 \mathrm{H}, 1$ '-H, (4-Pe)Pro], 5.41 (dq, J = 7.0, $2.5 \mathrm{~Hz}, 1 \mathrm{H}, 3-\mathrm{H}, \mathrm{a}-\mathrm{Thr}), 5.63$ [dq, J = 10.5, 7.0 Hz, $1 \mathrm{H}, 2$ '-H, (4-Pe)Pro], 6.13 (d, J = 5.0 Hz, $1 \mathrm{H}, 4-\mathrm{H}$, Chpca), 6.64 [d, $J=7.0 \mathrm{~Hz}, 1 \mathrm{H}, \mathrm{NH},(3-N c p) A l a$ I], $6.80[\mathrm{~d}, J=10.0 \mathrm{~Hz}, 1 \mathrm{H}, \mathrm{NH},(\beta M e) P h e I I], 6.83$ (d, $J=5.0 \mathrm{~Hz}, 1 \mathrm{H}, 3-\mathrm{H}$, Chpca), 6.89 [d, $J=9.5 \mathrm{~Hz}, 1 \mathrm{H}, \mathrm{NH},(\beta M e) P h e ~ I], 7.02-7.12(\mathrm{~m}, 4 \mathrm{H}$, $\operatorname{Ar}-\mathrm{H}), 7.14-7.18(\mathrm{~m}, 2 \mathrm{H}, \mathrm{Ar}-\mathrm{H}), 7.19-7.22(\mathrm{~m}, 4 \mathrm{H}, \mathrm{Ar}-\mathrm{H}), 7.27$ (d, J = 9.0 Hz, $1 \mathrm{H}, \mathrm{NH}, I l e)$, $8.10[\mathrm{~d}, J=9.0 \mathrm{~Hz}, 1 \mathrm{H}, \mathrm{NH},(3-N c p) A l a I I], 9.05(\mathrm{~d}, J=9.5 \mathrm{~Hz}, 1 \mathrm{H}, \mathrm{NH}, T h r)$. 


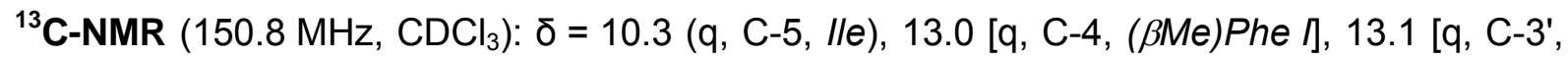
(4-Pe)Pro], 14.7 (q, C-1', Ile), 16.8 (q, C-4, a-Thr), 17.2 [t, C-3', (3-Ncp)Ala II] 17.4 [q, C-4, (BMe)Phe II], 17.4 [t, C-3', (3-Ncp)Ala I], 19.7 [d, C-1', (3-Ncp)Ala I], 21.5 [d, C-1', (3-Ncp)Ala II], 24.7 (t, C-4, Ile), 32.6 [t, C-3, (3-Ncp)Ala I], 34.8 [t, C-3, (3-Ncp)Ala II], 35.3 [t,

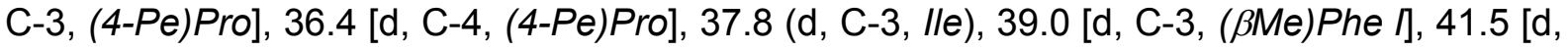

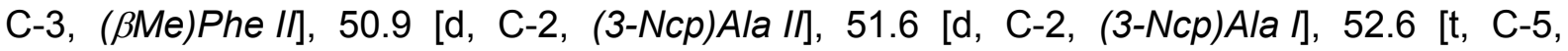
(4-Pe)Pro], 54.4 (d, C-2, Ile), 54.7 (d, C-2, a-Thr), 57.9 [d, C-2', (3-Ncp)Ala ], 58.9 [d, C-2',

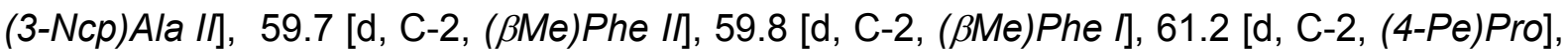
68.8 (d, C-3, a-Thr), 103.4 (d, C-4, Chpca), 109.8 (d, C-3, Chpca), 119.7 (s, C-2, Chpca), 121.3 (s, C-5, Chpca), 126.9, 127.1, 127.2, 127.5, 127.8, 128.3, 128.4, 128.6 [d, C-1', C-2', (4-Pe)Pro, Ar-C], 141.6, 141.8 (s, Ar-C), 159.3 (s, C-1, Chpca), 168.8, 169.5, 169.9, 170.9, $171.3,171.6,171.9(\mathrm{~s}, \mathrm{C}-1)$.

\section{Deionisiertes Hormaomycin (16-De)}

${ }^{1} \mathrm{H}-\mathrm{NMR}\left(600 \mathrm{MHz}, \mathrm{CDCl}_{3}\right): \delta=-0.71$ [ddd, $J=7.0,7.0,7.0 \mathrm{~Hz}, 1 \mathrm{H}, 3$ '- $\mathrm{H}_{\mathrm{a}}$, (3-Ncp)Ala I], -0.16 [ddd, $\left.J=14.0,9.0,4.5 \mathrm{~Hz}, 1 \mathrm{H}, 3-\mathrm{H}_{\mathrm{a}},(3-N c p) A l a ~ I\right], 0.26$ [m, $1 \mathrm{H}, 1$ '- H, (3-Ncp)Ala I], 0.50 [ddd, J = 14.0, 6.0, $5.0 \mathrm{~Hz}, 1 \mathrm{H}, 3-\mathrm{H}_{\mathrm{b}}$, (3-Ncp)Ala I], 0.88 (t, J = 7.0 Hz, $\left.3 \mathrm{H}, 5-\mathrm{H}, I l e\right)$, $0.98\left[\mathrm{~m}, 2 \mathrm{H}, 3\right.$ '- $\mathrm{H}_{\mathrm{b}}$, (3-Ncp)Ala I, 3'- $\mathrm{H}_{\mathrm{a}}$, (3-Ncp)Ala II], 1.02 (d, J = 7.0 Hz, $\left.3 \mathrm{H}, 1^{\prime}-\mathrm{H}, I l e\right), 1.30$ [d, J = 6.5 Hz, $3 \mathrm{H}, 4-\mathrm{H},(\beta M e) P h e ~ I l], 1.30-1.35\left(\mathrm{~m}, 1 \mathrm{H}, 4-\mathrm{H}_{\mathrm{a}}, I l e\right), 1.39$ [d, J = 7.2 Hz, $3 \mathrm{H}$, 4-H, (BMe)Phe l], $1.53(\mathrm{~d}, \mathrm{~J}=6.5 \mathrm{~Hz}, 3 \mathrm{H}, \mathrm{a}-\mathrm{Thr}), 1.54-1.60\left[\mathrm{~m}, 2 \mathrm{H}, 3-\mathrm{H}_{\mathrm{a}}\right.$, (3-Ncp)Ala II, 4- $\left.\mathrm{H}_{\mathrm{b}}, I l e\right], 1.67$ [dd, J = 7.0, $\left.2.0 \mathrm{~Hz}, 3 \mathrm{H}, 3{ }^{\prime}-\mathrm{H},(4-P e) P r o\right], 1.76-1.84\left[\mathrm{~m}, 2 \mathrm{H}, 3-\mathrm{H}_{\mathrm{b}}\right.$, (3-Ncp)Ala II, 3- $\mathrm{H}_{\mathrm{a}}$, (4-Pe)Pro], 1.84-1.95 [m, 3 H, 1'-H, 3'- $\mathrm{H}_{\mathrm{b}}$ (3-Ncp)Ala II, 3-H, Ile], 2.37 [ddd, $J=13.0,5.5,5.5 \mathrm{~Hz}, 1 \mathrm{H}, 3-\mathrm{H}_{\mathrm{b}},(4-P e) P r o$ ], 2.89 [ddd, $J=7.0,3.5,3.5 \mathrm{~Hz}, 1 \mathrm{H}, 2$ '- $\mathrm{H}$, (3-Ncp)Ala I], 3.01 [dq, J = 11.0, $6.5 \mathrm{~Hz}, 1 \mathrm{H}, 3-\mathrm{H},(\beta M e) P h e ~ I I], 3.25-3.32$ [m, $2 \mathrm{H}, 4-\mathrm{H}, 5-\mathrm{H}_{\mathrm{a}}$, (4-Pe)Pro], 3.46 [m, $1 \mathrm{H}, 2-\mathrm{H},(3-N c p) A l a ~ I], 3.67$ [dq, J = 7.0, $4.5 \mathrm{~Hz}, 1 \mathrm{H}, 3-\mathrm{H},(\beta M e) P h e ~ I]$, $3.97\left[\mathrm{~m}, 1 \mathrm{H}, 5-\mathrm{H}_{\mathrm{b}}\right.$, (4-Pe)Pro], 4.02 [ddd, J = 7.0, 3.5, $3.5 \mathrm{~Hz}, 1 \mathrm{H}, 2 \mathrm{-H}$, (3-Ncp)Ala II], 4.26 [dd, $J=11.5,6.0 \mathrm{~Hz}, 1 \mathrm{H}, 2-\mathrm{H}, \quad(4-P e) P r o], 4.36$ [dd, $J=11.0,11.0 \mathrm{~Hz}, 1 \mathrm{H}, 2-\mathrm{H}$,

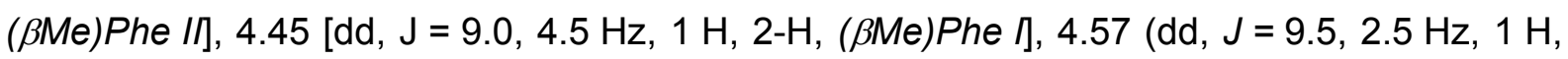
2-H, a-Thr), 4.65 (dd, J = 9.0, 9.0 Hz, $1 \mathrm{H}, 2-\mathrm{H}, I l e), 5.11[\mathrm{~m}, 1 \mathrm{H}, 2-\mathrm{H},(3-N c p) A l a ~ I I], 5.26[\mathrm{~m}$, $1 \mathrm{H}, 1^{\prime}-\mathrm{H},(4-P e) P r o$ ], 5.40 (dq, $\left.J=7.0,2.5 \mathrm{~Hz}, 1 \mathrm{H}, 3-\mathrm{H}, \mathrm{a}-\mathrm{Thr}\right), 5.62$ [dq, $J=10.5,7.0 \mathrm{~Hz}$, $1 \mathrm{H}, 2 '-\mathrm{H},(4-P e) P r o], 6.13(\mathrm{~d}, J=5.0 \mathrm{~Hz}, 1 \mathrm{H}, 4-\mathrm{H}$, Chpca), $6.44[\mathrm{~d}, J=7.0 \mathrm{~Hz}, 1 \mathrm{H}, \mathrm{NH}$, (3-Ncp)Ala I], 6.78 [d, J = 10.0 Hz, $1 \mathrm{H}, \mathrm{NH},(\beta M e) P h e I /], 6.79$ [d, J = 9.5 Hz, $1 \mathrm{H}, \mathrm{NH}$, (ßMe)Phe I], 6.84 (d, J = 5.0 Hz, $1 \mathrm{H}, 3-\mathrm{H}$, Chpca), 7.00-7.02 (m, $1 \mathrm{H}$, Ar-H), 7.02-7.12 (m, $4 \mathrm{H}, \mathrm{Ar}-\mathrm{H}), 7.14-7.18(\mathrm{~m}, 1 \mathrm{H}, \mathrm{Ar}-\mathrm{H}), 7.19-7.22(\mathrm{~m}, 4 \mathrm{H}, \mathrm{Ar}-\mathrm{H}), 7.26(\mathrm{~d}, J=9.0 \mathrm{~Hz}, 1 \mathrm{H}, \mathrm{NH}$, Ile), $8.06[\mathrm{~d}, J=9.0 \mathrm{~Hz}, 1 \mathrm{H}, \mathrm{NH},(3-N c p) A l a I I], 9.08$ (d, $J=9.5 \mathrm{~Hz}, 1 \mathrm{H}, \mathrm{NH}, T h r)$. 


\section{Kupfer-Hormaomycin (16-Cu)}

${ }^{1} \mathrm{H}-\mathrm{NMR}\left(600 \mathrm{MHz}, \mathrm{CDCl}_{3}\right): \delta=-0.55$ [ddd, $J=7.0,7.0,7.0 \mathrm{~Hz}, 1 \mathrm{H}, 3{ }^{\prime}-\mathrm{H}_{\mathrm{a}}$, (3-Ncp)Ala I], -0.02 [ddd, $J=14.0,9.0,4.5 \mathrm{~Hz}, 1 \mathrm{H}, 3-\mathrm{H}_{\mathrm{a}},(3-N c p)$ Ala I], 0.36 [m, $1 \mathrm{H}, 1$ '- H, (3-Ncp)Ala I], 0.59 [ddd, $J=14.0,6.0,5.0 \mathrm{~Hz}, 1 \mathrm{H}, 3-\mathrm{H}_{\mathrm{b}},(3-N c p) A l a$ ]], 0.86 (t, $\left.J=7.0 \mathrm{~Hz}, 3 \mathrm{H}, 5-\mathrm{H}, I l e\right)$, 0.98-1.00 [m, 2 H, 3'- $\mathrm{H}_{\mathrm{b}}$, (3-Ncp)Ala I, 3'- $\mathrm{H}_{\mathrm{a}}$, (3-Ncp)Ala II], 1.00 (d, J = 7.0 Hz, $\left.3 \mathrm{H}, 1^{\prime}-\mathrm{H}, I l e\right)$, $1.28[\mathrm{~d}, J=6.5 \mathrm{~Hz}, 3 \mathrm{H}, 4-\mathrm{H},(\beta M e) P h e I I], 1.24-1.29\left(\mathrm{~m}, 1 \mathrm{H}, 4-\mathrm{H}_{\mathrm{a}}, I l e\right), 1.39[\mathrm{~d}, J=7.2 \mathrm{~Hz}$, $3 \mathrm{H}, 4-\mathrm{H},(\beta M e) P h e$ I], 1.52 (d, J = 6.5 Hz, $3 \mathrm{H}, \mathrm{a}-T h r), 1.54-1.60$ [m, $2 \mathrm{H}, 3-\mathrm{H}_{\mathrm{a}}$, (3-Ncp)Ala II, 4- $\left.\mathrm{H}_{\mathrm{b}}, I l e\right], 1.67\left[\mathrm{dd}, J=7.0,2.0 \mathrm{~Hz}, 3 \mathrm{H}, 3{ }^{\prime}-\mathrm{H}, \quad(4-P e) P r o\right], 1.76-1.84\left[\mathrm{~m}, 2 \mathrm{H}, 3-\mathrm{H}_{\mathrm{b}}\right.$, (3-Ncp)Ala II, 3- $\mathrm{H}_{\mathrm{a}}$, (4-Pe)Pro], 1.84-1.95 [m, 3 H, 1'-H, 3'- $\mathrm{H}_{\mathrm{b}}$ (3-Ncp)Ala II, 3-H, Ile], 2.36 [ddd, $J=13.0,5.5,5.5 \mathrm{~Hz}, 1 \mathrm{H}, 3-\mathrm{H}_{\mathrm{b}},(4-P e) P r o$ ], 2.91 [dq, $J=11.0,6.5 \mathrm{~Hz}, 1 \mathrm{H}, 3-\mathrm{H}$,

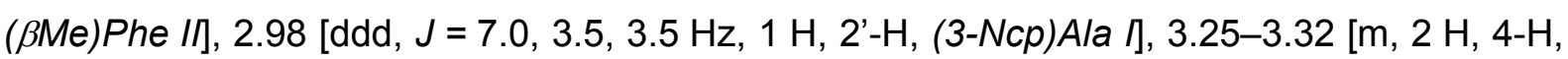
5- $\mathrm{H}_{\mathrm{a}}$, (4-Pe)Pro], $3.62[\mathrm{~m}, 1 \mathrm{H}, 2-\mathrm{H},(3-N c p) A l a ~ I], 3.69[\mathrm{dq}, J=7.0,4.5 \mathrm{~Hz}, 1 \mathrm{H}, 3-\mathrm{H}$,

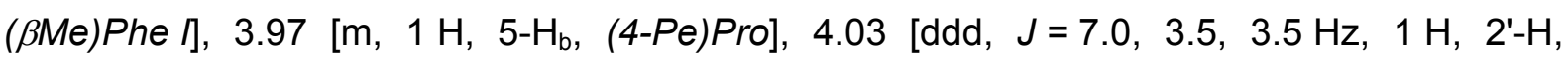
(3-Ncp)Ala II], 4.25 [dd, $J=11.5,6.0 \mathrm{~Hz}, 1 \mathrm{H}, 2-\mathrm{H},(4-P e) P r o], 4.39$ [dd, $J=11.0,11.0 \mathrm{~Hz}$, $1 \mathrm{H}, 2-\mathrm{H},(\beta M e) P h e I I], 4.51[\mathrm{dd}, \mathrm{J}=9.0,4.5 \mathrm{~Hz}, 1 \mathrm{H}, 2-\mathrm{H},(\beta M e) P h e l], 4.58(\mathrm{dd}, \mathrm{J}=9.5$, $2.5 \mathrm{~Hz}, 1 \mathrm{H}, 2-\mathrm{H}, \mathrm{a}-\mathrm{Thr}), 4.64$ (dd, $J=9.0,9.0 \mathrm{~Hz}, 1 \mathrm{H}, 2-\mathrm{H}, l l e), 5.09[\mathrm{~m}, 1 \mathrm{H}, 2-\mathrm{H}$, (3-Ncp)Ala II], 5.24 [m, $\left.1 \mathrm{H}, 1^{\prime}-\mathrm{H},(4-P e) P r o\right], 5.40$ (dq, J = 7.0, $\left.2.5 \mathrm{~Hz}, 1 \mathrm{H}, 3-\mathrm{H}, \mathrm{a}-T h r\right), 5.62$ [dq, J = 10.5, 7.0 Hz, $1 \mathrm{H}, 2 '-\mathrm{H},(4-P e) P r o], 6.11$ (d, J = 5.0 Hz, $1 \mathrm{H}, 4-\mathrm{H}$, Chpca), 6.74 [d, $J=7.0 \mathrm{~Hz}, 1 \mathrm{H}, \mathrm{NH},(3-N c p) A l a$ I] $6.75[\mathrm{~d}, J=10.0 \mathrm{~Hz}, 1 \mathrm{H}, \mathrm{NH},(\beta M e) P h e I I, 6.81[\mathrm{~d}$, $J=9.5 \mathrm{~Hz}, 1 \mathrm{H}, \mathrm{NH},(\beta M e) P h e ~ l], 6.84(\mathrm{~d}, J=5.0 \mathrm{~Hz}, 1 \mathrm{H}, 3-\mathrm{H}$, Chpca), $7.00-7.02(\mathrm{~m}, 1 \mathrm{H}$, Ar-H), 7.02-7.12 (m, $4 \mathrm{H}, \mathrm{Ar}-\mathrm{H}), 7.14-7.18(\mathrm{~m}, 1 \mathrm{H}, \mathrm{Ar}-\mathrm{H}), 7.19-7.22(\mathrm{~m}, 4 \mathrm{H}, \mathrm{Ar}-\mathrm{H}), 7.26(\mathrm{~d}$, $J=9.0 \mathrm{~Hz}, 1 \mathrm{H}, \mathrm{NH}, I l e), 8.23[\mathrm{~d}, J=9.0 \mathrm{~Hz}, 1 \mathrm{H}, \mathrm{NH},(3-N c p) A l a I I], 8.96(\mathrm{~d}, J=9.5 \mathrm{~Hz}, 1 \mathrm{H}$, $\mathrm{NH}$, Thr).

\section{Kalium-Hormaomycin (16-K)}

${ }^{1} \mathrm{H}-\mathrm{NMR}\left(600 \mathrm{MHz}, \mathrm{CDCl}_{3}\right): \delta=-0.69$ [ddd, $J=7.0,7.0,7.0 \mathrm{~Hz}, 1 \mathrm{H}, 3{ }^{\prime}-\mathrm{H}_{\mathrm{a}}$, (3-Ncp)Ala I], -0.14 [ddd, $\left.J=14.0,9.0,4.5 \mathrm{~Hz}, 1 \mathrm{H}, 3-\mathrm{H}_{\mathrm{a}},(3-N c p) A l a ~ I\right], 0.26$ [m, $1 \mathrm{H}, 1$ '- H, (3-Ncp)Ala I], 0.54 [ddd, $J=14.0,6.0,5.0 \mathrm{~Hz}, 1 \mathrm{H}, 3-\mathrm{H}_{\mathrm{b}},(3-N c p) A l a$ ]], $0.88(\mathrm{t}, \mathrm{J}=7.0 \mathrm{~Hz}, 3 \mathrm{H}, 5-\mathrm{H}, I l e)$, $0.98\left[\mathrm{~m}, 2 \mathrm{H}, 3\right.$ '- $\mathrm{H}_{\mathrm{b}}$, (3-Ncp)Ala I, 3'- $\mathrm{H}_{\mathrm{a}}$, (3-Ncp)Ala II], 1.02 (d, J = 7.0 Hz, $\left.3 \mathrm{H}, 1^{\prime}-\mathrm{H}, I l e\right), 1.31$ [d, J = 6.5 Hz, $3 \mathrm{H}, 4-\mathrm{H},(\beta M e) P h e I I], 1.30-1.35\left(\mathrm{~m}, 1 \mathrm{H}, 4-\mathrm{H}_{\mathrm{a}}, I l e\right), 1.39[\mathrm{~d}, J=7.2 \mathrm{~Hz}, 3 \mathrm{H}$, 4-H, (BMe)Phe I], $1.53(\mathrm{~d}, \mathrm{~J}=6.5 \mathrm{~Hz}, 3 \mathrm{H}, \mathrm{a}-\mathrm{Thr}), 1.54-1.60\left[\mathrm{~m}, 2 \mathrm{H}, 3-\mathrm{H}_{\mathrm{a}}\right.$, (3-Ncp)Ala II, $\left.4-\mathrm{H}_{\mathrm{b}}, \quad / l e\right], 1.67$ [dd, J = 7.0, 2.0 Hz, 3 H, 3'- $\left.\mathrm{H},(4-P e) P r o\right], 1.76-1.84\left[\mathrm{~m}, 2 \mathrm{H}, 3-\mathrm{H}_{\mathrm{b}}\right.$, (3-Ncp)Ala II, 3- $\mathrm{H}_{\mathrm{a}}$, (4-Pe)Pro], 1.84-1.95 [m, 3 H, 1'-H, 3'- $\mathrm{H}_{\mathrm{b}}$ (3-Ncp)Ala II, 3-H, Ile], 2.37 [ddd, $J=13.0,5.5,5.5 \mathrm{~Hz}, 1 \mathrm{H}, 3-\mathrm{H}_{\mathrm{b}},(4-P e) P r o$ ], 2.90 [ddd, $J=7.0,3.5,3.5 \mathrm{~Hz}, 1 \mathrm{H}, 2 \cdot-\mathrm{H}$, (3-Ncp)Ala I], 3.00 [dq, J =11.0, $6.5 \mathrm{~Hz}, 1 \mathrm{H}, 3-\mathrm{H},(\beta M e) P h e ~ I I], 3.25-3.32[\mathrm{~m}, 2 \mathrm{H}, 4-\mathrm{H}$, 
5- $\left.\mathrm{H}_{\mathrm{a}},(4-P e) P r o\right], 3.48[\mathrm{~m}, 1 \mathrm{H}, 2-\mathrm{H},(3-N c p) A l a ~], 3.67[\mathrm{dq}, J=7.0,4.5 \mathrm{~Hz}, 1 \mathrm{H}, 3-\mathrm{H}$, ( $\beta$ Me)Phe I], 3.97 [m, $\left.1 \mathrm{H}, 5-\mathrm{H}_{\mathrm{b}},(4-P e) P r o\right], 4.02$ [ddd, J = 7.0, 3.5, 3.5 Hz, $1 \mathrm{H}, 2 '-\mathrm{H}$, (3-Ncp)Ala II], 4.26 [dd, J = 11.5, $6.0 \mathrm{~Hz}, 1 \mathrm{H}, 2-\mathrm{H},(4-P e) P r o], 4.36$ [dd, J = 11.0, $11.0 \mathrm{~Hz}$, $1 \mathrm{H}, 2-\mathrm{H},(\beta M e) P h e I I], 4.45[\mathrm{dd}, \mathrm{J}=9.0,4.5 \mathrm{~Hz}, 1 \mathrm{H}, 2-\mathrm{H},(\beta M e) P h e l], 4.57(\mathrm{dd}, J=9.5$, $2.5 \mathrm{~Hz}, 1 \mathrm{H}, 2-\mathrm{H}, \mathrm{a}-T h r), 4.65(\mathrm{dd}, J=9.0,9.0 \mathrm{~Hz}, 1 \mathrm{H}, 2-\mathrm{H}, I l e), 5.11[\mathrm{~m}, 1 \mathrm{H}, 2-\mathrm{H}$, (3-Ncp)Ala II], 5.26 [m, $\left.1 \mathrm{H}, 1^{\prime}-\mathrm{H},(4-P e) P r o\right], 5.40$ (dq, J = 7.0, $2.5 \mathrm{~Hz}, 1 \mathrm{H}, 3-\mathrm{H}$, a-Thr), 5.62 [dq, J = 10.5, 7.0 Hz, $1 \mathrm{H}, 2$ '-H, (4-Pe)Pro], 6.13 (d, J = 5.0 Hz, $1 \mathrm{H}, 4-\mathrm{H}$, Chpca), 6.44 [d, $J=7.0 \mathrm{~Hz}, 1 \mathrm{H}, \mathrm{NH},(3-N c p) A l a$ I] $6.78[\mathrm{~d}, J=10.0 \mathrm{~Hz}, 1 \mathrm{H}, \mathrm{NH},(\beta M e) P h e I I], 6.79$ [d, $J=9.5 \mathrm{~Hz}, 1 \mathrm{H}, \mathrm{NH},(\beta M e) P h e ~ l], 6.84(\mathrm{~d}, J=5.0 \mathrm{~Hz}, 1 \mathrm{H}, 3-\mathrm{H}$, Chpca), 7.00-7.02 (m, $1 \mathrm{H}$, Ar-H), 7.02-7.12 (m, $4 \mathrm{H}, \mathrm{Ar}-\mathrm{H}), 7.14-7.18(\mathrm{~m}, 1 \mathrm{H}, \mathrm{Ar}-\mathrm{H}), 7.19-7.22(\mathrm{~m}, 4 \mathrm{H}, \mathrm{Ar}-\mathrm{H}), 7.26$ (d, $J=9.0 \mathrm{~Hz}, 1 \mathrm{H}, \mathrm{NH}, I l e), 8.06[\mathrm{~d}, J=9.0 \mathrm{~Hz}, 1 \mathrm{H}, \mathrm{NH},(3-N c p) A l a I], 9.08$ (d, $J=9.5 \mathrm{~Hz}, 1 \mathrm{H}$, $\mathrm{NH}$, Thr).

\section{Gallium-Hormaomycin (16-Ga)}

${ }^{1} \mathrm{H}-N M R\left(600 \mathrm{MHz}, \mathrm{CDCl}_{3}\right): \delta=-0.64$ [ddd, $J=7.0,7.0,7.0 \mathrm{~Hz}, 1 \mathrm{H}, 3$ '- $\mathrm{H}_{\mathrm{a}}$, (3-Ncp)Ala I], -0.11 [ddd, $J=14.0,9.0,4.5 \mathrm{~Hz}, 1 \mathrm{H}, 3-\mathrm{H}_{\mathrm{a}}$, (3-Ncp)Ala I], 0.28 [m, $1 \mathrm{H}, 1$ '-H, (3-Ncp)Ala I], 0.50 [ddd, $J=14.0,6.0,5.0 \mathrm{~Hz}, 1 \mathrm{H}, 3-\mathrm{H}_{\mathrm{b}},(3-N c p) A l a$ I], 0.88 (t, $J=7.0 \mathrm{~Hz}, 3 \mathrm{H}, 5-\mathrm{H}, I l e$ ), 0.98-1.00 [m, 2 H, 3'- $\mathrm{H}_{\mathrm{b}}$, (3-Ncp)Ala I, 3'- $\mathrm{H}_{\mathrm{a}}$, (3-Ncp)Ala II], 1.01 (d, J = 7.0 Hz, 3 H, 1'-H, Ile), $1.30[\mathrm{~d}, J=6.5 \mathrm{~Hz}, 3 \mathrm{H}, 4-\mathrm{H},(\beta M e) P h e I I], 1.30-1.35\left(\mathrm{~m}, 1 \mathrm{H}, 4-\mathrm{H}_{\mathrm{a}}, I l e\right), 1.39$ [d, J = 7.2 Hz, $3 \mathrm{H}, 4-\mathrm{H},(\beta M e) P h e ~], 1.53(\mathrm{~d}, \mathrm{~J}=6.5 \mathrm{~Hz}, 3 \mathrm{H}, \mathrm{a}-T h r), 1.54-1.60$ [m, $2 \mathrm{H}, 3-\mathrm{H}_{\mathrm{a}},(3-N c p) A l a ~ I I$, 4- $\left.\mathrm{H}_{\mathrm{b}}, I l e\right], 1.67$ [dd, J = 7.0, 2.0 Hz, 3 H, 3'-H, (4-Pe)Pro], 1.76-1.84 [m, $2 \mathrm{H}, 3-\mathrm{H}_{\mathrm{b}}$, (3-Ncp)Ala II, 3- $\mathrm{H}_{\mathrm{a}}$, (4-Pe)Pro], 1.84-1.95 [m, 3 H, 1'- $\mathrm{H}, 3{ }^{\prime}-\mathrm{H}_{\mathrm{b}}$ (3-Ncp)Ala II, 3-H, Ile], 2.37 [ddd, $J=13.0,5.5,5.5 \mathrm{~Hz}, 1 \mathrm{H}, 3-\mathrm{H}_{\mathrm{b}},(4-P e) P r o$ ], 2.90 [ddd, $J=7.0,3.5,3.5 \mathrm{~Hz}, 1 \mathrm{H}, 2$ '- $\mathrm{H}$, (3-Ncp)Ala I], 2.99 [dq, J = 11.0, 6.5 Hz, $1 \mathrm{H}, 3-\mathrm{H},(\beta M e) P h e ~ I I], 3.25-3.32[\mathrm{~m}, 2 \mathrm{H}, 4-\mathrm{H}$, 5- $\mathrm{H}_{\mathrm{a}}$, (4-Pe)Pro], 3.48 [m, $\left.1 \mathrm{H}, 2-\mathrm{H},(3-N c p) A l a ~ I\right], 3.67$ [dq, J =7.0, $4.5 \mathrm{~Hz}, 1 \mathrm{H}, 3-\mathrm{H}$, ( $\beta$ Me)Phe I], 3.97 [m, $\left.1 \mathrm{H}, 5-\mathrm{H}_{\mathrm{b}},(4-P e) P r o\right], 4.02$ [ddd, J = 7.0, 3.5, $3.5 \mathrm{~Hz}, 1 \mathrm{H}, 2^{\prime}-\mathrm{H}$, (3-Ncp)Ala II], 4.27 [dd, J = 11.5, 6.0 Hz, $1 \mathrm{H}, 2-\mathrm{H},(4-P e) P r o], 4.38$ [dd, $J=11.0,11.0 \mathrm{~Hz}$, $1 \mathrm{H}, 2-\mathrm{H},(\beta M e) P h e I I], 4.46[\mathrm{dd}, \mathrm{J}=9.0,4.5 \mathrm{~Hz}, 1 \mathrm{H}, 2-\mathrm{H},(\beta M e) P h e l], 4.57(\mathrm{dd}, \mathrm{J}=9.5$, $2.5 \mathrm{~Hz}, 1 \mathrm{H}, 2-\mathrm{H}, \mathrm{a}-T h r), 4.65$ (dd, J = 9.0, $9.0 \mathrm{~Hz}, 1 \mathrm{H}, 2-\mathrm{H}, \| l e), 5.11[\mathrm{~m}, 1 \mathrm{H}, 2-\mathrm{H}$, (3-Ncp)Ala II], 5.25 [m, $\left.1 \mathrm{H}, 1^{\prime}-\mathrm{H},(4-P e) P r o\right], 5.40$ (dq, J = 7.0, $2.5 \mathrm{~Hz}, 1 \mathrm{H}, 3-\mathrm{H}$, a-Thr), 5.62 [dq, J = 10.5, 7.0 Hz, $1 \mathrm{H}, 2$ '-H, (4-Pe)Pro], 6.13 (d, J = 5.0 Hz, $1 \mathrm{H}, 4-\mathrm{H}$, Chpca), 6.44 [d, $J=7.0 \mathrm{~Hz}, 1 \mathrm{H}, \mathrm{NH},(3-N c p) A l a$ I] $6.78[\mathrm{~d}, J=10.0 \mathrm{~Hz}, 1 \mathrm{H}, \mathrm{NH},(\beta M e) P h e I I], 6.79$ [d, $J=9.5 \mathrm{~Hz}, 1 \mathrm{H}, \mathrm{NH},(\beta M e) P h e ~ l], 6.81(\mathrm{~d}, J=5.0 \mathrm{~Hz}, 1 \mathrm{H}, 3-\mathrm{H}$, Chpca $), 7.00-7.02(\mathrm{~m}, 1 \mathrm{H}$, Ar-H), 7.02-7.12 (m, $4 \mathrm{H}, \mathrm{Ar}-\mathrm{H}), 7.14-7.18(\mathrm{~m}, 1 \mathrm{H}, \mathrm{Ar}-\mathrm{H}), 7.19-7.22(\mathrm{~m}, 4 \mathrm{H}, \mathrm{Ar}-\mathrm{H}), 7.26$ (d, $J=9.0 \mathrm{~Hz}, 1 \mathrm{H}, \mathrm{NH}, I l e), 8.06[\mathrm{~d}, J=9.0 \mathrm{~Hz}, 1 \mathrm{H}, \mathrm{NH},(3-N c p) A l a I I], 9.08$ (d, J = 9.5 Hz, $1 \mathrm{H}$, $\mathrm{NH}, \mathrm{Thr})$. 


\subsection{Vorläufer-dirigierte Biosynthese (PDB) an Streptomyces griseoflavus (Stamm W 384)}

Die Kultivierungen erfolgten unter Standardbedingungen wie in Kap. B.2.1.3. beschrieben. Die potentiellen Vorläufer wurden in $50 \mathrm{~mL}$ sterilem Wasser gelöst (Einstellung des $\mathrm{pH}$ auf 6.5-7.0) und $a b$ der 24. Stunde über einen Zeitraum von $10 \mathrm{~h}$ kontinuierlich $\mathrm{zu}$ der Kulturbrühe gepumpt.

\subsubsection{Variation der 3-(2'-Nitrocyclopropyl)alanin-Einheit}

Alle im Folgenden aufgelisteten Aminosäuren (Tab. 16) sind Syntheseprodukte ${ }^{67}$, hergestellt von DR. B.D. ZLATOPOLSKIJ, AK PROF. DR. A. DE MEIJERE, Universität Göttingen.

\begin{tabular}{|c|c|c|c|}
\hline Aminosäure & $\begin{array}{c}\text { Gefütterte Menge } \\
{[\mathrm{mmol}]}\end{array}$ & $\begin{array}{l}\text { Hormaomycin- } \\
\text { Produktion }\end{array}$ & $\begin{array}{l}\text { Hormaomycin- } \\
\text { Derivate }\end{array}$ \\
\hline \multirow{2}{*}{$\begin{array}{l}\text { rac-2-(2'-Nitrocyclo- } \\
\text { propyl)glycin }\end{array}$} & 1.0 & + & $21 a-c$ \\
\hline & 2.0 & + & $21 a-c$ \\
\hline rac-5-Nitronorvalin & 2.0 & + & $21 a-c$ \\
\hline L-5-Nitronorvalin & 2.0 & + & $21 a-c$ \\
\hline \multirow[t]{2}{*}{ D-5-Nitronorvalin } & 1.0 & + & - \\
\hline & 2.0 & + & - \\
\hline rac-6-Nitronorleucin & 2.0 & + & $26 a-c$ \\
\hline \multirow[t]{2}{*}{ L-6-Nitronorleucin } & 1.0 & + & $26 a-c$ \\
\hline & 2.0 & + & $26 a-c$ \\
\hline D-6-Nitronorleucin & 2.0 & + & - \\
\hline L-5-Nitro-4-thianorvalin ${ }^{a}$ & 2.0 & + & - \\
\hline \multirow[t]{2}{*}{$\begin{array}{l}\text { L-ortho- } \\
\text { Nitrophenylalanin }\end{array}$} & 1.0 & + & - \\
\hline & 2.0 & + & - \\
\hline L-Ornithin & 2.0 & + & $(22 a-c)^{b}$ \\
\hline
\end{tabular}

a) Endkonzentration $2.0 \mathrm{mmol}$, Fütterung in $5 \times 0.4 \mathrm{mmol}$ Portionen über jeweils $2 \mathrm{~h}$ aufgrund Instabilität der Aminosäure in Lösung; ${ }^{\text {b) }}$ Ergebnis nicht eindeutig (s. Kap. 2.3.1.2, S. 26).

Tab. 16: Zu Streptomyces griseoflavus (Stamm W 384) gefütterte Aminosäuren für den Austausch der (3-Ncp)Ala-Einheiten. 


\subsubsection{Isolierung und Charakterisierung der Hormaomycinderivate aus} Fütterungsexperimenten mit 5-Nitronorvalin und 2-(2'-Nitrocyclopropyl)glycin

Die Vorläufer wurden unter Standardbedingungen gefüttert. Das Rohprodukt wurde mit eiskaltem Pentan gewaschen und an Kieselgel (Aceton/Cyclohexan 2:3, $120 \times 45 \mathrm{~mm}$ ) chromatographiert. Die Trennung der Derivate 21a-c erfolgte mit präparativer HPLC (Säule A, 62 \% Acetonitril in Wasser + $0.1 \%$ TFA). Die Ausbeuten der Fütterungen sind in Tab. 17 dargestellt.

\begin{tabular}{cccc}
\hline & \multicolumn{3}{c}{ Ausbeuten [mg] } \\
& $\mathbf{2 1 a}$ & $\mathbf{2 1 b}$ & $\mathbf{2 1 c}$ \\
\hline $\begin{array}{c}\text { rac-2-(2'-Nitrocyclo- } \\
\text { propyl)glycin }\end{array}$ & $\sim 0.1$ & $\sim 0.1$ & $\sim 0.1$ \\
$\begin{array}{c}\text { rac-5-Nitronorvalin } \\
\text { L-5-Nitronorvalin }\end{array}$ & 2.0 & 1.3 & $\sim 0.1$ \\
\hline
\end{tabular}

Tab. 17: Ausbeuten der Fütterungsexperimente.

\section{Hormaomycin $D_{1}(21 a)$ \\ $\mathrm{C}_{54} \mathrm{H}_{69} \mathrm{~N}_{10} \mathrm{O}_{14} \mathrm{Cl}(1116.47)$ \\ farbloser Feststoff \\ UV-löschend (254 nm)}

Anfärbeverhalten: rosa (Ehrlich).

$\mathbf{R}_{\mathbf{t}}=23.9 \mathrm{~min}$

(Säule A, 62 \% Acetonitril in Wasser $+0.1 \%$ TFA).

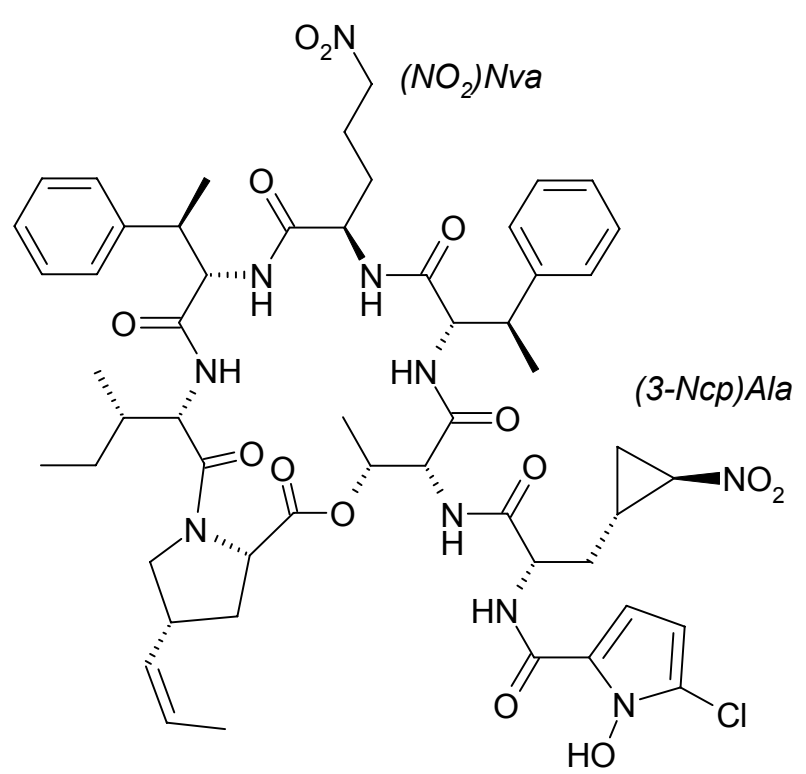

$21 a$

ESI-MS: (pos. lonen) $\mathrm{m} / \mathrm{z}=1139[\mathrm{M}+\mathrm{Na}]^{+}, 1117[\mathrm{M}+\mathrm{H}]^{+}$. (neg. lonen) $\mathrm{m} / \mathrm{z}=1115[\mathrm{M}-\mathrm{H}]^{-}$.

HR-ESI-MS: berechnet: $1117.47560[\mathrm{M}+\mathrm{H}]^{+}$. gefunden: $1117.47530(\Delta=0.27 \mathrm{ppm})$.

${ }^{1} \mathrm{H}-\mathrm{NMR}\left(600 \mathrm{MHz}, \mathrm{CDCl}_{3}\right): \delta=0.15-0.21\left[\mathrm{~m}, 2 \mathrm{H}, 4-\mathrm{H},\left(\mathrm{NO}_{2}\right) \mathrm{Nva}\right], 0.22-0.30[\mathrm{~m}, 2 \mathrm{H}$, 3-H, $\left(\mathrm{NO}_{2}\right) \mathrm{Nva}$ ], 0.89 (t, J = 7.2 Hz, 3 H, 5-H, Ile), 1.00 [m, $1 \mathrm{H}, 3^{\prime}-\mathrm{H}_{\mathrm{a}}$, (3-Ncp)Ala] 1.02 (d, 
$J=7.2 \mathrm{~Hz}, 3 \mathrm{H}, 1 '-\mathrm{H}, I / e), 1.29[\mathrm{~d}, J=6.6 \mathrm{~Hz}, 3 \mathrm{H}, 4-\mathrm{H},(\beta M e) P h e I I], 1.30-1.35(\mathrm{~m}, 1 \mathrm{H}$, 4- $\left.\mathrm{H}_{\mathrm{a}}, I l e\right), 1.39$ [d, J = 7.2 Hz, 3 H, 4-H, $\left.(\beta M e) P h e ~ I\right], 1.53$ (d, J = 6.6 Hz, $\left.3 \mathrm{H}, a-T h r\right), 1.54-$ $1.60\left[\mathrm{~m}, 2 \mathrm{H}, 3-\mathrm{H}_{\mathrm{a}}(3-\mathrm{Ncp}) A l a, 4-\mathrm{H}_{\mathrm{b}}, I l e\right], 1.67$ [dd, J = 7.2, $1.8 \mathrm{~Hz}, 3 \mathrm{H}, 3 '-\mathrm{H},(4-P e)$ Pro], 1.73-1.94 [m, $7 \mathrm{H}, 3-\mathrm{H}, 1^{\prime}-\mathrm{H}, 3^{\prime}-\mathrm{H}_{\mathrm{b}}$ (3-Ncp)Ala, 3-Ha, (4-Pe)Pro, 3-H, Ile], 2.35 [ddd, J = 13.2,

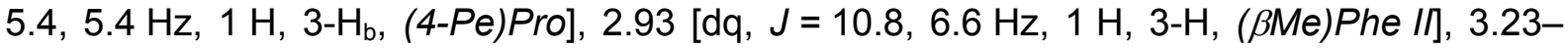
$3.33\left[\mathrm{~m}, 3 \mathrm{H}, 4-\mathrm{H}, 5-\mathrm{H}_{\mathrm{a}},(4-\mathrm{Pe}) \operatorname{Pro}, 2-\mathrm{H},\left(\mathrm{NO}_{2}\right) \mathrm{Nva}\right.$ ], 3.43-3.52 [m, $2 \mathrm{H}, 5-\mathrm{H},\left(\mathrm{NO}_{2}\right) \mathrm{Nva}$ ], 3.66 [dq, J = 3.8, 7.2 Hz, $1 \mathrm{H}, 3-\mathrm{H},(\beta M e) P h e ~], ~ 3.97-4.01\left[\mathrm{~m}, 1 \mathrm{H}, 5-\mathrm{H}_{\mathrm{b}},(4-P e) P r o\right], 4.03$ [ddd, $J=6.9,3.3,3.3 \mathrm{~Hz}, 1 \mathrm{H}, 2 \mathrm{-H},(3-N c p) A l a], 4.26$ [dd, $J=11.1,6.3 \mathrm{~Hz}, 1 \mathrm{H}, 2-\mathrm{H},(4-P e) P r o]$, 4.38 [dd, $J=10.8,10.8 \mathrm{~Hz}, 1 \mathrm{H}, 2-\mathrm{H},(\beta M e) P h e I I], 4.59$ (dd, J = 9.0, 2.4 Hz, $1 \mathrm{H}, 2-\mathrm{H}$, a-Thr), $4.64[\mathrm{dd}, J=10.2,3.8 \mathrm{~Hz}, 1 \mathrm{H}, 2-\mathrm{H},(\beta M e) P h e$ ], 4.65 (dd, $J=9.0,9.0 \mathrm{~Hz}, 1 \mathrm{H}, 2-\mathrm{H}, I l e)$, 5.08-5.19 [m, $1 \mathrm{H}, 2-\mathrm{H},(3-N c p) A l a], 5.23-5.30\left[\mathrm{~m}, 1 \mathrm{H}, 1^{\prime}-\mathrm{H},(4-P e) P r o\right], 5.41$ (dq, J = 6.6, $2.4 \mathrm{~Hz}, 1 \mathrm{H}, 3-\mathrm{H}, \mathrm{a}-T h r), 5.62$ [dq, $\left.J=10.8,7.2 \mathrm{~Hz}, 1 \mathrm{H}, 2^{\prime}-\mathrm{H},(4-P e) P r o\right], 6.12$ (d, J = 4.8 Hz, $1 \mathrm{H}, 4-\mathrm{H}$, Chpca), 6.40 (d, J = 7.2 Hz, $1 \mathrm{H}, \mathrm{NH}), 6.77$ (d, J = 4.8 Hz, $1 \mathrm{H}, 3-\mathrm{H}$, Chpca), 6.86 (d, J = 10.2 Hz, $1 \mathrm{H}, \mathrm{NH}), 6.99(\mathrm{~d}, J=10.2 \mathrm{~Hz}, 1 \mathrm{H}, \mathrm{NH}), 7.02-7.12(\mathrm{~m}, 4 \mathrm{H}, \mathrm{Ar}-\mathrm{H}), 7.14-$ $7.18(\mathrm{~m}, 2 \mathrm{H}, \mathrm{Ar}-\mathrm{H}), 7.19-7.22(\mathrm{~m}, 4 \mathrm{H}, \mathrm{Ar}-\mathrm{H}, \mathrm{NH}), 7.33$ (d, J = 9.0 Hz, $1 \mathrm{H}, \mathrm{NH}), 8.00$ (d, $J=9.0 \mathrm{~Hz}, 1 \mathrm{H}, \mathrm{NH}), 9.11(\mathrm{~d}, J=9.0 \mathrm{~Hz}, 1 \mathrm{H}, \mathrm{NH})$;

${ }^{13} \mathrm{C}-\mathrm{NMR}\left(150.8 \mathrm{MHz}, \mathrm{CDCl}_{3}\right): \delta={ }^{13} \mathrm{C}$ NMR $\left(150.8 \mathrm{MHz}, \mathrm{CDCl}_{3}\right): \delta=10.5(+, \mathrm{C}-5, \mathrm{Ile}), 13.3$

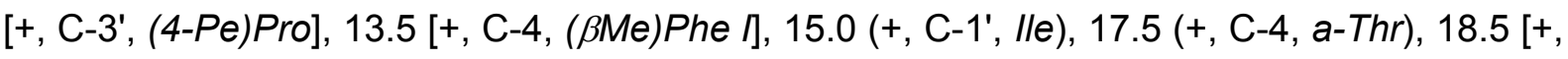
C-4, (BMe)Phe II], 19.3 [-, C-3', (3-Ncp)Ala], 21.7 [-, C-4, $\left.\left(\mathrm{NO}_{2}\right) \mathrm{Nva}\right], 22.7$ [+, C-1', (3-Ncp)Ala], 25.0 (-, C-4, Ile), 31.9 [-, C-3, $\left(\mathrm{NO}_{2}\right) \mathrm{Nva}$ ], 35.0 [-, C-3, (3-Ncp)Ala], 35.5 [-, C-3,

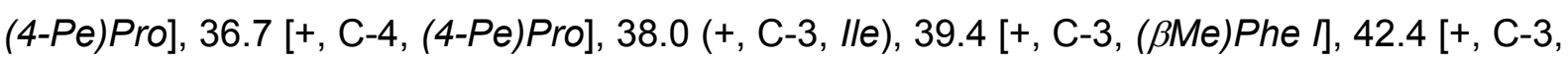
(BMe)Phe II], 50.9 [+, C-2, (3-Ncp)Ala], 51.2 [+, C-2, $\left(\mathrm{NO}_{2}\right) \mathrm{Nva}$ ], 52.4 [-, C-5, (4-Pe)Pro], 54.6 (+, C-2, Ile), 54.9 (+, C-2, a-Thr), 59.1 [+, C-2', (3-Ncp)Ala], 59.56 [+, C-2, ( $\beta M e) P h e ~ I I]$,

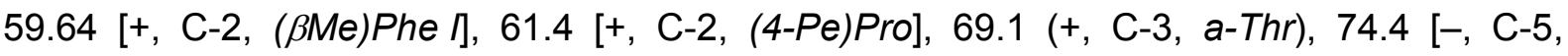
$\left(\mathrm{NO}_{2}\right) \mathrm{Nva}$ ], 103.8 (+, C-4, Chpca), 109.9 (+, C-3, Chpca), 119.7 (C quat, C-2, Chpca), 120.2 (C $\mathrm{C}_{\text {quat, }} \mathrm{C}-5$, Chpca $), 126.9,127.1,127.2,127.5,127.8,128.3,128.4,128.6$ [+, C-1', C-2', (4-Pe)Pro, Ar-C], 141.6, 141.8 ( $\left.\mathrm{C}_{\text {quat }}, \mathrm{Ar}-\mathrm{C}\right), 159.3$ ( $\left.\mathrm{C}_{\text {quat }}, \mathrm{C}-1, \mathrm{Chpca}\right), 168.8,169.5,169.9$, $170.9,171.3,171.6,171.9\left(\mathrm{C}_{\text {quat }}, \mathrm{C}-1\right)$. 
Hormaomycin $\mathrm{D}_{\mathbf{2}}$ (21b)

$\mathrm{C}_{54} \mathrm{H}_{69} \mathrm{~N}_{10} \mathrm{O}_{14} \mathrm{Cl}(1116.47)$

farbloser Feststoff

UV-löschend (254 nm)

Anfärbeverhalten: rosa (Ehrlich).

$\mathbf{R}_{\mathbf{t}}=21.9 \mathrm{~min}$

(Säule A, $62 \%$ Acetonitril in Wasser $+0.1 \%$ TFA).

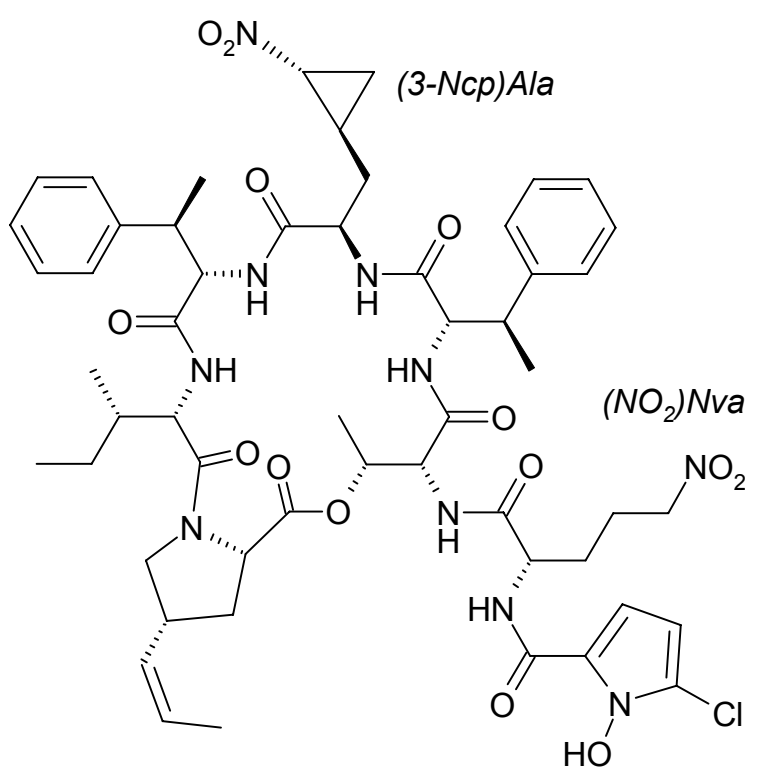

21b

ESI-MS: (pos. lonen) $\mathrm{m} / \mathrm{z}=1139[\mathrm{M}+\mathrm{Na}]^{+}, 1117[\mathrm{M}+\mathrm{H}]^{+}$.

(neg. lonen) $\mathrm{m} / \mathrm{z}=1115[\mathrm{M}-\mathrm{H}]^{-}$.

HR-ESI-MS: berechnet: $1117.47557[\mathrm{M}+\mathrm{H}]^{+}$.

gefunden: $1117.47526(\Delta=0.28 \mathrm{ppm})$.

${ }^{1} \mathrm{H}-\mathrm{NMR}\left(600 \mathrm{MHz}, \mathrm{CDCl}_{3}\right): \delta=-0.72-0.59\left[\mathrm{~m}, 1 \mathrm{H}, 3{ }^{\prime}-\mathrm{H}_{\mathrm{a}},(3-N c p) A l a\right],-0.19-0.06[\mathrm{~m}, 1 \mathrm{H}$, 3- $\mathrm{H}_{\mathrm{a}}$, (3-Ncp)Ala], 0.25-0.34 [m, $\left.1 \mathrm{H}, 1^{\prime}-\mathrm{H},(3-N c p) A l a\right], 0.55$ [ddd, J = 14.4, 4.8, 4.8 Hz, $1 \mathrm{H}$, 3- $\mathrm{H}_{\mathrm{b}}$, (3-Ncp)Ala], 0.92 (t, J = 7.2 Hz, $\left.3 \mathrm{H}, 5-\mathrm{H}, I l e\right), 0.97-1.04\left[\mathrm{~m}, 1 \mathrm{H}, 3{ }^{\prime}-\mathrm{H}_{\mathrm{b}},(3-N c p) A l a\right]$, $1.06\left(\mathrm{~d}, J=7.2 \mathrm{~Hz}, 3 \mathrm{H}, 1^{\prime}-\mathrm{H}, I l e\right), 1.24-1.32\left(\mathrm{~m}, 1 \mathrm{H}, 4-\mathrm{H}_{\mathrm{a}}, I l e\right), 1.30$ [d, $J=7.2 \mathrm{~Hz}, 3 \mathrm{H}, 4-\mathrm{H}$,

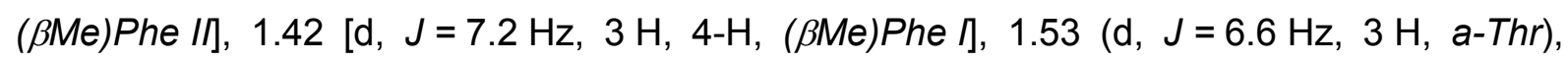
1.58-1.65 (m, $\left.1 \mathrm{H}, 4-\mathrm{H}_{\mathrm{b}}, I l e\right), 1.67-1.76\left[\mathrm{~m}, 1 \mathrm{H}, 3-\mathrm{H}_{\mathrm{a}},\left(\mathrm{NO}_{2}\right) \mathrm{Nva}\right.$ ], 1.69 [dd, $J=7.2,1.8 \mathrm{~Hz}$, $\left.3 \mathrm{H}, 3{ }^{\prime}-\mathrm{H},(4-P e) P r o\right], 1.76-1.84\left[\mathrm{~m}, 2 \mathrm{H}, 3-\mathrm{H}_{\mathrm{b}},\left(\mathrm{NO}_{2}\right) \mathrm{Nva}, 3-\mathrm{H}_{\mathrm{a}},(4-P e) P r o\right], 1.85-1.92$ (m, $1 \mathrm{H}, 3-\mathrm{H}, \mathrm{Ile}), 1.92-2.09$ [m, $2 \mathrm{H}, 4-\mathrm{H},\left(\mathrm{NO}_{2}\right) \mathrm{Nva}$ ], 2.38 [ddd, J = 12.0, 5.4, 5.4 Hz, $1 \mathrm{H}, 3-\mathrm{H}_{\mathrm{b}}$, (4-Pe)Pro], 2.91 [ddd, $J=6.6,3.0,3.0 \mathrm{~Hz}, 1 \mathrm{H}, 2 '-\mathrm{H}$, (3-Ncp)Ala], 3.04 [dq, $J=11.1,7.2 \mathrm{~Hz}$, $1 \mathrm{H}, 3-\mathrm{H},(\beta M e) P h e I I], 3.24-3.34\left[\mathrm{~m}, 2 \mathrm{H}, 4-\mathrm{H}, 5-\mathrm{H}_{\mathrm{a}},(4-P e) P r o\right], 3.45-3.52[\mathrm{~m}, 1 \mathrm{H}, 2-\mathrm{H}$, (3-Ncp)Ala], 3.69 [dq, J = 4.2, 7.2 Hz, $1 \mathrm{H}, 3-\mathrm{H},(\beta M e) P h e ~ I], 3.95-4.03\left[\mathrm{~m}, 1 \mathrm{H}, 5-\mathrm{H}_{\mathrm{b}}\right.$, (4-Pe)Pro], 4.26 [dd, J = 11.7, $6.0 \mathrm{~Hz}, 1 \mathrm{H}, 2-\mathrm{H},(4-P e) P r o], 4.36$ [t, J = 6.6 Hz, $2 \mathrm{H}, 5-\mathrm{H}$, $\left.\left(N_{2}\right) N v a\right], 4.37$ [dd, $\left.J=11.0,11.0 \mathrm{~Hz}, 1 \mathrm{H}, 2-\mathrm{H},(\beta M e) P h e I\right], 4.49[\mathrm{dd}, J=9.3,4.2 \mathrm{~Hz}, 1 \mathrm{H}$,

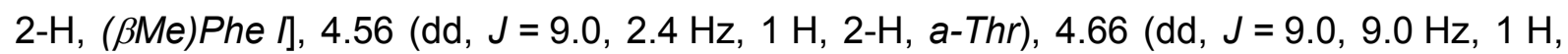
2-H, Ile), 5.04 [ddd, $\left.J=9.0,9.0,7.2 \mathrm{~Hz}, 1 \mathrm{H}, 2-\mathrm{H},\left(\mathrm{NO}_{2}\right) N v a\right], 5.24-5.31\left[\mathrm{~m}, 1 \mathrm{H}, 1^{\prime}-\mathrm{H}\right.$, (4-Pe)Pro], 5.38 (dq, J = 7.2, $2.4 \mathrm{~Hz}, 1 \mathrm{H}, 3-\mathrm{H}, a-T h r), 5.64$ [dq, J = 10.8, 7.2 Hz, $1 \mathrm{H}, 2^{\prime}-\mathrm{H}$, (4-Pe)Pro], 6.14 (d, J = 4.8 Hz, $1 \mathrm{H}, 4-\mathrm{H}$, Chpca), 6.46 (d, J = 6.6 Hz, $1 \mathrm{H}, \mathrm{NH}$ ), 6.75-6.84 (br, $1 \mathrm{H}, \mathrm{NH}$ ), 6.82 (d, J = 4.8 Hz, $1 \mathrm{H}, 3-\mathrm{H}$, Chpca), 6.88 (d, J = 9.6 Hz, $1 \mathrm{H}, \mathrm{NH}$ ), 7.02-7.05 
(m, $1 \mathrm{H}, \mathrm{Ar}-\mathrm{H}), 7.10-7.20(\mathrm{~m}, 5 \mathrm{H}, \mathrm{Ar}-\mathrm{H}), 7.21-7.27(\mathrm{~m}, 5 \mathrm{H}, \mathrm{Ar}-\mathrm{H}, \mathrm{NH}), 7.33(\mathrm{~d}, J=9.0 \mathrm{~Hz}$, $1 \mathrm{H}, \mathrm{NH}), 7.94-8.09(\mathrm{br}, 1 \mathrm{H}, \mathrm{NH}), 9.08(\mathrm{~d}, J=9.0 \mathrm{~Hz}, 1 \mathrm{H}, \mathrm{NH})$

${ }^{13}$ C-NMR (150.8 MHz, CDCl 3$): \delta=10.5(+, \mathrm{C}-5, \quad / l e), 13.3[+, \mathrm{C}-3$ ', (4-Pe)Pro, C-4, (BMe)Phe I], 14.8 (+, C-1', Ile), 17.0 (+, C-4, a-Thr), 17.1 [-, C-3', (3-Ncp)Ala], 17.7 [+, C-4, (BMe)Phe II], 20.1 [+, C-1', (3-Ncp)Ala], 23.7 [-, C-4, $\left(\mathrm{NO}_{2}\right) \mathrm{Nva}$ ], 25.1 (-, C-3, Ile), 30.7 [-, C-3, $\left(\mathrm{NO}_{2}\right) \mathrm{Nva}$ ], 33.0 [-, C-3, (3-Ncp)Ala], 35.5 [-, C-3, (4-Pe)Pro], 36.7 [+, C-4, (4-Pe)Pro], $38.1(+, \mathrm{C}-3, I l e), 39.3[+, \mathrm{C}-3,(\beta M e) P h e I], 41.7[+, \mathrm{C}-3,(\beta M e) P h e I I], 51.2[+, \mathrm{C}-2$, $\left(\mathrm{NO}_{2}\right) \mathrm{Nva}$ ], 51.8 [+, C-2, (3-Ncp)Ala], 52.8 [-, C-5, (4-Pe)Pro], 54.5 (+, C-2, Ile), 54.9 (+, C-2,

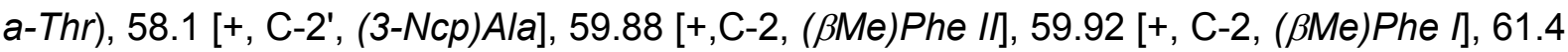
[+, C-2, (4-Pe)Pro], 69.3 (+, C-3, a-Thr), 75.0 [-, C-5, (NO $)_{2}-\mathrm{Nva}$, 103.5 (+, C-4, Chpca), 109.6 (+, C-3, Chpca), 119.8 ( $\mathrm{C}_{\text {quat, }}$ C-2, Chpca), 121.7 ( $\mathrm{C}_{\text {quat }}, \mathrm{C}-5$, Chpca), 127.0, 127.2, 127.4, 127.7, 128.5, 128.6 (+, Ar-C), 127.5 [+, C-1', (4-Pe)Pro], 128.3 [+, C-2', (4-Pe)Pro], 141.6, 142.1 ( $\left.\mathrm{C}_{\text {quat }}, \mathrm{Ar}-\mathrm{C}\right), 159.3$ ( $\left.\mathrm{C}_{\text {quat }}, \mathrm{C}-1, \mathrm{Chpca}\right), 168.5,168.7,169.7,170.7,171.3$, $171.6,172.3\left(C_{\text {quat }}, \mathrm{C}-1\right)$.

\section{Hormaomycin $D_{3}(21 c)$}

$\mathrm{C}_{53} \mathrm{H}_{69} \mathrm{~N}_{10} \mathrm{O}_{14} \mathrm{Cl}(1104.47)$

farbloser Feststoff

UV-löschend (254 nm)

Anfärbeverhalten: rosa (Ehrlich).

$\mathbf{R}_{\mathbf{t}}=20.9 \min$

(Säule A, 62 \% Acetonitril in Wasser $+0.1 \%$ TFA).

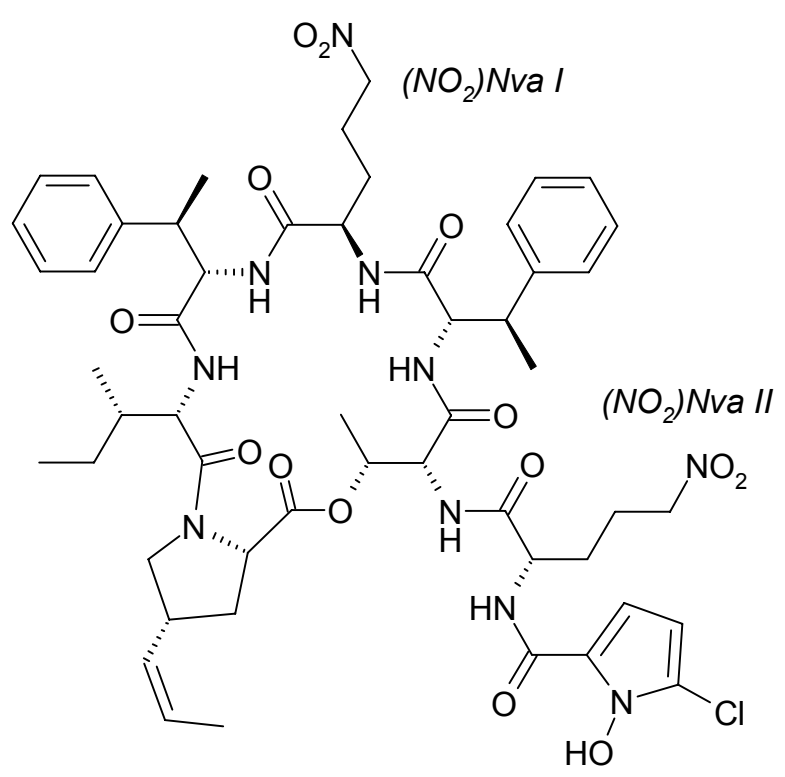

21c

ESI-MS: (pos. lonen) $\mathrm{m} / \mathrm{z}=1127[\mathrm{M}+\mathrm{Na}]^{+}, 1105[\mathrm{M}+\mathrm{H}]^{+}$.

(neg. lonen) $\mathrm{m} / \mathrm{z}=1103[\mathrm{M}-\mathrm{H}]^{-}$.

HR-ESI-MS: berechnet: $1105.47560[\mathrm{M}+\mathrm{H}]^{+}$.

gefunden: $1105.47511(\Delta=0.44 \mathrm{ppm})$.

${ }^{1} \mathrm{H}-\mathrm{NMR}\left(600 \mathrm{MHz}, \mathrm{CDCl}_{3}\right): \delta=0.11-0.21\left[\mathrm{~m}, 2 \mathrm{H}, 4-\mathrm{H},\left(\mathrm{NO}_{2}\right) \mathrm{Nva}\right.$ l], 0.21-0.32 [m, $2 \mathrm{H}, 3-\mathrm{H}$, $\left(\mathrm{NO}_{2}\right) \mathrm{Nva}$ i], 0.89 (t, J = 7.2 Hz, $\left.3 \mathrm{H}, 5-\mathrm{H}, I l e\right), 1.05$ (d, J = 7.2 Hz, $\left.3 \mathrm{H}, 1 '-\mathrm{H}, I / e\right), 1.29$ [d, $J=7.8 \mathrm{~Hz}, 3 \mathrm{H}, 4-\mathrm{H},(\beta M e) P h e \mathrm{i}], 1.40[\mathrm{~d}, J=7.2 \mathrm{~Hz}, 3 \mathrm{H}, 4-\mathrm{H},(\beta M e) P h e l], 1.52$ (d, $J=7.2 \mathrm{~Hz}, 3 \mathrm{H}, \mathrm{a}-T h r), 1.55-1.63\left(\mathrm{~m}, 1 \mathrm{H}, 4-\mathrm{H}_{\mathrm{a}}, I l e\right), 1.67$ [dd, $J=6.6,1.8 \mathrm{~Hz}, 3 \mathrm{H}, 3^{\prime}-\mathrm{H}$, 
(4-Pe)Pro], 1.68-1.73 [m, $\left.1 \mathrm{H}, 3-\mathrm{H}_{\mathrm{a}},\left(\mathrm{NO}_{2}\right) \mathrm{Nva} I /\right], 1.75-1.83\left[\mathrm{~m}, 3 \mathrm{H}, 3-\mathrm{H}_{\mathrm{b}}, 4-\mathrm{H}_{\mathrm{a}},\left(\mathrm{NO}_{2}\right) \mathrm{Nva}\right.$ II, 4- $\mathrm{H}_{\mathrm{b}}$, Ile], 1.83-2.03 [m, $3 \mathrm{H}, 4-\mathrm{H}_{\mathrm{b}}$, $\left(\mathrm{NO}_{2}\right) \mathrm{Nva} I I, 3-\mathrm{H}, I l e, 3-\mathrm{H}_{\mathrm{a}}$, (4-Pe)Pro], 2.35 [ddd, J = 12.0, 6.0, 6.0 Hz, $\left.1 \mathrm{H}, 3-\mathrm{H}_{\mathrm{b}},(4-P e) P r o\right], 2.94$ [dq, J = 10.6, 7.2 Hz, $\left.1 \mathrm{H}, 3-\mathrm{H},(\beta M e) P h e I I\right], 3.21-$ $3.31\left[\mathrm{~m}, 3 \mathrm{H}, 4-\mathrm{H}, 5-\mathrm{H}_{\mathrm{a}},(4-\mathrm{Pe}) \operatorname{Pro}, 2-\mathrm{H},\left(\mathrm{NO}_{2}\right) \mathrm{Nva}\right.$ l], 3.42-3.54 [m, $\left.2 \mathrm{H}, 5-\mathrm{H},\left(\mathrm{NO}_{2}\right) \mathrm{Nva} \mathrm{l}\right]$, $3.66[\mathrm{dq}, J=5.4,7.8 \mathrm{~Hz}, 1 \mathrm{H}, 3-\mathrm{H},(\beta M e) P h e l]$, 3.96-4.00 [m, $\left.1 \mathrm{H}, 5-\mathrm{H}_{\mathrm{b}},(4-P e) P r o\right], 4.24$ [dd, J = 11.7, $6.0 \mathrm{~Hz}, 1 \mathrm{H}, 2-\mathrm{H},(4-P e) P r o], 4.34\left[\mathrm{dd}, \mathrm{J}=6.6,6.6 \mathrm{~Hz}, 2 \mathrm{H}, 5-\mathrm{H},\left(\mathrm{NO}_{2}\right) \mathrm{Nva} / \mathrm{l}\right]$, 4.37 [dd, $J=10.6,10.6 \mathrm{~Hz}, 1 \mathrm{H}, 2-\mathrm{H},(\beta M e) P h e I I], 4.57$ (dd, $J=9.3,2.4 \mathrm{~Hz}, 1 \mathrm{H}, 2-\mathrm{H}$, a-Thr), 4.61-4.67 [m, $2 \mathrm{H}, 2-\mathrm{H},(\beta M e) P h e I, 2-\mathrm{H}, I l e], 5.00$ [ddd, J =7.2, 7.2, 7.2 Hz, $1 \mathrm{H}, 2-\mathrm{H}$, $\left(\mathrm{NO}_{2}\right) \mathrm{Nva} I \mathrm{I}$ ], 5.22-5.28 [m, $1 \mathrm{H}, 1^{\prime}-\mathrm{H},(4-\mathrm{Pe}) \operatorname{Pro}$ ], 5.37 (dq, J = 7.2, $2.4 \mathrm{~Hz}, 1 \mathrm{H}, 3-\mathrm{H}, \mathrm{a}-\mathrm{Thr}$ ), 5.62 [dq, $\left.J=10.8,6.6 \mathrm{~Hz}, 1 \mathrm{H}, 2^{\prime}-\mathrm{H},(4-P e) P r o\right], 6.12$ (d, J = 4.5 Hz, $1 \mathrm{H}, 4-\mathrm{H}$, Chpca), 6.36 (d, $J=7.2 \mathrm{~Hz}, 1 \mathrm{H}, \mathrm{NH}), 6.75(\mathrm{~d}, J=4.5 \mathrm{~Hz}, 1 \mathrm{H}, 3-\mathrm{H}$, Chpca), $6.92(\mathrm{~d}, J=9.6 \mathrm{~Hz}, 1 \mathrm{H}, \mathrm{NH})$, $6.94(\mathrm{~d}, J=9.0 \mathrm{~Hz}, 1 \mathrm{H}, \mathrm{NH}), 7.06-7.13(\mathrm{~m}, 4 \mathrm{H}, \mathrm{Ar}-\mathrm{H}), 7.14-7.17(\mathrm{~m}, 2 \mathrm{H}, \mathrm{Ar}-\mathrm{H}), 7.18-7.21$ $(\mathrm{m}, 4 \mathrm{H}, \mathrm{Ar}-\mathrm{H}, \mathrm{NH}), 7.38(\mathrm{~d}, J=9.0 \mathrm{~Hz}, 1 \mathrm{H}, \mathrm{NH}), 7.91(\mathrm{~d}, J=9.6 \mathrm{~Hz}, 1 \mathrm{H}, \mathrm{NH}), 9.11$ (d, $J=9.6 \mathrm{~Hz}, 1 \mathrm{H}, \mathrm{NH})$.

${ }^{13}$ C-NMR (150.8 MHz, CDCl 3 ): $\delta=10.5(+, \mathrm{C}-5$, Ile), 13.3 [+, C-3', (4-Pe)Pro], 13.6 [+, C-4,

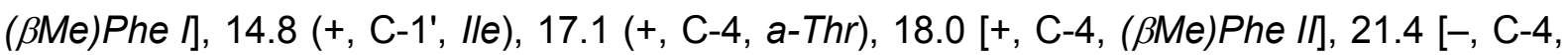
$\left.\left(\mathrm{NO}_{2}\right) \mathrm{Nva} I /\right], 21.8$ [-, C-4, $\left(\mathrm{NO}_{2}\right) \mathrm{Nva}$ I], 25.0 (-, C-3, Ile), 29.4 [-, C-3, $\left.\left(\mathrm{NO}_{2}\right) \mathrm{Nva} I I\right], 31.9$ [-, C-3, $\left(\mathrm{NO}_{2}\right) \mathrm{Nva}$ I], 35.6 [-, C-3, (4-Pe)Pro], 36.7 [+, C-4, (4-Pe)Pro], 38.1 (+, C-3, Ile), 39.4 [+,

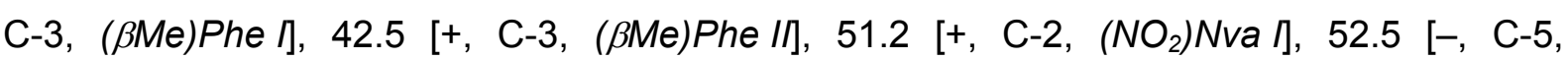
(4-Pe)Pro], 52.8 [+, C-2, $\left.\left(\mathrm{NO}_{2}\right) \mathrm{Nva} I I\right], 54.6$ (+, C-2, Ile), 54.9 (+, C-2, a-Thr), 59.56 [+,C-2,

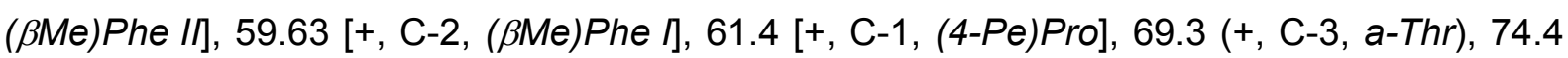
[-, C-5, $\left(\mathrm{NO}_{2}\right) \mathrm{Nva}$ I], 75.0 [-, C-5, $\left(\mathrm{NO}_{2}\right) \mathrm{Nva}$ II], 103.8 (+, C-4, Chpca), 109.8 (+, C-3, Chpca), 119.7 ( $\left.\mathrm{C}_{\text {quat }}, \mathrm{C}-2, \mathrm{Chpca}\right), 121.7$ ( $\left.\mathrm{C}_{\text {quat }}, \mathrm{C}-5, \mathrm{Chpca}\right), 126.9,127.16,127.20,127.6,128.5$, 128.6 [+, Ar-C], 127.8 [+, C-1', (4-Pe)Pro], 128.3 [+, C-2', (4-Pe)Pro], 141.6, $141.8\left(\mathrm{C}_{\text {quat }}\right.$, Ar-C), 159.3 (C quat $_{1}$ C-1, Chpca), 168.8, 169.4, 169.9, 170.9, 171.3, 171.7, 172.3 (C quat, C-1).

\subsubsection{Isolierung und Charakterisierung der Hormaomycinderivate aus Fütterungsexperimenten mit 6-Nitronorleucin}

Die Vorläufer wurden unter Standardbedingungen (s. Kap. B.2.3) gefüttert. Das Rohprodukt wurde mit eiskaltem Pentan gewaschen und an Kieselgel (Aceton/Cyclohexan 2:3, $120 \times 45 \mathrm{~mm}$ ) chromatographiert. Die Trennung der Derivate 26a-c erfolgte mit präparativer HPLC (63\% Acetonitril in Wasser, Säule E). Die Ausbeuten sind in Tab. 18 dargestellt. 


\begin{tabular}{|c|c|c|c|}
\hline & $26 a$ & $26 b$ & $26 c$ \\
\hline rac-6-Nitronorleucin & 1.9 & 1.0 & $\sim 1.5^{\mathrm{a}}$ \\
\hline L-6-Nitronorleucin & 2.2 & 0.9 & $\sim 1.3^{\mathrm{a}}$ \\
\hline
\end{tabular}

Tab. 18: Ausbeuten der Fütterungsexperimente mit Nitronorleucin-Vorläufern.

\section{Hormaomycin $\mathrm{E}_{1}$ (26a)}

$\mathrm{C}_{55} \mathrm{H}_{71} \mathrm{~N}_{10} \mathrm{O}_{14} \mathrm{Cl}(1130.48)$

farbloser Feststoff

UV-löschend (254 nm)

Anfärbeverhalten: rosa (Ehrlich).

$\mathbf{R}_{\mathbf{t}}=48.4 \mathrm{~min}$

(Säule $\mathrm{E} ; 63 \%$ Acetonitril in $\mathrm{H}_{2} \mathrm{O}$ ).

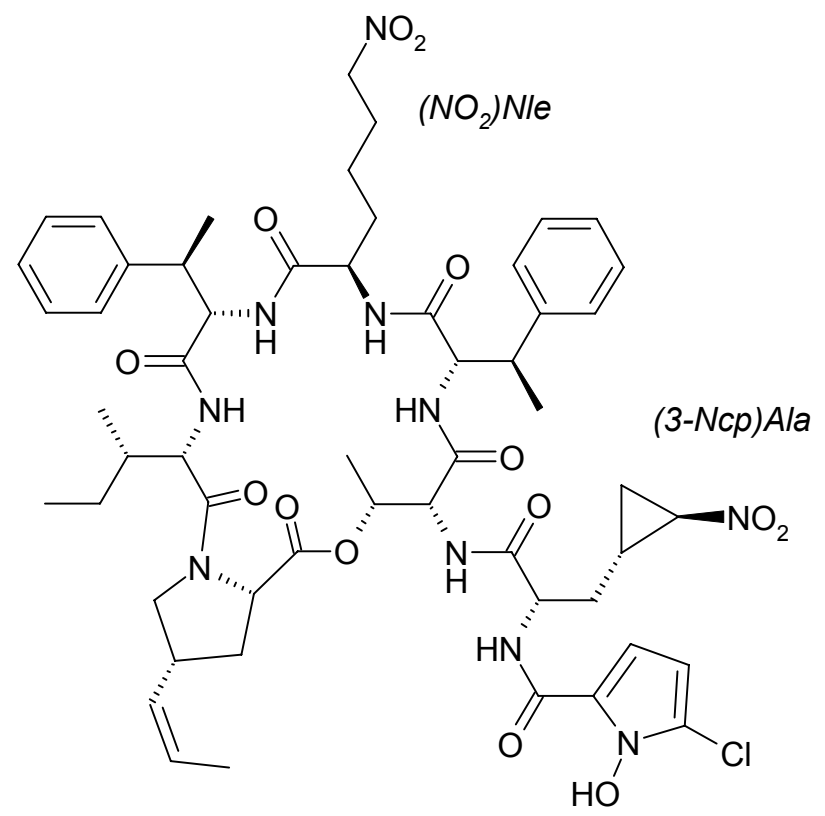

$26 a$

ESI-MS: (pos. lonen) $\mathrm{m} / \mathrm{z}=1153[\mathrm{M}+\mathrm{Na}]^{+}, 1131[\mathrm{M}+\mathrm{H}]^{+}$.

(neg. lonen) $\mathrm{m} / \mathrm{z}=1129[\mathrm{M}-\mathrm{H}]^{-}$.

HR-ESI-MS: berechnet: $1131.49125[\mathrm{M}+\mathrm{H}]^{+}, 1148.51780\left[\mathrm{M}+\mathrm{NH}_{4}\right]^{+}, 1153.47320[\mathrm{M}+\mathrm{Na}]^{+}$. gefunden: $1131.49133(\Delta=0.07 \mathrm{ppm}), 1148.51836(\Delta=0.49 \mathrm{ppm})$, $1153.47282(\Delta=0.33 \mathrm{ppm})$.

UV $(\mathrm{MeOH}): \quad \lambda_{\max }(\lg \varepsilon)=281(4.12) \mathrm{nm} ;$

$(\mathrm{MeOH}, \mathrm{HCl}): \quad \lambda_{\max }(\lg \varepsilon)=273(4.07) \mathrm{nm}$;

$(\mathrm{MeOH}, \mathrm{NaOH}): \quad \lambda_{\max }(\lg \varepsilon)=281(4.05) \mathrm{nm}$.

CD (MeOH): $\lambda_{\max }\left([\Theta]^{20}\right)=276(+27000), 223(-44000), 207(-1100) \mathrm{nm}$.

IR $(\mathrm{KBr}): \widetilde{v}=3409(\mathrm{br}), 2937,2358,1642,1538,1445$ (sh), 1376, 1249, 1181, $1048(\mathrm{sh}) \mathrm{cm}^{-1}$.

${ }^{1} \mathrm{H}-\mathrm{NMR}\left(600 \mathrm{MHz}, \mathrm{CDCl}_{3}\right): \delta=-0.29\left[\mathrm{~m}, 2 \mathrm{H}, 4-\mathrm{H},\left(\mathrm{NO}_{2}\right) \mathrm{Nle}\right], 0.12\left[\mathrm{~m}, 2 \mathrm{H}, 5-\mathrm{H},\left(\mathrm{NO}_{2}\right) \mathrm{Nle}\right]$, 0.88 (t, J = 7.5 Hz, $3 \mathrm{H}, 5-\mathrm{H}, / l e), 1.00$ [m, $1 \mathrm{H}, 3^{\prime}-\mathrm{H}_{\mathrm{a}}$, (3-Ncp)Ala], 1.02 (d, J = 7.0 Hz, $3 \mathrm{H}, 5-$ 
$\mathrm{H}, I l e), 1.15-1.20\left[\mathrm{~m}, 2 \mathrm{H}, 3-\mathrm{H},\left(\mathrm{NO}_{2}\right) \mathrm{Nle}\right], 1.28[\mathrm{~d}, \mathrm{~J}=6.6 \mathrm{~Hz}, 3 \mathrm{H}, 4-\mathrm{H},(\beta M e) P h e ~ I l], 1.30-$ $1.32\left(\mathrm{~m}, 1 \mathrm{H}, 4-\mathrm{H}_{\mathrm{a}}, I l e\right), 1.40[\mathrm{~d}, J=7.0 \mathrm{~Hz}, 3 \mathrm{H}, 4-\mathrm{H},(\beta M e) P h e$ I], $1.53(\mathrm{~d}, J=7.0 \mathrm{~Hz}, 3 \mathrm{H}, 4-$ $\mathrm{H}, \mathrm{a}-\mathrm{Thr}), 1.55-1.61$ [m, $2 \mathrm{H}, 4-\mathrm{H}_{\mathrm{b}}$, Ile, 3- $\left.\mathrm{H}_{\mathrm{a}},(3-N c p) A l a\right], 1.67$ [dd, J = 7.0, $1.5 \mathrm{~Hz}, 3 \mathrm{H}, 3^{\prime}-\mathrm{H}$, (4-Pe)Pro], 1.80-1.90 [m, $5 \mathrm{H}, 3-\mathrm{H}_{\mathrm{b}}, 1^{\prime}-\mathrm{H}, 3{ }^{\prime}-\mathrm{H}_{\mathrm{b}}$ (3-Ncp)Ala, 3- $\mathrm{H}_{\mathrm{a}}$, (4-Pe)Pro, 3-H, Ile], 2.35 [ddd, $J=11.5,6.0,5.5 \mathrm{~Hz}, 1 \mathrm{H}, 3-\mathrm{H}_{\mathrm{b}},(4-P e)$ Pro], 2.95 [dq, $J=10.5,7.0 \mathrm{~Hz}, 1 \mathrm{H}, 3-\mathrm{H}$,

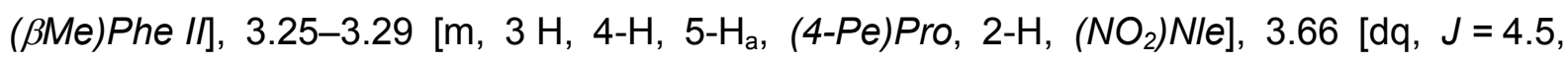
7.0 Hz, $1 \mathrm{H}, 3-\mathrm{H},(\beta M e) P h e ~], ~ 3.83-3.87\left[\mathrm{~m}, 2 \mathrm{H}, 6-\mathrm{H},\left(\mathrm{NO}_{2}\right) \mathrm{Nle}\right], 3.97-4.01\left[\mathrm{~m}, 1 \mathrm{H}, 5-\mathrm{H}_{\mathrm{b}}\right.$, (4-Pe)Pro], 4.03 [ddd, J = 7.0, 3.5, 3.5 Hz, $\left.1 \mathrm{H}, 2^{\prime}-\mathrm{H},(3-N c p) A l a\right], 4.26$ [dd, J = 11.5, $6.0 \mathrm{~Hz}$, $1 \mathrm{H}, 2-\mathrm{H},(4-P e) P r o], 4.40$ [dd, $J=10.5,10.5 \mathrm{~Hz}, 1 \mathrm{H}, 2-\mathrm{H},(\beta M e) P h e ~ I], 4.60$ (dd, J = 9.5, $2.5 \mathrm{~Hz}, 1 \mathrm{H}, 2-\mathrm{H}, \mathrm{a}-T h r), 4.64$ [dd, J = 10.0, $5.0 \mathrm{~Hz}, 1 \mathrm{H}, 2-\mathrm{H},(\beta M e) P h e ~ I], 4.64$ (dd, J = 9.0, $9.0 \mathrm{~Hz}, 1 \mathrm{H}, 2-\mathrm{H}, I l e), 5.09-5.17[\mathrm{~m}, 1 \mathrm{H}, 2-\mathrm{H},(3-N c p) A l a], 5.23-5.29\left[\mathrm{~m}, 1 \mathrm{H}, 1^{\prime}-\mathrm{H}\right.$, (4Pe)Pro], 5.41 (dq, J = 7.0, 2.5 Hz, $1 \mathrm{H}, 3-\mathrm{H}, \mathrm{a}-T h r), 5.62$ [dq, $J=10.5,7.0 \mathrm{~Hz}, 1 \mathrm{H}, 2 '-\mathrm{H}$, (4Pe)Pro], 6.09 (d, J = 4.5 Hz, $1 \mathrm{H}, 4-\mathrm{H}$, Chpca), 6.80 (d, J = $4.5 \mathrm{~Hz}, 1 \mathrm{H}, 3-\mathrm{H}$, Chpca), 6.81 (d, $J=7.0 \mathrm{~Hz}, 1 \mathrm{H}, \mathrm{NH}), 6.86(\mathrm{~d}, J=10.0 \mathrm{~Hz}, 1 \mathrm{H}, \mathrm{NH}), 7.08-7.14(\mathrm{~m}, 4 \mathrm{H}, \mathrm{Ar}-\mathrm{H}), 7.18-7.25(\mathrm{~m}$, $7 \mathrm{H}, \mathrm{Ar}-\mathrm{H}, \mathrm{NH}), 7.35$ (d, $J=9.0 \mathrm{~Hz}, 1 \mathrm{H}, \mathrm{NH}), 7.98(\mathrm{~d}, J=9.0 \mathrm{~Hz}, 1 \mathrm{H}, \mathrm{NH}), 9.09$ (d, $J=9.0$ $\mathrm{Hz}, 1 \mathrm{H}, \mathrm{NH})$.

${ }^{13} \mathrm{C}-\mathrm{NMR}\left(150.8 \mathrm{MHz}, \mathrm{CDCl}_{3}\right): \delta=10.5(+, \mathrm{C}-5, \mathrm{lle}), 13.3$ [+, C-3', (4-Pe)Pro], 13.5 [+, C-4, (BMe)Phe I], 14.9 (+, C-1', Ile), 17.0 (+, C-4, a-Thr), 17.5 [-, C-3', (3-Ncp)Ala], 18.4 [+, C-4,

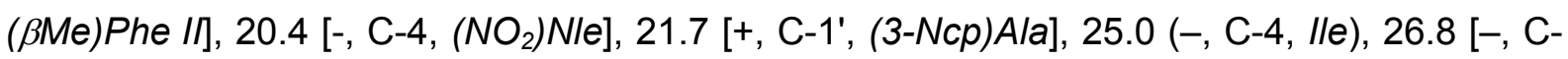
3, $\left(\mathrm{NO}_{2}\right) \mathrm{Nle}$ ], 32.2 [-, C-5, $\left(\mathrm{NO}_{2}\right) \mathrm{Nle}$ ], 34.9 [-, C-3, (3-Ncp)Ala], 35.5 [-, C-3, (4-Pe)Pro], 36.7 [+, C-4, (4-Pe)Pro], 37.9 (+, C-3, Ile), 39.3 [+, C-3, ( $\beta M e) P h e I], 42.2[+, \mathrm{C}-3,(\beta M e) P h e I I]$, 51.1 [+, C-2, (3-Ncp)Ala], 52.8 [-, C-5, (4-Pe)Pro], 53.0 [+, C-2, $\left(\mathrm{NO}_{2}\right) \mathrm{Nle}$ ], $54.6(+, \mathrm{C}-2, \mathrm{lle})$,

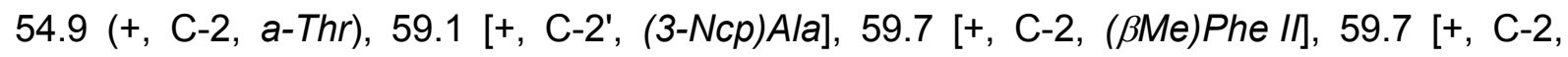

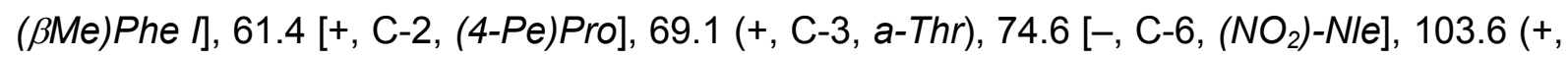

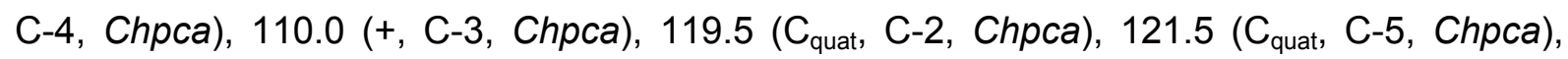
127.0, 127.2, 127.4, 127.7, 128.5, 128.7 [+, C-1', C-2', (4-Pe)Pro, Ar-C], 141.7, 141.9 (C quat, $\operatorname{Ar}-\mathrm{C}), 159.3$ ( $\left.\mathrm{C}_{\text {quat }}, \mathrm{C}-1, \mathrm{Chpca}\right), 168.8,169.7,170.0,170.7,171.2,171.6,171.8$ ( $\left.\mathrm{C}_{\text {quat }}, \mathrm{C}-1\right)$. 
Hormaomycin $\mathrm{E}_{2}(26 \mathrm{~b})$

$\mathrm{C}_{55} \mathrm{H}_{71} \mathrm{~N}_{10} \mathrm{O}_{14} \mathrm{Cl}(1130.48)$

farbloser Feststoff

UV-löschend (254 nm)

Anfärbeverhalten: rosa (Ehrlich).

$\mathbf{R}_{\mathbf{t}}=43.0 \mathrm{~min}$

(Säule E; $63 \%$ Acetonitril in $\mathrm{H}_{2} \mathrm{O}$ ).

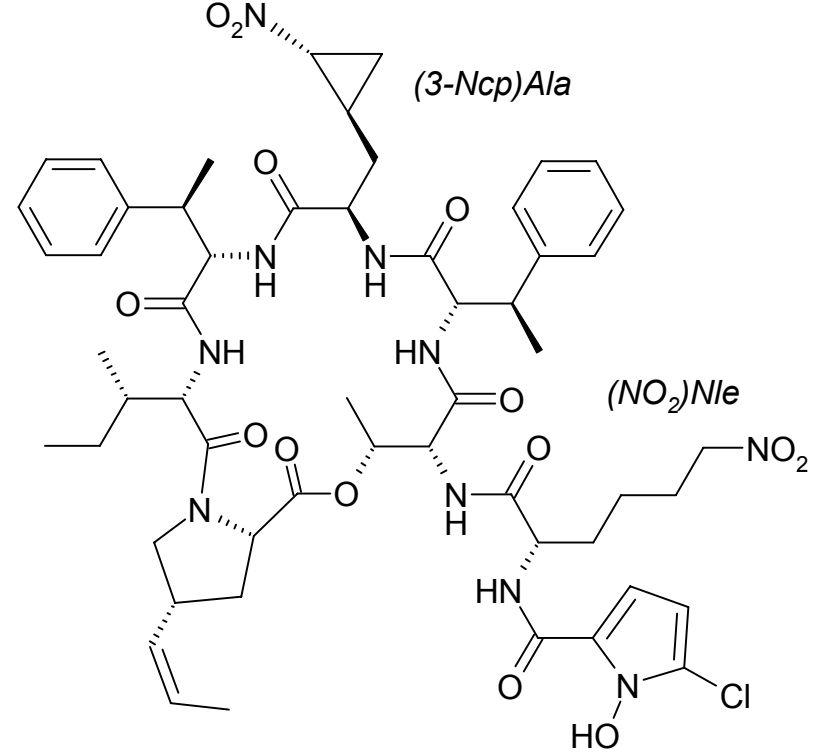

26b

ESI-MS: (pos. Ionen) $\mathrm{m} / \mathrm{z}=1153[\mathrm{M}+\mathrm{Na}]^{+}, 1131[\mathrm{M}+\mathrm{H}]^{+}$.

(neg. lonen) $\mathrm{m} / \mathrm{z}=1129[\mathrm{M}-\mathrm{H}]^{-}$.

HR-ESI-MS: berechnet: $1131.49125[\mathrm{M}+\mathrm{H}]^{+}, 1148.51780\left[\mathrm{M}+\mathrm{NH}_{4}\right]^{+}, 1153.47320[\mathrm{M}+\mathrm{Na}]^{+}$. gefunden: $1131.49080(\Delta=0.40 \mathrm{ppm}), 1148.51781(\Delta=0.01 \mathrm{ppm})$, $1153.47240(\Delta=0.70 \mathrm{ppm})$.

UV $(\mathrm{MeOH})$ : $\lambda_{\max }(\lg \varepsilon)=275(4.19) \mathrm{nm} ;$ $(\mathrm{MeOH}, \mathrm{HCl}): \quad \lambda_{\max }(\lg \varepsilon)=272(4.06) \mathrm{nm}$; $(\mathrm{MeOH}, \mathrm{NaOH}): \quad \lambda_{\max }(\lg \varepsilon)=283(3.91) \mathrm{nm}$.

CD (MeOH): $\lambda_{\max }\left([\Theta]^{20}\right)=219(-52000), 280(11100) \mathrm{nm}$.

IR $(\mathrm{KBr}): \widetilde{v}=3430$ (br), 2939, 2356, 1637, 1544, 1443, 1382, 1253 (sh), 1185, 1079 (sh) $\mathrm{cm}^{-1}$.

${ }^{1} \mathrm{H}-N M R\left(600 \mathrm{MHz}, \mathrm{CDCl}_{3}\right): \delta=-0.65$ [ddd, $J=7.0,7.0,7.0 \mathrm{~Hz}, 1 \mathrm{H}, 3^{\prime}-\mathrm{H}_{\mathrm{a}}$, (3-Ncp)Ala], -0.13 [ddd, $\left.J=14.0,9.0,4.5 \mathrm{~Hz}, 1 \mathrm{H}, 3-\mathrm{H}_{\mathrm{a}},(3-N c p) A l a\right], 0.27-0.33\left[\mathrm{~m}, 1 \mathrm{H}, 1^{\prime}-\mathrm{H}\right.$, (3-Ncp)Ala], 0.51 [ddd, $\left.J=14.0,5.0,5.0 \mathrm{~Hz}, 1 \mathrm{H}, 3-\mathrm{H}_{\mathrm{b}},(3-N c p) A l a\right], 0.90$ (t, J = 7.0 Hz, $3 \mathrm{H}$, 5-H, Ile), 0.98-1.00 [m, 1 H, 3'- $\left.\mathrm{H}_{\mathrm{b}},(3-N c p) A l a\right], 1.02$ (d, J = 7.0 Hz, $\left.3 \mathrm{H}, 1^{\prime}-\mathrm{H}, I l e\right), 1.28-1.30$ [m, $\left.2 \mathrm{H}, 3-\mathrm{H},\left(\mathrm{NO}_{2}\right) \mathrm{Nle}\right], 1.30[\mathrm{~d}, \mathrm{~J}=7.0 \mathrm{~Hz}, 3 \mathrm{H}, 4-\mathrm{H},(\beta M e) P h e I I], 1.29-1.32\left(\mathrm{~m}, 1 \mathrm{H}, 4-\mathrm{H}_{\mathrm{a}}\right.$,

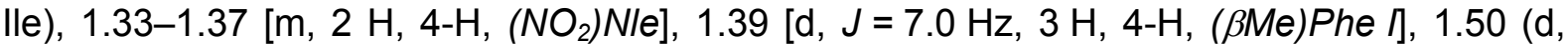
$J=7.0 \mathrm{~Hz}, 3 \mathrm{H}, 4-\mathrm{H}, \mathrm{a}-\mathrm{Thr}), 1.52-1.56\left(\mathrm{~m}, 1 \mathrm{H}, 4-\mathrm{H}_{\mathrm{b}}, / l e\right), 1.67$ [dd, J = 7.0, $1.5 \mathrm{~Hz}, 3 \mathrm{H}, 3^{\prime}-\mathrm{H}$, (4-Pe)Pro], 1.80-1.86 [m, $\left.2 \mathrm{H}, 3-\mathrm{H}_{\mathrm{a}},(4-\mathrm{Pe}) \operatorname{Pro}, 3-\mathrm{H}, \mathrm{Ile}\right], 1.94-1.98$ [m, $\left.2 \mathrm{H}, 5-\mathrm{H},\left(\mathrm{NO}_{2}\right) \mathrm{Nle}\right]$, 2.36 [ddd, $J=11.5,6.0,5.5 \mathrm{~Hz}, 1 \mathrm{H}, 3-\mathrm{H}_{\mathrm{b}},(4-P e) P r o$ ], 2.93 [ddd, $J=7.0,3.5,3.5 \mathrm{~Hz}, 1 \mathrm{H}$, 2'-H, (3-Ncp)Ala], 2.98-3.00 [m, $1 \mathrm{H}, 3-\mathrm{H},(\beta M e) P h e I I], 3.25-3.28\left[\mathrm{~m}, 2 \mathrm{H}, 4-\mathrm{H}, 5-\mathrm{H}_{\mathrm{a}}\right.$, (4-Pe)Pro], 3.49-3.53 [m, $1 \mathrm{H}, 2-\mathrm{H},(3-N c p) A l a], 3.67$ [dq, J = 7.0, $4.5 \mathrm{~Hz}, 1 \mathrm{H}, 3-\mathrm{H}$, 
( $\beta$ Me)Phe I], 3.96-4.00 [m, $\left.1 \mathrm{H}, 5-\mathrm{H}_{\mathrm{b}},(4-P e) P r o\right], 4.29$ [dd, $J=12.0,5.5 \mathrm{~Hz}, 1 \mathrm{H}, 2-\mathrm{H}$, (4-Pe)Pro], 4.36 [t, J = 7.0 Hz, $2 \mathrm{H}, 6-\mathrm{H},\left(\mathrm{NO}_{2}\right) \mathrm{Nle}$ ], 4.40 [dd, $J=10.0,10.0 \mathrm{~Hz}, 1 \mathrm{H}, 2-\mathrm{H}$, ( $\beta M e) P h e ~ I I] ~ 4.48[\mathrm{dd}, J=9.0,4.5 \mathrm{~Hz}, 1 \mathrm{H}, 2-\mathrm{H},(\beta M e) P h e ~ I], 4.54(\mathrm{dd}, J=9.0,2.5 \mathrm{~Hz}, 1 \mathrm{H}$, 2-H, a-Thr), 4.64 (dd, J = 9.0, $9.0 \mathrm{~Hz}, 1 \mathrm{H}, 2-\mathrm{H}, I l e), 4.95[\mathrm{dt}, J=8.0,8.0 \mathrm{~Hz}, 1 \mathrm{H}, 2-\mathrm{H}$, $\left(\mathrm{NO}_{2}\right) \mathrm{Nle}$ ], 5.22-5.28 [m, $\left.1 \mathrm{H}, 1^{\prime}-\mathrm{H},(4-P e) P r o\right], 5.38$ (dq, J = 7.0, $2.5 \mathrm{~Hz}, 1 \mathrm{H}, 3-\mathrm{H}$, a-Thr), 5.62 [dq, $J=10.5,7.0 \mathrm{~Hz}, 1 \mathrm{H}, 2 \mathrm{-H},(4-P e) P r o], 6.12$ (d, J = 4.5 Hz, $1 \mathrm{H}, 4-\mathrm{H}$, Chpca), 6.63 $(\mathrm{d}, J=7.0 \mathrm{~Hz}, 1 \mathrm{H}, \mathrm{NH}), 6.81(\mathrm{~d}, J=4.5 \mathrm{~Hz}, 1 \mathrm{H}, 3-\mathrm{H}$, Chpca), $6.88(\mathrm{~d}, J=10.0 \mathrm{~Hz}, 1 \mathrm{H}$, $\mathrm{NH}), 7.06-7.13(\mathrm{~m}, 4 \mathrm{H}, \mathrm{Ar}-\mathrm{H}), 7.14-7.17(\mathrm{~m}, 2 \mathrm{H}, \mathrm{Ar}-\mathrm{H}), 7.18-7.21(\mathrm{~m}, 5 \mathrm{H}, \mathrm{Ar}-\mathrm{H}, \mathrm{NH}), 7.37$ (d, $J=9.0 \mathrm{~Hz}, 1 \mathrm{H}, \mathrm{NH}), 7.97(\mathrm{~d}, J=9.6 \mathrm{~Hz}, 1 \mathrm{H}, \mathrm{NH}), 8.99(\mathrm{~d}, J=9.6 \mathrm{~Hz}, 1 \mathrm{H}, \mathrm{NH})$.

${ }^{13} \mathrm{C}-\mathrm{NMR}\left(150.8 \mathrm{MHz}, \mathrm{CDCl}_{3}\right): \delta=10.6(+, \mathrm{C}-5, \mathrm{Ile}), 13.3$ [+, C-3', (4-Pe)Pro], 13.3 [+, C-4, (BMe)Phe I], 14.9 (+, C-1', Ile), 14.9 (-, C-3', (3-Ncp)Ala], 17.0 (+, C-4, a-Thr), 17.8 [+, C-4, (BMe)Phe Il], 20.0 [+, C-1', (3-Ncp)Ala], 22.3 [-, C-4, $\left(\mathrm{NO}_{2}\right) \mathrm{Nle}$ ], 25.0 (-, C-4, Ile), 27.2 [-, C3, $\left.\left(\mathrm{NO}_{2}\right) \mathrm{Nle}\right], 29.7$ [-, C-5, $\left.\left(\mathrm{NO}_{2}\right) \mathrm{Nle}\right], 33.1$ [-, C-3, (3-Ncp)Ala], 35.6 [-, C-3, (4-Pe)Pro], 36.7 [+, C-4, (4-Pe)Pro], $37.9(+, \mathrm{C}-3, I l e), 39.3[+, \mathrm{C}-3,(\beta M e) P h e I], 41.8[+, \mathrm{C}-3,(\beta M e) P h e I I]$, $51.7\left[+, \mathrm{C}-2,\left(\mathrm{NO}_{2}\right) \mathrm{Nle}\right], 51.7$ [+, C-2, (3-Ncp)Ala], 52.8 [-, C-5, (4-Pe)Pro], $54.6(+, \mathrm{C}-2, \mathrm{lle})$, 54.8 (+, C-2, a-Thr), 58.1 [+, C-2', (3-Ncp)Ala], 59.8 [+, C-2, (BMe)Phe II], 59.9 [+, C-2, (BMe)Phe ], 61.4 [+, C-2, (4-Pe)Pro], 69.3 (+, C-3, a-Thr), 75.1 [-, C-6, $\left.\left(\mathrm{NO}_{2}\right)-\mathrm{Nle}\right], 103.5(+$, C-4, Chpca), 109.5 (+, C-3, Chpca), 127.0, 127.2, 127.2, 127.4 (+, Ar-C), 127.5 [+, C-1', (4Pe)Pro], 127.7 (+, Ar-C), 128.3 [+, C-2', (4-Pe)Pro], 128.5, 128.6 (+, Ar-C), 142.1, 141.8 ( $\left.\mathrm{C}_{\text {quat }}, \mathrm{Ar}-\mathrm{C}\right), 168.7,170.7,171.3,171.5,172.5\left(\mathrm{C}_{\text {quat }}, \mathrm{C}-1\right)$.

\section{Hormaomycin (16)/ Hormaomycin $\mathrm{E}_{3}(26 \mathrm{c})$}

\section{Mischfraktion (1:3)}

$\mathrm{C}_{55} \mathrm{H}_{73} \mathrm{~N}_{10} \mathrm{O}_{14} \mathrm{Cl}(1132.50)$

farbloser Feststoff

UV-löschend (254 nm)

Anfärbeverhalten: rosa (Ehrlich).

$\mathbf{R}_{\mathbf{t}}=45.1 \mathrm{~min}$

(Säule E; $63 \%$ Acetonitril in $\mathrm{H}_{2} \mathrm{O}$ ).

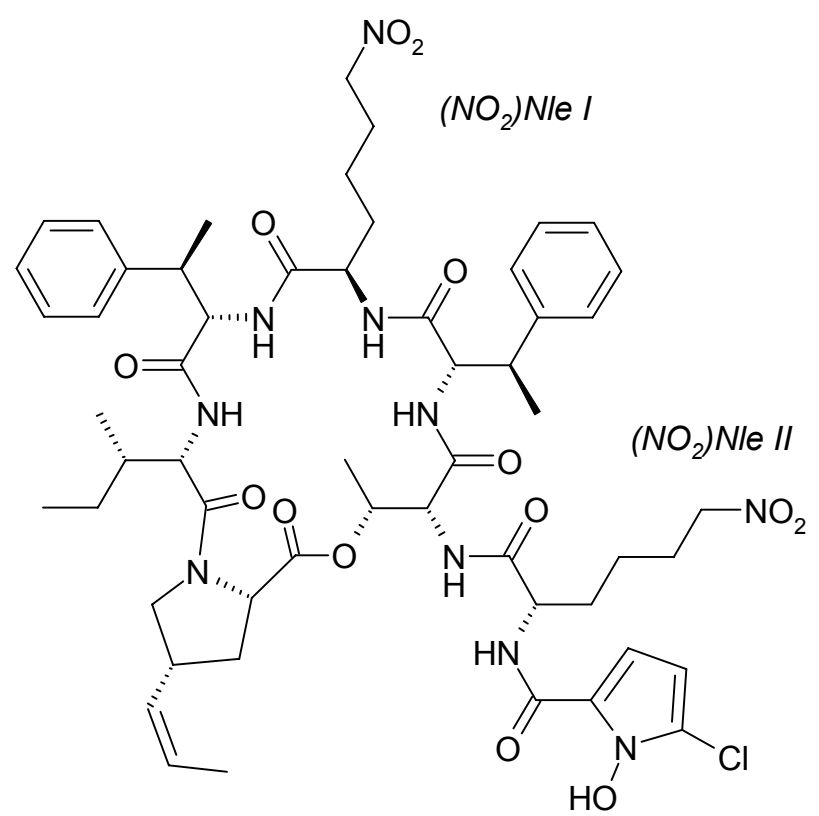

26c 
ESI-MS: (pos. lonen) $\mathrm{m} / \mathrm{z}=1155[\mathrm{M}+\mathrm{Na}]^{+}, 1133[\mathrm{M}+\mathrm{H}]^{+}$.

(neg. lonen) $\mathrm{m} / \mathrm{z}=1131[\mathrm{M}-\mathrm{H}]^{-}$.

HR-ESI-MS: Aufgrund von Überlagerungen der Signale von 26c mit Isotopenpeaks von 16 lässt sich keine Hochauflösung gewinnen (s. Kap. 2.3.1.4).

IR $(\mathrm{KBr}): \widetilde{v}=3444(\mathrm{br}), 2932,1636,1384,1165,1114,1073,1028(\mathrm{sh}) \mathrm{cm}^{-1}$.

${ }^{1} \mathrm{H}-\mathrm{NMR}\left(600 \mathrm{MHz}, \mathrm{CDCl}_{3}\right): \delta=-0.29\left[\mathrm{~m}, 2 \mathrm{H}, 4-\mathrm{H},\left(\mathrm{NO}_{2}\right) \mathrm{Nle}\right], 0.12[\mathrm{~m}, 2 \mathrm{H}, 5-\mathrm{H}$, $\left(\mathrm{NO}_{2}\right) \mathrm{Nle}$ ], 0.88 (t, J = 7.5 Hz, $\left.3 \mathrm{H}, 5-\mathrm{H}, I l e\right), 1.02$ (d, $\left.J=7.0 \mathrm{~Hz}, 3 \mathrm{H}, 5-\mathrm{H}, I l e\right), 1.15-1.20$ [m, $\left.2 \mathrm{H}, 3-\mathrm{H},\left(\mathrm{NO}_{2}\right) \mathrm{Nle} I\right], 1.28[\mathrm{~d}, J=6.6 \mathrm{~Hz}, 3 \mathrm{H}, 4-\mathrm{H},(\beta M e) P h e I I], 1.28-1.30[\mathrm{~m}, 2 \mathrm{H}, 3-\mathrm{H}$, $\left(N_{2}\right)$ Nle Il], 1.30-1.32 (m, $\left.1 \mathrm{H}, 4-\mathrm{H}_{\mathrm{a}}, I l e\right), 1.40[\mathrm{~d}, \mathrm{~J}=7.0 \mathrm{~Hz}, 3 \mathrm{H}, 4-\mathrm{H},(\beta M e) P h e ~ I], 1.53$ (d, $J=7.0 \mathrm{~Hz}, 3 \mathrm{H}, 4-\mathrm{H}, \mathrm{a}-\mathrm{Thr}), 1.55-1.61\left(\mathrm{~m}, 1 \mathrm{H}, 4-\mathrm{H}_{\mathrm{b}}, I l e\right), 1.67$ [dd, J = 7.0, $1.5 \mathrm{~Hz}, 3 \mathrm{H}, 3^{\prime}-\mathrm{H}$, (4-Pe)Pro], 1.77-1.83 [m, $\left.2 \mathrm{H}, 3-\mathrm{H}_{\mathrm{a}},(4-P e) P r o, 3-\mathrm{H}, I l e\right], 1.93-1.98\left[\mathrm{~m}, 2 \mathrm{H}, 5-\mathrm{H},\left(\mathrm{NO}_{2}\right) \mathrm{Nle} I /\right]$ 2.35 [ddd, $J=11.5,6.0,5.5 \mathrm{~Hz}, 1 \mathrm{H}, 3-\mathrm{H}_{\mathrm{b}},(4-P e) P r o$ ], 2.95 [dq, $J=10.5,7.0 \mathrm{~Hz}, 1 \mathrm{H}, 3-\mathrm{H}$,

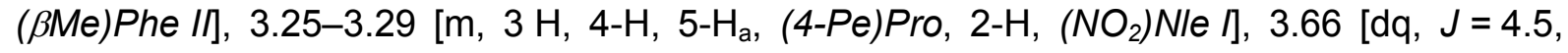
7.0 Hz, $1 \mathrm{H}, 3-\mathrm{H},(\beta M e) P h e ~ I], 3.81-3.90\left[\mathrm{~m}, 2 \mathrm{H}, 6-\mathrm{H},\left(\mathrm{NO}_{2}\right) \mathrm{Nle} l\right], 3.97-4.01\left[\mathrm{~m}, 1 \mathrm{H}, 5-\mathrm{H}_{\mathrm{b}}\right.$, (4-Pe)Pro], 4.23 [dd, $J=11.5,6.0 \mathrm{~Hz}, 1 \mathrm{H}, 2-\mathrm{H}$, (4-Pe)Pro], 4.34-4.40 [m, $3 \mathrm{H}, 2-\mathrm{H}$,

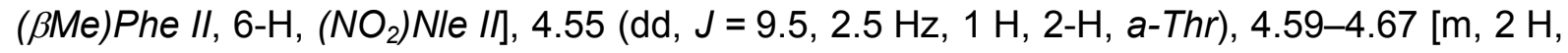

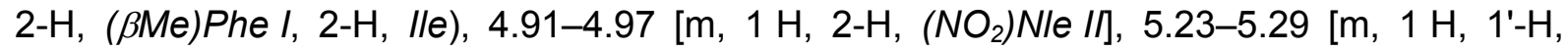
(4-Pe)Pro], 5.34 (dq, J = 7.0, $2.5 \mathrm{~Hz}, 1 \mathrm{H}, 3-\mathrm{H}, a-T h r), 5.62$ [dq, J = 10.5, 7.0 Hz, $1 \mathrm{H}, 2^{\prime}-\mathrm{H}$, (4-Pe)Pro], 6.08 (d, J = 4.5 Hz, $1 \mathrm{H}, 4-\mathrm{H}$, Chpca), 6.75 (d, J = 4.5 Hz, $1 \mathrm{H}, 3-\mathrm{H}$, Chpca), 6.81 (d, J = 7.0 Hz, $1 \mathrm{H}, \mathrm{NH}), 6.86$ (d, J = 10.0 Hz, $1 \mathrm{H}, \mathrm{NH}), 7.08-7.14(\mathrm{~m}, 4 \mathrm{H}, \mathrm{Ar}-\mathrm{H}), 7.18-7.25$ $(\mathrm{m}, 7 \mathrm{H}, \mathrm{Ar}-\mathrm{H}, \mathrm{NH}), 7.35(\mathrm{~d}, J=9.0 \mathrm{~Hz}, 1 \mathrm{H}, \mathrm{NH})$. 


\subsubsection{Variation der 3-Methylphenylalanin-Einheiten}

Die Vorläufer wurden in $50 \mathrm{~mL}$ sterilem Wasser/DMSO (4:1) gelöst und unter Standardbedingungen (s. Kap. B.2.3) gefüttert.

\begin{tabular}{|c|c|c|c|}
\hline Aminosäure & $\begin{array}{l}\text { Gefütterte Menge } \\
{[\text { [mmol }]}\end{array}$ & $\begin{array}{l}\text { Hormaomycin- } \\
\text { Produktion }\end{array}$ & Derivate \\
\hline o-Fluorphenylalanin & 2.0 & + & $30 a-c^{a}$ \\
\hline$m$-Fluorphenylalanin & 2.0 & + & $31 a-c^{a}$ \\
\hline$p$-Fluorphenylalanin & 2.0 & + & $32 a, b / 33 a, b^{a}$ \\
\hline$p$-Chlorphenylalanin & 2.0 & + & $33 a-c$ \\
\hline$p$-Bromphenylalanin & 2.0 & + & $33 a-c$ \\
\hline L-Tyrosin & 2.0 & + & - \\
\hline$p$-Nitrophenylalanin & 2.0 & + & $33 a, b$ \\
\hline Phenylglycin & 2.0 & + & - \\
\hline
\end{tabular}

Tab. 19: Fütterungen von Vorläufern der $(\beta M e) P h e-E i n h e i t e n$.

\subsubsection{Isolierung und Charakterisierung der Hormaomycinderivate aus Fütterungsexperimenten mit para-substituierten Phenylalaninderivaten}

Das Rohprodukt wurde mit eiskaltem Pentan gewaschen und an Kieselgel (Aceton/Cyclohexan 2:3, $120 \times 45 \mathrm{~mm}$ ) chromatographiert. Die Trennung von 16 und den Derivaten 33a-c erfolgte mit präparativer HPLC (70 \% Acetonitril in $\mathrm{H}_{2} \mathrm{O}+0.1 \%$ TFA; Säule B). Die Ausbeuten sind in Tab. 20 dargestellt. Die fluorierten Derivate 32a,b konnten nicht von 16 getrennt werden.

\begin{tabular}{lccc}
\hline & \multicolumn{3}{c}{ Ausbeute $[\mathrm{mg}]$} \\
& $\mathbf{3 3 a}$ & $\mathbf{3 3 b}$ & $\mathbf{3 3 c}$ \\
\hline$p$-Fluorphenylalanin & $\approx 0.2$ & $\approx 0.2$ & - \\
$p$-Chlorphenylalanin & 1.4 & 1.4 & 0.7 \\
$p$-Bromphenylalanin & 0.5 & 0.5 & $\approx 0.1$ \\
$p$-Nitrophenylalanin & $\approx 0.1$ & $\approx 0.1$ & - \\
\hline
\end{tabular}

Tab. 20: Ausbeuten aus Fütterungen von para-halogenierten Phenylalaninen. 


\section{Hormaomycin $\mathrm{J}_{1}(33 \mathrm{a})$}

$\mathrm{C}_{54} \mathrm{H}_{67} \mathrm{~N}_{10} \mathrm{O}_{14} \mathrm{Cl}(1114.45)$

farbloser Feststoff

UV-löschend (254 nm)

Anfärbeverhalten: rosa (Ehrlich).

$\mathbf{R}_{\mathbf{t}}=16.2 \mathrm{~min}$

(Säule B; 70 \% Acetonitril in Wasser, $+0.1 \%$ TFA)

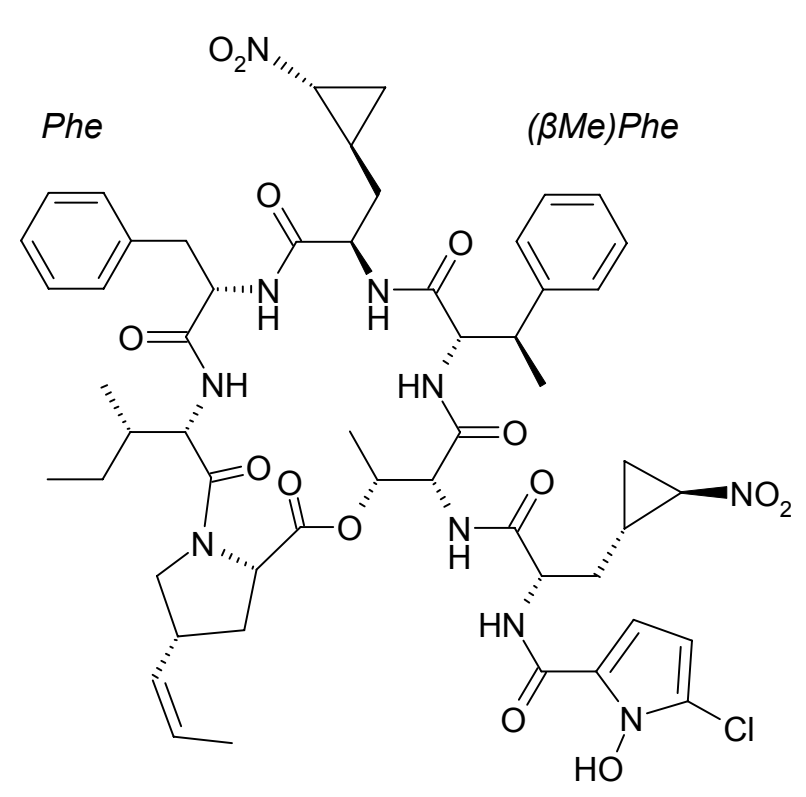

$33 a$

ESI-MS: (pos. lonen) $\mathrm{m} / \mathrm{z}=1151[\mathrm{M}+\mathrm{Na}]^{+}, 1129[\mathrm{M}+\mathrm{H}]^{+}$.

(neg. lonen) $\mathrm{m} / \mathrm{z}=1127[\mathrm{M}-\mathrm{H}]^{-}$.

HR-ESI-MS: berechnet: $1137.44190[\mathrm{M}+\mathrm{Na}]^{+}, 1132.48650\left[\mathrm{M}+\mathrm{NH}_{4}\right]^{+}, 1115.45995[\mathrm{M}+\mathrm{H}]^{+}$. gefunden: $1137.44182(\Delta=0.07 \mathrm{ppm}), \quad 1132.48710 \quad(\Delta=0.53 \mathrm{ppm})$, $1115.45963(\Delta=0.29 \mathrm{ppm})$.

UV (MeOH): $\quad \lambda_{\max }(\lg \varepsilon)=269(4.00) \mathrm{nm}$;

$(\mathrm{MeOH}, \mathrm{HCl}): \quad \lambda_{\max }(\lg \varepsilon)=267(3.92) \mathrm{nm}$;

$(\mathrm{MeOH}, \mathrm{NaOH}): \quad \lambda_{\max }(\lg \varepsilon)=273(3.84) \mathrm{nm}$.

CD (MeOH): $\lambda_{\max }\left([\Theta]^{20}\right)=275(+6400), 221(-40700), 208(+2500) \mathrm{nm}$.

$[\alpha]_{\mathrm{D}}^{20}=+4^{\circ}(\mathrm{c}=0.1, \mathrm{MeOH})$.

IR (KBr): $\widetilde{v}=3416(\mathrm{br}), 2940,2353,1649,15341369,1184,1064 \mathrm{~cm}^{-1}$.

${ }^{1} \mathrm{H}-\mathrm{NMR}\left(600 \mathrm{MHz}, \mathrm{CDCl}_{3}\right): \delta=-0.26$ [ddd, $J=7.0,3.5,3.5 \mathrm{~Hz}, 1 \mathrm{H}, 3{ }^{\prime}-\mathrm{H}_{\mathrm{a}}$, (3-Ncp)Ala I], $-0.05\left[\mathrm{~m}, 1 \mathrm{H}, 3-\mathrm{H}_{\mathrm{a}},(3-N c p) A l a ~\right], 0.55\left[\mathrm{~m}, 1 \mathrm{H}, 1^{\prime}-\mathrm{H},(3-N c p) A l a ~\right], 0.60\left[\mathrm{~m}, 1 \mathrm{H}, 3-\mathrm{H}_{\mathrm{b}}\right.$, (3-Ncp)Ala I], 0.88 (t, J = 7.0 Hz, 3 H, 5-H, Ile), 1.00 (d, J = 7.0 Hz, $3 \mathrm{H}, 1$ '-H, Ile), 1.01 [m, $1 \mathrm{H}, 3^{\prime}-\mathrm{H}_{\mathrm{a}}$, (3-Ncp)Ala II] $1.10\left[\mathrm{~m}, 1 \mathrm{H}, 3^{\prime}-\mathrm{H}_{\mathrm{b}},(3-N c p) A l a\right.$ l], $1.30\left[\mathrm{~d}, J=7.0 \mathrm{~Hz}, 3 \mathrm{H}, 1^{\prime}-\mathrm{H}\right.$, ( $\beta M e) P h e], 1.30\left(\mathrm{~m}, 1 \mathrm{H}, 4-\mathrm{H}_{\mathrm{a}}, I l e\right), 1.53(\mathrm{~d}, J=7.0 \mathrm{~Hz}, 3 \mathrm{H}, \mathrm{a}-\mathrm{Thr}), 1.55\left(\mathrm{~m}, 1 \mathrm{H}, 4-\mathrm{H}_{\mathrm{b}}, I l e\right)$, $1.60\left[\mathrm{~m}, 1 \mathrm{H}, 3-\mathrm{H}_{\mathrm{a}},(3-\mathrm{Ncp}) A / \mathrm{l} I /\right], 1.67$ [dd, $\left.J=7.0,2.0 \mathrm{~Hz}, 3 \mathrm{H}, 3-\mathrm{H},(4-P e) P r o\right], 1.78-1.92$ [m, $5 \mathrm{H}, 3-\mathrm{H}_{\mathrm{b}}, 1^{\prime}-\mathrm{H}, 3^{\prime}-\mathrm{H}_{\mathrm{b}}$, (3-Ncp)Ala II, 3- $\left.\mathrm{H}_{\mathrm{a}},(4-P e) P r o, 3-\mathrm{H}, I l e\right], 2.36$ [ddd, $J=11.5,6.0$, $6.0 \mathrm{~Hz}, 1 \mathrm{H}, 3-\mathrm{H}_{\mathrm{b}},(4-P e) P r o$ ], 2.80 (dd, $J=14.5,11.0 \mathrm{~Hz}, 1 \mathrm{H}, 3-\mathrm{H}_{\mathrm{a}}, P h e$ ), 2.95 [dq, $J=10.0$, $7.0 \mathrm{~Hz}, 1 \mathrm{H}, 3-\mathrm{H},(\beta M e) P h e], 3.08$ [ddd, $\left.J=7.0,3.5,3.5 \mathrm{~Hz}, 1 \mathrm{H}, 2^{\prime}-\mathrm{H},(3-N c p) A l a ~ l\right], 3.26-$ $3.29\left[\mathrm{~m}, 2 \mathrm{H}, 4-\mathrm{H}, 5-\mathrm{H}_{\mathrm{a}},(4-P e) P r o\right], 3.37$ (dd, $\left.J=14.5,4.5 \mathrm{~Hz}, 1 \mathrm{H}, 3-\mathrm{H}_{\mathrm{b}}, P h e\right), 3.46[\mathrm{~m}, 1 \mathrm{H}$, 2-H, (3-Ncp)Ala I], 3.97-4.04 [m, $2 \mathrm{H}, 5-\mathrm{H}_{\mathrm{b}}$, (4-Pe)Pro, 2'-H, (3-Ncp)Ala II], 4.27 [dd, J = 11.5, $6.0 \mathrm{~Hz}, 1 \mathrm{H}, 2-\mathrm{H},(4-P e) P r o], 4.41[\mathrm{dd}, J=11.0,10.0 \mathrm{~Hz}, 1 \mathrm{H}, 2-\mathrm{H},(\beta M e) P h e$ ], 4.47 [ddd, 
$J=10.0,8.5,4.5 \mathrm{~Hz}, 1 \mathrm{H}, 2-\mathrm{H}, P h e], 4.57$ (dd, $J=9.5,2.5 \mathrm{~Hz}, 1 \mathrm{H}, 2-\mathrm{H}, a-T h r), 4.60$ (dd,

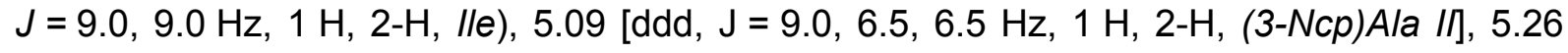
$\left[\mathrm{m}, 1 \mathrm{H}, 1^{\prime}-\mathrm{H},(4-P e) P r o\right], 5.40(\mathrm{dq}, J=7.0,2.5 \mathrm{~Hz}, 1 \mathrm{H}, 3-\mathrm{H}, \mathrm{a}-\mathrm{Thr}), 5.62[\mathrm{dq}, J=10.5$, $\left.7.5 \mathrm{~Hz}, 1 \mathrm{H}, 2^{\prime}-\mathrm{H},(4-P e) P r o\right], 6.15$ (d, J = 5.0 Hz, $1 \mathrm{H}, 4-\mathrm{H}$, Chpca), 6.65 (d, J = 5.0 Hz, $1 \mathrm{H}$, 3-H, Chpca), $6.70(\mathrm{~d}, \mathrm{~J}=10.0 \mathrm{~Hz}, 1 \mathrm{H}, \mathrm{NH}), 6.82(\mathrm{~d}, \mathrm{~J}=8.5 \mathrm{~Hz}, 1 \mathrm{H}, \mathrm{NH}), 7.04(\mathrm{~m}, 1 \mathrm{H}$, Ar-H), 7.08-7.16 (m, $4 \mathrm{H}, \mathrm{Ar}-\mathrm{H}), 7.18-7.28(\mathrm{~m}, 5 \mathrm{H}, \mathrm{Ar}-\mathrm{H}), 7.30(\mathrm{~d}, J=9.0 \mathrm{~Hz}, 1 \mathrm{H}, \mathrm{NH}), 8.03$ (d, $J=9.0 \mathrm{~Hz}, 1 \mathrm{H}, \mathrm{NH}), 9.06(\mathrm{~d}, J=9.5 \mathrm{~Hz}, 1 \mathrm{H}, \mathrm{NH})$.

${ }^{13} \mathrm{C}-\mathrm{NMR}\left(150.8 \mathrm{MHz}, \mathrm{CDCl}_{3}\right): \delta=10.6(+, \mathrm{C}-5, \mathrm{lle}), 13.3$ [+, C-3', (4-Pe)Pro], 14.8 (+, C-1',

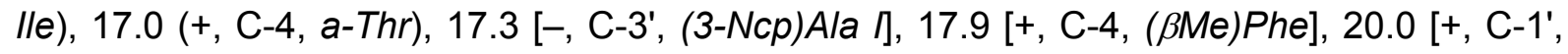
(3-Ncp)Ala I], 21.6 [+, C-1', (3-Ncp)Ala II], 25.1 (-, C-3, Ile), 33.4 [-, C-3, (3-Ncp)Ala I], 34.8 [-, C-3, (3-Ncp)Ala II], 35.6 [-, C-3, (4-Pe)Pro], 36.6 [+, C-4, (4-Pe)Pro], 37.6 (+, C-3, Ile), 38.2 [-, C-3, Phe], 42.0 [+, C-3, (BMe)Phe], 51.4 [+, C-2, (3-Ncp)Ala II], 51.6 [+, C-2, (3Ncp)Ala I], 52.8 [-, C-5, (4-Pe)Pro], 54.7 (+, C-2, Ile), 55.1 (+, C-2, a-Thr), 56.2 (+,C-2, Phe], 58.2 [+, C-2', (3-Ncp)Ala I], 59.2 [+, C-2', (3-Ncp)Ala II], 59.9 [+, C-2, (BMe)Phe], 61.4 [+, C-2, (4-Pe)Pro], 69.2 (+, C-3, a-Thr), 103.8 (+, C-4, Chpca), 110.6 (+, C-3, Chpca), 120.1 (C quat, C-2, Chpca), 120.5 ( $\mathrm{C}_{\text {quat, }}$ C-5, Chpca), 127.2, 127.29, 127.33, 127.67, 127.73, 128.6, 128.8, 128.9 [+, C-1', C-2', (4-Pe)Pro, Ar-C], 141.6, 141.8 ( (quat $_{\text {q }}$ Ar-C), 159.3 ( $\left.\mathrm{C}_{\text {quat }}, \mathrm{C}-1, \mathrm{Chpca}\right)$, $168.8,169.5,169.9,170.9,171.3,171.6,171.9$ (C quat $\left._{1} \mathrm{C}-1\right)$.

\section{Hormaomycin $\mathrm{J}_{2}(\mathbf{3 3 b})$}

$\mathrm{C}_{54} \mathrm{H}_{67} \mathrm{~N}_{10} \mathrm{O}_{14} \mathrm{Cl}(1114.45)$

farbloser Feststoff

UV-löschend (254 nm)

Anfärbeverhalten: rosa (Ehrlich).

$\mathbf{R}_{\mathbf{t}}=18.5 \mathrm{~min}$

(Säule B; $70 \%$ Acetonitril in $\mathrm{H}_{2} \mathrm{O}$, $+0.1 \%$ TFA).

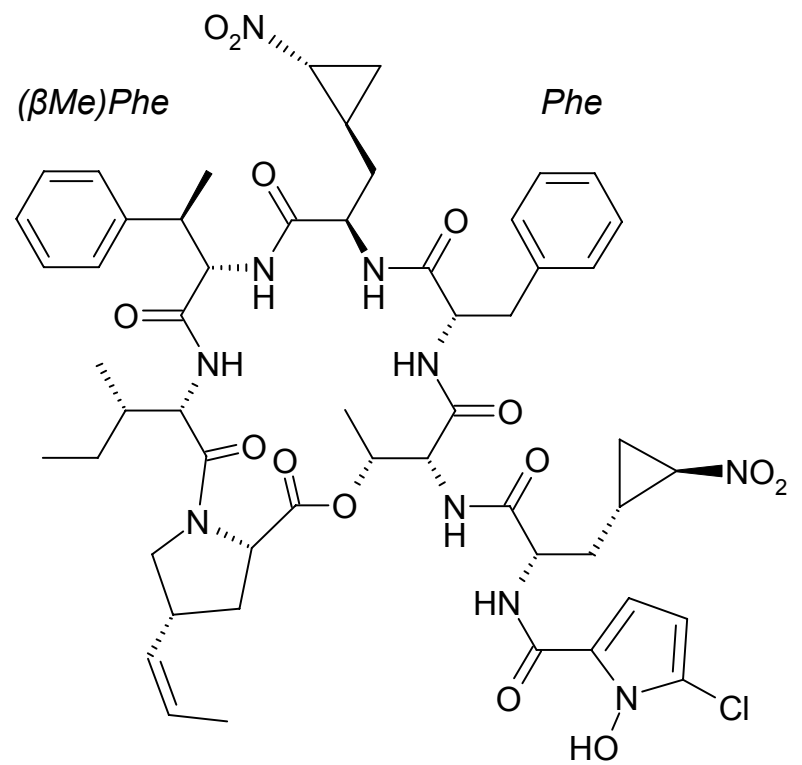

33b

ESI-MS: (pos. lonen) $\mathrm{m} / \mathrm{z}=1151[\mathrm{M}+\mathrm{Na}]^{+}, 1129[\mathrm{M}+\mathrm{H}]^{+}$.

(neg. lonen) $\mathrm{m} / \mathrm{z}=1127[\mathrm{M}-\mathrm{H}]^{-}$.

HR-ESI-MS: berechnet: $1137.44190[\mathrm{M}+\mathrm{Na}]^{+}, 1132.48650\left[\mathrm{M}+\mathrm{NH}_{4}\right]^{+}, 1115.45995[\mathrm{M}+\mathrm{H}]^{+}$. gefunden: $1137.44160(\Delta=0.26 \mathrm{ppm}), 1132.48664(\Delta=0.12 \mathrm{ppm})$, $1115.45946(\Delta=0.44 \mathrm{ppm})$. 


$$
\text { UV } \begin{aligned}
(\mathrm{MeOH}): & \lambda_{\max }(\lg \varepsilon)=278(4.07) \mathrm{nm} ; \\
(\mathrm{MeOH}, \mathrm{HCl}): & \lambda_{\max }(\lg \varepsilon)=271(3.48) \mathrm{nm} ; \\
(\mathrm{MeOH}, \mathrm{NaOH}): & \lambda_{\max }(\lg \varepsilon)=283(3.80) \mathrm{nm} .
\end{aligned}
$$

$[\alpha]_{\mathrm{D}}^{20}=-8^{\circ}(\mathrm{c}=0.1, \mathrm{MeOH})$.

CD (MeOH): $\lambda_{\max }\left([\Theta]^{20}\right)=280(+22800), 226(-50300), 207(+8000) \mathrm{nm}$.

IR $(\mathrm{KBr}): \widetilde{v}=3423,2929,1741$ (sh), 1630, 1543, 1445, 1377, 1255, 1178, 1129, 1075, 1025 (sh) $\mathrm{cm}^{-1}$.

${ }^{1} \mathrm{H}-\mathrm{NMR}\left(600 \mathrm{MHz}, \mathrm{CDCl}_{3}\right): \delta=-0.20\left[\mathrm{~m}, 1 \mathrm{H}, 33^{\prime}-\mathrm{H}_{\mathrm{a}},(3-\mathrm{Ncp}) A l a I\right], 0.24\left[\mathrm{~m}, 1 \mathrm{H}, 3-\mathrm{H}_{\mathrm{a}}\right.$, (3-Ncp)Ala I], 0.68 [m, $\left.1 \mathrm{H}, 1^{\prime}-\mathrm{H},(3-N c p) A l a ~ I\right], 0.78$ [m, $\left.1 \mathrm{H}, 3-\mathrm{H}_{\mathrm{b}},(3-N c p) A l a ~ I\right], 0.88$ (t, $J=7.0 \mathrm{~Hz}, 3 \mathrm{H}, 5-\mathrm{H}, I l e), 0.92-0.97$ [m, $2 \mathrm{H}, 3^{\prime}-\mathrm{H}_{\mathrm{a}}$, (3-Ncp)Ala II, 3'- $\mathrm{H}_{\mathrm{b}}$, (3-Ncp)Ala I], 1.00 (d, $\left.J=7.0 \mathrm{~Hz}, 3 \mathrm{H}, 1^{\prime}-\mathrm{H}, / l e\right), 1.25-1.30\left(\mathrm{~m}, 1 \mathrm{H}, 4-\mathrm{H}_{\mathrm{a}}, I / e\right), 1.40\left[\mathrm{~d}, J=7.5 \mathrm{~Hz}, 3 \mathrm{H}, 1^{\prime}-\mathrm{H}\right.$, (BMe)Phe], 1.48 (d, J = 7.0 Hz, 3 H, a-Thr), 1.53-1.56 [m, $2 \mathrm{H}, 4-\mathrm{H}_{\mathrm{b}}$, Ile, 3- $\mathrm{H}_{\mathrm{a}}$, (3-Ncp)Ala II], $1.66[\mathrm{dd}, J=7.0,2.0 \mathrm{~Hz}, 3 \mathrm{H}, 3 '-\mathrm{H},(4-P e) P r o], 1.77-1.82\left[\mathrm{~m}, 2 \mathrm{H}, 3-\mathrm{H}_{\mathrm{a}},(4-P e) P r o, 3-\mathrm{H}_{\mathrm{b}}\right.$, (3-Ncp)Ala II], 1.87-1.92 [m, 3 H, 1'-H, 3'-H $5.0 \mathrm{~Hz}, 1 \mathrm{H}, 3-\mathrm{H}_{\mathrm{b}},(4-P e)$ Pro], 2.88 (dd, J = 13.0, $11.0 \mathrm{~Hz}, 1 \mathrm{H}, 3-\mathrm{H}_{\mathrm{a}}, P h e$ ), 2.96 (dd, J = 13.0, $5.0 \mathrm{~Hz}, 1 \mathrm{H}, 3-\mathrm{H}_{\mathrm{b}}$, Phe), 3.10-3.12 [m, $1 \mathrm{H}, 2 \mathrm{-H}$, (3-Ncp)Ala l], 3.24-3.29 [m, $2 \mathrm{H}, 4-\mathrm{H}, 5-\mathrm{H}_{\mathrm{a}}$, (4-Pe)Pro], 3.64-3.67 [m, $2 \mathrm{H}, 2-\mathrm{H}$, (3-Ncp)Ala I, 3-H, ( $\beta M e) P h e], 3.98-4.02\left[\mathrm{~m}, 1 \mathrm{H}, 5-\mathrm{H}_{\mathrm{b}}\right.$, (4-Pe)Pro], 4.06 [ddd, J = 7.0, 3.5, 3.5 Hz, $1 \mathrm{H}, 2 '-\mathrm{H}$, (3-Ncp)Ala II], 4.25 [dd, J=11.5, $6.0 \mathrm{~Hz}, 1 \mathrm{H}, 2-\mathrm{H},(4-P e) P r o], 4.52-4.55$ [m, $2 \mathrm{H}, 2-\mathrm{H},(\beta M e) P h e, 2-\mathrm{H}, \mathrm{a}-\mathrm{Thr}], 4.61-4.66$ (m, $2 \mathrm{H}, 2-\mathrm{H}, I l e, 2-\mathrm{H}$, Phe), 5.03-5.06 [m, $1 \mathrm{H}, 2-\mathrm{H}$, (3-Ncp)Ala II], 5.23-5.27 [m, $1 \mathrm{H}, 1^{\prime}-\mathrm{H}$, (4-Pe)Pro], 5.38-5.40 (m, $1 \mathrm{H}, 3-\mathrm{H}, \mathrm{a}-\mathrm{Thr}), 5.62$ [dq, $J=10.5,7.0 \mathrm{~Hz}, 1 \mathrm{H}, 2$ '-H, (4-Pe)Pro], $6.13(\mathrm{~d}, J=5.0 \mathrm{~Hz}, 1 \mathrm{H}, 4-\mathrm{H}$, Chpca), $6.73(\mathrm{~d}, J=7.0 \mathrm{~Hz}, 1 \mathrm{H}, \mathrm{NH}), 6.80(\mathrm{~d}, J=5.0 \mathrm{~Hz}, 1 \mathrm{H}$, 3-H, Chpca), $6.93(\mathrm{~d}, J=9.0 \mathrm{~Hz}, 1 \mathrm{H}, \mathrm{NH}), 7.08-7.11(\mathrm{~m}, 4 \mathrm{H}, \operatorname{Ar}-\mathrm{H}), 7.14-7.24(\mathrm{~m}, 6 \mathrm{H}$, $\operatorname{Ar}-\mathrm{H}), 7.98(\mathrm{~d}, J=9.0 \mathrm{~Hz}, 1 \mathrm{H}, \mathrm{NH}), 8.89(\mathrm{br}, 1 \mathrm{H}, \mathrm{NH})$;

Aufgrund zu geringer Substanzmenge konnte kein ${ }^{13} \mathrm{C}$-NMR Spektrum gewonnen werden. 
Hormaomycin $\mathrm{J}_{3}(33 \mathrm{c})$

$\mathrm{C}_{53} \mathrm{H}_{65} \mathrm{~N}_{10} \mathrm{O}_{14} \mathrm{Cl}(1100.44)$

farbloser Feststoff

UV-löschend (254 nm)

Anfärbeverhalten: rosa (Ehrlich).

$\mathbf{R}_{\mathbf{t}}=14.9 \min$

(Säule B; $70 \%$ Acetonitril in $\mathrm{H}_{2} \mathrm{O}$, $0.1 \%$ TFA).

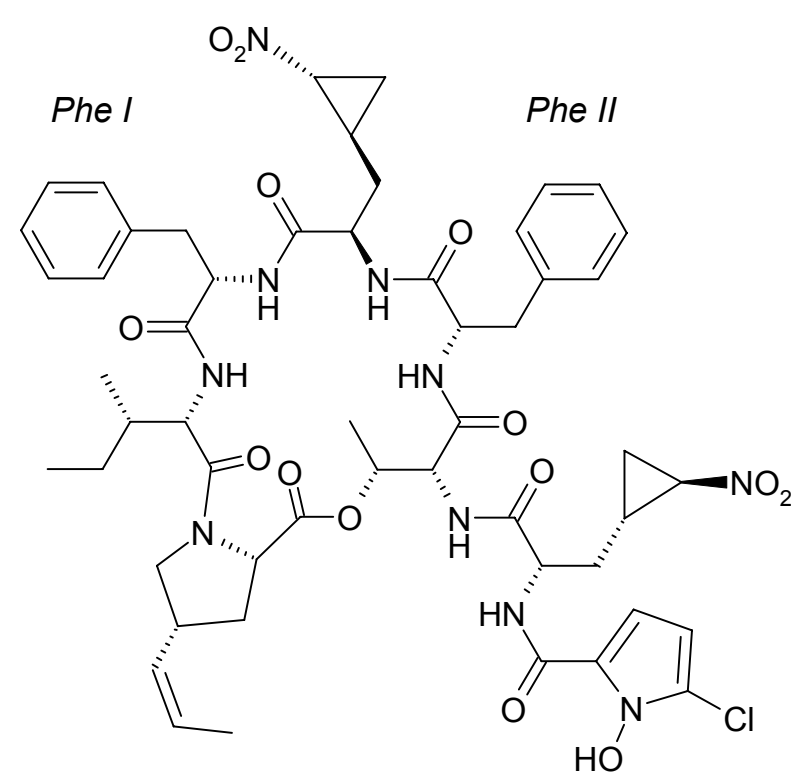

$33 c$

ESI-MS: (pos. lonen) $\mathrm{m} / \mathrm{z}=1151[\mathrm{M}+\mathrm{Na}]^{+}, 1129[\mathrm{M}+\mathrm{H}]^{+}$.

(neg. lonen) $\mathrm{m} / \mathrm{z}=1127[\mathrm{M}-\mathrm{H}]^{-}$.

HR-ESI-MS: berechnet: $1123.42625[\mathrm{M}+\mathrm{Na}]^{+}, 1118.47085\left[\mathrm{M}+\mathrm{NH}_{4}\right]^{+}, 1101.44430[\mathrm{M}+\mathrm{H}]^{+}$.

gefunden: $1123.42646 \quad(\Delta=0.19 \mathrm{ppm}), \quad 1118.47005 \quad(\Delta=0.72 \mathrm{ppm})$, $1101.44438(\Delta=0.07 \mathrm{ppm})$.

UV $(\mathrm{MeOH})$ :

$\lambda_{\max }(\lg \varepsilon)=279(4.06) \mathrm{nm}$;

$(\mathrm{MeOH}, \mathrm{HCl}): \quad \lambda_{\max }(\lg \varepsilon)=270(3.89) \mathrm{nm}$;

$(\mathrm{MeOH}, \mathrm{NaOH}): \quad \lambda_{\max }(\lg \varepsilon)=282(3.97) \mathrm{nm}$.

CD (MeOH): $\lambda_{\max }\left([\Theta]^{20}\right)=281(+10500), 223(-49500), 207(+4200) \mathrm{nm}$.

IR $(\mathrm{KBr}): \widetilde{\mathbf{v}}=3419(\mathrm{br}), 2941,2356,1649,1536,1442,1387,1442,1387,1264,1185$, $1028 \mathrm{~cm}^{-1}$.

Aufgrund zu geringer Substanzmenge konnte kein ${ }^{1} \mathrm{H}-\mathrm{NMR}$ Spektrum gewonnen werden (s. Kap. 2.3.2.2). 


\subsubsection{Isolierung und Charakterisierung der Hormaomycinderivate aus Fütterungsexperimenten mit Fluorphenylalaninderivaten}

Das Rohprodukt wurde mit eiskaltem Pentan gewaschen und an Kieselgel (Aceton/Cyclohexan 2:3, $120 \times 45 \mathrm{~mm}$ ) chromatographiert. Die fluorierten Derivate 30a-c, 31a-c und 32a,b konnten nicht von 16 getrennt werden. Alle spektroskopischen und spektrometrischen Daten sind, soweit möglich, aus den Mischfraktionen gewonnen worden.

\begin{tabular}{cccc}
\hline & $\begin{array}{c}\text { Monosubstitutierte } \\
\text { Analoga } \mathbf{a}, \mathbf{b}[\%]\end{array}$ & $\begin{array}{c}\text { Disubstituierte } \\
\text { Analoga c [\%] }\end{array}$ & $\begin{array}{c}\text { Hormaomycin } \\
(\mathbf{1 6})[\%]\end{array}$ \\
\hline $\begin{array}{c}\text { rac-o- } \\
\text { Fluorphenylalanin } \\
\text { rac- } m \text { - }\end{array}$ & 23 & 45 & 32 \\
$\begin{array}{c}\text { Fluorphenylalanin } \\
\text { rac- } p \text { - }\end{array}$ & 32 & 45 & 23 \\
Fluorphenylalanin & 35 & - & 65 \\
\hline
\end{tabular}

Tab. 21: Prozentualer Anteil der gewonnenen Derivate an der Gesamtproduktion.

\section{Hormaomycin (16)/ Hormaomycin $\mathrm{F}_{1-3}(30 \mathrm{a}-\mathrm{c})$}

\section{Mischfraktion}

$\mathrm{C}_{55} \mathrm{H}_{69} \mathrm{~N}_{10} \mathrm{O}_{14} \mathrm{Cl}(1128.47)$

$\mathrm{C}_{55} \mathrm{H}_{68} \mathrm{~N}_{10} \mathrm{O}_{14} \mathrm{FCl}(1146.46)$

$\mathrm{C}_{55} \mathrm{H}_{67} \mathrm{~N}_{10} \mathrm{O}_{14} \mathrm{~F}_{2} \mathrm{Cl}(1164.45)$

farbloser Feststoff

UV-löschend (254 nm)

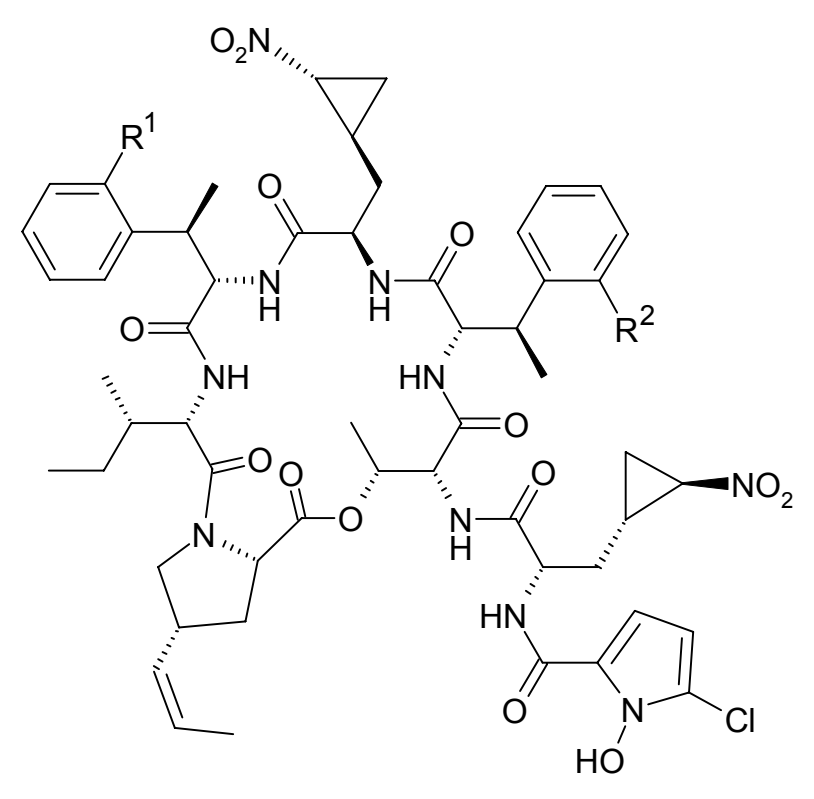

ESI-MS: (pos. lonen) $\mathrm{m} / \mathrm{z}=1151\left[\mathrm{M}_{1}+\mathrm{Na}\right]^{+}, 1170\left[\mathrm{M}_{2}+\mathrm{Na}\right]^{+}, 1187\left[\mathrm{M}_{3}+\mathrm{Na}\right]^{+}$; (neg. lonen) $\mathrm{m} / \mathrm{z}=1127\left[\mathrm{M}_{1}-\mathrm{H}\right]^{-}, 1146\left[\mathrm{M}_{2}-\mathrm{H}\right]^{-}, 1163\left[\mathrm{M}_{3}-\mathrm{H}\right]^{-}$. 
HR-ESI-MS:

\begin{tabular}{|c|c|c|c|c|}
\hline & & {$[\mathrm{M}+\mathrm{H}]^{+}$} & {$\left[\mathrm{M}+\mathrm{NH}_{4}\right]^{+}$} & {$[\mathrm{M}+\mathrm{Na}]^{+}$} \\
\hline \multirow{2}{*}{$30 a, b$} & berechnet & 1147.46671 & - & 1169.44869 \\
\hline & gefunden $^{a}$ & $1147.46879(0.18)$ & - & $1169.44880(0.09)$ \\
\hline \multirow{2}{*}{$30 c$} & berechnet & 1165.45730 & 1182.48001 & 1187.43927 \\
\hline & gefunden $^{a}$ & $1165.45853(0.90)$ & $1182.48385(1.20)$ & $1187.43877(0.04)$ \\
\hline
\end{tabular}

UV (MeOH): $\quad \lambda_{\max }(\lg \varepsilon)=270(4.03), 277(4.05) \mathrm{nm}$;

$(\mathrm{MeOH}, \mathrm{HCl}): \quad \lambda_{\max }(\lg \varepsilon)=266(3.99) \mathrm{nm}$;

$(\mathrm{MeOH}, \mathrm{NaOH}): \quad \lambda_{\max }(\lg \varepsilon)=279(3.95) \mathrm{nm}$.

CD $(\mathrm{MeOH}): \lambda_{\max }\left([\Theta]^{20}\right)=280(+25900), 222(-32400) \mathrm{nm}$.

$[\alpha]_{\mathrm{D}}^{20}=+11^{\circ}(\mathrm{c}=0.1, \mathrm{MeOH})$.

IR $(\mathrm{KBr}): \widetilde{\mathbf{v}}=3428(\mathrm{br}), 2930,2862,1735,1641,1542,1450,1374,1246,1177,1094$ (sh) $\mathrm{cm}^{-1}$.

Hormaomycin (16)/ Hormaomycin $\mathrm{G}_{1-3}(31 \mathrm{a}-\mathrm{c})$

Mischfraktion

$\mathrm{C}_{55} \mathrm{H}_{69} \mathrm{~N}_{10} \mathrm{O}_{14} \mathrm{Cl}(1128.47)$

$\mathrm{C}_{55} \mathrm{H}_{68} \mathrm{~N}_{10} \mathrm{O}_{14} \mathrm{FCl},(1146.46)$

$\mathrm{C}_{55} \mathrm{H}_{67} \mathrm{~N}_{10} \mathrm{O}_{14} \mathrm{~F}_{2} \mathrm{Cl}(1164.45)$

farbloser Feststoff

UV-löschend (254 nm)

\begin{tabular}{ccc}
\hline & $\mathbf{R}^{1}$ & $\mathbf{R}^{2}$ \\
\hline $31 a$ & $F$ & $H$ \\
$31 b$ & $H$ & $F$ \\
$31 c$ & $F$ & $F$
\end{tabular}

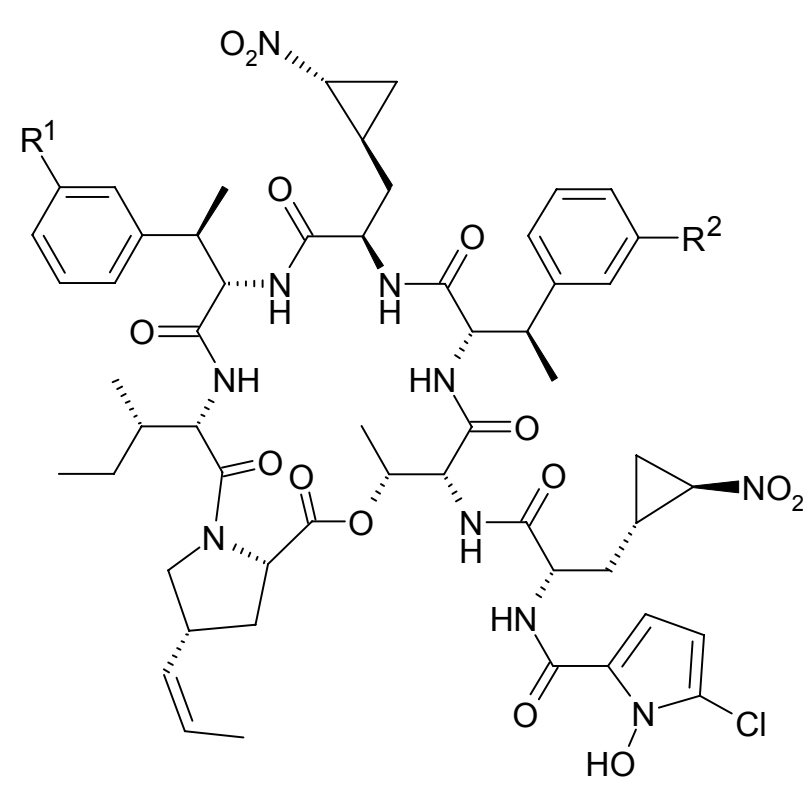

ESI-MS: (pos. Ionen) $\mathrm{m} / \mathrm{z}=1151\left[\mathrm{M}_{1}+\mathrm{Na}\right]^{+}, 1170\left[\mathrm{M}_{2}+\mathrm{Na}\right]^{+}, 1187\left[\mathrm{M}_{3}+\mathrm{Na}\right]^{+}$;

(neg. lonen) m/z = $1127\left[\mathrm{M}_{1}-\mathrm{H}\right]^{-}, 1146\left[\mathrm{M}_{2}-\mathrm{H}\right]^{-}, 1163\left[\mathrm{M}_{3}-\mathrm{H}\right]^{-}$. 
HR-ESI-MS:

\begin{tabular}{ccccc}
\hline & & {$[\mathrm{M}+\mathrm{H}]^{+}$} & {$\left[\mathrm{M}+\mathrm{NH}_{4}\right]^{+}$} & {$[\mathrm{M}+\mathrm{Na}]^{+}$} \\
\hline \multirow{2}{*}{ 31a,b } & berechnet & 1147.46671 & - & - \\
& gefunden $^{\mathrm{a}}$ & $1147.46877(0.17)$ & - & - \\
\multirow{3}{*}{ 31c } & berechnet & 1165.45730 & - & 1187.43927 \\
& gefunden $^{\mathrm{a}}$ & $1165.45853(0.90)$ & - & $1187.43901(0.02)$ \\
\hline
\end{tabular}

UV $(\mathrm{MeOH}): \lambda_{\max }(\lg \varepsilon)=274(4.18) \mathrm{nm}$;

$(\mathrm{MeOH}, \mathrm{HCl}): \lambda_{\max }(\lg \varepsilon)=274(4.18) \mathrm{nm}$;

$(\mathrm{MeOH}, \mathrm{NaOH}): \lambda_{\max }(\lg \varepsilon)=274(4.18) \mathrm{nm}$.

CD (MeOH): $\lambda_{\max }\left([\Theta]^{20}\right)=275(+27500), 224(-60600), 207(+11500) \mathrm{nm}$.

IR $(\mathrm{KBr}): \widetilde{v}=3384(\mathrm{br}), 2939,1740,1628(\mathrm{br}), 1544,1447,1370 \mathrm{~cm}^{-1}$. 
Hormaomycin (16)/ Hormaomycin $\mathrm{H}_{1,2}(32 \mathrm{a}, \mathrm{b})$

\section{Mischfraktion}

$\mathrm{C}_{55} \mathrm{H}_{69} \mathrm{~N}_{10} \mathrm{O}_{14} \mathrm{Cl}$ (1128.47)

$\mathrm{C}_{55} \mathrm{H}_{68} \mathrm{~N}_{10} \mathrm{O}_{14} \mathrm{FCl}$, (1146.46)

$\mathrm{C}_{55} \mathrm{H}_{67} \mathrm{~N}_{10} \mathrm{O}_{14} \mathrm{~F}_{2} \mathrm{Cl}(1164.45)$

farbloser Feststoff

UV-löschend (254 nm)

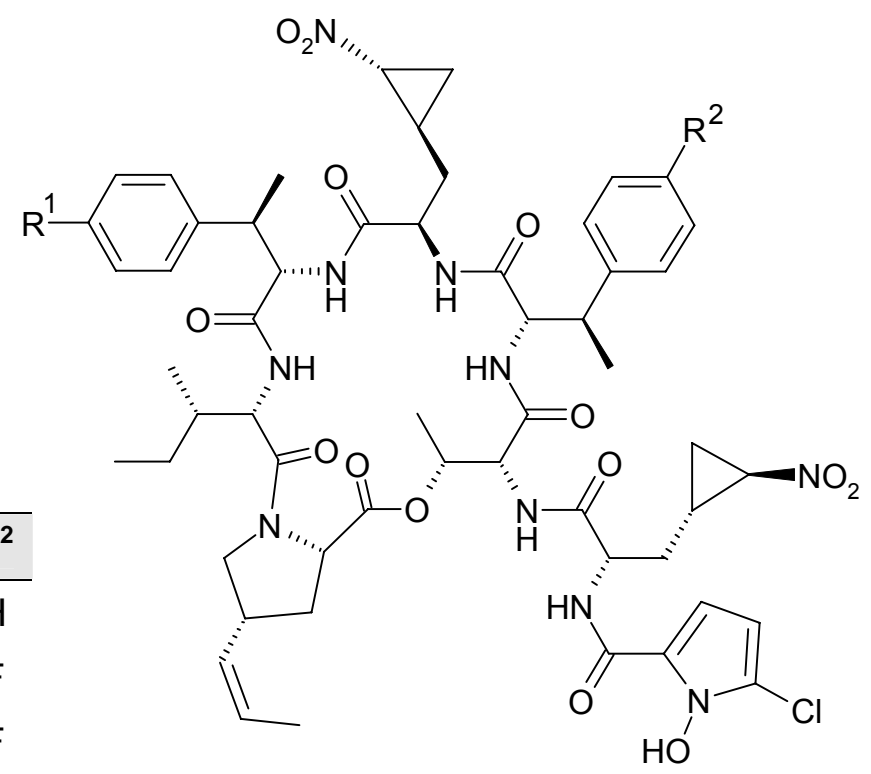

ESI-MS: (pos. lonen) $\mathrm{m} / \mathrm{z}=1151\left[\mathrm{M}_{1}+\mathrm{Na}\right]^{+}, 1170\left[\mathrm{M}_{2}+\mathrm{Na}\right]^{+}, 1187\left[\mathrm{M}_{3}+\mathrm{Na}\right]^{+}$; (neg. Ionen) $\mathrm{m} / \mathrm{z}=1127\left[\mathrm{M}_{1}-\mathrm{H}\right]^{-}, 1146\left[\mathrm{M}_{2}-\mathrm{H}\right]^{-}, 1163\left[\mathrm{M}_{3}-\mathrm{H}\right]^{-}$.

HR-ESI-MS:

\begin{tabular}{|c|c|c|c|c|}
\hline & & {$[\mathrm{M}+\mathrm{H}]^{+}$} & {$\left[\mathrm{M}+\mathrm{NH}_{4}\right]^{+}$} & {$[\mathrm{M}+\mathrm{Na}]^{+}$} \\
\hline \multirow{2}{*}{$30 a, b$} & berechnet & 1147.46671 & - & 1169.44869 \\
\hline & gefunden $^{a}$ & $1147.46879(0.18)$ & - & $1169.44880(0.09)$ \\
\hline \multirow{2}{*}{$30 c$} & berechnet & 1165.45730 & 1182.48001 & 1187.43927 \\
\hline & gefunden $^{a}$ & $1165.45853(0.90)$ & $1182.48385(1.20)$ & $1187.43877(0.04)$ \\
\hline
\end{tabular}

UV $(\mathrm{MeOH}): \quad \quad \lambda_{\max }(\lg \varepsilon)=276(3.81) \mathrm{nm}$;

$(\mathrm{MeOH}, \mathrm{HCl}): \quad \lambda_{\max }(\lg \varepsilon)=269(3.86) \mathrm{nm}$;

$(\mathrm{MeOH}, \mathrm{NaOH}): \quad \lambda_{\max }(\lg \varepsilon)=278(3.80) \mathrm{nm}$.

CD $(\mathrm{MeOH}): \lambda_{\max }\left([\Theta]^{20}\right)=276(+34500), 223(-34700) \mathrm{nm}$.

IR $(\mathrm{KBr}): \widetilde{v}=3384(\mathrm{br}), 2928,1742,1628(\mathrm{br}), 1544,1447,1370 \mathrm{~cm}^{-1}$. 


\subsubsection{Variation der 5-Chlor-N-hydroxy-pyrrol-2-carbonsäure-Einheit}

Die in Tab. 22 aufgelisteten Vorläufer wurden in $50 \mathrm{~mL}$ sterilem Wasser unter Zusatz von $1 \mathrm{M}$ $\mathrm{NaOH}$ gelöst und unter Standardbedingungen (siehe Kap. B.2.3) gefüttert.

Das Rohprodukt wurde mit eiskaltem Pentan gewaschen und an Kieselgel (Aceton/Cyclohexan 2:3, $120 \times 45 \mathrm{~mm}$ ) chromatographiert. Aus den Fütterungen konnten keine neuen Derivate gewonnen werden.

\begin{tabular}{lccc}
\hline \multicolumn{1}{c}{ Carbonsäure } & $\begin{array}{c}\text { Gefütterte Menge } \\
{[\mathrm{mmol}]}\end{array}$ & $\begin{array}{c}\text { Hormaomycin- } \\
\text { Produktion }\end{array}$ & $\begin{array}{c}\text { Hormaomycin- } \\
\text { Derivate }\end{array}$ \\
\hline 2-Pyrrolcarbonsäure & 1.0 & + & - \\
& 2.0 & + & - \\
& 4.0 & + & - \\
& 8.0 & + & - \\
2-Thiophencarbonsäure & 2.0 & + & - \\
2-Tetrahydrofuran- & 2.0 & + & - \\
carbonsäure & 2.0 & + & - \\
2-Furancarbonsäure & 2.0 & + & - \\
Picolinsäure & 2.0 & + & + \\
3-Chlorsalicylsäure & 2.0 & + & + \\
Pipecolinsäure & & + & - \\
\hline
\end{tabular}

Tab. 22: Vorläufer für die Variation der Startereinheit. 


\subsection{Untersuchung der Hormaomycin-Biosynthese an Escherichia coli-Mutanten}

\subsubsection{Stammhaltung}

\subsubsection{Agarplatten}

Die Mutanten E. coli pKZ 72 und 73 wurden auf Petrischalen mit LB $_{\text {Kn50-Nährmedium }}$ gehalten. Sie wurden bei $37^{\circ} \mathrm{C} 2-3$ Tage inkubiert und bei $4^{\circ} \mathrm{C}$ für maximal drei Monate gelagert.

\subsubsection{Langzeitkonservierung}

Aus einer gut bewachsenen Agarplatte wurden mit einseitig zugeschweißten und mit einem Bleistück beschwerten sterilen Halmen aus Polypropylen Agarstückchen ausgestanzt, bis der Halm gefüllt war. Dieser wurde in einen zweiten äußeren Halm gesteckt, der mit einer ausgeglühten Tiegelzange an beiden Seiten zugeschmolzen wurde. Die Halme wurden in einem Dewar über flüssigem Stickstoff bei $-196^{\circ} \mathrm{C}$ gelagert.

\subsubsection{Kultivierung}

Vorkultur: Die Stämme wurden in $3 \mathrm{~mL}$ flüssiges $\mathrm{LB}_{\mathrm{Kn} 50^{-}}$-Medium in Reagenzgläsern inokuliert und bei $37^{\circ} \mathrm{C}$ und $180 \mathrm{rpm}$ für $12 \mathrm{~h}$ wachsen gelassen.

Hauptkultur: Die Hauptkulturen $\left(30 \mathrm{~mL}\right.$ LB$_{\mathrm{Kn} 50}-$ Medium in $100 \mathrm{~mL}$ Erlenmeyerkolben mit und ohne Schikane) wurden mit $10 \%$ Vorkultur inokuliert und bis zu $\mathrm{OD}_{600}=0.5$ (ca. $2 \mathrm{~h}$ ) wachsen gelassen. Anschließend wurden die Vorläufer (pKZ 72: L-Phenylpyruvat sowie L-Phenylalanin; pKZ 73: L-Lysin) bis zu einer Endkonzentration von $0.3 \mathrm{mM}$ zusammen mit meta-Toluylsäure (Endkonzentration 0.1, 0.2 und $0.3 \mathrm{mM}$ ) über einen Zeitraum von $12 \mathrm{~h}$ in vier Intervallen gefüttert. Die Gesamtfermentationsdauer betrug $36 \mathrm{~h}$.

\subsubsection{Aufarbeitung}

Die Kulturbrühen wurden lyophilisiert und der Rückstand mit $20 \mathrm{~mL}$ (pro $100 \mathrm{~mL}$ Kulturlösung) $50 \mathrm{mM} \mathrm{Na} \mathrm{HPO}_{4} /$ Ethanol 1:1 ( $\mathrm{pH}$ 7)-Puffer extrahiert. Die Lösungen wurden zentrifugiert und HPLC-MS analytisch (Säule B, Programm 2) untersucht. 


\section{Strukturaufklärung von Sekundärmetaboliten}

\subsection{Substanzen aus dem chemischen Screening}

\subsubsection{Stammhaltung}

Agarplatten

Die Haltung von Actinomyces sp. M1-M4 und P1-P4 erfolgte auf Petrischalen mit M2Nährmedium. Sie wurden bei $28^{\circ} \mathrm{C} 7-10$ Tage inkubiert und bei $28^{\circ} \mathrm{C}$ für maximal einen sowie bei $4^{\circ} \mathrm{C}$ maximal drei Monate gelagert.

Langzeitkonservierung

Aus einer gut bewachsenen Agarplatte wurden mit einseitig zugeschweißten und mit einem Bleistück beschwerten sterilen Halmen aus Polypropylen Agarstückchen ausgestanzt, bis der Halm gefüllt war. Dieser wurde in einen zweiten äußeren Halm gesteckt, der mit einer ausgeglühten Tiegelzange an beiden Seiten zugeschmolzen wurde. Die Halme wurden in einem Dewar über flüssigem Stickstoff bei $-196^{\circ} \mathrm{C}$ gelagert.

\subsubsection{Chemisches Screening}

Die Kultivierung der zu untersuchenden Stämme erfolgte in vier verschiedenen Nährmedien (M2, SM, SGG und Hafer) in $300 \mathrm{~mL}$ Erlenmeyerkolben mit drei Schikanen die mit jeweils $50 \mathrm{~mL}$ Nährmedium befüllt waren. Die Nährmedien wurden mit jeweils einem ca. $1 \mathrm{~cm}^{2}$ großen Agarstück beimpft und bei $28^{\circ} \mathrm{C}$ und $180 \mathrm{rpm}$ für $72 \mathrm{~h}$ inkubiert. Unter Zugabe von Celite wurden die vereinigten Kulturbrühen (je $100 \mathrm{~mL}$ ) filtriert. Das Mycel wurde $15 \mathrm{~min}$ im Ultraschallbad mit $100 \mathrm{~mL}$ Aceton, das Kulturfiltrat mit $100 \mathrm{~mL}$ Ethylacetat extrahiert. Anschließend wurde das Lösungsmittel in vacuo entfernt und die so erhaltenen Extrakte in $2 \mathrm{~mL} \mathrm{MeOH} / \mathrm{H}_{2} \mathrm{O}$ 1:1 gelöst. $5 \mu \mathrm{L}$ dieser Lösungen wurden auf HPTLC-Kieselgelplatten aufgetragen und in $\mathrm{CHCl}_{3} / \mathrm{MeOH}$ 9:1 entwickelt. Die Analyse des Metabolitenmusters erfolgte durch Eigenfarbe, UV-Licht bei 254 und $366 \mathrm{~nm}$ sowie Sprühreagenzien (Anisaldehyd, Ehrlich, Orcin). 


\subsubsection{Substanzen aus Actinomyces sp. Stamm P4}

\section{Kultivierung und Aufarbeitung}

Der Stamm P4 wurde in $300 \mathrm{~mL}$ Erlenmeyerkolben mit Schaumstoffkappen in $100 \mathrm{~mL}$ SMMedium bei $28^{\circ} \mathrm{C}$ und $180 \mathrm{rpm}$ für $72 \mathrm{~h}$ kultiviert. Mycel und Kulturfiltrat wurden durch Filtration im Vakuum getrennt, der pH-Wert des Kulturfiltrats vor der Extraktion auf 5 eingestellt. Die Extraktion des Kulturfiltrats erfolgte mit $2 \times 1 \mathrm{~L}$ (pro $\mathrm{L}$ Kultur) Ethylacetat, die des Mycels mit $2 \times 1 \mathrm{~L}$ (pro L Kultur) Aceton für 15 min im Ultraschallbad.

\section{Isolierung der Metaboliten}

Die jeweiligen Extrakte wurden zweimal an Kieselgel $\left(\mathrm{CH}_{2} \mathrm{Cl}_{2} / \mathrm{MeOH}\right.$ 95:5 $\rightarrow$ 9:1, $450 \times 55 \mathrm{~mm}$ sowie $\mathrm{CH}_{2} \mathrm{Cl}_{2} / \mathrm{MeOH} 9: 1,550 \times 40 \mathrm{~mm}$ ) chromatographiert, wobei $35.3 \mathrm{mg}$ Chartreusin (44) aus dem Kulturfiltrat und $45.1 \mathrm{mg} 44$ aus dem Mycel erhalten wurden.

\section{Chartreusin (44)}

$\mathrm{C}_{32} \mathrm{H}_{32} \mathrm{O}_{14}(640.60)$

gelber Feststoff

UV-löschend (254 nm)

blau fluoreszierend $(366 \mathrm{~nm})$

Anfärbeverhalten: gelb (Anis).

$\mathbf{R}_{\mathrm{f}}=0.37\left(\mathrm{KG}, \mathrm{CHCl}_{3} / \mathrm{MeOH} 9: 1\right)$.

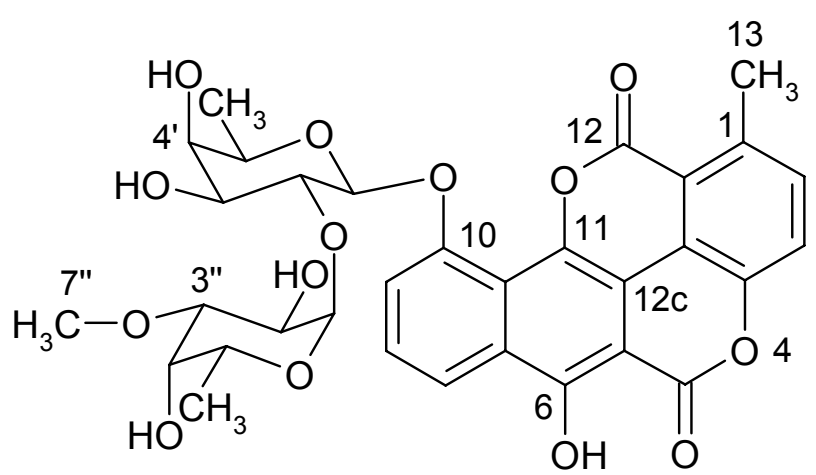

44

ESI-MS: (pos. lonen) $\mathrm{m} / \mathrm{z}=663[\mathrm{M}+\mathrm{Na}]^{+}, 1303[2 \mathrm{M}+\mathrm{Na}]^{+}$.

(neg. lonen) $\mathrm{m} / \mathrm{z}=639[\mathrm{M}-\mathrm{H}]^{-}, 1279[2 \mathrm{M}-\mathrm{H}]^{-}$.

HR-ESI-MS: berechnet: $658.21303\left[\mathrm{M}+\mathrm{NH}_{4}\right]^{+}$. gefunden: $658.21316(\Delta=0.20 \mathrm{ppm})$.

UV $(\mathrm{MeOH})$ : $\lambda_{\max }(\lg \varepsilon)=236$ (4.63), 265 (4.61), 334 (4.03), 379 (4.03), 400 (4.19), 422 (4.23) nm; $(\mathrm{MeOH}, \mathrm{HCl}): \quad \lambda_{\max }(\lg \varepsilon)=235$ (4.54), 264 (4.56), $333(3.77), 372(3.88), 400$ (4.12), $422(4.15) \mathrm{nm}$;

$(\mathrm{MeOH}, \mathrm{NaOH}): \quad \lambda_{\max }(\lg \varepsilon)=238$ (4.65), 257 (sh) (4.47), 311 (3.75), 362 (3.85), $438(4.09) \mathrm{nm}$.

CD $(\mathrm{MeOH}): \lambda_{\max }\left([\Theta]^{20}\right)=211(+6200), 237(-26300), 276(+6000) \mathrm{nm}$.

$[\alpha]_{\mathrm{D}}^{20}=-27^{\circ}(\mathrm{c}=0.33, \mathrm{MeOH})$. 
IR $(\mathrm{KBr}): \widetilde{\mathrm{v}}=3432(\mathrm{br}), 2929,2364,1720,1624,1501,1377,1246,1141,1069 \mathrm{~cm}^{-1}$.

${ }^{1} \mathrm{H}-\mathrm{NMR}\left(600 \mathrm{MHz}\right.$, DMSO-d 6 ): $\delta=0.98\left(\mathrm{~d}, J=6.5 \mathrm{~Hz}, 3 \mathrm{H}, 6{ }^{\prime \prime}-\mathrm{H}\right), 1.21(\mathrm{~d}, J=6.5 \mathrm{~Hz}, 3 \mathrm{H}$, 6'-H), 2.82 (s, $3 \mathrm{H}, 13-\mathrm{H}$ ), 3.12 (dd, J = 10.0, 3.0 Hz, $1 \mathrm{H}, 3$ "'-H), 3.16 (s, $3 \mathrm{H}, 7$ '- $-\mathrm{H}$ ), 3.41 (m,

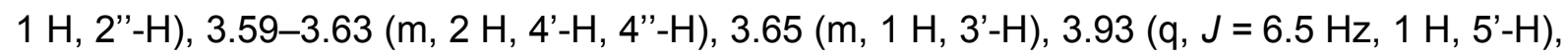
3.99 (dd, $\left.J=9.5,8.0 \mathrm{~Hz}, 1 \mathrm{H}, 2^{\prime}-\mathrm{H}\right), 4.17\left(\mathrm{~d}, J=4.0 \mathrm{~Hz}, 1 \mathrm{H}, 4^{\prime}-\mathrm{OH}^{*}\right), 4.22$ (q, J = $6.5 \mathrm{~Hz}$, $1 \mathrm{H}, 5$ "'-H), 4.51 (d, J =5.5Hz, $1 \mathrm{H}, 3$ '-OH), 4.81 (d, J=3.0 Hz, $1 \mathrm{H}, 4$ "'-OH), 5.36 (d, $\left.J=8.0 \mathrm{~Hz}, 1 \mathrm{H}, 1^{\prime}-\mathrm{H}\right), 5.44\left(\mathrm{~d}, J=4.0 \mathrm{~Hz}, 1 \mathrm{H}, 1^{\prime \prime}-\mathrm{H}\right), 7.47$ (d, J = 8.0 Hz, $\left.1 \mathrm{H}, 9-\mathrm{H}\right), 7.60$ (d, $J=8.0 \mathrm{~Hz}, 1 \mathrm{H}, 2-\mathrm{H}), 7.63(\mathrm{dd}, J=8.0,8.0 \mathrm{~Hz}, 1 \mathrm{H}, 8-\mathrm{H}), 7.66(\mathrm{~d}, J=8.0 \mathrm{~Hz}, 1 \mathrm{H}, 3-\mathrm{H}), 8.14$ (d, $J=8.0 \mathrm{~Hz}, 1 \mathrm{H}, 7-\mathrm{H}) \mathrm{ppm}$.

${ }^{1} \mathrm{H}-\mathrm{NMR}\left(300 \mathrm{MHz}\right.$, Pyridin- $\left.\mathrm{d}_{5}\right): \delta=1.56\left(\mathrm{~d}, J=6.5 \mathrm{~Hz}, 3 \mathrm{H}, 6^{\prime}-\mathrm{H}_{3}\right), 1.57(\mathrm{~d}, J=6.5 \mathrm{~Hz}, 3 \mathrm{H}$, 6"'- $\mathrm{H}_{3}$ ), 2.75 (s, $3 \mathrm{H}, 13-\mathrm{H}_{3}$ ), 3.35 (s, $3 \mathrm{H}, 7$ ''- $\mathrm{H}_{3}$ ), 3.85 (dd, $J=10.0,3.0 \mathrm{~Hz}, 1 \mathrm{H}, 3$ 3'-H), 4.12 (m, 2 H, 5'-H, 4'- $-\mathrm{H}$ ), 4.21 (d, J = 3.5 Hz, $1 \mathrm{H}, 4^{\prime}-\mathrm{H}$ ), 4.32 (dd, J = 9.5, 3.5 Hz, $1 \mathrm{H}, 3^{\prime}-\mathrm{H}$ ), 4.54 (dd, $J=10.0,4.0 \mathrm{~Hz}, 1 \mathrm{H}, 2$ '- $-\mathrm{H}$ ), 5.00 (q, $J=6.5 \mathrm{~Hz}, 1 \mathrm{H}, 5$ "'-H), 5.06 (dd, $J=9.5,8.0 \mathrm{~Hz}$, $\left.1 \mathrm{H}, 2^{\prime}-\mathrm{H}\right), 5.82\left(\mathrm{~d}, J=8.0 \mathrm{~Hz}, 1 \mathrm{H}, 1^{\prime}-\mathrm{H}\right), 6.52\left(\mathrm{~d}, J=4.0 \mathrm{~Hz}, 1 \mathrm{H}, 1^{\prime \prime}-\mathrm{H}\right), 7.31(\mathrm{~d}, J=8.0 \mathrm{~Hz}$, $1 \mathrm{H}, 2-\mathrm{H}), 7.44(\mathrm{~d}, J=8.0 \mathrm{~Hz}, 1 \mathrm{H}, 3-\mathrm{H}), 7.64(\mathrm{dd}, J=8.0,8.0 \mathrm{~Hz}, 1 \mathrm{H}, 8-\mathrm{H}), 7.76(\mathrm{~d}$, $J=8.0 \mathrm{~Hz}, 1 \mathrm{H}, 7-\mathrm{H}), 8.36(\mathrm{~d}, J=8.0 \mathrm{~Hz}, 1 \mathrm{H}, 9-\mathrm{H}) \mathrm{ppm}$.

${ }^{13}$ C-NMR (150.8 MHz, DMSO-d 6 ): $\delta=16.4$ (q, C-6”), 16.5 (q, C-6'), 21.6 (q, C-13), 65.8 (d, C-5”), 66.9 (d, C-2”), 67.5 (d, C-4"), 70.1 (d, C-5'), 71.2 (d, C-4'), 71.9 (d, C-3'), 77.8 (d, C2'), 79.8 (d, C-3'), 99.3 (d, C-1'), 99.4 (d, C-1'), 109.4 (s, C-12c), 114.1 (d, C-9), 117.1 (d, C7), 117.1 (s, C-12a), 118.2 (s, C-10a), 120.2 (d, C-8), 132.5 (d, C-2), 137.6 (s, C-10b), 137.7 (s, C-1), 146.9 (s, C-3a), 153.8 (s, C-10), 155.5 (s, C-6), 158.8 (s, C-12), 168.9 (s, C-5) ppm. 


\subsubsection{Substanzen aus Actinomyces sp. Stamm M4-1}

\section{Kultivierung und Aufarbeitung}

Der Stamm P4 wurde in $300 \mathrm{~mL}$ Erlenmeyerkolben mit Schaumstoffkappen in $100 \mathrm{~mL}$ SMMedium bei $28^{\circ} \mathrm{C}$ und $180 \mathrm{rpm}$ für $72 \mathrm{~h}$ kultiviert. Mycel und Kulturfiltrat wurden durch Filtration im Vakuum getrennt, der pH-Wert des Kulturfiltrats vor der Extraktion auf 6.5 eingestellt. Die Extraktion des Kulturfiltrats erfolgte mit $2 \times 1 \mathrm{~L}$ (pro L Kultur) Ethylacetat, das Mycel wurde verworfen.

\section{Isolierung der Metaboliten}

Der Kulturfiltratextrakt wurde an Kieselgel $\left(\mathrm{CH}_{2} \mathrm{Cl}_{2} / \mathrm{MeOH} 9: 1,120 \times 45 \mathrm{~mm}\right)$ und Sephadex LH-20 (MeOH, $120 \times 35 \mathrm{~mm})$ chromatographiert, wobei $6.7 \mathrm{mg}$ Borrelidin (15), $7.8 \mathrm{mg}$ Daidzein(12a) und 8.3 mg Genistein (45) gewonnen wurden.

\section{Genistein (45)}

(4',5,7-Trihydroxyisoflavon)

$\mathrm{C}_{15} \mathrm{H}_{10} \mathrm{O}_{5}(270.04)$

farbloser Feststoff

stark UV-löschend (254 nm)<smiles>O=c1c(-c2ccc(O)cc2)coc2cc(O)cc(O)c12</smiles>

45

Anfärbeverhalten: braun (Anis).

$\mathbf{R}_{\mathbf{f}}=0.14\left(\mathrm{KG}, \mathrm{CHCl}_{3} / \mathrm{MeOH} 9: 1\right)$.

ESI-MS: (neg. lonen) $\mathrm{m} / \mathrm{z}=269[\mathrm{M}-\mathrm{H}]^{-}, 539[2 \mathrm{M}-\mathrm{H}]^{-}$.

HR-ESI-MS: berechnet: $269.04555[\mathrm{M}-\mathrm{H}]^{-}$.

gefunden: $269.04570(\Delta=0.56 \mathrm{ppm})$.

$$
\text { UV } \begin{aligned}
(\mathrm{MeOH}): & \lambda_{\max }(\lg \varepsilon)=262(4.57) \mathrm{nm} ; \\
(\mathrm{MeOH}, \mathrm{HCl}): & \lambda_{\max }(\lg \varepsilon)=262(4.57) \mathrm{nm} ; \\
(\mathrm{MeOH}, \mathrm{NaOH}): & \lambda_{\max }(\lg \varepsilon)=275(4.57) \mathrm{nm}
\end{aligned}
$$

${ }^{1} \mathrm{H}-N M R\left(300 \mathrm{MHz}, \mathrm{CD}_{3} \mathrm{OD}\right): \delta=6.19(\mathrm{~d}, \mathrm{~J}=2.0 \mathrm{~Hz}, 1 \mathrm{H}, 6-\mathrm{H}), 6.31(\mathrm{~d}, \mathrm{~J}=2.0 \mathrm{~Hz}, 1 \mathrm{H}, 4-\mathrm{H})$, 6.82 (dd, J = 8.5, 2.0 Hz, 2 H, 2'-H, 6'-H), 7.37 (dd, J = 8.5, 2.0 Hz, 2 H, 3'-H, 5'-H), 8.03 (s, $1 \mathrm{H}, 2-\mathrm{H})$. 
${ }^{13}$ C-NMR (75.5 MHz, CD 3 OD): $\delta=94.8$ (d, C-4), 100.2 (d, C-6), 106.2 (s, C-7a), 116.3 (d, C3',5'), 123.3 (s, C-1'), 124.7 (s, C-1a), 131.4 (d, C-2',6'), 154.8 (d, C-2), 158.8 (s, C-4'), 159.7 (s, C-3a), 163.8 (s, C-7), 166.2 (s, C-5), 182.2 (s, C-1).

\section{Daidzein (12a)}

(4',5-Dihydroxyisoflavon)

$\mathrm{C}_{15} \mathrm{H}_{10} \mathrm{O}_{4}(270.04)$

farbloser Feststoff<smiles>O=c1c(-c2ccc(O)cc2)coc2cc(O)ccc12</smiles>

stark UV-löschend (254 nm)

$12 a$

Anfärbeverhalten: braun (Anis).

$\mathbf{R}_{\mathbf{f}}=0.31\left(\mathrm{KG}, \mathrm{CHCl}_{3} / \mathrm{MeOH}\right.$ 9:1).

ESI-MS: (neg. lonen) $\mathrm{m} / \mathrm{z}=253[\mathrm{M}-\mathrm{H}]^{-}, 507[2 \mathrm{M}-\mathrm{H}]^{-}$.

HR-ESI-MS: berechnet: $253.05063[\mathrm{M}-\mathrm{H}]^{-}$.

gefunden: $253.05080(\Delta=0.67 \mathrm{ppm})$.

${ }^{1} \mathrm{H}-\mathrm{NMR}\left(300 \mathrm{MHz}, \mathrm{DMSO}-\mathrm{d}_{6}\right): \delta=6.80\left(\mathrm{~d}, \mathrm{~J}=8.0 \mathrm{~Hz}, 2 \mathrm{H}, 3^{\prime}-\mathrm{H}^{\prime}, 5^{\prime}-\mathrm{H}\right), 6.84(\mathrm{~d}, J=2.0 \mathrm{~Hz}$, $1 \mathrm{H}, 4-\mathrm{H}), 6.92(\mathrm{dd}, J=8.0,2.0 \mathrm{~Hz}, 1 \mathrm{H}, 6-\mathrm{H}), 7.37$ (d, J = 8.0 Hz, $2 \mathrm{H}, 2$ '- H, 6-H'), 7.95 (d, $J=8.0 \mathrm{~Hz}, 1 \mathrm{H}, 7-\mathrm{H}), 8.25(\mathrm{~s}, 1 \mathrm{H}, 2-\mathrm{H})$.

\section{Borrelidin (15)}

$\mathrm{C}_{28} \mathrm{H}_{43} \mathrm{NO}_{6}$ (489.66)

farbloser Feststoff

stark UV-löschend (254 nm)

Anfärbeverhalten: grau-braun (Anis).

$\mathbf{R}_{\mathrm{f}}=0.54\left(\mathrm{KG}, \mathrm{CHCl}_{3} / \mathrm{MeOH}\right.$ 9:1).

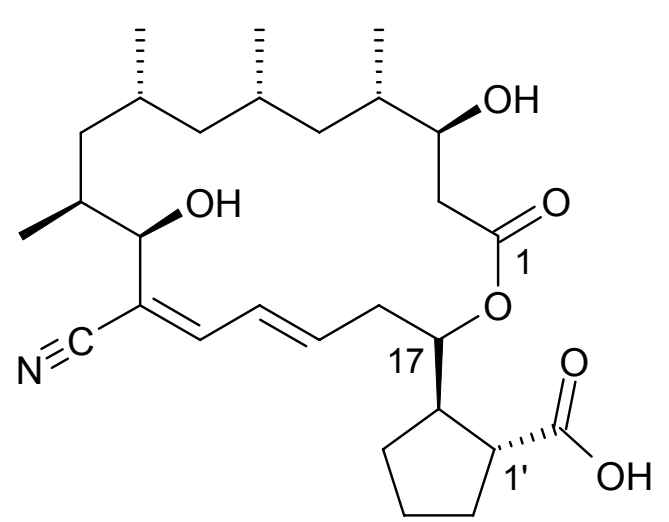

15

ESI-MS: (pos.) $\mathrm{m} / \mathrm{z}=512[\mathrm{M}+\mathrm{Na}]^{+}, 1001[2 \mathrm{M}+\mathrm{Na}]^{+}, 1490[3 \mathrm{M}+\mathrm{Na}]^{+}$.

(neg.) $\mathrm{m} / \mathrm{z}=488[\mathrm{M}-\mathrm{H}]^{-}, 977[2 \mathrm{M}-\mathrm{H}]^{-}$.

HR-ESI-MS: berechnet: $507.34286\left[\mathrm{M}+\mathrm{NH}_{4}\right]^{+}, 512.29826[\mathrm{M}+\mathrm{Na}]^{+}$. gefunden: $507.34296(\Delta=0.20 \mathrm{ppm}), 512.29836(\Delta=0.20 \mathrm{ppm})$. 
IR $(\mathrm{KBr})$ :

$\widetilde{v}=3435,2958,2924,2213,1709,1636,1560,1458,1411,1382,1268$ (sh), $1187,1042 \mathrm{~cm}^{-1}$.

$[\alpha]_{\mathrm{D}}^{20}=+67^{\circ}(\mathrm{c}=0.1, \mathrm{MeOH})$.

${ }^{1} \mathrm{H}-\mathrm{NMR}\left(600 \mathrm{MHz}, \mathrm{CD}_{3} \mathrm{OD}\right): \delta=0.68\left(\mathrm{dt}, J=12.0,3.0 \mathrm{~Hz}, 1 \mathrm{H}, 9-\mathrm{H}_{\mathrm{a}}\right), 0.83(\mathrm{~d}, J=5.0 \mathrm{~Hz}, 3 \mathrm{H}$, 8- $\mathrm{CH}_{3}$ ), 0.84 (d, $\left.J=5.0 \mathrm{~Hz}, 3 \mathrm{H}, 6-\mathrm{CH}_{3}\right), 0.85$ (d, $J=7.0 \mathrm{~Hz}, 3 \mathrm{H}, 4-\mathrm{CH}_{3}$ ), 0.95 (ddd, $J=12.5,6.0$, $\left.3.5 \mathrm{~Hz}, 1 \mathrm{H}, 7-\mathrm{H}_{\mathrm{a}}\right), 0.97\left(\mathrm{~m}, 1 \mathrm{H}, 5-\mathrm{H}_{\mathrm{a}}\right), 1.02\left(\mathrm{~d}, J=6.5 \mathrm{~Hz}, 3 \mathrm{H}, 10-\mathrm{CH}_{3}\right), 1.05$ (ddd, $J=12.5,2.5$, $\left.2.5 \mathrm{~Hz}, 1 \mathrm{H}, 7-\mathrm{H}_{\mathrm{b}}\right), 1.19-1.23\left(\mathrm{~m}, 2 \mathrm{H}, 5-\mathrm{H}_{\mathrm{b}}, 9-\mathrm{H}_{\mathrm{b}}\right), 1.40$ (ddt, $\left.J=8.0,8.0,3.5 \mathrm{~Hz}, 1 \mathrm{H}, 3{ }^{\prime}-\mathrm{H}_{\mathrm{a}}\right), 1.59-$ $1.66(\mathrm{~m}, 1 \mathrm{H}, 8-\mathrm{H}), 1.72-1.88\left(\mathrm{~m}, 5 \mathrm{H}, 4-\mathrm{H}, 6-\mathrm{H}, 10-\mathrm{H}, 4^{\prime}-\mathrm{H}_{\mathrm{a}}, 5^{\prime}-\mathrm{H}_{\mathrm{a}}\right), 1.96-2.03\left(\mathrm{~m}, 2 \mathrm{H}, 3{ }^{\prime}-\mathrm{H}_{\mathrm{b}}\right.$, $4^{\prime}-\mathrm{H}_{\mathrm{b}}$ ), 2.21 (dd, $J=16.5,10.5 \mathrm{~Hz}, 1 \mathrm{H}, 2-\mathrm{H}_{\mathrm{a}}$ ), 2.37 (dd, $J=16.5,3.5 \mathrm{~Hz}, 1 \mathrm{H}, 2-\mathrm{H}_{\mathrm{b}}$ ), 2.41 (dt, $\left.J=8.0,8.0 \mathrm{~Hz}, 1 \mathrm{H}, 1^{\prime}-\mathrm{H}\right), 2.49-2.54\left(\mathrm{~m}, 1 \mathrm{H}, 16-\mathrm{H}_{\mathrm{a}}\right), 2.56$ (ddd, $\left.J=15.0,5.0,4.5 \mathrm{~Hz}, 1 \mathrm{H}, 16-\mathrm{H}_{\mathrm{b}}\right)$, 2.66 (ddt, $J=11.0,8.0,8.0 \mathrm{~Hz}, 1 \mathrm{H}, 2 '-\mathrm{H}$ ), 3.92 (ddd, $J=10.5,6.0,3.0 \mathrm{~Hz}, 1 \mathrm{H}, 3-\mathrm{H}$ ), 4.17 (d, $J=9.5 \mathrm{~Hz}, 1 \mathrm{H}, 11-\mathrm{H}$ ), 4.97 (dt, $J=10.5,3.5 \mathrm{~Hz}, 1 \mathrm{H}, 17-\mathrm{H}$ ), 6.31 (ddd, $J=15.0,10.0,4.5 \mathrm{~Hz}$, $1 \mathrm{H}, 15-\mathrm{H}), 6.59$ (dd, J = 15.0, $12.0 \mathrm{~Hz}, 1 \mathrm{H}, 14-\mathrm{H}), 6.90(\mathrm{~d}, J=12.0 \mathrm{~Hz}, 1 \mathrm{H}, 13-\mathrm{H})$.

${ }^{13}$ C-NMR (150.8 MHz, CD ${ }_{3} \mathrm{OD}$ ): $\delta=15.4$ (q, $\mathrm{C} 10-\mathrm{CH}_{3}$ ), 18.7 (q, C8-CH ), 19.1 (q, C4-CH $\mathrm{CH}_{3}, 20.9$ (q, C6-CH ( $_{3}, 26.2$ (t, C-4'), 27.6 (d, C-8), 28.5 (d, C-6), 30.5 (t, C-3'), 32.5 (t, C-5'), 36.0 (d, C-10), 36.7 (t, C-16), 37.0 (d, C-4), 37.9 (t, C-2), 39.1 (t, C-9), 44.6 (t, C-5), 47.5 (d, C-2'), 49.4 (t, C-7), 50.3 (d, C-1'), 72.9 (d, C-3), 73.1 (d, C-11), 77.4 (d, C-17), 117.4 (s, C12-CN), 119.9 (s, C-12), 129.0 (d, C-14), 140.2 (d, C-15), 145.5 (d, C-13), 173.2 (s, C-1), 180.7 (s, C-1'-COOH). 


\subsection{Charakterisierung der Metaboliten aus Streptomyces sp. Stamm Tü 6319}

Fogacin (46)

$\mathrm{C}_{16} \mathrm{H}_{18} \mathrm{O}_{6}(306.32)$

farbloser Feststoff

schwach UV-löschend (254 nm)

Anfärbeverhalten: braun (Anis).

$\mathbf{R}_{\mathrm{f}}=0.06\left(\mathrm{KG}, \mathrm{CHCl}_{3} / \mathrm{MeOH} 9: 1\right)$.

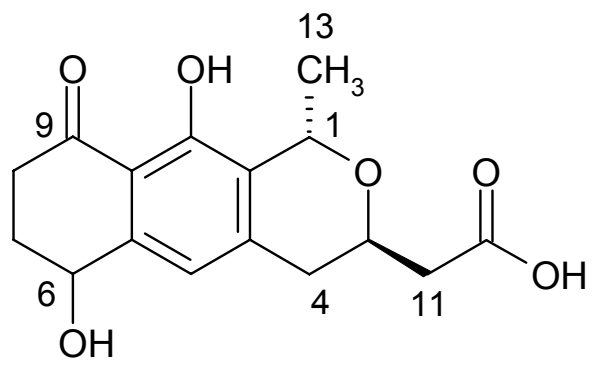

46

ESI-MS: (pos. lonen) $\mathrm{m} / \mathrm{z}=635[2 \mathrm{M}+\mathrm{Na}]^{+}, 329[\mathrm{M}+\mathrm{Na}]^{+}, 307[\mathrm{M}+\mathrm{H}]^{+}$.

(neg. lonen) $\mathrm{m} / \mathrm{z}=305[\mathrm{M}-\mathrm{H}]$.

HR-ESI-MS: berechnet: $307.11762[\mathrm{M}+\mathrm{H}]^{+}$. gefunden: $307.11763(\Delta=0.03 \mathrm{ppm})$.

UV (MeOH): $\lambda_{\max }(\lg \varepsilon)=222$ (3.63), $272(3.40), 333(2.95) \mathrm{nm}$; $(\mathrm{MeOH}, \mathrm{HCl}): \quad \lambda_{\max }(\mathrm{lg} \varepsilon)=221$ (3.64), $271(3.40), 331$ (3.02) nm; $(\mathrm{MeOH}, \mathrm{NaOH}): \quad \lambda_{\max }(\lg \varepsilon)=223(3.67), 271(3.49), 333(3.11) \mathrm{nm}$.

CD (MeOH): $\lambda_{\max }\left([\Theta]^{20}\right)=268(-4200), 214(+8000) \mathrm{nm}$.

IR (KBr): $\widetilde{v}=3428(\mathrm{br}), 2937,2354,1707,1625,1370,1264,1155,1085 \mathrm{~cm}^{-1}$. $[\alpha]_{\mathrm{D}}^{20}=+7^{\circ}(\mathrm{c}=0.1, \mathrm{MeOH})$.

${ }^{1} \mathrm{H}-\mathrm{NMR}\left(600 \mathrm{MHz}, \mathrm{CD}_{3} \mathrm{OD}\right): \delta=1.55\left(\mathrm{~d}, J=6.5 \mathrm{~Hz}, 3 \mathrm{H}, 13-\mathrm{H}_{3}\right), 2.10$ (dddd, $J=14.0,9.0$, 4.5, $\left.3.5 \mathrm{~Hz}, 1 \mathrm{H}, 7-\mathrm{H}_{\mathrm{a}}\right), 2.29$ (dddd, $\left.J=14.0,8.5,8.0,4.5 \mathrm{~Hz}, 1 \mathrm{H}, 7-\mathrm{H}_{\mathrm{b}}\right), 2.56\left(\mathrm{~m}, 2 \mathrm{H}, 11-\mathrm{H}_{2}\right)$, 2.65 (ddd, $J=15.0,9.0,4.5 \mathrm{~Hz}, 1 \mathrm{H}, 8-\mathrm{H}_{\mathrm{a}}$ ), 2.68 (dd, $J=17.0,11.0 \mathrm{~Hz}, 1 \mathrm{H}, 4-\mathrm{H}_{\mathrm{a}}$ ), 2.85 (dd, $\left.J=17.0,3.0 \mathrm{~Hz}, 1 \mathrm{H}, 4-\mathrm{H}_{\mathrm{b}}\right), 2.89$ (ddd, $\left.J=15.0,8.0,4.5 \mathrm{~Hz}, 1 \mathrm{H}, 8-\mathrm{H}_{\mathrm{b}}\right), 4.43(\mathrm{~m}, 1 \mathrm{H}, 3-\mathrm{H})$, 4.81 (dd, $J=8.0,3.5 \mathrm{~Hz}, 1 \mathrm{H}, 6-\mathrm{H}), 5.06(\mathrm{q}, J=6.5 \mathrm{~Hz}, 1 \mathrm{H}, 1-\mathrm{H}), 6.86(\mathrm{~s}, 1 \mathrm{H}, 5-\mathrm{H})$.

${ }^{13} \mathrm{C}-\mathrm{NMR}\left(150.8 \mathrm{MHz}, \mathrm{CD}_{3} \mathrm{OD}\right): \delta=19.3$ (q, C-13), 32.5 (t, C-7), 35.4 (t, C-4), 35.8 (t, C-8), 42.9 (t, C-11), 65.4 (d, C-3), 68.1 (d, C-6), 69.3 (d, C-1), 114.2 (s, C-9a), 119.1 (d, C-5), 127.8 (s, C-10a), 144.1 (s, C-4a), 145.9 (s, C-5a), 159.7 (s, C-10), 176.0 (s, C-12), 206.1 (s, C-9). 
SEK 4b (47)

$\mathrm{C}_{16} \mathrm{H}_{14} \mathrm{O}_{7}(318.29)$

farbloser Feststoff

schwach UV-löschend (254 nm)<smiles>Cc1c[Z7](O)cc2c1C(=O)C[C@@](O)(Cc1cc(=O)cc(O)o1)O2</smiles>

Anfärbeverhalten: braun (Anis).

$\mathbf{R}_{\mathbf{f}}=0.12\left(\mathrm{KG}, \mathrm{CHCl}_{3} / \mathrm{MeOH}\right.$ 9:1).

ESI-MS: (pos. lonen) $\mathrm{m} / \mathrm{z}=659[2 \mathrm{M}+\mathrm{Na}]^{+}, 341[\mathrm{M}+\mathrm{Na}]^{+}$.

(neg. lonen) $\mathrm{m} / \mathrm{z}=635[2 \mathrm{M}-\mathrm{H}]^{-}, 317[\mathrm{M}-\mathrm{H}]^{-}$.

HR-ESI-MS: berechnet: $319.08123[\mathrm{M}+\mathrm{H}]^{+}, 341.06317[\mathrm{M}+\mathrm{Na}]^{+}$.

gefunden: $319.08140(\Delta=0.53 \mathrm{ppm}), 341.06329(\Delta=0.35 \mathrm{ppm})$.

${ }^{1} \mathrm{H}-\mathrm{NMR}\left(300 \mathrm{MHz}, \mathrm{DMSO}-\mathrm{d}_{6}\right): \delta=2.45\left(\mathrm{~s}, 3 \mathrm{H}, 5-\mathrm{CH}_{3}\right), 2.58\left(\mathrm{~d}, J=14.0 \mathrm{~Hz}, 1 \mathrm{H}, 3-\mathrm{H}_{\mathrm{a}}\right), 2.98$ (d, $J=14.0 \mathrm{~Hz}, 1 \mathrm{H}, 3-\mathrm{H}_{\mathrm{b}}$ ), 3.00 (d, J = $\left.10.0 \mathrm{~Hz}, 2 \mathrm{H}, 1^{\prime}-\mathrm{H}_{2}\right), 5.25$ (d, J=3.0 Hz, 1H, 5'-H), $6.05\left(\mathrm{~d}, J=3.0 \mathrm{~Hz}, 1 \mathrm{H}, 3^{\prime}-\mathrm{H}\right), 6.18(\mathrm{~d}, J=2.5 \mathrm{~Hz}, 1 \mathrm{H}, 8-\mathrm{H}), 6.30(\mathrm{~d}, J=2.5 \mathrm{~Hz}, 1 \mathrm{H}, 6-\mathrm{H})$.

${ }^{13}$ C-NMR (75.5 MHz, DMSO-d $\left.\mathrm{d}_{6}\right): \delta=22.4$ (q, 5-CH $), 44.1$ (t, C-1'), 47.5 (t, C-3), 88.9 (d, C5’), 100.1 (s, C-2), 101.6 (d, C-8), 103.5 (d, C-3'), 111.9 (s, C-4a), 112.7 (d, C-6), 142.4 (s, C5), 160.4 (s, C-2'), 160.9 (s, C-8a), 162.7 (s, C-7), 163.9 (s, C-6'), 170.6 (s, C-4'), 190.2 (s, C-4).

\section{AnhydroSEK4b (48)}

$\mathrm{C}_{16} \mathrm{H}_{12} \mathrm{O}_{6}(300.27)$

farbloser Feststoff

schwach UV-löschend (254 nm)<smiles>Cc1cc(O)cc2oc(Cc3cc(=O)cc(O)o3)cc(=O)c12</smiles>

Anfärbeverhalten: braun (Anis).

$\mathbf{R}_{\mathbf{f}}=0.10\left(\mathrm{KG}, \mathrm{CHCl}_{3} / \mathrm{MeOH}\right.$ 9:1).

ESI-MS: (pos. lonen) $\mathrm{m} / \mathrm{z}=623[2 \mathrm{M}+\mathrm{Na}]^{+}, 323[\mathrm{M}+\mathrm{Na}]^{+}$.

(neg. lonen) $\mathrm{m} / \mathrm{z}=599[2 \mathrm{M}-\mathrm{H}]^{-}, 299[\mathrm{M}-\mathrm{H}]^{-}$.

HR-ESI-MS: berechnet: $301.07066[\mathrm{M}+\mathrm{H}]^{+}, 323.05261[\mathrm{M}+\mathrm{Na}]^{+}$.

gefunden: $301.07083(\Delta=0.56 \mathrm{ppm}), 323.05288(\Delta=0.84 \mathrm{ppm})$. 
${ }^{1} \mathrm{H}-\mathrm{NMR}\left(300 \mathrm{MHz}\right.$, DMSO-d $\left.\mathrm{d}_{6}\right): \delta=2.56\left(\mathrm{~s}, 3 \mathrm{H}, 5-\mathrm{CH}_{3}\right), 3.87\left(\mathrm{~s}, 2 \mathrm{H}, 1{ }^{\prime}-\mathrm{H}_{2}\right), 5.28(\mathrm{~d}$, $\left.J=2.0 \mathrm{~Hz}, 1 \mathrm{H}, 5^{\prime}-\mathrm{H}\right), 6.09(\mathrm{~s}, 1 \mathrm{H}, 3-\mathrm{H}), 6.16\left(\mathrm{~d}, J=2.0 \mathrm{~Hz}, 1 \mathrm{H}, 3^{\prime}-\mathrm{H}\right), 6.60(\mathrm{~d}, J=2.5 \mathrm{~Hz}, 1 \mathrm{H}$, 8-H), $6.64(\mathrm{~d}, \mathrm{~J}=2.5 \mathrm{~Hz}, 1 \mathrm{H}, 6-\mathrm{H})$.

${ }^{13}$ C-NMR (75.5 MHz, DMSO-d $\mathrm{d}_{6}$ ): $\delta=22.3$ (q, 5- $\mathrm{CH}_{3}$ ), 37.0 (t, C-1'), 89.1 (d, C-5'), 100.5 (d, C-8), 102.0 (d, C-3'), 112.1 (d, C-3), 114.3 (s, C-4a), 116.8 (d, C-6), 141.7 (s, C-5), 159.1 (s, C-7), 160.0 (s, C-2'), 160.9 (s, C-2), 161.2 (s, C-8a), 163.4 (s, C-6'), 170.3 (s, C-4'), 178.0 (s, C-4).

\section{Germicidin A (49)}

$\mathrm{C}_{11} \mathrm{H}_{16} \mathrm{O}_{3}(196.25)$

farbloses Öl.

schwach UV-löschend (254 nm)

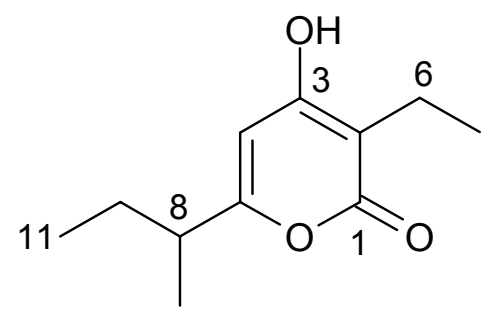

Anfärbeverhalten: braun (Anis).

49

$\mathbf{R}_{\mathbf{f}}=0.85\left(\mathrm{KG}, \mathrm{CHCl}_{3} / \mathrm{MeOH} 9: 1\right)$.

ESI-MS: (pos. lonen) $\mathrm{m} / \mathrm{z}=415[2 \mathrm{M}+\mathrm{Na}]^{+}, 219[\mathrm{M}+\mathrm{Na}]^{+}, 197[\mathrm{M}+\mathrm{H}]^{+}$.

(neg. lonen) $\mathrm{m} / \mathrm{z}=391[2 \mathrm{M}-\mathrm{H}]^{-}, 195[\mathrm{M}-\mathrm{H}]^{-}$.

HR-ESI-MS: berechnet: 197.11722 $[\mathrm{M}+\mathrm{H}]^{+}$.

gefunden: $197.11722(\Delta<0.01 \mathrm{ppm})$.

UV $\quad(\mathrm{MeOH}): \quad \lambda_{\max }(\lg \varepsilon)=290(3.50) \mathrm{nm}$

$[\alpha]_{\mathrm{D}}^{20}=+13^{\circ}(\mathrm{c}=0.1, \mathrm{MeOH})$.

${ }^{1} \mathrm{H}-\mathrm{NMR}\left(600 \mathrm{MHz}, \mathrm{CD}_{3} \mathrm{OD}\right): \delta=0.89(\mathrm{dd}, J=7.5,7.5 \mathrm{~Hz}, 3 \mathrm{H}, 11-\mathrm{H}), 1.02(\mathrm{t}, J=7.5 \mathrm{~Hz}, 3 \mathrm{H}$, $7-\mathrm{H}), 1.19(\mathrm{~d}, J=7.0 \mathrm{~Hz}, 3 \mathrm{H}, 9-\mathrm{H}), 1.54\left(\mathrm{~m}, 1 \mathrm{H}, 10-\mathrm{H}_{\mathrm{a}}\right), 1.67\left(\mathrm{~m}, 1 \mathrm{H}, 10-\mathrm{H}_{\mathrm{b}}\right), 2.38$ (q, $J=7.5 \mathrm{~Hz}, 2 \mathrm{H}, 6-\mathrm{H}), 2.45$ (tq, $J=7.0,7.0 \mathrm{~Hz}, 1 \mathrm{H}, 8-\mathrm{H}), 5.95(\mathrm{~s}, 4-\mathrm{H})$.

${ }^{13} \mathrm{C}-\mathrm{NMR}\left(150.8 \mathrm{MHz}, \mathrm{CD}_{3} \mathrm{OD}\right): \delta=11.9$ (q, C-11), 12.9 (q, C-7), 17.3 (t, C-6), 18.3 (q, C-9), 28.5 (t, C-10), 40.9 (d, C-8), 101.3 (d, C-4), 104.9 (s, C-2), 168.1 (s, C-3), 169.0 (s, C-5), 169.3 (s, C-1). 
Germicidin B (50)

$\mathrm{C}_{10} \mathrm{H}_{14} \mathrm{O}_{3}(182.22)$

farbloses Öl.

schwach UV-löschend (254 nm)<smiles>CCc1c(O)cc(C(C)C)oc1=O</smiles>

Anfärbeverhalten: braun (Anis).

50

$\mathbf{R}_{\mathbf{f}}=0.80\left(\mathrm{KG}, \mathrm{CHCl}_{3} / \mathrm{MeOH}\right.$ 9:1).

ESI-MS: (pos. lonen) $\mathrm{m} / \mathrm{z}=387[2 \mathrm{M}+\mathrm{Na}]^{+}, 205[\mathrm{M}+\mathrm{Na}]^{+}$. (neg. lonen) $\mathrm{m} / \mathrm{z}=195[\mathrm{M}-\mathrm{H}]^{-}$.

HR-ESI-MS: berechnet: $183.10157[\mathrm{M}+\mathrm{H}]^{+}$.

gefunden: $183.10159(\Delta=0.11 \mathrm{ppm})$.

UV $\quad(\mathrm{MeOH}): \quad \lambda_{\max }(\lg \varepsilon)=292(3.48) \mathrm{nm}$

${ }^{1} \mathrm{H}-\mathrm{NMR}\left(600 \mathrm{MHz}, \mathrm{CD}_{3} \mathrm{OD}\right): \delta=, 1.02\left(\mathrm{t}, J=7.5,7.5 \mathrm{~Hz}, 3 \mathrm{H}, 7-\mathrm{H}_{3}\right), 1.21(\mathrm{~d}, J=7.0 \mathrm{~Hz}, 6 \mathrm{H}$, 9,10- $\mathrm{H}_{3}$ ), 2.38 (q, $J=7.5 \mathrm{~Hz}, 2 \mathrm{H}, 6-\mathrm{H}$ ), 2.70 (dsept., $J=7.0,0.5 \mathrm{~Hz}, 1 \mathrm{H}, 8-\mathrm{H}$ ), 5.95 (d, $J=0.5 \mathrm{~Hz}, 1 \mathrm{H}, 4-\mathrm{H})$.

${ }^{13} \mathrm{C}-N M R\left(150.8 \mathrm{MHz}, \mathrm{CD}_{3} \mathrm{OD}\right): \delta=12.9$ (q, C-7), 17.3 (t, C-6), 20.4 (q, C-9,10), 33.6 (d, C8), 99.7 (d, C-4), 105.0 (s, C-2), 168.9 (s, C-3), 169.1 (s, C-5), 169.4 (s, C-1).

\section{Ferulasäure (51)}

$\mathrm{C}_{10} \mathrm{H}_{10} \mathrm{O}_{4}(194.19)$

farbloser Feststoff

schwach UV-löschend (254 nm)<smiles>COc1cc(C=CC(=O)O)ccc1O</smiles>

Anfärbeverhalten: braun (Anis).

51

$\mathbf{R}_{\mathbf{f}}=0.04\left(\mathrm{KG}, \mathrm{CHCl}_{3} / \mathrm{MeOH}\right.$ 9:1).

El-MS: $\mathrm{m} / \mathrm{z}(\%)=194(100)[\mathrm{M}], 179(16)\left[\mathrm{M}-\mathrm{CH}_{3}\right], 133(18)$.

HR-EI-MS: berechnet: 194.05791.

gefunden: 194.05840 .

${ }^{1} \mathrm{H}-\mathrm{NMR}\left(300 \mathrm{MHz}, \mathrm{CD}_{3} \mathrm{OD}\right): \delta=3.88\left(\mathrm{q}, 3 \mathrm{H},-\mathrm{OCH}_{3}\right), 6.30(\mathrm{~d}, J=16.0 \mathrm{~Hz}, 1 \mathrm{H}, 8-\mathrm{H}), 6.80(\mathrm{~d}$, $J=8.5 \mathrm{~Hz}, 1 \mathrm{H}, 5-\mathrm{H}), 7.05(\mathrm{dd}, J=8.5,2.0 \mathrm{~Hz}, 1 \mathrm{H}, 6-\mathrm{H}), 7.18(\mathrm{~d}, J=2.0 \mathrm{~Hz}, 1 \mathrm{H}, 2-\mathrm{H}), 7.58$ (d, $J=16.0 \mathrm{~Hz}, 1 \mathrm{H}, 7-\mathrm{H})$. 
${ }^{13}$ C-NMR (75.5 MHz, CD $\left.{ }_{3} \mathrm{OD}\right): \delta=56.4$ (q, $-\mathrm{OCH}_{3}$ ), 111.6 (d, C-2), 116.2 (d, C-8), 116.4 (d, C-5), 123.9 (d, C-6), 127.8 (s, C-1), 146.7 (d, C-7), 149.3 (s, C-3), 150.4 (s, C-4), 171.2 (s, C9).

\subsection{Charakterisierung der Metaboliten aus Streptomyces sp. Stamm} Tü 2561

\section{Substanz 2561-1 (56)}

$\mathrm{C}_{73} \mathrm{H}_{86} \mathrm{O}_{14}(1186.59)$

farbloser Feststoff

schwach UV-löschend (254 nm)

Anfärbeverhalten: braun (Anis).

$\mathbf{R}_{\mathbf{f}}=0.48\left(\mathrm{KG}, \mathrm{CHCl}_{3} / \mathrm{MeOH}\right.$ 9:1).

ESI-MS: $\quad$ (pos. Ionen) $\mathrm{m} / \mathrm{z}=617[\mathrm{M}+2 \mathrm{Na}]^{2+}, 1209[\mathrm{M}+\mathrm{Naa}]^{+}$. (neg. lonen) $\mathrm{m} / \mathrm{z}=1186[\mathrm{M}-\mathrm{H}]^{-}$.

HR-ESI-MS: berechnet: $1209.59098[\mathrm{M}+\mathrm{Na}]^{+}$. gefunden: $1209.59106(\Delta<0.06 \mathrm{ppm})$.

IR $(\mathrm{KBr}): \widetilde{\mathrm{v}}=3431(\mathrm{br}), 2970,2931,1720,1624,1543,1457,1421,1377,1345,1312$, 1250, 1123, 1096, 1058, 1013, 946, $866 \mathrm{~cm}^{-1}$.

Eine Partialstruktur der Substanz ist auf S. 86 zu finden.

${ }^{1} \mathrm{H}-\mathrm{NMR}\left(600 \mathrm{MHz}, \mathrm{CDCl}_{3}\right.$ ): s. Tab. 10 und 12, S. 87.

${ }^{13} \mathrm{C}-\mathrm{NMR}\left(150.8 \mathrm{MHz}, \mathrm{CDCl}_{3}\right)$ : s. Tab. 10 und 11, S. 87. 


\section{Untersuchungen an Streptomyces sp. S 1495}

Für die Biosyntheseuntersuchungen wurde aufgrund besserer Ausbeuten (bis 20 mg 15) der Borrelidin-Produzent Streptomyces sp. S 1495 verwendet.

\subsection{Fermentationskurve}

Der Stamm wurde wie Actinomyces sp. M4-1 unter Standardbedingungen (s. Kap. B.3.1.4) für 96 h kultiviert und aufgearbeitet. Alle 12 h wurden zwei Kolben (200 mL) entnommen, die Extrakte in $2 \mathrm{~mL}$ Methanol gelöst und an der analytischen HPLC (Säule A, Programm 1, Detektion bei $280 \mathrm{~nm}$ ) untersucht.

\subsection{Biosynthese}

Die Kultivierung erfolgte wie unter Kap. B.3.1.4 angegeben im 1 L-Maßstab, die isotopenmarkierten Verbindungen wurden in $30 \mathrm{~mL}$ sterilem Wasser gelöst und zur 36., 42. und 48. Stunde zu den Kulturen gegeben. Die Kultivierung wurde nach der 60. Stunde abgebrochen, die Aufarbeitung erfolgte gemäß 4.1. Der Kulturfiltratextrakt wurde an Kieselgel $\left(\mathrm{CH}_{2} \mathrm{Cl}_{2} / \mathrm{MeOH}\right.$ 9:1, $\left.120 \times 45 \mathrm{~mm}\right)$ und der präparativen HPLC (Säule $\mathrm{G}, 55 \%$ Acetonitril in $\mathrm{H}_{2} \mathrm{O}$ ) chromatographiert, die Ausbeuten sind in Tab. 23 wiedergegeben. Die Anreicherungen und Kopplungskonstanten von markiertem 15 aus den Fütterungsexperimenten sind in Tab. 24 (S. 154) zu finden.

\begin{tabular}{lccc}
\hline Markierte Substanz & \multicolumn{2}{c}{ Gefütterte Menge } & Ausbeute \\
& {$[\mathrm{mmol}]$} & {$[\mathrm{mg}]$} & {$[\mathrm{mg}]$} \\
\hline $\mathrm{Na}-\left[1-{ }^{13} \mathrm{C}\right]$ Acetat & 12.0 & 1000 & 1.3 \\
$\mathrm{Na}-\left[2-{ }^{13} \mathrm{C}\right]$ Acetat & 12.0 & 1000 & 14.2 \\
$\mathrm{Na}-\left[1,2-{ }^{13} \mathrm{C}_{2}\right]$ Acetat & 12.0 & 1000 & 15.2 \\
$\mathrm{Na}-\left[2-\mathrm{d}_{3}\right]$ Acetat & 12.0 & 1000 & 20.7 \\
$\mathrm{Na}-\left[1-{ }^{13} \mathrm{C}\right]$ Propionat & 5.0 & 385 & 6.6 \\
{$\left[\mathrm{U}-{ }^{13} \mathrm{C}_{3}\right] \mathrm{Glycerin}$} & 5.0 & 575 & 12.4 \\
{$\left[1-{ }^{13} \mathrm{C}\right] \mathrm{Ty}$ rosin } & 2.8 & 500 & 0.7 \\
{$\left[2,3,5,6-\mathrm{d}_{4}\right]$ Tyrosin } & 2.8 & 500 & 13.3 \\
\hline
\end{tabular}

Tab. 23: Gefütterte isotopenmarkierte Vorläufer und Ausbeuten an Borrelidin (15). 


\begin{tabular}{|c|c|c|c|c|c|c|}
\hline & $\delta[p p m]$ & $1^{\text {a) }}$ & $I^{\text {b) }}$ & $\mathrm{III}^{\mathrm{c})}$ & IV & V \\
\hline C-1 & 173.2 & 2.39 & -0.07 & 0.18 & 58.2 & 58.3 \\
\hline C-2 & 37.9 & 0.15 & -0.40 & 0.51 & 58.2 & 58.3 \\
\hline C-3 & 72.9 & 0.50 & 9.45 & 0.20 & & \\
\hline C-4 & 37.0 & 0.01 & -0.24 & 0.17 & & \\
\hline C-5 & 44.6 & 0.53 & 11.10 & 0.21 & & \\
\hline C-6 & 28.5 & -0.03 & -0.31 & 0.26 & & \\
\hline C-7 & 49.4 & 0.56 & 10.11 & 0.00 & & \\
\hline C-8 & 27.6 & 0.02 & -0.21 & 0.18 & & \\
\hline C-9 & 39.1 & 0.53 & 9.30 & 0.23 & & \\
\hline C-10 & 36.0 & -0.08 & -0.20 & 0.06 & & \\
\hline C-11 & 73.1 & 0.40 & 13.19 & -0.06 & & \\
\hline C-12 & 119.9 & 0.08 & -0.06 & 0.06 & & \\
\hline C-13 & 145.5 & 2.39 & 0.17 & -0.06 & 55.5 & 55.9 \\
\hline C-14 & 129.0 & 0.04 & 0.13 & -0.05 & 56.0 & 55.9 \\
\hline C-15 & 140.2 & 2.31 & 0.19 & 0.05 & 43.8 & 43.5 \\
\hline C-16 & 36.7 & -0.01 & 0.08 & 0.05 & 43.2 & 43.5 \\
\hline C-17 & 77.4 & 0.17 & 0.56 & 0.08 & 40.5 & 40.8 \\
\hline $12-\mathrm{CN}$ & 117.4 & 0.02 & -0.05 & 0.10 & & \\
\hline $4-\mathrm{CH}_{3}$ & 19.1 & 0.06 & 0.05 & -0.10 & & \\
\hline $6-\mathrm{CH}_{3}$ & 20.9 & -0.02 & 0.06 & -0.06 & & \\
\hline $8-\mathrm{CH}_{3}$ & 18.7 & 0.02 & -0.08 & 0.17 & & \\
\hline $10-\mathrm{CH}_{3}$ & 15.4 & -0.07 & 0.04 & -0.03 & & \\
\hline C-1' & 50.3 & 0.59 & 0.16 & 0.47 & $57.1^{*}$ & 57.3 \\
\hline C-2' & 47.5 & 0.13 & 0.21 & 0.11 & 40.5 & 40.8 \\
\hline C-3' & 30.5 & 1.22 & -0.03 & 0.08 & 32.6 & 32.6 \\
\hline C-4' & 26.3 & 0.03 & 0.10 & 0.11 & 32.6 & $32.0 / 32.6$ \\
\hline C-5' & 32.5 & 1.09 & 0.13 & 0.07 & 32.3 & 32.0 \\
\hline 1'-COOH & 180.7 & 2.13 & 1.49 & 0.90 & $57.1^{*}$ & 57.3 \\
\hline
\end{tabular}

Tab. 24: ${ }^{13} \mathrm{C}$-Anreicherungen in Borrelidin (15) nach Fütterungsexperimenten: I) $\left[1-{ }^{13} \mathrm{C}\right]$ Acetat, II) $\left[1-{ }^{13} \mathrm{C}\right]$ Propionat, III) $\left[1-{ }^{13} \mathrm{C}\right]$ Tyrosin (Normierung auf den Mittelwert von 9-, 11-, 13- und $\left.15-\mathrm{CH}_{3} ; \mathrm{IV}\right)\left[1,2-{ }^{13} \mathrm{C}_{2}\right]$ Acetat, V) $\left[\mathrm{U}-{ }^{13} \mathrm{C}_{3}\right]$ Glycerin $\left({ }^{1} J_{\mathrm{C}-\mathrm{C}} /[\mathrm{Hz}]\right)$. 


\subsection{Vorläufer-dirigierte Biosynthese}

Die Kultivierung erfolgte wie unter Kap. B.3.1.4 angegeben in 2 × $100 \mathrm{~mL}$ Maßstab je Ansatz. Die potentiellen Vorläufer (für eine Auflistung s. Tab. 15, S. 102) wurden in $6 \mathrm{~mL}$ sterilem Wasser/1 M NaOH 1:1 gelöst und zur 36., 42. und 48. Stunde zu den Kulturen gegeben, so dass eine $2 \mathrm{mM}$ Endkonzentration erreicht wurde. Die Kultivierung wurde nach der 60. Stunde abgebrochen. Die Kulturbrühen wurden lyophilisiert und mit $20 \mathrm{~mL}$ Methanol extrahiert. Die Abtrennung der festen Bestandteile erfolgte durch Filtration im Vakuum. Die organische Phase wurde bis zur Trockne eingeengt und für die Untersuchung an der HPLCMS (Säule A, Programm 1) in $2 \mathrm{~mL}$ Methanol gelöst. 


\section{LITERATURVERZEICHNIS}

1 M.L. Cohen, Nature 2000, 406, 762-767.

2 National Center for Health Statistics, Health, United States 1999, US Govt. Printing Office, Washington DC, 1999.

3 A. Fleming, Brit. J. Pat. 1929, 10, 226.

4 D.J. Newman, G.M. Cragg, K.M. Snader, Nat. Prod. Rep. 2000, 17, 215-234.

5 H. Umezawa, I.R. Hooper, Aminoglycoside Antibiotics, Springer Verlag, New York, Heidelberg, Berlin, Tokyo, 1982.

6 W. Schönfeldt, H.A. Kirst, Macrolide Antibiotics, Birkhäuser Verlag, Basel, Boston, Berlin, 2002.

7 J.J. Hlava, J.H. Boothe, The Tetracyclines, Springer Verlag, New York, Heidelberg, Berlin, Tokyo, 1985.

8 G.L. Armstrong, L.A. Conn, Y. Pinner, J. Am. Med. Assoc. 1999, 281, 61-66.

9 a) G.G.F. Newton, E.P. Abraham, Nature 1955, 175, 548; b) G.G.F. Newton, E.P. Abraham, Biochem. J. 1956, 62, 651.

10 J.R. Knowles, Acc. Chem. Res. 1985, 18, 97-105.

11 a) M.D. Song, M. Wachi, M. Doi, F. Ishino, M. Matsuhashi, FEBS Lett. 1987, 221, 167; b) B.G. Spratt, Science 1994, 264, 388-393.

G.M. Sheldrick, P.G. Jones, O. Kennard, D.H. Williams, G.A. Smith, Nature 1978, 271, 223-225.

C.T. Walsh, Nature 2000, 406, 775-781.

T.D.H. Bugg, Biochemistry 1991, 30, 10408-10415.

J. Riedlinger, A. Reicke, H. Zähner, B. Krismer, A.T. Bull, L.A. Maldonado, A.C. Ward, M. Goodfellow, B. Bister, D. Bischoff, R.D. Süssmuth, H.-P. Fiedler, J. Antibiot. 2004, 57, 271-279.

B. Bister, D. Bischoff, M. Ströbele, J. Riedlinger, A. Reicke, F. Wolter, A.T. Bull, H. Zähner, H.-P. Fiedler, R.D. Süssmuth, Angew. Chem. 2004, 116, 2628-2630; Angew. Chem. Int. Ed. 2004, 43, 2574-2576.

a) K.C. Nicolaou, S.T. Harrison, Angew. Chem. Int. Ed. 2006, 45, 3256-3260; b) B.B. Snider, Y. Zou, ChemInform 2006, 37, 10; c) Jean-Philippe Rath, Stephan Kinast, Martin E. Maier, ChemInform 2005, 36, 47; d) C.W. Zapf, B.A.. Harrison, C. Drahl, E.J. Sorensen, Angew. Chem. 2005, 117, 6691-6695; Angew. Chem. Int. Ed. 2005, 44, 6533-6537. 
a) J.S. Blanchard, Nature Med. 2005, 11, 1045-1046; b) H. Brötz-Oesterhelt, D. Beyer, H.-P. Kroll, R. Endermann, C. Ladel, W. Schroeder, B. Hinzen, S. Raddatz, H. Paulsen, K. Henninger, J.E. Bandow, H.-G. Sahl, H. Labischinski, Nature Med. 2005, 11, 1082-1087.

M.D. Lee, T.M. Dunne, C.C. Chang, G.O. Morton, D.B. Borders, J. Am. Chem. Soc. 1987, 109, 3464-3466.

J.S. Thorson, E.L. Sievers, J. Ahlert, E. Shepard, R.E. Whitwam, K.C. Onwueme, M. Ruppen, Curr. Pharm. Des. 2000, 6, 1841-1879.

F. Giles, E. Estey, S. O'Brien, Cancer 2003, 98, 2095-2104.

M.S. Butler, Nat. Prod. Rep. 2005, 22, 162-195.

M. Kamsteeg, T. Rutherford, E. Sapi, B. Hanczaruk, S. Shahabi,M. Flick, D. Brown, G. Mor, Oncogene 2003, 22, 2611-2620.

National Center for Biotechnology Information (www.ncbi.nlm.nih.gov), TaxBrowser, Stand: Mai 2006.

R. Daniel, Nature Rev. Microbiol. 2005, 3, 470-478.

S.D. Bentley, K.F. Chater, A.-M. Cerdeño-Tárraga, G.L. Challis, N.R. Thomson, K.D. James, D.E. Harris, M.A. Quail, H. Kieser, D. Harper, A. Bateman, S. Brown, G. Chandra, C.W. Chen, M. Collins, A. Cronin, A. Fraser, A. Goble, J. Hidalgo, T. Hornsby, S. Howarth, C.-H. Huang, T. Kieser, L. Larke, L. Murphy, K. Oliver, S. O'Neil, E. Rabbinowitsch, M.-A. Rajandream, K. Rutherford, S. Rutter, K. Seeger, D. Saunders, S. Sharp, R. Squares, S. Squares, K. Taylor, T. Warren, A. Wietzorrek, J. Woodward, B. G. Barrell, J. Parkhill, D.A. Hopwood, Nature 2002, 417, 141-147. G.L. Challis, Nature Chem. Biol. 2005, 1, 265-268.

M. Schlitzer, Anti-Malaria Wirkstoffe - Status und Perspektiven, 18. Irseer Naturstofftage der DECHEMA e.V., 2006.

G.L. Challis, D.A. Hopwood, Proc. Natl. Acad. Sci. USA 2003, 100, 14555-14561.

J. Piel, Universität Bonn, persönliche Mitteilung.

H.B. Bode, R. Müller, Angew. Chem. Int. Ed. 2005, 44, 6828-6846.

H.B. Bode, B. Bethe, R. Höfs, A. Zeeck, ChemBioChem 2002, 3, 619.

E. Guenzi, G. Galli, I. Grgurina, D.C. Gross, G. Grandi, J. Biol. Chem. 1998, 273, 32857-32863.

a) B.O. Bachmann, Nature Chem. Biol. 2005, 1, 244-245; b) S. Lautru, R.J. Deeth, L.M. Bailey,

R.W. Snow, C.A. Guerra, A.M. Noor, H.Y. Myint, S.I. Hay, Nature 2005, 434, 214-217.

R. Pink, A. Hudson, M.-A. Mouriès, M. Bendig, Nature Rev. Drug Discov. 2005, 4, 727-740.

K. Ströch, Dissertation, Universität Göttingen, 2003.

J. Wiesner, R. Ortmann, H. Jomaa, M. Schlitzer, Angew. Chem. 2003, 115, 5432-5451.

D.L. Klayman, Science 1985, 228, 1049-1055.

J.L. Vennerstrom, S. Arbe-Barnes, R. Brun, S.A. Charman, F.C.K. Chiu, J. Chollet, Y. Dong, A. Dorn, D. Hunziker, H. Matile, K. Mclntosh, M. Padmanilayam, J.S. Tomas, C. Scheurer, B. Scorneaux, Y. Tang, H. Urwyler, S. Wittlin, W.N. Charman, Nature 2004, 430, 900-904.

K. Shiomi, S. Omura, Proc. Jpn. Acad., Ser. B 2004, 80, 245-258.

H.M. Staines, T. Powell, S.L.Y. Thomas, J.C. Ellory, Int. J. Parasitol. 2004, 34, 665-673. 
C. Gumila, M.-L. Ancelin, G. Jeminet, A.-M. Delort, G. Miquel, H.J. Vial, Antimicrob. Agents Chemother. 1996, 40, 602-608.

C. Gumila, M.-L. Ancelin, A.-M. Delort, G. Jeminet, H.J. Vial, Antimicrob. Agents Chemother. 1997, 41, 523-529.

C. Nilanonta, M. Isaka, R. Chanphen, N. Thong-orn, M. Tanticharoen, Y. Thebtaranonth, Tetrahedron 2003, 59, 1015-1020.

K. Otoguro, H. Ui, A. Ishiyama, N. Arai, M. Kobayashi, Y. Takahashi, R. Masuma, K. Shiomi, H. Yamada, S. Omura, J. Antibiot. 2003, 56, 322-324. R.G. Ridley, Nature 2002, 415, 686-693.

a) I. Paterson, E.A. Anderson, Science 2005, 310, 451-453; b) J.J. Kohler, Nature Chem. Biol. 2006, 2, 288-292.

C. Olano, B. Wilkinson, C. Sánchez, S.J. Moss, R. Sheridan, V. Math, A.J. Weston, A.F. Braña, C.J. Martin, M. Oliynyk, C. Méndez, P.F. Leadley, J.A. Salas, Chem. Biol. 2004, 11, 87-97.

N. Andres, H. Wolf, H. Zähner, E. Rössner, A. Zeeck, W.A. König, V. Sinnwell, Helv. Chim. Acta 1989, 72, 426-437.

N. Andres, Dissertation, Universität Tübingen 1989.

S. Omura, H. Mamada, N.-J. Wang, N. Imamura, R. Oiwa, Y. Iwai, N. Muto, J. Antibiot. 1984, 37, 700-705.

E. Rössner, A. Zeeck, W.A. König, Angew. Chem. 1990, 102, 84-85; E. Rössner, A. Zeeck, W.A. König, Angew. Chem. Int. Ed. 1990, 29, 64-65.

P. Henne, Dissertation, Universität Göttingen 1994.

M. Ritzau, Dissertation, Universität Göttingen 1992.

A. Zeeck, E. Rössner, M. Ritzau, P. Henne, DECHEMA Monogr. 1993, 129, 63-72.

P. Alvermann, Dissertation, Universität Göttingen 2001.

B.D. Zlatopolskiy, Dissertation, Universität Göttingen 2003.

B.D. Zlatopolskiy, K. Loscha, P. Alvermann, S.I. Kozhushkov, S.V. Nikolaev, A. Zeeck, A. de Meijere, Chem. Eur. J. 2004, 10, 4708-4717.

B.D. Zlatopolskiy, A. de Meijere, Chem. Eur. J. 2004, 10, 4718-4727.

B. Rauch, Dissertation, Universität Tübingen 1992.

B. Geers, Dissertation, Universität Göttingen 1998.

Y. Iwai, S. Omura, J. Antibiot. 1982, 35, 123-141.

H. Wolf, N. Andres, DECHEMA Monogr. 1993, 129, 53-62.

A. de Meijere, S.I. Kozhushkov, Georgia Augusta Wissenschaftsmagazin, Georg-August Universität Göttingen, 2005, 4, 106-111.

K.L. Rinehart, Pure. Appl. Chem. 1977, 49, 1361-1381.

W.T. Shier, K.L. Rinehart, D. Gottlieb, Proc. Natl. Acad. Soc. 1969, 63, 198-204.

S. Weist, C. Kittel, D. Bischoff, B. Bister, V. Pfeifer, G.J. Nicholson, W. Wohlleben, R.D. Süssmuth, J. Am. Chem. Soc. 2004, 126, 5942-5943. 
S. Weist, B. Bister, O. Puk, D. Bischoff, S. Pelzer, G.J. Nicholson, W. Wohlleben, G. Jung, R.D. Süssmuth, Angew. Chem. Int. Ed. 2002, 41, 3383-3385.

O. Puk, P. Huber, D. Bischoff, J. Recktenwald, G. Jung, R.D. Süssmuth, K.-H. van Pée, W. Wohlleben, S. Pelzer, Chem. Biol. 2002, 9, 2025-2035.

H.B. Bode, A. Zeeck, Phytochemistry 2000, 54, 597-601.

R. Thiericke, J. Rohr, Nat. Prod. Rep. 1993, 10, 265-289.

C. Nilanonta, M. Isaka, P. Kittakoop, S. Trakulnaleamsai, M. Tanticharoen, Y. Thebtaranonth, Tetrahedron 2002, 58, 3355-3360.

H.D. Mootz, D. Schwarzer, M.A. Marahiel, ChemBioChem 2002, 3, 490-504.

T. Stachelhaus, H.D. Mootz, M.A. Marahiel, Chem. Biol. 1999, 6, 493-505.

R. Traber, H. Hoffmann, H. Kobel, J. Antibiot. 1989, 41, 591-597.

R. Traber, Biotechnology of Antibiotica $2^{\text {nd }}$ ed., M. Dekker Inc., New York, Basel, Hongkong 1997.

C. Khosla, R.S. Gokhale, J.R. Jacobsen, D.E. Cane, Annu. Rev. Biochem. 1999, 68, 219.

B.D. Zlatopolskiy, M. Radzom, A. de Meijere, A. Zeeck, Eur. J. Org. Chem. 2006, 6, 1525-1534.

D.J. Aberhart, J.-A. Cotting, H.-J. Lin, Anal. Biochem. 1985, 151, 88-91.

K. Hoffmann, E. Schneider-Scherzer, H. Kleinkauf, R. Zocher, J. Biol. Chem. 1994, 269, 12710 12714.

M. Hesse, H. Meier, B. Zeeh, Spektroskopische Methoden in der organischen Chemie, 4. Auflage, Georg Thieme Verlag Stuttgart, New York 1991.

A.L.J. Beckwith, K.U. Ingold, in: Rearrangements in Ground and Excited States, vol. 1 (Ed. P. de Mayo), Academic Press, New York, 1980, 161-310.

J.C. Walton, in: Methods of Organic Chemistry (Houben-Weyl), vol. E17c, (Ed.: A. de Meijere) Thieme, Stuttgart 1997, 2438-2525.

D. Wendisch, in: Methoden der Organischen Chemie (Houben-Weyl), vol. 4/3 (Ed.: E. Müller), Thieme, Stuttgart, 1971, 399-405.

G. Boche, H.M. Walborsky, Cyclopropane-Derived Reactive Intermediates (Eds.: S. Patai, Z. Rappoport), Wiley, Chichester, 1990.

D.B. Stein, U. Linne, M.A. Marahiel, FEBS Journal 2005, 272, 4506-4520.

C.H. Hassal, K. Reyle, Biochem. J. 1955, 60, 334.

M.-t. Lai, L.-d. Liu, H.-w. Liu, J. Am. Chem. Soc. 1991, 113, 7388-7397.

M.-t. Lai, H.-w. Liu, J. Am. Chem. Soc. 1992, 114, 3160-3162.

A. Wenz, C. Thorpe, S. Ghisla, J. Biol. Chem. 1981, 256, 9809.

C. Thorpe, R.G. Matthews, C.H. Williams, Biochemistry 1979, 18, 331.

C.A. Bewley, J.D.Faulkner, J. Org. Chem. 1994, 59, 4849-4852.

S. Nakamura, J. Antibiot. 1965, 18, 47-65.

I. Uemura, H. Miyagawa, T. Uemo, Tetrahedron 2002, 58, 2351-2358.

R. Hatta, K. Ito, Y. Hosaki, T. Tanaka, A. Tanaka, M. Yamamoto, K. Akimitsu, T. Tsuge, Genetics 2002, 161, 59-70.

C.D. Murphy, J. Appl. Microbiol. 2003, 94, 539-548.

D. O'Hagan, D.B. Harper, J. Fluorine Chem. 1999, 100, 127-133. 

Deboy, A.S. Durkin, J.F. Kolonay, R. Madupu, S. Daugherty, L. Brinkac, M.J. Beanan, D.H. Haft, W.C. Nelson, T. Davidsen, N. Zafar, L. Zhou, J. Liu, Q. Yuan, H. Khouri, N. Fedorova, B. Tran, D. Russell, K. Berry, T. Utterback, S.E. Van Aken, T.V. Feldblyum, M. D'Ascenzo, W.-L. Deng, A.R. Ramos, J.R. Alfano, S. Cartinhour, A.K. Chatterjee, T.P. Delaney, S.G. Lazarowitz, G.B. Martin, D.J. Schneider, X. Tang, C.L. Bender, O. White, C.M. Fraser, A. Collmer, Proc. Natl. Acad. Sci. USA 2003, 100, 10181-10186.

R.J.M. Goss, H. Hong, Chem. Commun. 2005, 3983-3985.

F.H. Vaillancourt, E. Yeh, D.A. Vosburg, S.E. O'Connor, C.T. Walsh, Nature 2005, 436, $1191-$ 1194.

N.A. Schnarr, C. Khosla, Nature 2005, 436, 1094-1095.

R.J. Parry, M.-T. Lin, A.E. Walker, S. Mhaskar, J. Am. Chem. Soc. 1991, 113, 1849-1850.

R.J. Parry, M.-T. Lin, A.E. Walker, S. Mhaskar,R. Mafotti, Can. J. Chem. 1994, 72, 86-97.

C.R. Buell, V. Joardar, M. Lindeberg, J. Selengut, I.T. Paulsen, M.L. Gwinn, R.J. Dodson, R.T.

R. Couch, S.E. O'Connor, H. Seidle, C.T. Walsh, R.J. Parry, J. Bacteriol. 2004, 186, 35-42.

L.C. Blasiak, F.H. Vaillancourt, C.T. Walsh, C.L. Demain, Nature 2006, 440, 368-371.

S.D. Barton, K. Nakanishi, O. Meth-Cohn, Comprehensive Natural Products Chemistry, Vol. 1, Elsevier Verlag, Amsterdam, Lausanne, New York, Oxford, Shannon, Singapore, Tokyo 1999.

K. Zimmermann, Diplomarbeit 2004, MPI für Chemische Ökologie, Jena.

J. Piel, persönliche Mitteilung, 2005.

D.H. Ripins, D.A. Evans, Advanced Organic Chemistry, Hrsg.: J.Marsh, 3rd Ed., 1985.

U.M. Reinscheid, J. Farjon, M. Radzom, P. Haberz, A. Zeeck, M. Blackledge, C. Griesinger, ChemBioChem 2006, 7, 287-296.

P. Haberz, J. Farjon, C. Griesinger, Angew. Chem. 2005, 117, 431-433.

U.M. Reinscheid, B.D. Zlatopolskiy, C. Griesinger, A. Zeeck, A. de Meijere, Chem. Eur. J. 2005, 11, 2929-2945.

S. Lautru, R.J. Deeth, L.M. Bailey, G.L. Challis, Nat. Chem. Biol. 2005, 1, 265-269.

E.F. Paulus, M. Kurz, H. Matter, L. Vértesy, J. Am. Chem. Soc. 1998, 120, 8209-8221.

J. Hardy, D.J. Selkoe, Science 2002, 297, 353-356.

Y. Mekmouche, Y. Coppel, K. Hochgräfe, L. Guilloreau, C. Talmard, H. Mazarguil, P. Faller, ChemBioChem 2005, 6,1663-1671.

T. Baltz, D. Baltz, C. Giroud, J. Crockett, EMBO J. 1985, 4, 1273-1277.

B. Räz, M. Iten, Y. Grethen-Bühler, R. Kaminsky, R. Brun, ActaTrop. 1997, 68, 139-147.

S.M. Jones, J.E. Urch, M. Kaiser, R. Brun, J.L. Harwood, C. Berry, I.H. Gilbert, J. Med. Chem. 2005, 48, 5932-5941.

RÖMPP-Lexikon Naturstoffe, Hrsg.: W. Steglich, B. Fugmann, S. Lang-Fugmann, Thieme, Stuttgart, New York, 1997.

H.P. Fiedler, Nat. Prod. Lett. 1993, 2, 119-128.

H.Zähner, H. Drautz, W. Weber, in Bioactive Microbial Product-Search and Discovery, Hrsg.: J.D.

Bullock, L.J. Nisbet, D.J. Winstley, Academic Press, London, New York, 1982, 51-70. 
S. Grabley, R. Thiericke, A. Zeeck, in Drug Discovery from Nature, Hrsg.: S. Grabley, R. Thiericke, Springer-Verlag, Heidelberg, 1999, 124-148.

S. Breiding-Mack, A. Zeeck, J. Antibiot. 1987, 40, 953-960.

S. Umezawa, T. Tsuchiya, K.Tatsuna, Y. Horiychi, T. Usi, H. Umezawa, M. Hamada, A. Yagi, J. Antibiot.1970, 23, 20-27.

B.E. Leach, K.M. Calhoun, L.R. Johnson, C.M. Teeters, W.G. Jackson, J. Am. Chem. Soc. 1953, 75, 4011-4012.

140 L.H. Sternbach, S. Kaiser, M.W. Goldberg, J. Am. Chem. Soc. 1958, 80, 1639-1647.

a) E. Simonitsch, W. Eisenhut, O.A. Stamm, H. Schmid, Helv. Chim. Acta 1960, 43, 58-63. b) E. Simonitsch, W. Eisenhut, O.A. Stamm, H. Schmid, Helv. Chim. Acta 1964, 47, 1459-1475. c) W. Eisenhut, O.A. Stamm, H. Schmid, Helv. Chim. Acta 1964, 47, 1475-1484.

P. Canham, L.C. Vining, A. McInnes, W.J.A. Gavin, J.L.C. Wright, Can. J. Chem. 1977, 55, 2450 2457.

J.P. McGovren, G.L. Neil, S.L. Crampton, M.I. Robinson, J.D. Douros, Cancer Res. 1977, 37, 1666-1672.

J. Goto, Y. Matsuda, K. Asano, I. Kawamoto, T. Yasuzawa, K. Shirahata, H. Sano, H. Kase, Agric. Biol. Chem. 1987, 51, 3003-3009.

a) Y. Inuoye, K. Yamaguchi, Y. Take, S. Nakamura, J. Antibiot. 1989, 32, 1523; b) T. Akiyama, J. Ishida, S. Nakagawa, H. Ogawara, S. Watanabe, N. Itoh, M. Shibuya, Y. Fukami, J. Biol. Chem. 1987, 262, 5592.

a) H. Chimura, T. Sawa, Y. Kumada, H. Nagawa, M. Matsuzaki, T. Takita, M. Hamada, T. Takeuchi, H. Umezawa, J. Antibiot. 1975, 28, 619; b) K. Komiyama, S. Funayama, Y. Anraku, A. Mita, Y. Takahashi, S. Omura, J. Antibiot. 1989, 42, 1344.

Dictionary of Natural Products on CD-ROM, Version 13:2, Chapman \& Hall/ CRC, Boca Raton (FL), 2004.

a) M.S. Kuo, D.A. Yurek, D.A. Kloosterman, J. Antibiot. 1989, 42, 1006-1007. b) B.F. Anderson, A.J. Herlt, R.W. Rickards, G.B. Robertson, Austr. J. Chem. 1989, 42, 717-730. c) H. Maehr, R.H. Evans, J. Antibiot. 1987, 40, 1455-1456.

F. Petersen, H. Zähner, J.W. Metzger, S. Freund, R.-P. Hummel, J. Antibiot. 1993, 46, 11261138. 
M. Radzom, A. Zeeck, N. Antal, H.-P. Fiedler, J. Antibiot. 2006, 59, 315-317.

A. Zeeck, P. Christiansen, Liebigs Ann. Chem. 1969, 724, 172-182.

a) R. McDaniel, C.R. Hutchinson, C. Khosla, J. Am. Chem. Soc. 1995, 117, 6806-6811;

b) B. Shen, R.G. Summers, E. Wendt-Pienkowski, C.R. Hutchinson, J. Am. Chem. Soc. 1995, 117, 6811-6821.

C. Bisang, P.F. Long, J. Cortes, J. Westcott, J. Crosby, A.L. Matharu, R.J. Cox, T.J. Simpson, J. Staunton, P.F. Leadlay, Nature 1999, 401, 502.

W.L. Bao, E. Wendt-Pienkowski, C.R. Hutchinson, Biochemistry 1998, 87, 8132.

a) A.L. Matharu, R.J. Cox, J. Crosby, K.J. Byrom, T.J. Simpson, Chem. Biol. 1998, 5, 699; b) T.P. Nicholson, C. Winfield, J. Westcott, J. Crosby, T.J. Simpson, R.J. Cox, Chem. Comm. 2003, 686687.

T.S. Lee, C. Khosla, Y. Tang, J. Antibiot. 2005, 58, 663-666.

P.L. Bartel, C.B. Zhu, J.S. Lampel, D.C. Dosch, S.P. Conners, W.R. Strohl, J.M. Beale, H.G. Floss, J. Bacteriol. 1990, 172, 4816-4826.

T. Taguchi, K. Itou, Y. Ebizuka, F. Malpartida, D.A. Hopwood, C.M. Surti, K.I. Booker-Milburn, G.R. Stephenson, K. Ichinose, J. Antibiot. 2000, 53, 144-152.

T. Taguchi, Y. Ebizuka, D.A. Hopwood, K. Ichinose, Tetrahedron Lett. 2000, 5253-5256.

a) B. Shen, R. Hutchinson, Proc. Natl. Acad. Sci. USA 1996, 93, 6600-6604; b) P.J. Kramer, R.J.X. Zawada, R. McDaniel, C.R. Hutchinson, D.A. Hopwood, C. Khosla, J. Am. Chem. Soc. 1997, 119, 635-639.

H. Fu, S. Ebert-Khosla, D.A. Hopwood, C. Khosla, J. Am.Chem. Soc. 1994, 116, 4166-4170.

K.U. Bindseil, P. Hug, H.H. Peter, F. Petersen, B.E. Roggo, J. Antibiot. 1995, 48, 457-461.

Y. Hayakawa, K. Shin-Ya, K. Furihata, H. Seto, J. Antibiot. 1993, 46, 1563-1569.

J. Berger, L.M. Jampolsky, M.W. Goldberg, Arch. Biochem. 1949, 22, 476-478.

K. Anderton, R.W. Rickards, Nature 1965, 498, 269.

W. Keller-Schierlein, Helv. Chim. Acta. 1967, 50, 731-753.

F.F. Fleming, Nat. Prod. Rep. 1999, 16, 597-606.

S.K. Singh, S. Gurusiddaiah, J.W. Whalen, Antimicrob. Agents Chemother. 1985, 27, 239-245.

W. Paetz, G. Nass, Eur. J. Biochem. 1973, 35, 331-337.

M. Ibba, D. Soll, Annu. Rev. Biochem. 2000, 96, 617-650.

J.G. Hurdle, A.J. O'Neill, I. Chopra, Antimicrob. Agents Chemother. 2005, 49, 4821-4833.

E.B. Chain, G. Mellows, J. Chem. Soc. Perkins Trans. I 1977, 1, 294-309.

R. Sutherland, R.J. Boon, K.E. Griffin, P.J. Masters, B. Slocombe, A.R. White, Antimicrob. Agents Chemother. 1985, 27, 495-498.

S. Fujimura, A. Watanabe, Chemotherapy 2003, 49, 36-38.

T. Wakabayashi, R. Kageyama, N. Naruse, N. Tsukahara, Y. Funahashi, K. Kitoh, Y. Watanabe, J. Antibiot. 1997, 50, 671-676.

A. Matter, Drug Discov. Today 2001, 6, 1055-1024.

T. Kawamura, D. Liu, M.J. Towle, R. Kageyama, N. Tsukahara, T. Wakabayashi, B.A. Littlefield, J. Antibiot. 2003, 56, 709-715. 
a) E. Tsuchiya, M. Yukawa, T. Miyakawa, K.I. Kimura, H. Takahashi, J. Antibiot. 2001, 54, 84-90.

b) M. Lumb, P.E. Macey, J. Spyvee, J.M. Whitmarsh, R.D. Wright, Nature 1965, 206, 263-265; L. Dickinson, A.J. Griffiths, C.G. Mason, R.F.N. Mills, Nature 1965, 206, 265-267. c) K. Otoguro, H. Ui, A. Ishiyama, M. Kobayashi, H. Togashi, Y. Takahashi, R. Masuma, H.Tanaka, H. Tomoda, H. Yamada, S. Omura, J. Antibiot. 2003, 56, 727-729.

C. Olano, B. Wilkinson, S.J. Moss, A.F. Braña, C. Méndez, P.F. Leadley, J.A. Salas, Chem. Commun. 2003, 2780-2782.

C. Olano, B. Wilkinson, C. Sánchez, S.J. Moss, R. Sheridan, V. Math, A.J. Weston, A.F. Braña, C.J. Martin, M. Oliynyk, C. Méndez, P.F. Leadley, J.A. Salas, Chem. Biol. 2004, 11, 87-97.

S. Mochizuki, K. Hiratsu, M. Suwa, T. Ishii, F. Sugino, K. Yamada, H. Kinashi, Mol. Microbiol. 2003, 48, 1501-1510.

N. Gaitatzis, B. Silakowski, B. Kunze, G. Nordsiek, H. Blöcker, G. Höfle, R. Müller, J. Biol. Chem. 2002, 277, 13082-13088.

B. Wilkinson, G. Foster, B.A.M. Rudd, N.L Taylor, A.P.Blackaby, P.J. Sidebottom, D.J. Cooper, M.J. Dawson, A.D. Buss, S. Gaisser, I.U. Böhm, C.J. Rowe, J. Cortés, P.F. Leadlay, J. Staunton, Chem. Biol. 2000, 7, 111-117.

a) Y. Kato, K. Nakamura, H. Sakiyama, S.G. Mayhew, Y. Asano, Biochemistry 2000, 39, 800809. b) Y. Kato, R. Ooi, Y. Asaon, Appl. Environ. Microbiol. 2000, 66, 2290-2296.

C. Olano, S.J. Moss, A.F. Braña, R. Sheridan, V. Math, A.J. Weston, C. Méndez, P.F. Leadley, B. Wilkinson, J.A. Salas, Mol. Microbiol. 2004, 52, 1745-1756.

T. Wakabayashi, R. Kageyama, N. Naruse, Y. Yokoyama, Y. Watanabe, K. Dobashi, Japanese Patent Application JP09227549A. ChemABS, 127, 277250 S. 93.

a) S. Fushimi, K. Furihata, H. Seto, J. Antibiot. 1989, 42, 1026; b) T. Ozasa, K. Tanaka, M. Sasamata, H. Kaniwa, M. Shimizu, H. Matsumoto, M. Iwanami, J. Antibiot. 1989, 42, 1339.

a) A.M. Hill, J.P. Harris, A.P. Siskos, Chem. Commun. 1998, 2361; b) G. Höfle, H. Reichenbach in: Sekundärmetabolismus bei Mikroorganismen, ed. W. Kuhn, H.-P. Fiedler, Attempto Verlag, Tübingen, 1995, 61-78; c) T. Schupp, C. Toupet, B. Cluzel, S. Neff, S. Hill, J.J. Beck, J.M. Ligon, J. Bacteriol. 1995, 177, 3673.

a) T.S. Chen, E.S.Inamine, O.D. Hensens, D. Zink, D.A. Ostlind, Arch. Biochem. Biophys. 1989, 269, 544; b) T.S. Chen, B.H. Arison, V.P. Gullo, E.S.Inamine, J. Ind.Microbiol. 1989, 4, 231.

M.D. Schulman, D. Valentino, O. Hensens, J. Antibiot. 1986, 39, 541.

a) E.W. Hafner, B.W. Holley, K.S. Holdom, S.E. Lee, R.G. Wax, D. Beck, H.A.I. McArthur, W.C. Wernau, J. Antibiot. 1991, 44, 349; C.D. Denoya, R.W. Fedechko, E.W. Hafner, H.A.I. McArthur, 
M.R. Morgenstern, D.B. Skinner, K. Stutzmann-Engwall, R.G. Wax, W.C. Wernau, J. Bacteriol. 1995, 177, 3504.

203

C.J. Dutton, S.P. Gibson, A.C. Goudie, K.S. Holdom, M.S. Pacey, J.C. Ruddock, J.D. Bu'Lock, M.K. Richards, J. Antibiot. 1991, 44, 357.

204 M.S. Pacey, J.P. Dirlam, R.W. Geldart, P.F. Leadlay, H.A. McArthur, E.L. McCormick, R.A. Monday, T.N. O'Connell, J. Staunton, T.J. Winchester, J. Antibiot. 1998, 51, 1029-1034.

B.S. Moore, C. Hertweck, Nat. Prod. Rep. 2002, 19, 70-99.

206 MERCK, Anfärbereagenzien für die Dünnschicht- und Papierchromatographie, E. MERCK, Darmstadt, 1998.

207 H.G. Schlegl, Allgemeine Mikrobiologie, Georg Thieme Verlag, Stuttgart, 1992. 


\section{Danksagung}

Das Hormaomycin-Thema der vorliegenden Dissertation ist Teil eines Kooperationsprojektes und sein Erfolg war ohne die Partner nicht vorstellbar. Für die gute Zusammenarbeit möchte ich mich deshalb bei Prof. Dr. Armin de Meijere und seinen Mitarbeitern Dr. Boris Zlatopolskij und Vitalij Raev bedanken. Gleiches gilt für Dr. Uwe Reinscheid, Jonathan Farjon, Peter Haberz und Dr. Tim Grüne aus den Gruppen von Prof. Dr. Christian Griesinger und Prof. Dr. George M. Sheldrick sowie Kathrin Zimmermann, Daniel Flachshaar und Prof. Dr. Jörn Piel. Für die antiparasitären Tests danke ich Dr. Marcel Kaiser und seinen Mitarbeitern.

Weiterer Dank gebührt Prof. Dr. Hans-Peter Fiedler und Dr. Noémi Antal für die Isolierung der Substanzen aus dem Actapharm-Projekt sowie Prof. Dr. W. Beil für die Cytotoxizitätstests.

Für die Aufnahme der NMR-Spektren danke ich Carola Zolke, Martin Weitemeyer und R. Machinek, sowie den Operatoren aus der Abteilung, insbesondere Dr. Sven Meyer und Dr. Oliver Schlörke.

Györgyi Udvarnoki, Frau Krökel, Dr. Karsten Ströch und Dr. Holm Frauendorf danke ich für die MS-Messungen bzw. die Unterstützung an der LC-MS.

Für das Messen der physiko-chemischen Daten meiner Substanzen sowie die Unterstützung bei Fermentationen danke ich Michaela Klingebiel und Hans-Peter Kroll; Jutta Gerber-Nolte für die Bereitstellung von Testplatten. Hans-Jörg Langer gilt zudem großer Dank für die technische Unterstützung, die Schachduelle und den Austausch an Fußballerfahrungen.

Weiterhin möchte ich mich für das sorgfältige Korrekturlesen bei Marko Gentzsch, Tobias Bender und Sandra Lösgen bedanken.

Der wichtigste Dank geht an meine Familie, Nina und meine Freunde für ihre stete Unterstützung und die Freude, die sie in mein Leben bringen. 


\section{Lebenslauf}

Ich bin deutscher Staatsbürger und wurde am 02.07.1977 in Bad Gandersheim geboren.

Von 1984-1988 besuchte ich die Grundschule in Kreiensen, von 1988-1990 die Orientierungsstufe am Schulzentrum Kreiensen/ Greene. 1990 wechselte ich an das Roswitha-Gymnasium in Bad Gandersheim, dessen Besuch ich 1997 nach erfolgtem Abitur abschloss.

1997 nahm ich an der Universität Fridericiana zu Karlsruhe (TH) das Studium des Chemieingenieurwesens auf, 1998 erfolgte ein Studienfachwechsel zu Chemie (Diplom). 2001 schloss ich das Vorstudium im Studiengang Chemie mit der Diplomvorprüfung ab.

Von 2001-2003 absolvierte ich das Hauptstudium der Chemie an der Georg-AugustUniversität Göttingen, welches ich am 14.11.2003 mit der Diplomhauptprüfung (Titel der Diplomarbeit: „Isolierung und Charakterisierung von Phenazinderivaten und anderen Sekundärmetaboliten aus Actinomyceten“) erfolgreich beendete.

Seit Januar 2004 arbeite ich unter Anleitung von Prof. Dr. A. Zeeck an der vorliegenden Dissertation.

Göttingen, 30. Mai 2006

Markus Radzom 